

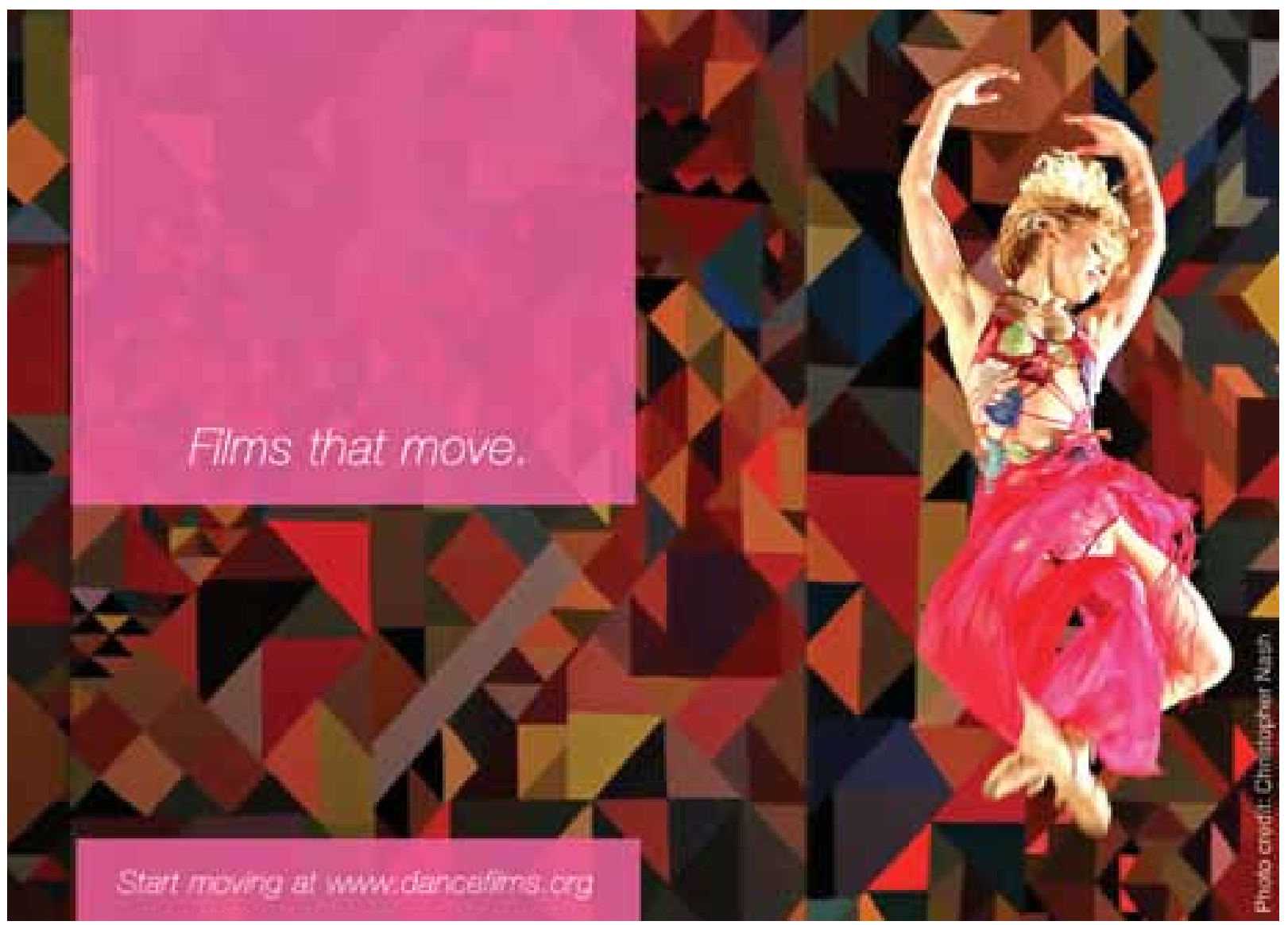

6142927977 | dance.osu.edu

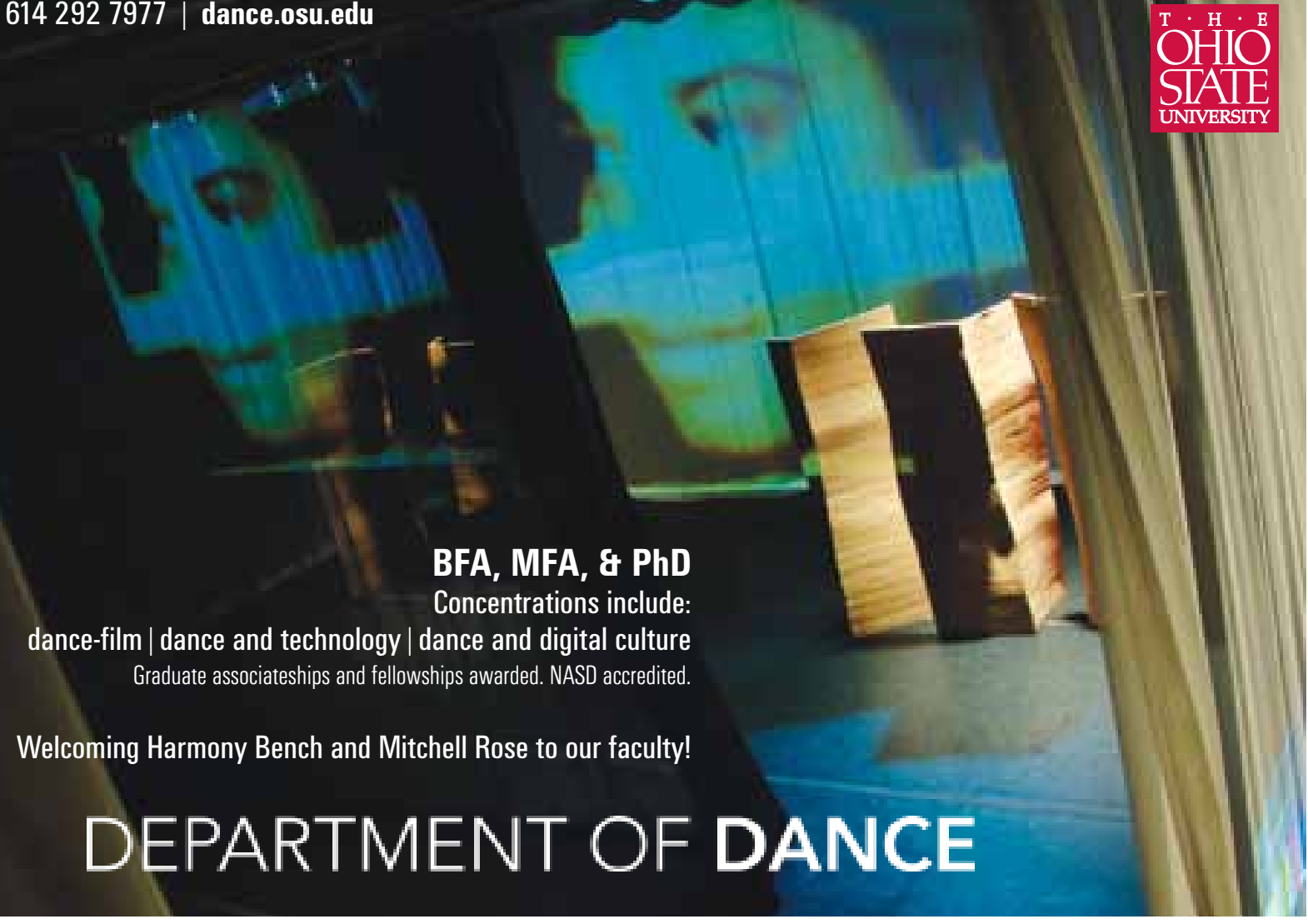




\section{The International Journal of Screendance}

SPRING 2012 • VOLUME 2

ISSN 2154-6878

\section{EDITORS}

Douglas Rosenberg and Claudia Kappenberg

\section{EDITORIAL ASSISTANTS}

Virginia M. Piper

Dominique C. Bourg Hacker

Nathan J. Jandl 



\section{THE INTERNATIONAL JOURNAL OF SCREENDANCE EDITORIAL BOARD}

\section{DR. ANN COOPER ALBRIGHT}

Professor of Theater and Dance

Oberlin College

\section{ELLEN BROMBERG}

Associate Professor, Department of Modern Dance

University of Utah

\section{DR. HARMONY BENCH}

Assistant Professor, Dance Department

Ohio State University

\section{DR. SIMON ELLIS}

Senior Lecturer (Practice-based)

Roehampton University

\section{DR. FRANK GRAY}

Director of Screen Archive South East (SASE)

University of Brighton

\section{CLAUDIA KAPPENBERG}

Senior Lecturer, Performance and Visual Art

School of Arts and Media

University of Brighton

\section{MIRANDA PENNELL}

Independent film and video artist

London, UK

\section{DOUGLAS ROSENBERG}

Professor of Art, Department of Art

University of Wisconsin-Madison

\section{DR. THERON SCHMIDT}

Researcher

Queen Mary University of London

\section{SILVINA SZPERLING}

Director, Internacional Festival de Videodanza

Buenos Aires, Argentina

\section{DR. SARAH WHATLEY}

Professor of Dance

Coventry School of Art and Design

Coventry University

\section{MARISA ZANOTTI}

Senior Lecturer Dance

University of Chichester 


\section{Cover and Publication Design}

Barry Roal Carlsen, University Communications, University of Wisconsin-Madison

\section{Cover Image}

Scaffolding: Construction work at the Lehrter Bahnhof, Berlin, by Tup Wanders

\section{The International Journal of Screedance}

ISSN 2154-6878

Parallel Press

University of Wisconsin-Madison Libraries

Madison, Wisconsin

http://parallelpress.library.wisc.edu

Website: journals.library.wisc.edu/screendance

Email: screendance@gmail.com 


\section{Table of Contents}

\section{EDITORIAL COMMENT}

1 Scaffolding the Medium

Claudia Kappenberg

Douglas Rosenberg

\section{INTRODUCTION}

4 Cinema Has Not Yet Been Invented: Lecture by lan Christie Claudia Kappenberg

\section{CURATED DISCUSSIONS}

\section{ON MARTIN HEIDEGGER}

21 The Tensions of Techné: On Heidegger and Screendance Ann Cooper Albright

24 Moving Across Time with Words: Toward An Etymology of Screendance Ann Dils

27 The Sorry and the Pithy: Six Short Statements on Heidegger and Technology Kent de Spain

31 Reflections on Heidegger: Performing Translations in Active Space Environments Lisa Naugle and John Crawford

34 The Twins Paradox: Bifurcation \& Unification Tom Lopez

\section{ON AMELIA JONES}

39 Introduction: Amelia Jones Harmony Bench

44 Notation Score as Embodied Documentary Presence: A Response to Amelia Jones's "Presence' in Absentia" Hannah Kosstrin

48 Mobile Media Performances as Asynchronous Embodiment Jason Farman

52 Dancing in Music Videos, or How I Learned to Dance Like Janet ... Miss Jackson Melissa Blanco Borelli

\section{ON ROSALIND KRAUSS}

56 Introduction: Rosalind Krauss Douglas Rosenberg

58 Screendance: The Aesthetics of Ironic Consciousness Virginia Piper

61 Screendance: Aesthetics of Media and Consumer Visual Culture Terry Sprague

66 The Kraussian Condition of the Medium Rodrigo Alonso

68 Video and its Narcissistic Potential in Dance: Four Examples in Video Art and Experimental Film, Stage Dance, and Screendance

Claudia Rosiny 


\section{ON LAURA MULVEY}

71 The Parallel Universe and the Pensive Practitioner: Reflections on Screendance Prompted by Laura Mulvey's "Pensive Spectator"

Kyra Norman

72 Some Thoughts on "Nowness" and "Thenness" Miranda Pennell

78 Giving Up the World for an Image Augusto Corrieri

81 Delayed Reactions Kyra Norman

\section{ON PIA EDNIE-BROWN}

85 Falling again Pia Ednie-Brown

86 Through Screens Simon Ellis

89 making things visible Dianne Reid

93 Finding the Turn Lucy Cash

99 Falling into the Surface (toward a materiality of affect) Pia Ednie-Brown

\section{ARTISTS' PAGES}

107 Notes on Filming Dance Adam Roberts

\section{RE-VIEWS}

114 Review Essay: Line Dances (seven cinematic journeys) by Daniel Belton Claudia Rosiny

116 Review Essay: Becoming Beside Ourselves: The Alphabet, Ghosts and Distributed Human Being by Brian Rotman Scott delahunta

\section{RE-PRINT}

118 An Introduction to the Films Maya Deren

121 Thinking Deren Elinor Cleghorn

129 Manus Operandi: Film, Sculpture, choreography Elinor Cleghorn

\section{REPORT}

140 A Report on the Screendance Symposium, University of Brighton, February 4, 2011 Claudia Kappenberg and Sarah Whatley 


\section{Editorial Comment}

\section{Scaffolding the Medium}

"Scaffolding the Medium" is the title of the second issue of the International Journal of Screendance; the title and its structure were developed during a seminar of the Screendance Network at the American Dance Festival in Durham, North Carolina in June 2010. This issue brings a number of historical texts into the debate on screendance practices as part of an endeavor to build a variable scaffolding, one that begins to both create a common knowledge base and also to support a kind of cantilevered interdisciplinarity. This issue contains five curated discussions which each take as their initial premise a key text that speaks to concerns relevant to the discourse of contemporary screendance. Each section editor then invited a number of artists and scholars to comment on the writings. The writings that catalyzed each section (which are not re-published here) include texts by Martin Heidegger, Amelia Jones, Laura Mulvey, Rosalind Krauss and Pia Ednie-Brown. The selected texts are not obvious screendance must-reads, but rather writings that have proved significant within different fields such as film theory, philosophy, and the visual arts. We hope that these texts and their commentaries will serve to stimulate current debates on screendance by creating common reference points and proposing possible histories and trajectories.

Screendance artist Kyra Norman selected a chapter entitled "The Pensive Spectator" from Laura Mulvey's Death 24x a Second: Stillness and the Moving Image (2006), in order to explore changes that have occurred in response to contemporary mechanical means of stilling the image. In response, filmmaker Miranda Pennell reflects on two of her works to explore different performative qualities of still and moving images. Drawing on Mulvey's text, she argues that a choreographic approach explores the materiality of the body much like the materiality of the filmic apparatus was questioned by avant-garde practices. Disruptions of a conventional flow of movement as well as displacements and delays in the moving image thereby invite a more reflective response on the side of the spectator whilst questioning perception itself. Performance artist Augusto Corrieri revisits a childhood memory to reflect on how the manipulation of time in media, domestic television, and the VCR have had an impact on how we understand the world and how we view ourselves.

Theorist Harmony Bench invited three dance scholars to reflect on Amelia Jones's essay, "'Presence' in Absentia: Experiencing Performance as Documentation" from 1997, arguing that while screendance does not need to concern itself with questions of authenticity, it is nevertheless haunted by the debate surrounding live performance practices. As one of the respondents, Hannah Kosstrin compares and contrasts a notator's process of committing a choreography to the page with a videographer's production of a screenic document. For Bench, the different processes of observation and distillation of both these practices constitute methodological alternatives that could inform screendance aesthetics. Meanwhile, Jason Farman explores the asynchronous sensory engagement with screen media and its capacity to foster intimacy between participants. Jason Farman as well as Melissa Blanco Borelli's reflection on the impact of the bodily spectacle of popular music videos invite the question: what kind of sensory experiences, forms of embodiment, and 
relational experience might screendance be able to generate in the receiver, given the proliferation of mobile platforms and interactive devices that permeate the everyday?

Scholar Ann Cooper Albright uses Martin Heidegger's 1954 treatise, "The Question Concerning Technology" as a portal to engage her respondents in questions about technological intentionality. Lisa Naugle and John Crawford focus on Heidegger's ideas about "enframing" as it relates to their own research in interactive technologies. Tom Lopez contributes a performative text from "the bifurcated twins' of Techné and Poïesis. Kent de Spain ruminates on the place of the body and nature within Heidegger's technological ideologies. And finally, Ann Dils undertakes an etymological investigation of screendance and the attendant metaphors which flow from its linguistic origins.

Artist/theorist Douglas Rosenberg chose Rosalind Krauss's 1976 essay, "Video: The Esthetics of Narcissism" as a look-back to the critical responses toward video art in its early days. Virginia Piper draws out Krauss's psychoanalytic and semiotic references in a consideration of the aesthetics of video art in 1976 in the context of screendance in 2011. Rodrigo Alonso notes Krauss's identification of a "new kind of performance art, one at the crossroads of the body and the media," while Claudia Rosiny focuses on video and its narcissistic potential in dance. Finally, Terry Sprague looks at the Krauss essay through the lens of "consumer visual culture."

Choreographer/artist Simon Ellis asked Pia Ednie-Brown to revisit an essay she had written over a decade ago, a piece that was originally written through the lens of architecture. Brown looks at the built environment and the virtual, posing philosophical questions about the affect of both. Dianne Reid and Lucy Cash offer commentaries in response to Brown, each improvising and performing Brown's text in individually personal ways.

This issue also features an edited transcript of a presentation by Professor lan Christie, originally delivered at the first seminar of the Screendance Network at the University of Brighton in September 2009. Drawing on lectures he delivered as part of the Slade Lecture Series at the University of Cambridge, UK in 2006, Christie surveyed a history of cinema under the title "Cinema Has Not Yet Been Invented." In this presentation Christie places the research of the Screendance Network into the context of a wider contemporary review of cinema as an art form and examines debates across the twentieth century, which considered film variously as a mechanical advance, as popular entertainment, and as a discrete artform. Today, media practices such as popular narrative cinema and experimental film continue to represent conflicting views with regards to the potential and use of the medium. Such differences have created a healthy diversity within the field adding to theoretical discourses and references, distribution, and audiences. This is pertinent to the field of screendance, as artists and researchers attempt to differentiate distinctive bodies of critical enquiry. In order to fully grasp particular approaches, shared concerns and visions within the hybrid field of screendance a review of some of the concerns of the twentieth century may be useful.

The Artist's Pages feature an essay by filmmaker Adam Roberts, who reflects on his own shift from narrative filmmaking to screendance and the particularity of this later body of work. The discussion of Mulvey's "Pensive Spectator" is echoed in Robert's exploration of the flexibility of filmic time and space and the emphasis on presence within screendance. More specifically, Roberts contemplates the impossibility of stillness within the passing of 
film time and the intrusion of the mechanism that the freeze frame constitutes, both of which play with the expectations, tension, and attention of the spectator.

To mark the $50^{\text {th }}$ anniversary of Maya Deren's death and coinciding with a season of films and events dedicated to Maya Deren at the British Film Institute in London, UK, the issue includes a section on Maya Deren. This section has been put together by Elinor Cleghorn, who also curated the BFI season. For this issue of the International Journal of Screendance, Cleghorn reviews Deren's cinematic legacy in the context of early filmmaking and reflects on her writing, lecturing, and passionate advocacy of independent filmmaking. Following research in the Maya Deren Collection of the Howard Gotlieb Archival Research Centre at Boston University, Cleghorn also selected a previously unpublished draft of a 1945 lecture by Maya Deren, entitled "Introduction to the Films," which Deren appears to have delivered as part of a film screening.

In the Re-Views section, we feature Scott deLahunta on Brian Rotman's Becoming Beside Ourselves: The Alphabet, Ghosts and Distributed Human Being (Duke University Press, 2008) and Claudia Rosiny on Daniel Belton's Line Dances, which is a program of seven dance films "for web and new media." Finally, Claudia Kappenberg and Sarah Whatley offer a report on the Screendance Symposium held at the University of Brighton in February 2011.

The aim of this, the second issue of the International Journal of Screendance, is not simply to cast a wide net or to determine what is inside and what is outside the canon of screendance. Rather, we are interested in exploring multiple lenses from diverse points of view in order to articulate contemporary concerns and visions within screendance. The broadening of the debates reflects a wider contemporary concern with discourse in a global community. In a first issue of a new bilingual, German and English edition of the art publication frieze, editor Jennifer Allen reflects on the problem of provincialism which has haunted most of the Western world for the last 300 years, but argues that is has finally given way to a perpetual motion of globalization. ' The International Journal of Screendance feels a strong kinship with this position. In upcoming issues we aim to further expand the circle of contributors and readers and to also make space for regional voices or initiatives.

We hope that the texts and debates from across such polyvocal disciplines and practices will offer an interesting and stimulating read.

Claudia Kappenberg and Douglas Rosenberg, editors

\section{References}

Allen, Jennifer. "Hat die Kunbstwelt noch ein Zentrum/ Does the art world still have a centre?" frieze d/e (Summer 2011): 11-12.

Christie, lan. "Cinema has not yet been invented." Slade Lecture Series, 2006. Cambridge, UK. Information at http://www.admin.cam.ac.uk/news/press/dpp/2006012001.

Deren, Maya. "Introduction to the Films." 1945. Carbon copy of original material from the Maya Deren Collection, Howard Gotlieb Archival Research Center, Boston University, Boston, Massachusetts.

\section{Notes}

1. Allen, "Hat die,"11-12. 


\title{
Cinema Has Not Yet Been Invented: Lecture by lan Christie
}

\author{
Claudia Kappenberg
}

\section{Introduction}

For the first seminar of the AHRC Screendance Network at the University of Brighton (September 2009), Claudia Kappenberg invited Professor lan Christie to give a presentation based on his Slade Lectures at Cambridge University in 2006, in which he surveyed the history of cinema under the title: The Cinema has not yet been invented.

Appropriated as "Screendance has not yet been invented," Professor Christie's phrase has constituted a useful starting point for the Screendance Network, facilitating a critical review of the development of screendance in the context of twentieth century film and a reflection on the possibilities inherent in the art form. ${ }^{2}$

In his Slade Lectures, Ian Christie examined debates across the twentieth century, which considered film variously as a mechanical advance, as popular entertainment or as a form of art. Today, different bodies of work such as popular narrative cinema and experimental film practices continue to hold conflicting views as to the potential and use of the medium. The different points of view create a healthy diversity of discourses and references, and also allow for the development of a variety of platforms and audiences.

The original series of Slade Lectures consisted of eight lectures; the transcribed material below summarizes the key points and issues that were presented in the lecture to the Screendance Network.

Ian Christie: To begin with I will show you an extract from a compilation by the German filmmaker and collector Werner Nekes. His collection of optical devices and apparatus from the centuries before moving pictures appeared on the strips we call "film" is probably the largest in the world and has toured in the form of various exhibitions. One of these was The Eyes, Lies and Illusions, at the Hayward Gallery, London, in 2004-05. Nekes has put a lot of his archive material onto six DVDs, under the general title Media Magica, and I want to show you one section of Volume II, which is called Historical Shadow Theatre. What I find valuable and thought provoking about this is that it gives us the option of not regarding cinema as beginning in 1893 or 1895 (depending on whether you regard Edison or the Lumières as founders), but thinking of it being at least a 300-year span.

Shadow theatre is really the longest tradition of projected entertainment before cinema began, alongside the magic lantern. It covers a vast amount of traditional entertainment, and while we may all have some sense of shadow theatre, none of us has seen anything like the full range of it. A surprising number of countries have their own tradition of shadow theatre; they are all different, and what you can see in very condensed form on this DVD is a selection of about six or eight of these surviving traditions. They have been 
filmed both in front of the screen-in "audience view" - and also behind the screen, so you get a sense of what the range of this form might be. And I think it might be especially interesting to you as screendance practitioners and historians.

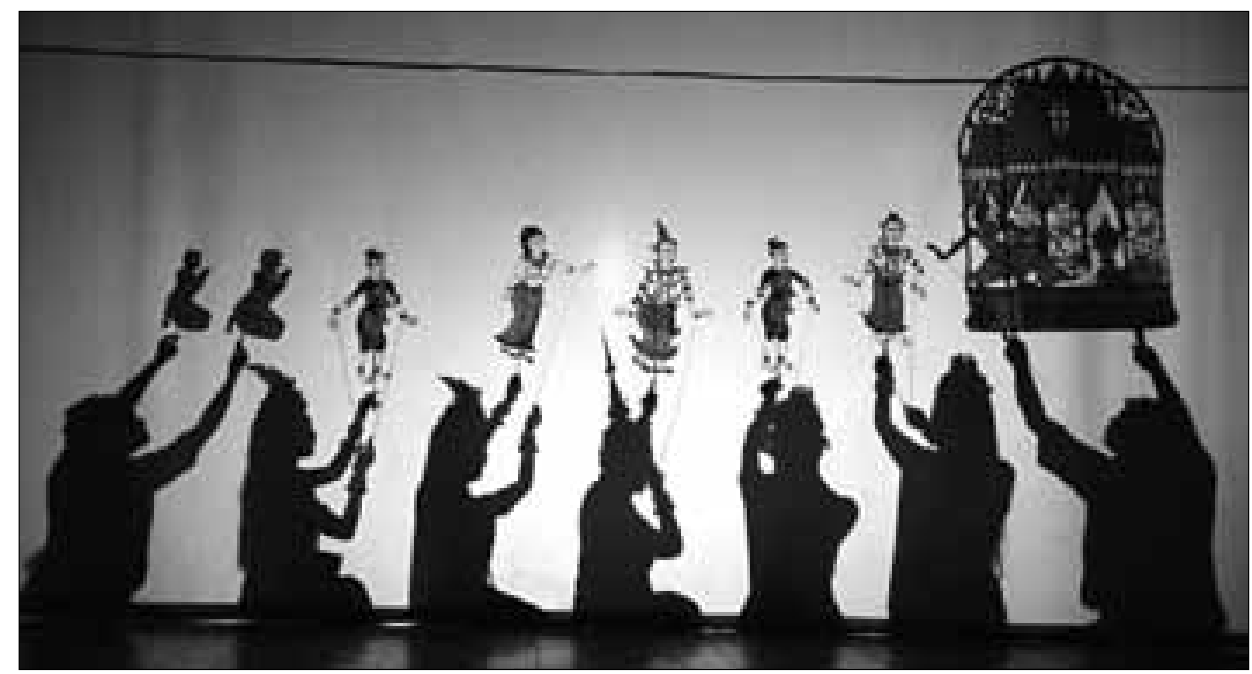

Screen shot of traditional Cambodian Nang shek or shadow theatre. Werner Nekes, Media Magica, Volume II. Mülheim an der Ruhur, Germany: Arte, 2004. DVD.

This reminder of shadowplay as both an ancient and continuing tradition raises the whole question of the limitations of our concept of cinema, and I think provides a useful starting point for our discussion. The starting point for my Slade lectures, and the title "The Cinema has not yet been invented," came from an article by the French critic André Bazin, who was influential through the 1940s and 50s, and became a sort of father figure to the "new wave" film-makers, especially François Truffaut and Jean-Luc Godard, before his premature death in 1958. Bazin's essays from the 1940s are particularly important and have become canonic in film studies. ${ }^{3}$ One of these is a review of the first volume of a huge history of cinema by George Sadoul, and towards the end of it Bazin says: "The more you look at the nineteenth century the more you realize that the pioneers of cinema, the people we think of as pioneers, were actually imagining something that was total, integral realism." ${ }^{4}$ What has happened since, Bazin suggested, is a series of approximations towards that ideal; and he ends up saying, paradoxically (writing in 1946), that "cinema has not yet been invented," even though it keeps getting closer and closer to the original dream of its pioneers.

Question: So the dream of the pioneers was a total realism that has only been approximated?

IC. Yes it has been approximated by various developments such as the introduction of sound and color, stereo and things like that.

Q. Do you think this is true?

IC. No, in fact I think it's quite misleading. Bazin was offering a Catholic idealist interpretation of a Marxist history, which he either failed to understand or didn't want to. 
The problem is that today all film students are taught Bazin in college, using the rather poorly translated California University Press texts, and they're rarely encouraged to question him. But even if I disagree with Bazin's interpretation of pre-cinema history, I still think he provides a valuable stimulus to think about "what cinema is."

Let me set alongside the Bazin quotation one by Virginia Woolf about the future of film, from the only essay she wrote on cinema, in 1926:

Is there ... some secret language, which we feel and see, but never speak, and if so, could this be made visible to the eye? ... Something abstract, something which moves with controlled and conscious art, something which calls for the very slightest help from words or music ... of such movements and abstractions the films may, in time to come, be composed. ${ }^{5}$

Woolf wrote this essay immediately after seeing The Cabinet of Dr Caligari (1919) at the Film Society in London. However, she was less interested in the film than in a blob of dirt that got stuck on the projector and became on screen"a shadow shaped like a tadpole ... that swelled to an immense size." This inspired her to wonder if film could move beyond the "disastrous" photoplays that she despised, to express the subjectivity of the inner life. Here I might add that I've had a special affection for Woolf's vision of film even since I wrote a television series for the centenary of cinema, in the mid-1990s, and we managed to get Fiona Shaw to play Virginia Woolf. The

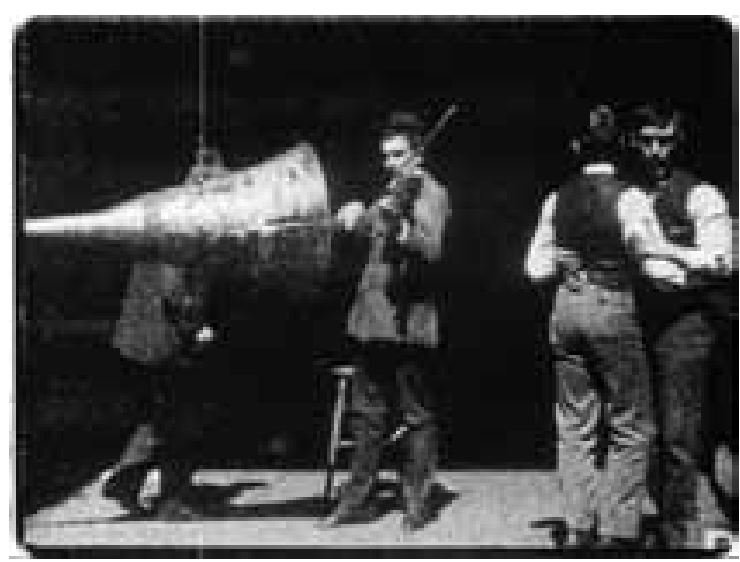

Film still of Dickson's Experimental Sound Film (1895) with W. K. L. Dickson playing the violin. Courtesy FilmSound.org. speech I wrote for her took some lines from the 1926 essay, and extended them in a way I hope Woolf would have approved of.

We could say that 1896 marked the official beginning of cinema, or rather of moving pictures, when they went public and projection on the screen before an audience began. But Edison had been making subjects for his Kinetoscope peepshow machines since 1894, and most of these were performance-based. They were all shot in his "Black Maria" studio in New Jersey and the performers were mostly popular performers from Broadway. One, however, is strikingly different. It shows two men dancing together, with a third playing the violin beside a large Phonogram horn. This Experimental Sound Film dates from 1894, and the director (and violinist) was W. K. L. Dickson, a Scot born in France, who became the key figure in Edison's team working on moving pictures. Edison always thought that moving pictures would combine with recorded sound, which of course he had pioneered with the Phonograph in 1877. This film was apparently made to demonstrate the principle of the Kinetophone, an early attempt to synchronize phonograph cylinders to moving pictures. For a long time it was thought to be something of a fake or at least ahead of what was possible at the time. Then the original cylinder was discovered, and it could indeed be synchronized, as the editor and sound designer, Walter Murch, has demonstrated. ${ }^{8}$ We might want to consider this the founding work of screendance: modest in its choreography, yet focused on what the new apparatus could deliver. ${ }^{9}$ 
A decade after the first films appeared in music halls and fairgrounds, the standard programmed had increased in length to an average of 70 minutes, but still consisted of a mix of mostly ten-minute films of different genres-topical, knockabout comedy and trick films. These last made use of reverse-motion and stop-motion substitution for magical effect, keeping alive the novelty of "animated photography" that had seized the imagination of early viewers. Then, from about 1908, things began to change. One aspect of this was what had depressed Virginia Woolf: the trend towards "realistic" drama, often drawing on wellknown literary works. Yet despite those who deplored this trend, many more saw in it a new dramatic mastery that integrated all the elements of film to create a convincing "world."

The key work in this new vein was The Assassination of the Duc de Guise (France, 1908, Calmettes and Le Bargy), which drew on the resources of the Comédie Française, France's leading classical theatre, to dramatize a famous episode in French history, when the Duc de Guise was lured to his death at the court of Henry III. With its richly authentic costume and decor, and well-plotted movement and editing, the film also benefited from a score by the leading composer, Camille Saint-Saens. This was the first major score written for the cinema, an extremely successful piece of music, which anticipates the next twenty years of film music, and much beyond. And yet, for all its achievement, many historians of cinema subsequently repeated the claim that the Duc de Guise marked a "wrong turn," subordinating film to theatre. What is undeniable is the influence of the "film d'art" movement that the Duc de Guise spearheaded, and which soon gave rise to a wave of historical subjects in many countries. Whether this distracted cinema from other possibilities remains open to debate, but it undoubtedly broadened the medium's appeal to the educated classes and paved the way to its tackling more ambitious subjects.

Ambition flourished particularly among Italian producers during the next five years, as they developed the distinctive new genre of the epic portrayal of antiquity. Using stories from Roman history and Greek mythology, with lavish sets and large casts, they created a taste for spectacle that would take film into the 'teens, filling existing concert halls and vast new cinemas with an ever-growing audience, which now included royalty. ${ }^{10}$ Despite the ostensibly Christian themes of Quo Vadis? (1912), The Last Days of Pompeii (1913), and Cabiria (1914), these films also had a frankly sensational and exotic appeal, harking back to the popular paintings of ancient Rome by Gerôme and Alma-Tadema, and establishing film as a medium of popular spectacle. Their scale and popular success prompted other filmmakers to consider treating more recent national history on a similar scale: hence, a rash of battle films and, strongly influenced by the Italian model, D. W. Griffith's account of the American Civil War, Birth of a Nation (1915).

But during this crucial development, as the new longer "feature" films displaced the previous standard programmed of varied short films, there was an important moment of reflection. 1913 saw a cluster of polemics

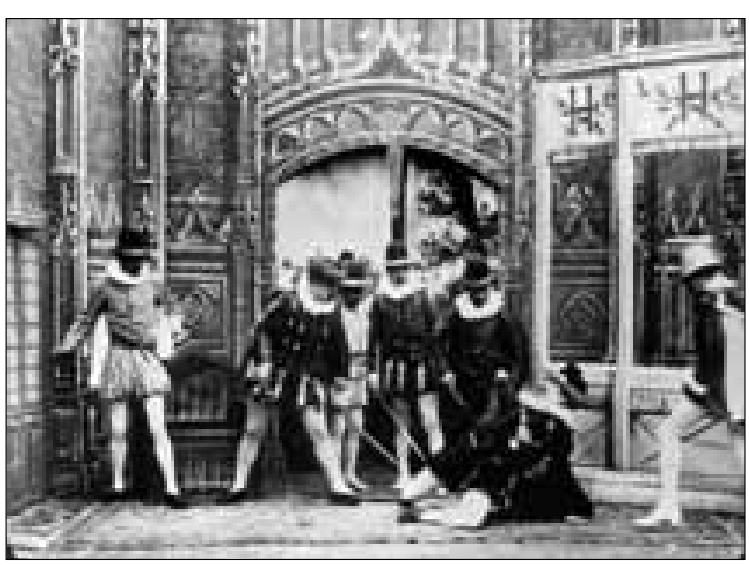

Screen shot of a pioneering "art" film: The Assassination of the Duc de Guise. Directed by André Calmettes and Charles Le Bargy, 1908. 
and experiments that would change the status of film and ultimately establish its claim to be considered a new artistic medium. The Russian Futurist Vladimir Mayakovsky, a firebrand young poet at this time, was skeptical about cinema and he spoke for many when he insisted that it "obviously" could not be an independent art form, in a series of articles for an early Russian film journal. ${ }^{11}$ Yes, he agreed, it could certainly provide "aesthetic enjoyment," but "cinema and art are phenomena of a different order." Embedded in Mayakovsky's position at the time - a time, as we now know, when Russian filmmakers were creating some of their earliest masterpieces - is the old charge that film depends on machinery, or that it merely multiplies and distributes images, like the printing press or the typewriter. ${ }^{12}$ Another Russian, the playwright Leonid Andreyev, argued at this time that the cinema would take over the stage's role in popular entertainment and that this would leave drama free to do different things..$^{13}$ To some extent they were right, a certain kind of play or spectacle that had been done on stage was taken over by the screen; and five years later, after the October revolution, Mayakovsky would throw himself into film, writing and starring in three highly experimental works that explored and exploited the ontological ambiguity of film as representation. ${ }^{14}$

Then there were still others whom we might consider the visionaries of 1912-1913, who already began to see a new art form coming into existence. Let me give some examples of these very different characters. Certainly the most distinguished was Sir Hubert Von Herkomer (1849-1914), who was an established artist, a Royal Academician, and painter of some of the most famous pictures of the nineteenth century, such as Hard Times (1885) and On Strike (1891). Herkomer announced in 1913 that he was giving up painting in favor of cinema, since he saw "the greatest possibility of art in the film."15 He set up a studio in the grounds of his suburban house and plunged into film production, but unfortunately died just a year later and all the films have been lost. His move, however, marked quite a profound shift and indicated that for social realists like himself, films were beginning to seem the best way to reach a mass audience, as he had previously done through his illustrations for The Graphic in the 1870s. ${ }^{16}$

Artists of a very different stamp, Wassily Kandinsky and the composer Arnold Schönberg (who also painted), both speculated from 1911 to 1913 about the possibility of using animated film in complex experimental stage works they were both wrestling withKandinsky's Der Gelbe Klang [The Yellow Sound], a "colour-tone drama," and Schönberg's quasi-opera Die Glückliche Hand [The Lucky Hand]. Both wanted to avoid having actual bodies on stage in what were essentially abstract expressionist works, and wondered if animated film might produce a suitably spectral image. ${ }^{17}$ As it turned out, neither proceeded with the idea of commissioning a film, probably for the same reasons that Picasso did not proceed with his idea of making a film around the same time, or that Léopold Survage failed to secure backing for his "coloured rhythm" series of paintings in 1912-1913. ${ }^{18}$ Few artists had any contact with the world of filmmaking at this time, and although color tinting and toning were routine for commercial films, these industrialized processes would hardly have satisfied the requirements of a Kandinsky or a Picasso. ${ }^{19}$

If visual artists would not engage directly in filmmaking for another decade, there are plenty of examples from the 'teens of what could perhaps be described as a "proto-filmic" impulse. The Bloomsbury painter Duncan Grant, for instance, produced an uncharacteristic work in 1914, entitled Abstract Kinetic Painting with Sound, which consists of a 4.8-metre scroll 
decorated with geometric shapes that was intended to be wound by a motor slowly past a rectangular viewing aperture to the accompaniment of one of Bach's Brandenburg Concertos. ${ }^{20}$ Now too fragile to be operated, this singular work-very different from anything else by Grant_-was filmed and with accompanying music in 1974 and can now experienced as the abstract animation that it points towards. Grant was not the only artist of this period to experiment with the "scroll" form: Sonia Delaunay collaborated with the poet Blaise Cendrars to make a"simultaneous" fold-out book of his modernist narrative poem La Prose du Transsibérien et de la petite Jehanne de France in 1913 that extends as a two-meter scroll.

The 1920s is probably the era we all know best as the cradle of avant-garde film, with a number of fully-fledged alternatives

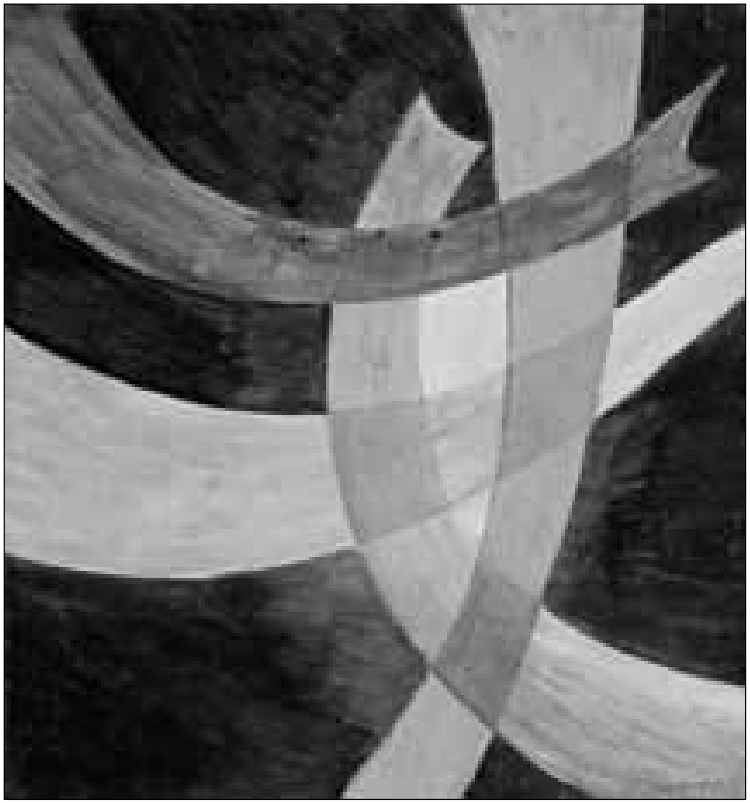

Léopold Survage, from the series Le Rythme coloré (1913). Image courtesy Scala Archives, SCALA Group S.P.A., Florence. to mainstream cinema produced by what are sometimes called the "historic avant-gardes." A curious feature of this period of intense productivity is that these off-shoots of Futurism, Cubism and Expressionism are all ten to fifteen years "late" — as if cinema had to reach a level of technical sophistication and diversity to allow the original impulses behind these earlier movements to reach the screen. In the case of the French avant-garde formed by Louis Delluc, Jean Epstein, Marcel L'Herbier and Germaine Dulac, this has been labeled "Impressionist," although only some aspects of Delluc's and Epstein's work corresponds to the original Impressionist agenda, with Art Deco a more obvious correlate. Among all these "delayed"'20s film avant-gardes, only Dada and Constructivism really produced contemporary film equivalents: Dada in Man Ray's films and the Picabia-Clair Entr'acte (1924), and in the animation of Hans Richter and Viking Eggeling; and Constructivism primarily in Dziga Vertov's and Sergei Eisenstein's films.

From a distance, avant-garde film of the'20s can easily seem to belong to a common aspiration to "free" cinema from conventional narrative and bourgeois values, but it was actually a period of intense struggle between competing groups and movements. Many of these struggles were over rival definitions of film's intrinsic or essential quality-what sets it apart from all other media and is "specific" to it. In France this coalesces around the idea of photogénie, meaning that the moving photographic image has a particular hypnotic or arresting quality, especially when showing close-ups of faces and objects. ${ }^{21}$ This theory or belief was sharply challenged by the "montage" school, mainly Soviet Russian filmmaker-theorists, who argued that, on the contrary, the specificity of film lay in the juxtaposition of images rather than in their content or photographic qualities. This clash was well illustrated by an exchange over The Battleship Potemkin in 1926. The Hungarian-born critic Béla Balázs had praised the "hidden symbolic expressiveness" of Potemkin 's images in an article entitled "The Future of Film," which was republished in 


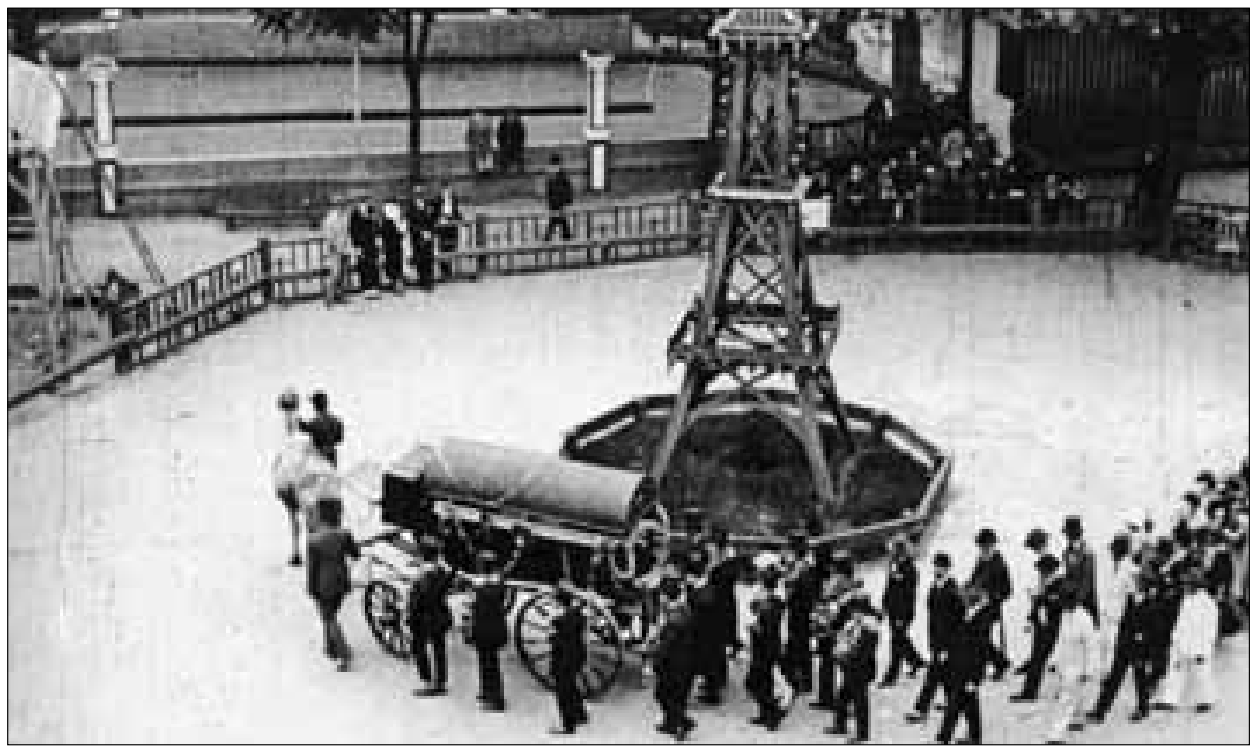

Screen shot, Entr'acte (1924), directed by René Clair from a script by the Dada painter and activist Francis Picabia. Paris: Re-Voir, 2005. DVD.

Russia. ${ }^{22}$ Eisenstein retorted with a stinging rebuke, "Béla forgets the Scissors," in which he pours scorn on the "individualism" of single shots and on the "honest" narrative of American cinema, insisting that "the expressive effect of cinema is the result of juxtapositions."23 (I should add here that seeing this as a straight choice rather oversimplifies a more complex field of possibilities. Among German filmmakers in particular there was an intense development of the "plasticity" of the image, which amounted to sculpting in light, in films by Robison, Murnau and Lang; and I think this should be regarded as neither impressionist nor montage-based, but really amounted to building film as a kind of dramatic architecture, and it would lay the foundations for the mature Hollywood cinema of the 1930s and 40s).

Despite their differences, a

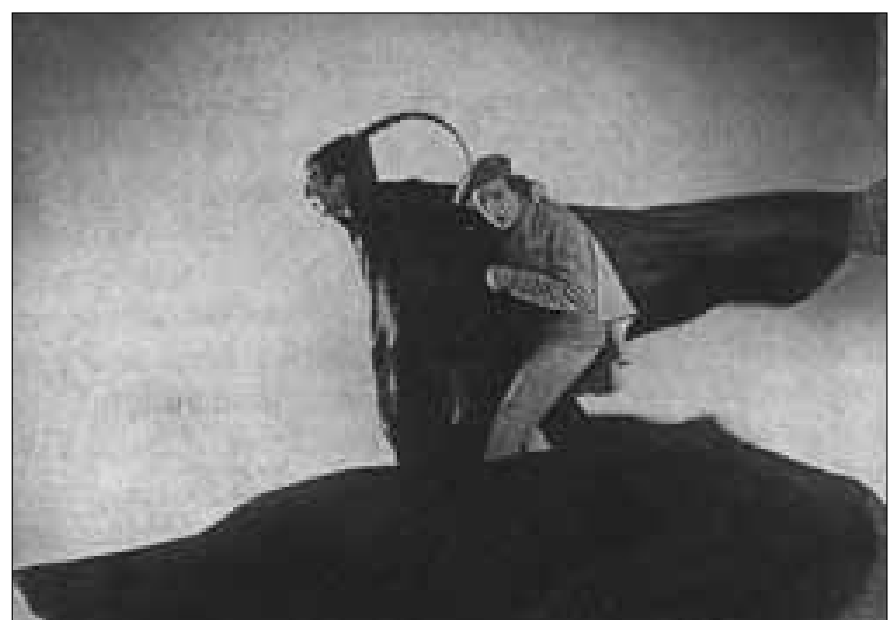

Screen shot of the intense plasticity of the image in Murnau's European masterpiece, Faust (1926). Courtesy http://www.archive.org. common feature of the 20s avantgardes was what I would call a utopian aspiration. Amid the many manifestos of the inter-war period, film is increasingly seen as having the potential to create a "new language" of the image_in Soviet Russia and France above all, but also in many other countries that had apparently shown little interest in the artistic potential of the new medium. Even a figure such as Kazimir Malevich, convinced of the importance of his Suprematist revolution in painting, believed that film 
could achieve still more, if it could overcome its attachment to mere narrative and figurative representation. Writers other than Woolf, from Pirandello to Joyce and Dos Passos, were intrigued by the potential of film to carry forward their experiments in multi-dimensional construction. And works such as Gance's Napoleon (1927), Murnau's Faust (1926), and Eisenstein's October (1928) pointed towards the possibility of a new Gesamtkunstwerk.

Then came the Talkies. It's a failure of a rather myopic film history to overplay this technological transformation. Synchronized sound-on-film certainly arrived as an industrial fact of life between 1928 and 1930. But its impact can scarcely be separated from profound changes in the economic and political structure of the world, due to the Wall Street crash, Stalin's drive for industrialization in Russia and the rise of Hitler-not to mention those filmmakers who believed in progress. Many factors conspired to de-rail the historic avant-gardes, which found themselves dispersed and in disarray at the beginning of the 1930s. At the same time, new avant-gardes began to emerge, along with new genres and opportunities for filmmakers to reach vast new audiences.

Recorded music was the most obvious beneficiary of the new technology-and the "intended" use for synchronized sound. The "talkies" were never expected to talk, except as an adjunct to musical performance, as in the early Vitaphone demonstration films, and the realization that audiences were prepared to listen to a lot of speech came as something of a surprise. But the rapid development of the "musical" in the early '30s created what was substantially a new cinematic form, and one in which dance would prove as important as music per se. Documentary film was a less predictable creation of the sound era. There had of course been many earlier forms of non-fiction film, but the '30s saw the documentary become established and recognized as a genre, giving rise to many different practices and to a body of theory.

There were inevitably very different attitudes towards the new genres made possible by recorded sound. Some mourned the loss of what had now become "silent" cinema's universality, and regarded the talkies as responsible for a loss of artistic or radical potential. In the United States, for elites such as the left-leaning intellectuals of Partisan Review and connoisseurs of Modernism involved with the Museum of Modern Art, "Hollywood" became synonymous with a debased mass culture. And when Soviet cinema began to produce its own musicals, led by Eisenstein's former associate Grigori Alexandrov, these were denounced as the equivalent of, but inferior to, Hollywood's own opium for the masses. ${ }^{24}$ We, of course, now tend to see considerable aesthetic and even political value in the Depression-era musicals to which Busby Berkeley

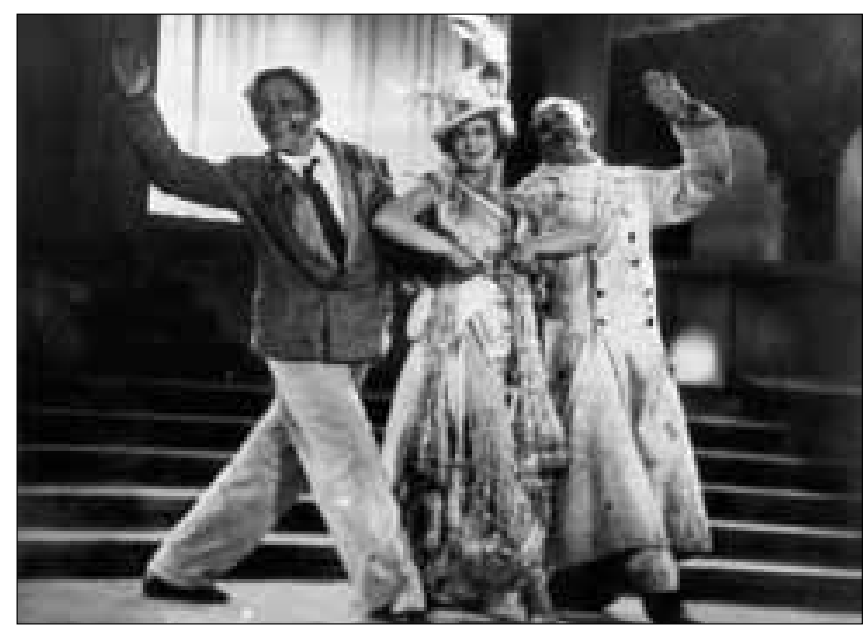

Grigori Alexandrov's Jolly Fellows (1934) disappointed many left-wing intellectuals who prized the seriousness of Soviet cinema-which now seemed to be converging with Hollywood's new musicals, as the critic Dwight McDonald lamented in his Partisan Review articles of 1938. Mosfilm, 1934. Image courtesy of Grading Dimension Pictures, Inc. 
contributed pyrotechnic routines. But there were real culture wars in the 1930s over which side were you on, and we're still living with the legacy of these to some extent.

Question 1: There are a number of feminist readings of Berkeley's work.

Question 2: But in the context of screendance, it is generally not discussed in a critical way.

IC. There were many voices in these critical debates, and I want to mention just two, by way of contrast. Erwin Panofsky was a great art historian and the founder of the study of "iconology" as an art historical method. A refugee in America, he gave an important paper in 1934, in support of the Museum of Modern Art's film collection, which was published as "Style and Medium in the Motion Picture."25 Perhaps surprisingly, this advances a trenchant argument in favor of popular Hollywood cinema. Panofsky took a stand on the Marx Brothers, the Western and popular genres, arguing that these can be traced back to earlier periods of culture, and that such commercially viable culture is always superior to subsidized art which is intended for the elite. Film, he maintains, is the only contemporary art whose disappearance would register with the public as a disaster. And Panofsky was probably the first major critic to identify a "nostalgia" for the silent era, while insisting that every gain in artistic progress involves some loss, but remains a gain "provided that the basic nature of the medium is realized and respected."26 Another key figure from the 1930s, Walter Benjamin, did not escape Europe to a new life in America, and did not advocate Hollywood as a model for popular culture. In his pioneering 1936 essay on "The Work of Art in the Age of Mechanical Reproduction," Benjamin looked to Soviet cinema and radical documentary as models, where "any man today can lay claim to being filmed."27 From opposed ideological positions, Panofsky and Benjamin are both arguing for cinema as the paradigm art form of the twentieth century, intrinsically popular and democratic.

Amid the major upheavals of the early'30s in cinema, one strand is often overlooked. This is the growing use of film for public information and commercial advertising, which

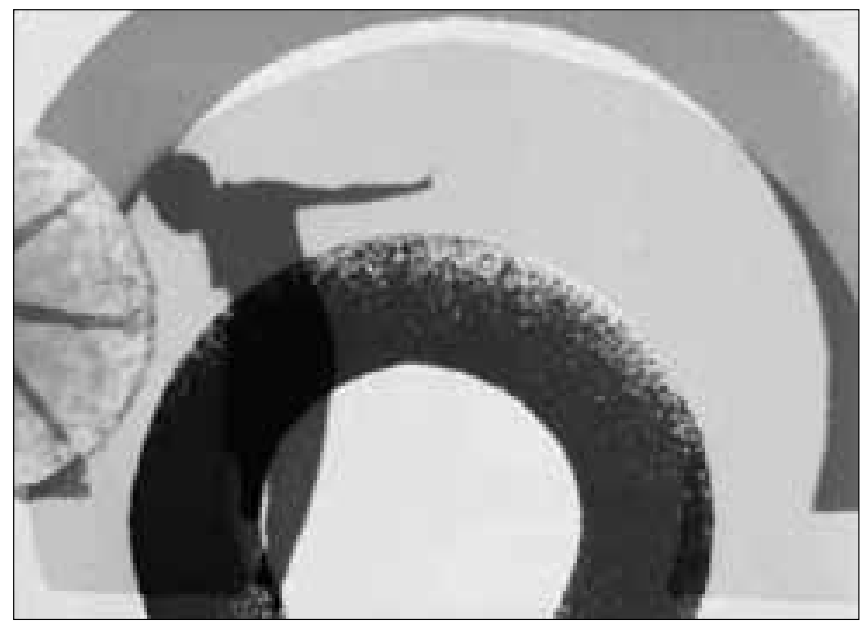

Screen shot from Len Lye's Rainbow Dance (1936), which combines graphic and choreographic elements in an exuberant display of "screendance." Image courtesy of the Len Lye Foundation, the GovettBrewster Art Gallery, the New Zealand Film Archive, and the British Post Office. was another innovation of the sound era. John Grierson managed to persuade the British establishment that there were important lessons to be learned from such otherwise antipathetic examples as Soviet cinema, and secured funding for an Empire Marketing Board film unit, from which would follow his work at the Post Office's equivalent unit, where he brought together many of the period's most talented young artists to work on films such as Colour Box, Night Mail and Coal Face. Advertising was also undergoing change, and as director of publicity for Shell-Mex and BP, Jack Beddington was instrumental in employing artists to produce the 
Shell Guides and many collectable posters, and to make innovative and entertaining films such as The Birth of a Robot (1936), co-directed by Humphrey Jennings and Len Lye. Between them, Grierson and Beddington paved the way for a recognizably modern pact between artists and sponsors, where the latter support the former's experimentation, without insisting on a "hard sell."

Two of Grierson's protégés at the GPO film unit were important pioneers of screendance: Norman McLaren and Len Lye. Lye's earliest and best-known films are abstract animation set to dance music, but his Rainbow Dance (1936) is different, in that it incorporates the human figure, photographed and "rotoscoped" into a series of stylized graphic "sets," so it has much more complex material. For me, this is Lye's greatest achievement. It's very interesting also in terms of the cultural history of the 1930s, because the figure of the dancer you see is Rupert Doone, the founder of the Group Theatre, which commissioned T. S. Eliot's first play, The Rock (1934), and presented Brecht and Weil's early collaborations. Doone was a dancer who wanted a fusion of dance and theatre, initially inspired by Diaghilev (for whom he had danced) and by the new German theatre. I've never discovered how he became involved with Lye, although some other artists like W. H. Auden and Benjamin Britten were involved with both Grierson's documentary unit and the Group theatre. ${ }^{28}$ In any case Rainbow Dance marked a real moment of coming together of different avant-garde currents and the film must have been seen by hundreds of thousands of people through being widely distributed in the cinemas.

I advised on several sections of the Modernism exhibition at the V\&A in 2006, and we ran this film in the last section of the show, where it played for about two and a half months. ${ }^{29}$ When I visited the exhibition, I felt people had their spirits lifted by Rainbow Dance - it's very infectious in a truly audiovisual manner, and an incredibly ambitious piece for that time, working just on the edge of what was possible with the new color processes. You feel that Lye is trying to do everything in one film, just in case he doesn't get a chance to do it again. So this would be my prize example of early screendance, because I think that it produces a wonderful synthesis.

Question: It sounds as if you're talking only about formal considerations.

IC. No, I think there's much more to it than that. These public-service films were produced at a time when the idea of the modern state was beginning to take shape. In 1930s Britain, the state was creating a "public sphere," as we would say today, with bodies that were funded through government, and which projected a vision of a cohesive society. So there is a kind of social philosophy underpinning these films, from the Empire Marketing Board, the Post Office and the Gas Council. They are really about how things will work for you as a citizen - the spoken text at the end of Rainbow Dance is rather quaintly poetic: "The Post Office Savings Bank puts a pot of gold at the end of the rainbow for you. No deposit too small for the Post Office Savings Bank." And I think this was something the filmmakers were very comfortable with; this was their philosophy too. I mentioned Edgar Anstey, who co-directed Housing Problems (1935), and carried his experience from the 1930s into the film units that were created by the nationalized industries post-war, like the National Coal Board and British Transport. These film units continued into the' 50 s and ' 60 s until they were dismantled. The Ford Foundation also became a very enlightened sponsor and really took up the whole idea of documentary with a very liberal social vision, as in a film like We 
Are the Lambeth Boys (1959, dir. Karel Reisz). They certainly weren't just trying to promote Ford products. So I think there is a social philosophy behind many of these works, which sits well with their formal liveliness and vivacity, and it's the kind of thing you also find in some French modernists, such as Léger. As a modernist and a Communist, Léger had a very clear social vision in his work of social inclusiveness. If you look at his later work it is all about co-operation and teamwork, workers working together as in The Builders (1950) or the cyclists and campers in other paintings. I think there is a lot of that in the 1930s and although we might be more likely to see the formal side of it, you've got to consider the broader ideology of democracy and citizenship as well.

Question: I respect this, but it seems important to start talking about these objects as works of art, if one can use that term, beyond works of culture, and within a larger context of aesthetics.

IC: I agree, and I think they are works of art, although sometimes they stand in an oblique relationship to the main currents of contemporary art. If you try to place a figure we are all familiar with, Maya Deren, within this landscape, then I would suggest her early films hark back to the 1920s avant-gardes - just as some of those films were themselves "belated." Of course Deren had been shaped by their vision and she was the inheritor of many of those traditions because of her education and background. But what helps to make her films very obviously "art" in the mid-40s is the sense that they refer back to what has now been canonized, as well

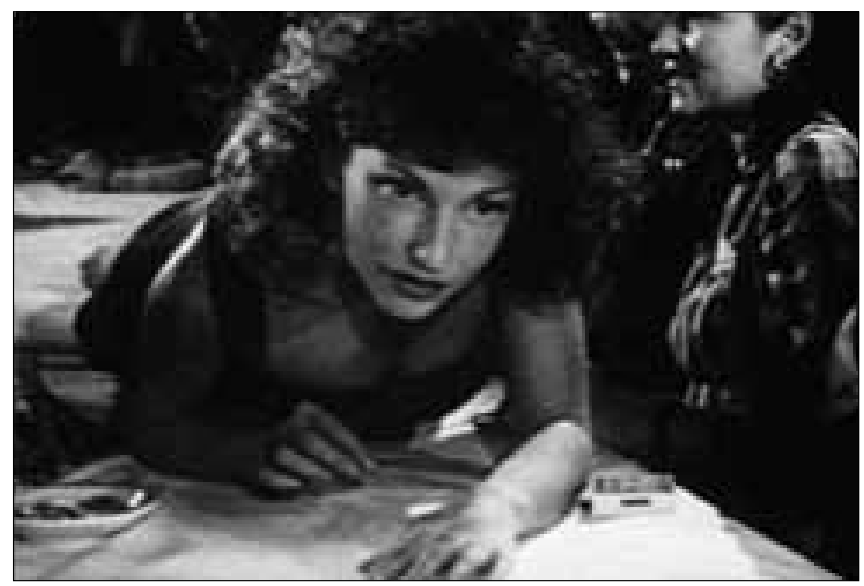

Screen shot from Maya Deren, At Land (1944). Paris: Re:Voir, 2008. DVD. as seeming out of step with the rest of the cinema by the 1940s.

By the 1940s, most of the "historic" avant-gardes had either run their course or reformulated their premises of the 1920s and moved on to a new agenda-which had been forced on them not only by the rise of Fascism and the outbreak of war, but also by accelerating technological development. The aesthetics of the 1940s are in danger of being overshadowed by these major issues, but in many ways this was a highly creative periodone of synthesis when, for instance, there was a fusion of the musical and the melodrama, and a return of phantasmagoric subjectivity (of which more later).

Far from Hollywood, the mid-1940s saw the climax of Eisenstein's artistic achievement. He had probably been the main inspiration for radical filmmakers and for artists in other media in the 1920s and even in the 1930s; and his essays provided the body of theory, which people were using right into the 50s and 60s. But after 1930, Eisenstein completed very few films, although his Alexander Nevsky (1938) was probably seen by more people than all his previous films had been, in view of the censorship they had faced.

After Nevsky "rehabilitated" Eisenstein in Stalin's Russia, he chose to use his new prestige to make another historical film, Ivan the Terrible, whose first part was overtaken by the 


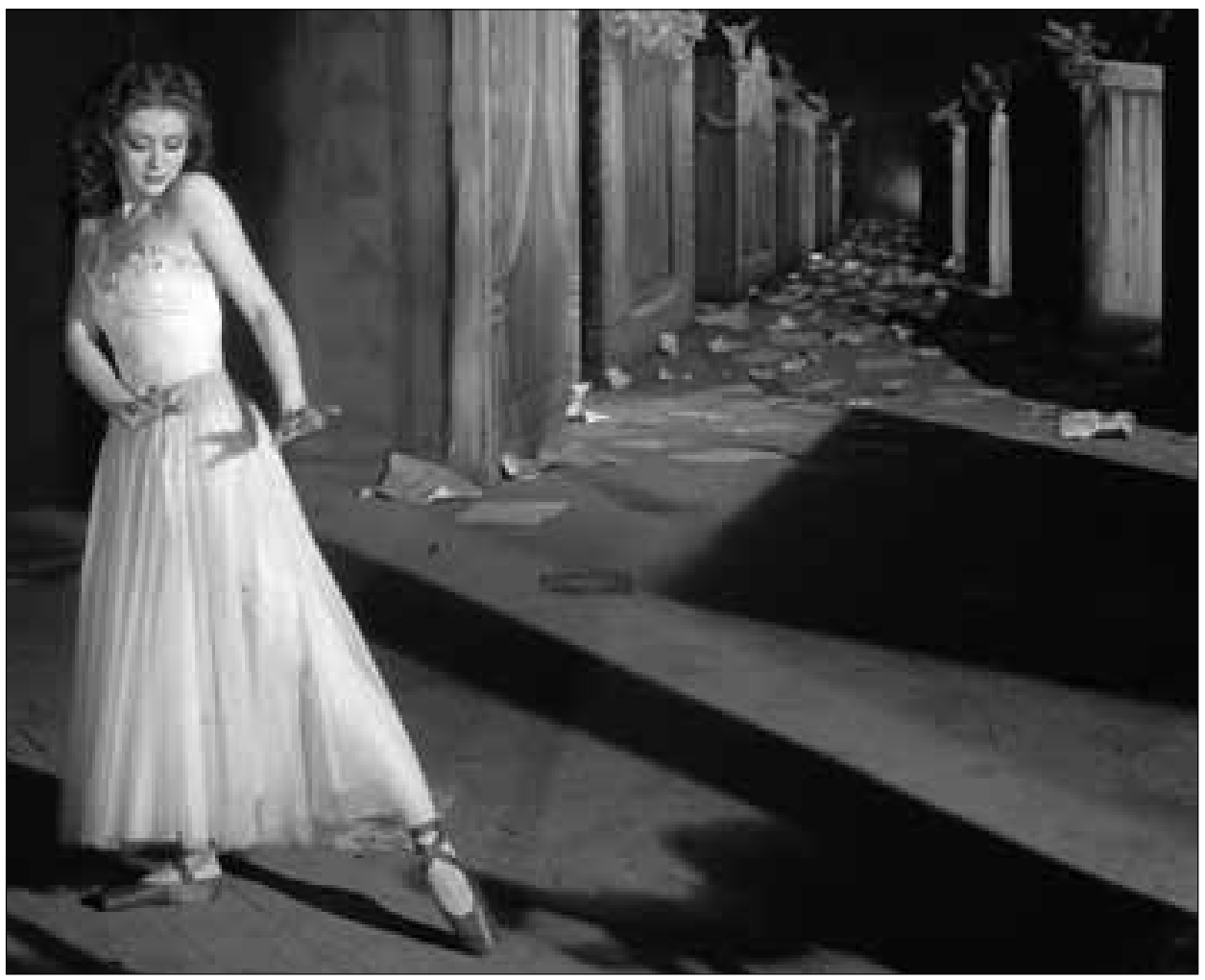

Screen shot from Powell and Pressburger's phantasmagoric The Red Shoes (1948): "Total cinema" of the post-war period. Directed by Michael Powell and Emeric Pressburger. UK: ITV, 2009. DVD.

war and came to be seen as a message from beleaguered Russia, awarded the Stalin Prize and subsumed into wartime propaganda. But the more daring and personal second part, The Boyars' Plot, was banned and not seen until 1958, ten years after Eisenstein's death. By then, it seemed completely out of time. Khrushchev had started the process of criticizing Stalin and Soviet cinema was showing a new modernity in films like The Cranes are Flying (Kalatozov, 1957) and The Ballad of a Soldier (Chukhrai, 1959). Audiences were about to see Les quatre cents coups (Truffaut, 1959) and Saturday Night and Sunday Morning (Reisz, 1960), so the late arrival of IvanThe Terrible, Part // with Eisenstein's later thinking about montage in the era of sound and color, attracted less attention than it might otherwise have done. And of course Eisenstein's vast body of writing, about montage, Disney and much else, was still to be translated. Seen in this light, I would argue that Ivan Part I/ is actually one of the great aesthetic statements of the mid-century — and its mise-en-scene still has a lot to contribute to the evolution of screendance.

After World War Two, Eisenstein still dreamed of a "total cinema" using color, stereoscopy and even variable screen shape. ${ }^{30}$ And, not coincidentally, Hollywood actively experimented with these variations on the classic film format. Hitchcock, in particular, was preoccupied by immersive techniques from 1946 onwards, using "seamless" sequence shots (Under Capricorn, Rope), dream imagery (Spellbound), and even 3D in Dial M for Murder (1954). Meanwhile Bazin, writing in 1946-48 and distinctly hostile to old-style Soviet montage, theorized a new realism, which was influenced by the deep-focus/long-take mise-en-scene of Welles's Citizen Kane 
and Wyler's The Little Foxes, and by Rossellini and Neo-realism. So we have real aesthetic choices here: the "total cinema" of Eisenstein, Hitchcock, and indeed Michael Powell (The Red Shoes, Tales of Hoffmann ) versus Bazinian "realism."

It was "les enfants de Bazin," the filmmakers of the French nouvelle vague, along with all the other new waves of the 1960s (Czech, Polish, Russian, British), who helped produce an international "art cinema" that in many ways seemed to fulfill the long-awaited promise of what cinema might achieve. It was a body of work which had the same kind of moral and formal complexity - the same sense of being rooted in its own national cultures, yet able to travel — that great literature, drama and painting had. And by the mid 1960s, cinema seemed in many ways more important than what was happening in those other media-I called it a "universal theatre" in the Slade Lectures. There was a certain moment when Bergman, Godard, Buñuel and maybe twenty other filmmakers seemed to constitute the front line of what was happening in world culture. It didn't last, but it did hold for a certain period in the' 60 s.

The same 1960s saw a contestation of art cinema, the international art cinema that had a very significant following amongst the international intelligentsia, and the challenge came from artists and theorists — often the same thing — who were interested in minimalism, serialism and the concept of art as a self-referential discourse. This of course goes back to Clement Greenberg's version of formalism, fixated on "medium specificity," which influenced a whole generation of artists. Examples in film are Michael Snow's Wavelength (1967), Yvonne Rainer's Lives of Performers (1972) and Laura Mulvey's and Peter Wollen's Riddles of the Sphinx (1977),

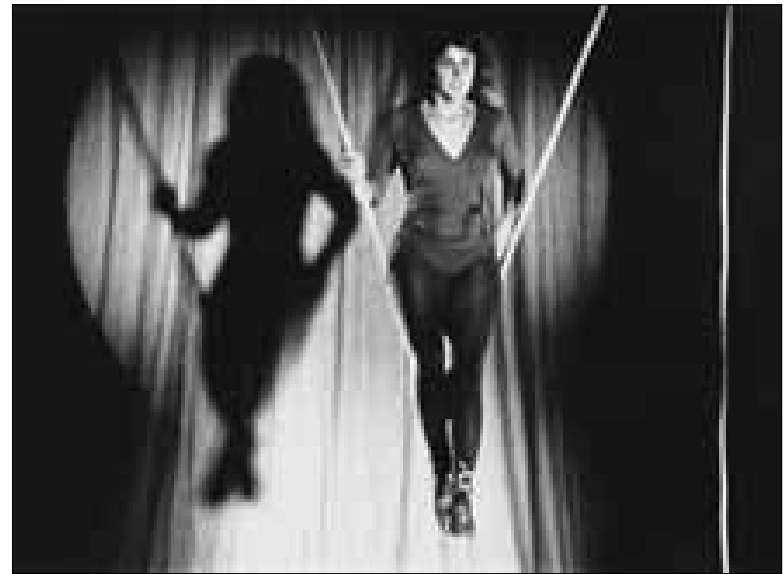

Screen shot from Mulvey and Wollen's Riddles of the Sphinx (1977) explored performance, feminism and film itself. British Film Institute Production B. three films that celebrated in different ways a highly self-referential discourse of film.

One of the leading artist-theorists figures of the movement known as "structural film" (which now seems a rather reductive label), Hollis Frampton, declared in a 1968 performance piece entitled A Lecture: "It seems that a film is anything that may be put into a projector, that will modulate the emerging beam of light."31 His actions during the performance, which essentially involved a $16 \mathrm{~mm}$ projector turned on and off, included holding a pipe cleaner in the light beam — an action which may recall for us Virginia Woolf's delight at that accidental "tadpole" seen on the Film Society screen. Another work from the same period, Anthony McCall's Light describing a cone, first shownin 1973, invited spectators to regard the projector's light-beam as a spectral sculpture, asserting a similarly minimalist/ materialist view of "film." 32

In the 1970s and '80s radical filmmakers took on board a series of critiques and aspirations that were driven by_variously — the rise of feminism, the claims of the Third World, radicalized psychoanalysis according to Lacan and Deleuze and Guattari, and many other challenges to the idea of film having what Frampton scorned as "a coherent normal 
paradigm."33 And while this was going on in one corner, the Hollywood studios, after their acute anxiety during the 60s, were busy devising bigger and better ways of increasing their revenues and keeping control of the international entertainment business. Need I remind you that Jaws (1975) is now regarded as the first "blockbuster"?

So, to end, two open questions that arise from thinking about the history of this approximation to "cinema." 1995-1996 saw widespread celebration of the centenary, and prompted much stocktaking and pondering about "what is cinema?" And this ontological anxiety over defining something that is clearly in flux has continued ever since. A recent example I would recommend is the essay by Yuri Tsivian, "What is Cinema?," subtitled "An Agnostic Answer," which he wrote originally in answer to a post-centenary questionnaire circulated by the French journal Trafic. ${ }^{34}$ The thrust of Tsivian's essay is to move away from essentialist definitions and to recognize that "what cinema is has changed enough times for a history of cinema's identities to be written." ${ }^{135}$ In common with a number of historians of the medium (such as myself), he recognizes that we are dealing with a plural phenomenon, and one that very definitely cannot usefully be defined by a single technological structure or canon of works. This last point is relevant to thinking about your field: screendance. While the practice of defining cinema according to "great works" and established traditions - mainly of narrative-based fiction film — continues, there are many other traditions and uses of, let us call it, the filmic apparatus. So, thinking about cinema from the standpoint of movement, of interaction, of "choreography for camera" could prove as legitimate as many other frameworks. Feel free to enter the business of canon-creation!

The second question, which we can hardly avoid, is one that has stoked the ontological anxiety I mentioned above: what difference has digitization made during the last decade? Is, for instance, Alexander Sokurov's Russian Ark (2003), entirely captured by a digital camera and composited rather than edited, still cinema, albeit by other means? For Sokurov, it was definitely cinema by other means, since he had no intention to make a break with the past. On the contrary, he simply used digital capture as a tool to realize a particular vision he had of making "a film in a single breath," as he calls it. He hasn't actually shot in digital much since then and seems to have no particular interest in it per se.

For many filmmakers (note how this word persists, indeed is becoming consolidated), digital is essentially a tool; but for some theorists, such as David Rodowick, its widespread adoption marks the start of a new era, which has actually replaced cinema, perhaps without anybody noticing. ${ }^{36}$ Or, to put it in older terms, could we describe it as an epistemological break, which is the sort of critical language popular in the 1970s, when people used to argue that there was an epistemological break between early and late Eisenstein (David Bordwell), or before and after Cubism (John Berger). Is it useful to think about an epistemological or ontological

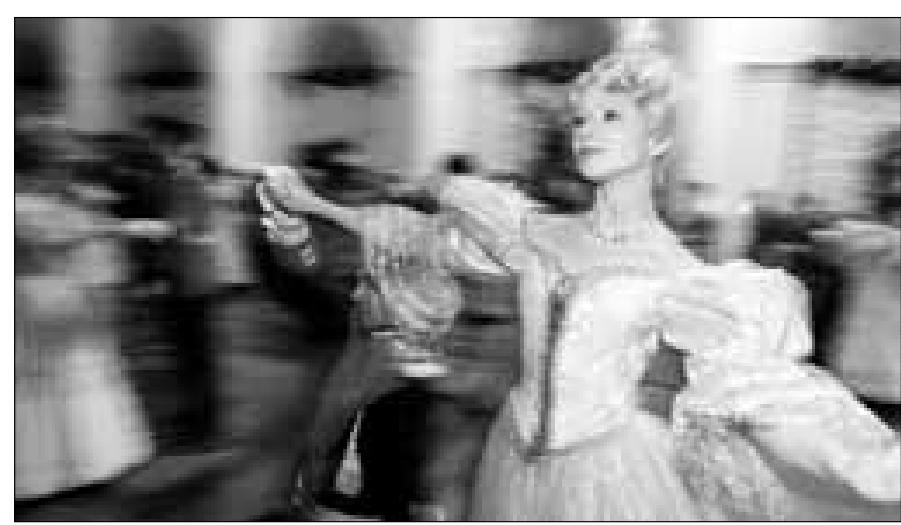

Screen shot from Russkiy kovcheg, or Russian Ark (2002). Cinema by other means, by Alexander Sokurov. Fora-Fil'm, 2003. DVD. 
"break" between the photochemical era and the increasingly all-digital one we're inhabiting? And what indeed are the implications of using digital media to "quote" films-as Godard has done in his Histoires du cinéma, and as I have been doing in this talk?

Question: Screendance has been invented and there is a body of work that one can look at, but one has to apply extant methodologies to reading those works - as was done in the 70 s and 80s in Feminist and Queer Studies and though various other lenses.

IC: Of course, but I think one of the questions for the screendance community is really what to do about work made outside of the concept of screendance, but which appears to belong to it. And clearly there are going to be different positions, with some wanting to be quite purist and consider only work which is produced within a defined set of parameters and intentions. This is going to be a narrow canon, which goes back to Maya Deren and perhaps sees her as its ideal progenitor. Or there is the other extreme, which would want to be quite heterodox and choose material from a wide range of sources, perhaps seeing screendance as a search system to remap cinema according to a set of ideas, which relate to dance in the widest sense. I've heard some of you use those terms when you've talked about the choreographic aspect of a film which has nothing resembling dance in it. So it's conceivably possible to recast the whole history of cinema in terms of a dance dimension and find it everywhere (Frampton cheekily suggested that "the whole history of art is no more than a massive footnote to the history of film"). ${ }^{37}$ But this perhaps loses what specificity you want, and runs the risk of dispersing the idea of "screendance" too widely? It depends what you want to do with the concept ...

\section{References}

Andreyev, Leonid. "Second Letter on Theatre." In Taylor and Christie, 37-38. Originally published as "Pis'mo o teatre.' Shipnovik 22 (1914): 245-47.

Bazin, André. What is Cinema?, Volumes 1 and 2. Edited and translated by Hugh Gray. Berkley: University of California Press, 1967, 1971.

Benjamin, Walter. "The Work of Art in the Age of Mechanical Reproduction." 1936.

Marxists.org. Last modified February 2005. http://www.marxists.org/reference/subject/philosophy/works/ge/ benjamin.htm.

Christie, lan. "Before the Avant-Gardes: Artists and Cinema, 1910-1914." In La decima musa: il cinema e le altre arts. Proceedings of the VI Domitor Conference/VII International Film Studies Conference, Udine, Italy, 2000. Edited by Leonardo Quaresima and Laura Vichi, 367-84. Udine: Forum, 2001.

. "Cinema has not yet been invented" lecture given as part of the Slade Lecture Series at the University of Cambridge, 20 January 2006. "A Cambridge First in Film." University of Cambridge. Last modified 2010. http:// www.admin.cam.ac.uk/news/press/dpp/2006012001.

. "Film as a Modernist Art." In Modernism: Designing a New World. Edited by Christopher Wilk. London: V\&A Publications, 2006.

."'The marvellous is popular!' Dali in the context of Hollywood surrealism." Lecture at the Tate Modern, London, 16 June 2007. "Surrealism and Film Study Day-Part 6." Tate Channel. Video, 61:08. http://channel.tate. org.uk/media/38501522001/24888974001.

. "Painting and the Visual Arts." In Encyclopedia of Early Cinema. Edited by Richard Abel, 497. Abingdon and New York: Routledge, 2005.

."Vladimir Mayakovsky: 1913-1917, Film and Theatre." Framework 18 (1982): 4-6.

Delaunay-Terk, Sonia and Blaise Cendrars, "La Prose du Transsibérien et de la petite Jehanne de France." MoMA. Information at: http://www.moma.org/collection/browse_results.php?object_id=11511. 
Deren, Maya. At Land. Originally produced in 1924. Paris: Re:Voir, 2008. DVD.

"Eye Music." A Century of Artists' Film in Britain. Exhibition at the Tate Britain, London, May 19-August 10, 2003. Information at: http://www.tate.org.uk/britain/artistsfilm/programme1/eyemusic.htm.

Frampton, Hollis. Circles of Confusion: Film, Photography, Video: Texts 1968-1980. Rochester: New York: Visual Studies Workshop Press, 1983.

Mayakovsky, Vladimir. "The Relationship between Contemporary Theatre and Cinema and Art." In Taylor and Christie, 35-37 (cited above). Originally published as "Otnoshenie segodnyashengo teatra I kinematografa k iskusstvu." Kine-Zhurnal. September 8, 1913.

Murch, Walter. "Dickson Experimental Sound Film 1895." FilmSound.org. http://www.filmsound.org/murch/ dickson.htm.

Nekes, Werner. Media Magica. Mülheim an der Ruhur, Germany: Arte, 2004. DVD, 53 minutes.

Rodowick, D.N. The Virtual Life of Film. Cambridge, Massachusetts: Harvard University Press, 2007.

Sidnell, Michael. Dances of Death: The Group Theatre of London in the Thirties. London: Faber, 1984.

Taylor, Richard and lan Christie, eds. The Film Factory: Russian and Soviet Cinema in

Documents 1896-1939. New York: Routledge, 1988.

The Assassination of the Duc de Guise. Directed by André Calmettes and Charles Le Bargy. France: Le Film d'Art, 1908. 15 minutes.

The Eyes, Lies and Illusions: The Art of Deception. London: Lund Humphries in association with Laurent Mannoni and Marina Warner, 2004. Published in conjunction with the exhibition of the same name, shown at the Hayward Gallery, London, 2004-2005.

The Last Machine. Narrated by Terry Gilliam. Directed by Richard Curson Smith. Produced by lan Christie and John Wyver. London: BBC2, 1995.

Tsivian, Yuri. “What is Cinema? An Agnostic Answer." Critical Inquiry 34, no. 4 (Summer 2008): 754-76.

von Herkomer, Hubert. Editorial in The Bioscope (The Independent Film Trade Paper), October 30, 1913: 341.

Ward, John Owen, ed. Oxford Companion to Music. 10 $10^{\text {th }}$ ed. London: Oxford University Press, 1991. S.v. "Colour and Music."

Wollen, Peter. “Two Mayakovsky Scenarios with an Introduction." Screen 12, no.4 (1971): 122-51.

Woolf, Virginia. "The Cinema." The Crowded Dance of Modern Life: Selected Essays. Volume Two. Edited by Rachel Bowlby. London: Penguin, 1995. 54-58.

\section{Notes}

1. Christie, "Cinema."

2. The title was later to become the title of the first issue of the International Journal of Screendance.

3. Selections of Bazin's essays have appeared in the two volumes of What is Cinema?, which were edited and translated by Hugh Gray and published in 1967 and 1971.

4. Bazin,"The Myth of Total Cinema,"21.

5. Woolf,"The Cinema," 57.

6. Woolf,"The Cinema," 56.

7. Christie, The Last Machine.

8. The synchronized sound version now available online was restored in 2000 by Walter Murch and Rick Schmidlin, working at Industrial Light and Magic and George Lucas's Skywalker Sound, in collaboration with the Library of Congress and the Edison National Historic Site. The restoration shows the film with different degrees of digital "repair" (for details, see http://en.wikipedia.org/wiki/Dickson_Experimental_Sound_Film; and for the restoration, see http://www.youtube.com/watch?v=Y6b0wpBTR1s).

9. The fact that the film shows two men dancing has led to its adoption as an early film of significance to gay culture, although Edison scholars are at pains to point out that it is more likely Dickson simply used workmen from the factory when he needed a "performance" to music.

10. Schools were invited to arrange parties to see The Last Days of Pompeii in London in 1913; and King George V and Queen Mary visited the Albert Hall in 1915 to see Cabiria. 
11. Mayakovsky,"Relationship," 36, 37.

12. Evgeni Bauer's career as a director began in 1913 with Twilight of a Woman's Soul, but the rediscovery of pre-revolutionary Russian cinema's extraordinary riches did not begin until the Pordenone festival of 1989.

13. Leonid Andreyev, "Second Letter on Theatre," 37-38.

14. Mayakovsky wrote and appeared in The Young Lady and the Hooligan, Creation Can't be Bought and Shackled by Film, all in 1918, of which only the first survives. On Mayakovsky's complex, ultimately frustrated relationship to Soviet cinema, see Wollen: "Two Mayakovsky Scenarios with an Introduction", 122-51; and Christie, "Vladimir Mayakovsky: 1913-1927," 4-6.

15. Herkomer, Bioscope, 341.

16. On Herkomer and early film, see Christie, "Before the Avant-Gardes: Artists and Cinema, 1910-1914."

17. Christie, "Before the Avant-Gardes"; and Christie, "Film as a Modernist Art," 299.

18. Christie,"Painting and the Visual Arts," 497.

19. Projecting "colour music" was however undertaken by Bernard Klein in an exhibition in London in 1913. (Ward, Oxford Companion to Music, 209.)

20. See Christie, "Before the Avant-Gardes" and the works in the collection "Eye Music" in the 2003-2004 Exhibition "A Century of Artists' Film in Britain" at the Tate Britain.

21. Christie, "French Avant-Garde Film in the Twenties: From Specificity to Surrealism," 37-46. See also Christie, "Surrealism and Film Study Day - Part 6."

22. Bálazs, "The Future of Film,"144-45.

23. Eisenstein,"Béla Forgets the Scissors," 145-49 (italics in the original).

24. See for instance Dwight McDonald's writing for the Partisan Review in 1938-1939, in Taylor and Christie, The Film Factory, 2, 9.

25. Panofsky's paper is available in various contexts, including Gerald Mast and Marshall Cohen, eds., Film Theory and Criticism: Introductory Readings (New York: Oxford University Press, 1974), 151-169.

26. Ibid, 145.

27. Walter Benjamin, "The Work of Art," 10. The films cited, in which ordinary people could appear, are Dziga Vertov's Three Songs about Lenin and Joris Ivens's Borinage.

28. There was a short-lived attempt to form a Group Theatre offshoot, Film Group, in 1936. (Sidnell, Dances of Death, 171.)

29. Modernism: Designing a New World 1914-1939, Victoria and Albert Museum, London April-July 2006.

30. Eisenstein's essay on screen shape, "The Dynamic Square," originally given as a speech to the Academy of Motion Pictures Arts and Sciences in Hollywood in 1930, appeared in print in Close Up, March 1931, and is collected in Film Essays and a Lecture, edited and translated by Jay Leyda (Princeton: Princeton University Press, 1982), 48-65. His essay on "Stereoscopic Films" was written sometime in 1947-48 and appeared in shortened form in Notes of a Film Director (New York: Dover Publications, 1970), 129-137 (based on a Soviet collection edited by Rostislav Yurenev). A fuller version of the essay appears in French in François Albera and Naum Kleiman, eds. Eisenstein: le mouvement de l'art (Paris: Les Éditions du Cerf, 1986), 97-158.

31. Frampton, "A Lecture," 195-96.

32. McCall's work has been revived on a number of occasions and was included in Eyes, Lies and Illusions at the Hayward Gallery in 2004-05.

33. Frampton, Circles of Confusion, 123.

34. Tsivian, "What is Cinema? An Agnostic Answer," 754-776.

35. Ibid, 755.

36. Rodowick, The Virtual Life of Film.

37. Frampton, Circles of Confusion, 123. 


\title{
The Tensions of Technē: On Heidegger and Screendance
}

\author{
Ann Cooper Albright
}

$\mid$ entered the Screendance Network from a slightly oblique angle. On one hand, I was the most unschooled of many of my illustrious colleagues in contemporary examples of screendance, and I certainly was much less addicted to YouTube searching and my computer in general. On the other hand, I came to the table with a curiosity about the historical and theoretical intersections of bodies and machines throughout the twentieth century and a fair dose of feminist film theory. Thus, as people around me chatted about so-and-so's new film, or the latest politics of the latest curator at the latest screenings, I was busy looking out for the ways in which the act of filming dance was implicated in the screened representation and how the ubiquity of screens in contemporary dance affects how we watch movement. That is to say, I have become interested not only in what we are seeing (a particular filmmaker's signature, the long shots, the jump cuts, the choreography, etc.), but in how the very structure of our seeing (both on and off the screen) has been affected by filmic technologies. As we enter the second decade of the twenty-first century, I believe that we must think seriously about the implications of the increasing presence of screens in the dance field as a whole. In other words, how has looking at dance on screen made us look at dance on stage differently?

At first, I must admit that I was a wee-bit put off by what I perceived as the lack of attention to theoretical perspectives in discussions about screendance that I was witnessing in and around the various festivals. But then I began to see that maybe my role in the Screendance Network and The International Journal of Screendance was to call for more intentionality about how screendance helps construct our vision of twenty-first century dancing bodies. There are, of course, multiple tensions between live performance and mediated images, many of which relate to the radically different economies of their respective circulation and exchange. But I believe that these material and conceptual tensions can be very productive if we are willing to examine their interconnectedness. Attention, intention, tension: these words are in the forefront of my mind when I begin to think about the relationship between dance and technology.

In his 1954 treatise, The Question Concerning Technology, philosopher Martin Heidegger connects the terms technology and technique with their etymological root, techne, an ancient Greek concept that refers at once to the skills of the artisan and the visionary power of the artist. Heidegger also links techne to episteme, a way of knowing the world. Thus dance techniques and media technologies are not simply about the capacity of machines (or even the dancer's body-as-machine); they also concern how we come to know the world. For Heidegger, this knowledge is not a passive recognition of what already exists, but rather a method of "bringing forth," a "revealing" of a truth. He writes: 
Thus what is decisive in techne does not lie at all in making and manipulating nor in the using of means, but rather in the aforementioned revealing. It is as revealing, and not as manufacturing, that techne is a bringing-forth [. . .] Technology comes to presence in the realm where revealing and unconcealment takes place, where aletheia, truth, happens.'

Although his philosophical language is incredibly dense, and at times his use of gerunds is delightfully peculiar, what I appreciate in this essay is the idea that technology could render, rather than efface, presence-be it theatrical presence, or a more existential being-in-the-world.

My decision to curate a cluster of short responses to Heidegger's essay was prompted by a discussion in an editorial board meeting last June. There we were brainstorming which historical and theoretical essays might inspire or provoke a cluster of interesting responses. I turned to Heidegger, knowing, of course, that many people react fairly strongly to both his theoretical insights and the legacy of his association with National Socialism in Germany. And yet, despite the awkward fit of history (a lot has happened in the last 57 years) and discipline (philosophy), I felt this essay had helped me to articulate the inherent interconnectedness between dance and technologies, including the ways that dance techniques are, in fact, examples of very effective technologies of the body. Rereading the essay years later, I recognized that even back in the 1950s, Heidegger had thought through how often habit can masquerade as knowledge, as well as the intertwined issues concerning power, desire, and imagination that are embedded within the our relationship to technology. Right at the beginning of his essay, Heidegger elucidates the importance of being intentional about this relationship when he writes:

Thus we shall never experience our relationship to the essence of technology so long as we merely conceive and push forward the technological, put up with it, or evade it. Everywhere we remain unfree and chained to technology, whether we passionately affirm or deny it. But we are delivered over to it in the worst possible way when we regard it as something neutral; for this conception of it, to which today we particularly like to do homage, makes us utterly blind to the essence of technology. ${ }^{2}$

I asked four people who work as artists, screendance makers, and scholars to respond to Heidegger's The Question Concerning Technology from the perspective of their own interests in the field. What follows is a sequence of writings that both speak to Heidegger's essay and each other in unexpected and interesting ways. Prompted by Heidegger's use of etymology to think past the obvious, Ann Dils traces the roots of the words "screen" and "dance." These histories provide a slightly difference perspective on the term screendance which Ann uses as an opportunity to look again at Ghostcatching, a collaboration between Paul Kaiser, Shelley Eshkar, and Bill T. Jones about which she had written over a decade ago. In his essay, "The Sorrow and the Pithy," Kent de Spain provides a trenchant overview of Heidegger's main points, weaving into his analysis a tongue-in-cheek, but also very hopeful, commentary on the problems and possibilities of working in the folds of movement and screens. Lisa Naugle and John Crawford write about their collaboration with Active Space and the ways in which memory and illusion are called forth by their use of the latest interactive technologies. Finally, Tom Lopez channels the ancestral spirits of 
techne and poïesis, two of Heidegger's favorite terms. In Tom's multi-vocal writing, these "twins" are put into dialogue across the divide of time and space, each one commenting and cross-referencing (sometimes contradicting) the other's words. I cannot stop feeling as if Heidegger would be pleased to read these musings sponsored by his essay. I thank my colleagues for taking the time out of their busy lives to share their thoughts on "the tensions of techne."I have no doubt in my mind that the readers will be inspired to continue the dialogue begun on the following pages.

\section{References}

Heidegger, Martin. "The Question Concerning Technology." The Question Concerning Technology and Other Essays. Translated by W. Lovitt. New York: Harper Torchbooks, 1977. 3-35.

\section{Notes}

1. Heidegger, "The Question,"13.

2. Ibid. 4. 


\section{Moving Across Time with Words: Toward An Etymology of Screendance}

Ann Dils

( ne of the analytic strategies that Martin Heidegger uses in his 1954 essay, "The Question Concerning Technology," is etymological investigation. Thinking about the origins of words not only compels us to wonder about the environments in which words arise, but their changing meanings in varied times and places, and the assumptions that underlie our own discourse. Heidegger does this with the Greek root of "technology," techne, reconnecting the word to "the activities and skills of the craftsman [and] for the arts of the mind and the fine arts."1 Referencing Aristotle, Heidegger links techne to episteme —-knowing — and distinguishes technē as a particular kind of knowing: a "bringing-forth." Technology, then, "comes to presence in the realm where revealing and unconcealment takes place, where aletheia, truth, happens."2 This is tremendously affirmative for people involved in screendance, and a useful corrective to writers and other members of the dance community (including myself) who have worried that technology covers over the living presence of the dancing body. In fact, in an essay on the 1999 Ghostcatching collaboration between Paul Kaiser, Shelley Eshkar, and Bill T. Jones entitled Absent/Presence, I initially resisted the idea that we could effectively "capture" a person's movement identity through technology.l now think that we need to move past the dichotomy of immediate live presence versus denatured representation and begin to think about how screendance impacts our perceptions of bodies, movement, and space. It is important to note, however, that "screendance" isn't synonymous with "technology," and that there are further histories to account for in this compound word. Might an etymological investigation of "screendance" tell us something more?

According to the Online Etymology Dictionary, the words "screen" and "dance" come from late Medieval France. "Screen" as a noun (escren) stems from the late fourteenth century, and was associated with firescreens: flat, protective covers that helped disperse heat and light and shield people from flying sparks and exploding logs. "Screen" as a verb meaning "to shield from punishment, to conceal" is also a late medieval usage. Screen as the wire mesh object that sits in a window or door is from the late nineteenth century. Associations with film - screen as a projection space, and terms like screenplay and screen test-are from the early twentieth century. Although the origin of the word is uncertain, "dance" (dancier) as noun and verb came into prominent usage in late 1300s France and spread across Europe. Initially, it suggested the fashionable, early court dances of the period, as opposed to folk dances, which continued to be referred to by older, more place-specific names. The stature of French arts and culture eventually made dance the preferred term across many languages.

Interestingly enough, the words "screen" and "dance" came into common usage as Europeans moved into the Renaissance. Greek and Latin texts were re-discovered and 
through the influence of ancient thought, people began to understand themselves differently, moving away from religion and toward humanism with its emphases on secular life and individual thought and discovery. Both words suggest the employment of technologies to facilitate intellectual, social, and artistic experiences and stimulate ideas, or, echoing Heidegger, as means of revealing. Firescreens had to do with safety, but also with moderating the light in a room, helping people to see the books made more broadly available through Gutenberg's new printing process. Court dance was a means of personal refinement and a political tool. Like screendance today, court dance employed the latest technologies (in clothing design and movement training as opposed to digital technologies) and, through the technologies of print and travel, helped disperse new practices in social and art dance.

In the early twenty-first century (for some the beginnings of posthumanism), screen and dance are nested together as "screendance." No longer an adaptation of live dance to the screen, screendance is its own art form with interconnections to many contemporary arts practices, among them feature films, documentaries, art films, computer games, and digital installations. Early well-known works such as Ghostcatching and the Cunningham/ Kaiser/Eshkar collaboration Hand-drawn Spaces (1998), are now joined by Akram Kahn and Rachel Davies's Loose in Flight, and projects such as David Michalek's Slow Dancing and Ohio State University/ William Forsythe Synchronous Objects. The etymologies of "screen" and "dance" help me think about this more recent history more richly. While screendance is an art experience created for a particular space, it is also a means of restructuring our experience of screens and our perceptions of dancing.

I return to Ghostcatching, watching excerpts of it on the website of the new digital design group that Eshkar and Kaiser formed with Marc Downie, called OpenEnded Group. ${ }^{4}$ What truth is brought forth as I watch Ghostcatching in 2011? Am I aware that perceptual concerns have filtered into, or out of, my understanding of the work? Once my primary concern was with virtual space as a representation of real space, with how the hand-drawn, multicolored ghosts of Bill T. Jones echo live experiences of his dancing. Representations of the body's responses to gravity and to "the floor" were special concerns. Now I am more interested in watching the bodies as they inhabit the screen. In an opening sequence, one of the ghosts seems to push the edge of the screen, dancing out of its frame. Then the screen seems to shift, readjusting to reframe the ghost. Then there is a kind of gracious acknowledgement of this accommodation with the ghost pausing to lift its face towards the top of the screen as a hand reaches just to another edge. At other points, the ghost seems to hang from the top of the screen. The designer has created a duet between body and movement, space and frame. What's important? Top, bottom, or edge? The frame as enclosure or as opening to infinite space? The arms and head inscribe the space; the legs and pelvis, once my focus as indicators of the body's fight with gravity, are barely noticed. The absence of the real filters out or at least shifts over, as virtual space-as created by artists; as recreated through perception - filters in and becomes more present.

At several points a large ghost just begins to fade from view as a new ghost appears. I get a sense of depth from this, but it also makes me aware of a perceptual habit that perhaps I've always had, but have not articulated. Ghosts of other performances, and of images and ideas from many mediums and experiences, are perceived in and contribute to the meanings of dances. But dances are also self-referential, and I find myself keeping 
aspects of dances in memory, reviewing them even as the dance moves forward. Through this filtering process, the development of a dance takes shape and I begin to understand the implications of its rhythmic and spatial patterns, movement motifs, and performances. By keeping older images present, even as new images emerge, Ghostcatching reveals what I've been doing all along: constructing the "truth" of dances out of the previously and the currently seen.

In 1999 I saw the interactive mediation of screens in Ghostcatching as an example of how technology covers over the live presence of a dancing body. For me at the time, the screen veiled an important truth - the weightiness of movement. Over a decade later, I see the same technology as a sort of filter (what Heidegger describes as "enframing") that helps me become aware of my own process of seeing movement, both on and off the screen. Reading "The Question Concerning Technology" makes me wonder whether this change in my perception is due to the omnipresence of screens and their role in changing how I see dance, or due to technology's ability to reflect and refract my own habits. This conundrum - am I a slave to technology, or is it liberating? - is the double-edged sword that Heidegger delineates in his essay. At the end of his writing, Heidegger suggests that we can't readily resolve these questions: "Yet the more questioningly we ponder the essence of technology, the more mysterious the essence of art becomes." In thinking through the implications of technology in screendance, including through etymological investigation and by looking again and again, we can follow Heidegger's path of questioning in order to arrive at better questions and new "truths."

\section{References}

Dils, Ann. "Absent/ Presence." Moving History/ Dancing Cultures. Edited by A. Dils and A.C Albright. Hanover, CT: Wesleyan UP, 2001. 462-72.

Downie, Marc, Shelley Eshkar and Paul Kaiser. OpenEndedGroup. http://openendedgroup.com/. August 27, 2011.

Heidegger, Martin. "The Question Concerning Technology." The Question Concerning Technology and Other Essays. Translated by W. Lovitt. New York: Harper Torchbooks, 1977. 3-35.

Online Etymology Dictionary. Compiled by Douglas Harper. 2001-2010. http://www.etymonline.com/. August 12, 2011.

\section{Notes}

1. Heidegger, "The Question," 13.

2. Ibid.,13.

3. Online Etymology Dictionary, http://www.etymonline.com/.

4. See http://openendedgroup.com/.

5. Heidegger, "The Question,"35. 


\section{The Sorrow and the Pithy: Six Short Statements on Heidegger and Technology}

Kent de Spain

$\mathrm{O}$ $\mathrm{n}$ the 20th of February, 1909, in a brazenly public act of technophilia, F.T. Marinetti carved his initials on the front page of Le Figaro and fired a starting pistol for the headlong human race into the future. Forty-five years, two world wars, and 100 million casualties later, someone finally stopped to ask for directions. In his 1954 essay, "The Question Concerning Technology" (TQCT), Martin Heidegger digs both heels into the ground and, in his own inimitable way, undertakes a meandering philosophical pilgrimage to the "essence" of technology. That essence, as he develops it, has ominous implications for the future of mankind, and yet Heidegger also offers an avenue of hope. In the years since Heidegger's analysis, many dance artists — myself included — have been stretched between two poles: wanting to reach out a hand to embrace a technological future, while knowing the other must still cling to our embodied past. Heidegger's words - the reification of his struggles to understand and articulate the role of technology in his own experience and, through his experience, in human life-can shed some light on our choreographic and aesthetic concerns.

\section{Unfree}

Despite a clear attempt not to jump to conclusions in his careful dissection, Heidegger drops a bombshell early on in TQCT:" .. whether we passionately affirm or deny [technology] ... we are delivered over to it in the worst possible way when we regard it as something neutral."1 A tool is not just a means to an end, a telephone not teleological. Technology is now positioned between humans and being, between the dancer and her dancing. We all now understand the fact that live, three-dimensional movement is inevitably and irrevocably changed when "captured" and "processed" by imaging technologies. What is less clear, but more disturbing, is the thought that we, too-as dancers and humans — are changed in the technological encounter, migrating unnoticed from subject to object. It is no coincidence that Laura Mulvey developed her take on "gaze" theory through the cinematic lens. But with her eye fixed on gender dynamics she may have stopped short of the fuller implications. How we see and understand each other and ourselves is now framed and altered by the objectifying gaze of technology. We have become processed for our own consumption. I do not think that Heidegger would disagree with my adaptation of Lacan: modern man is a symptom of technology.

\section{Gestell}

For Heidegger, the essence of technology is gestell, a process of "enframing," a "challenging-forth" to reveal. Although this idea has some dire implications (see \#5 below), in its simplest form 
enframing is certainly an accurate description of screendance, both in theory and in praxis. But it is easy to be so mesmerized by the motion and meaning in front of us that we forget that the act of enframing is also an act of excluding, the revealing always also a concealing. ${ }^{2}$ Admittedly, making art is making choices. Often, the clearer the choices, the more successful the art. As Anne Bogart points out, "To be decisive is violent ... it destroys every other possible choice, every other option." $\mathrm{A}$ frame is an aperture into a world. It discloses a unique logos, a telos. But death rides piggyback on every act of creation, so we should glance, on occasion, beyond the frame and into the shadows to see what has been cast aside.

\section{Just us volk}

Despite his importance as a philosopher and thinker, it is now impossible, politically and historically, to separate Heidegger from his association with National Socialism in Germany, and his statements and actions in support of Hitler and the Nazi party. The idea of a powerful central government integrating technology, education, and politics in support of the German "people" (volk) must have sounded like nirvana after the chaos of the late Weimar Republic. But the frightening reality of the Nazi use of technology-and the narrowness and violence of their concept of "people" — clearly influenced Heidegger's later concerns in TQCT. Even in a field as innocuous as dance, the politics of technology persists. Who has access to technology? What "people" does it document and serve? Social media and the accessibility of low-end technologies have had a democratizing influence, but high-end equipment (mo-cap, infrared sensing systems, etc.), and the expertise necessary to program and use it, is still beyond the reach of most dancers, particularly those on the cultural margins. What are we missing without them?

\section{Gerund-ing}

Heidegger was in love with the gerund. In wresting control of language in order to articulate his understanding of being, Heidegger queered the surety of verbs, their tendency to be fixed in time and space. As pointed out by Fraleigh, "It seems he wanted to dance being with words. A thing (anything and everything —entity and phenomenon) is not merely a presence-it 'presences' as a 'presencing."'4 But Heidegger's gerunds also compel his ideas into forced labor camps, forever in constant action, an unending state of becoming. In gestell —enframing - Heidegger sees the essence of technology as something not technological, something moving beyond our control; omnipresencing. In his final interview in Der Spiegel he says: "Technology is in its essence something that human beings cannot master of their own accord." ${ }^{5}$ Without our own constant revealing, we could find ourselves in Richard Brautigan's poetic future, when we are "all watched over by machines of loving grace."

\section{Dasein of da times}

It is easy to get so lost in Heidegger's rhetoric that you can miss the practical consequences of his analysis, and this is especially true in TQCT. For Heidegger, the effect of gestell, that challenging-forth toward revealing, is that everything manifests as "standing-reserve." Nature is harnessed through technology to be kept at the ready. That doesn't sound so bad, does it? 
If we need electricity, it is there when we throw the switch. If we need to travel, an airplane is waiting at the terminal gate. But standing-reserve is more than just keeping "enough" of something handy. It is a fundamental reprogramming of being (dasein). In its "setting-upon that challenges forth the energies of nature," technology "unlocks and exposes" nature so that it can be "stockpiled."7 Screendance makes an interesting case study here. Dance was once a scarce resource. It was embodied, and dependent on place and context. Any particular manifestation of dance could happen only once. But Heidegger's construction of gestell would see imaging technologies such as film or video as setting-upon dance for the purpose of extracting some dance essence, challenging-forth dance by pulling it out of being to be stockpiled as standing-reserve. This not only allows spatial and temporal displacement of dance, but also encourages de-contextualization and re-contextualization based on nowpresent personal and/or cultural desires. It also allows the efficient and repeated use of something that was previously defined by its ephemerality. In many ways this is a gift, but I see it as one with Maussian implications. We may all understand that screendance and dance are fundamentally different entities, but the moment we accept the former in any way as a substitute for the latter (as opposed to a complement or comment) we are obligated to repay the giver. Do we know the price we are paying?

\section{The Piety of Thought}

Despite the slowly gathering gloom of Heidegger's essay, he does not, in the end, consign mankind to standing-reserve in service of technology. Instead, he offers a ray of hope through a very human process: poiesis. Heidegger sees in poiesis humanity's role in his metaphysics: a pursuit of truth, a fundamental questioning that uncovers the roots of being by helping being find form. As expounded by Di Pippo in his analysis of Heidegger's use of the term, "poiesis is a response to an overpowering experience of absence and instability," and art, emerging from the poietic, "opens up a world of stable intelligibility and so orients [being]."8 Okay, but how does that help?

Perhaps Heidegger anticipated the razor's edge upon which we now sit as screendance artists, balanced precariously between embodiment and technology, because his antidote to the dangers of technology is to deeply and relentlessly question the essence of technology, not just in abstraction, but through the process of creation. We need to make work. And as we delve into the materials of that working process-humans in motion, light and shadow, focus and framing - we need to attend to what we find out about ourselves. Will looking through a viewfinder make us see the world with technological eyes, capturing the essence of dance to fulfill digital desires? Will we want to embody the technologies, bringing them into our intimate sensory and kinesthetic spaces and, by so doing, somehow humanize them? If Heidegger could shape his human thought toward exposing the essence of technology, can we not somehow cleave a path with and through technology to reveal more about the essence of humanity?

There are still dangers, but they are of our own making. If we abdicate responsibility, if we say technology is a "tool," then we pretend that it exists apart from us, and Luddites and technophiles can sit back and argue its merits and morals. There is a reason we feel a tension between ourselves and technology: we are tethered, so much so that we can no longer find the border between us. If we want to move, we must move forward together. 
In the end, "The Question Concerning Technology" is less a philosophical treatise than it is an ethical call to arms. By example and through his ideas Heidegger exhorts us to engage, and through engagement question, and through questioning come to awareness, and through awareness act, and through action mold our being-in-the-world. "The Question Concerning Technology" is the question concerning humanity: can we maintain our values throughout our complex negotiations with the world around us? In the face of everything he understands about the essence of technology, Heidegger still votes yes.

\section{References}

Augstein, Rudolf and Georg Wolff. Interview with Martin Heidegger, September 23, 1966. Reprinted as "Nur noch ein Gott kann uns retten." Der Spiegel. May 31, 1976.193-219. Digitized at http://web.ics.purdue.edu/other1/ Heidegger\%20Der\%20Spiegel.pdf. 1-18.

Bogart, Anne. A Director Prepares: Seven Essays on Art and Theatre. London: Routledge, 2001.

Brautigan, Richard. The Pill Versus the Springhill Mine Disaster. New York: Dell Publishing, 1968.

Di Pippo, Alexander Ferrari. "The Concept of Poiesis in Heidegger's An Introduction to Metaphysics."Edited by David Shikiar. Thinking Fundamentals: IWM (Institut für die Wissenschaften vom Menschen) Junior Visiting Fellows Conferences 9, no.3 (2000): 1-33.

Fraleigh, Sondra Horton. Dance and the Lived Body: A Descriptive Aesthetics. Pittsburgh, PA: University of Pittsburgh Press, 1987.

Heidegger, Martin. "The Question Concerning Technology." The Question Concerning Technology and Other Essays. Translated by W. Lovitt. New York: Harper Torchbooks, 1977. 3-35.

\section{Notes}

1. Heidegger, "The Question," 4.

2. Choreography is also an enframing practice - a technology all its own-but, to my mind, it more easily exceeds its frame, spilling over into space and experience. Screendance tends to be more tightly controlled; it is both flattened and narrow and, therefore, more focused.

3. Bogart, A Director Prepares, 45.

4. Fraleigh, Dance and the Lived Body, 164.

5. Augstein and Wolff, Der Spiegel interview, 9.

6. The Pill Versus the Springhill Mine Disaster, 1.

7. Heidegger, "The Question," 15.

8. Di Pippo, The Concept of Poiesis, 32. 


\title{
Reflections on Heidegger: Performing Translations in Active Space Environments
}

\author{
Lisa Naugle and John Crawford
}

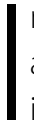

n recent years, digital media technologies have expanded our ability as performing artists to transcend the physical boundaries of where and how individuals and groups interact. Ubiquitous screen-based modalities such as Skype, Facebook, and Twitter invite us to consider the pervasiveness of technology as well as the transformative aspects of interacting through electronic media in real time. In Martin Heidegger's 1954 essay, "The Question Concerning Technology," he challenges us to consider the impact of technology "in the realm where revealing and unconcealment take place." His discussion of how human interaction with technology involves both a "danger" and a "saving power" provides us with a context to understand what happens when we bring the "machines and apparatus" of digital media into contact with live dancing bodies. In this paper, we reflect upon experiences drawn from bringing choreographer Lisa Naugle's explorations of structured improvisation into contact with intermedia artist John Crawford's investigation of interactive environments using the Active Space system. ${ }^{2}$

For almost twenty years we have engaged in collaborative research using digital media within dance, deriving real-time imagery from movement. We create interactive media and performance environments using an evolving collection of custom, real-time media objects called Active Space. These environments also may incorporate optical motion capture and other advanced technologies for representing human movement. While we believe that the essence of dance can never be captured or fully reproduced through any technology, digitally mediated spaces are useful because they allow us to synthesize multiple representations and to interact with these representations in space and in time. Embodied relationships between illusion and memory can create cognitive pathways for increasingly rich dance-media interactions.

For example, in Ootoo (2006), created with choreographer Ted Warburton, we deal with themes of illusion, identity, and multiplicity. Student dancers in two locations (Irvine and Santa Cruz, California) simultaneously interact with projections created by the Active Space system, merging live video from both sites into a painterly, abstract representation of movement, accompanied by more realistic views of the dance projected on other screens in each theatre space.

In Urban Fabric: Prague (2005), created with composer Martin Gotfrit, we combine abstracted cityscape images and sounds with live narration, dance, and musical accompaniment. Entering the stage space as a dancer, I (Naugle) am aware that where I locate myself is critical to being seen by the video cameras as well as by the audience. Once I find the location where all cameras, audience and other on-stage performers can see me, I begin to articulate small movements on a variety of levels, "testing" how much effort I need to expend for the system to activate and respond to me. In the moment of moving, 
I become more present, realizing the visual landscape projected on the screen behind me requires me to make internal notes. My proprioceptive skills tell me when I am out of camera range, and how long to wait until the mirror image of body disappears or changes into something else. In my role as an interactive performer I am challenged to be fully present in each moment, drawing a link between recognizable images, abstractions and my improvised dancing. The visual and sound elements performed live by Crawford and Gotfrit are new to me and I must pace my evolving relationship with these elements in an arc for the piece that connects with a live audience. The dance itself is fleeting but the images of my body are persistent and repeated on screen. Any part of my choreography can be arrested in time and framed in a layered montage of metaphors and abstractions. My inner voice hooks into a particular theme or performance dynamic and my movement follows. Long durations of stillness provide counterpoints while media elements collide, giving the appearance that nothing is complete. The Active Space system and I work together to generate imagery that converses with itself. My chance to build up a particular moment mobilizes a consciousness of multiple dimensions interacting and giving way to new possibilities for meaning.

Drawing on Heidegger's formulation, we posit that the interactive experience pushes the potential of enframing in our Active Space media objects, which include systems for multi-channel live video and audio processing, generative animation, musical composition, media base storage/retrieval, and high bandwidth networking. Techniques for locating oneself in multi-dimensional spaces have long been employed on the stage and in the studio. To be fully present in a responsive media environment, a performing artist must become available to an increased level of awareness, knowing that even the smallest movement can be amplified, mediated, translated and presented many miles away from the actual place and time of performance. Furthering Heidegger's notion of enframing, the dancer becomes an active participant to create frames of representation and continues to be part of the enframing process as movement material is captured and re-presented. For example, Active Space motion tracking objects can perform real-time sensing and analysis of location, speed, duration and various other characteristics of dancers' movement, and the results of this analysis may be used to synthesize video and audio materials. This occurs not only in the same location and the current time, but also may involve artifacts, which are presented in remote environments or at a future time.

In creating an Active Space performance, installation, or workshop, we base our process on the understanding that exploratory research is a way of "bringing-forth" and a necessary first step toward developing knowledge and skill. We attend to language and watch the descriptors emerge, learning how embodied interaction actually evolves from one kind to another through movement, voice, and other forms of dynamic expression. Looking for the "essence" of interactions with technology and affirming body-centered practices, we develop a series of compositional and improvisational approaches to stage space, screen space, and sound space. As the technological apparatus interfaces with human bodies, we aspire to build systems with the potential to evolve through trial and error, remaining open to technological limitations while seeking opportunities for intuitive learning.

The interplay between improvisational and compositional elements is of particular interest when we combine motion tracking with motion capture. Motion tracking involves real-time sensing and analysis of location, speed, duration, and various other characteristics 
of movement. The results of this analysis are fed to a computer system that generates video and audio in response to the movement. Motion capture is the technique of sampling movement in 3D space and creating graphical representations of that movement. Typical applications of motion capture tend to produce realistic animations, but the aesthetic focus of our Active Space work extends beyond realism to explore non-linear associations, along with issues of embodiment and reflexivity.

Heidegger's concerns with the dangers of "enframing" and his notion of "stockpiling" are particularly relevant in the performance context, where dancers can sometimes feel that the technology on stage is "happening to them," or "out of their control." Situations where performers influence technical elements in a direct, immediate way have the potential to challenge such perceptions, creating opportunities to generate new internal imagery and proprioceptions to enhance motivation and stimulate interactions between the performers themselves as well as with the technical elements. Dancers in mediated environments develop increasingly sophisticated vocabularies of responses and apply them to create contexts and mechanisms for communication. The media system itself becomes a message, or a series of messages, an embodied sequence of codes, exchanged between performers and with audiences.

To date, we have worked with dancers, choreographers, musicians, composers, scenic and lighting designers, directors, actors, visual artists, animators, filmmakers, interface designers, computer scientists, engineers, architects, and others intrigued by issues of embodiment, technology and interactive experience. A collaborative research approach encourages all participants to explore a variety of dance/media approaches. Such experiences can contribute to a convergence between artistic practice and emerging technology.

\section{References}

emptLab: Embodied Media + Performance Technology Lab. http://embodied.net/active-space. August 18, 2011.

Heidegger, Martin. "The Question Concerning Technology." The Question Concerning Technology and Other Essays. Translated by W. Lovitt. New York: Harper Torchbooks, 1977. 3-35.

\section{Notes}

1. Heidegger, "The Question," 13.

2. Developed by intermedia artist and software designer John Crawford in association with choreographer Lisa Naugle and composer Martin Gotfrit. See: http://embodied.net/active-space. 


\section{The Twins Paradox: Bifurcation \& Unification}

\section{Tom Lopez}

"Once there was a time when the bringing-forth of the true into the beautiful was called techne. And the Poiēsis of the fine arts also was called technē."

$$
\text { —Martin Heidegger (trans. by William Lovitt) }
$$

In this thought experiment, Technē and Poiēsis will be twins.

We will set them on their separate ways and see if they reunite.

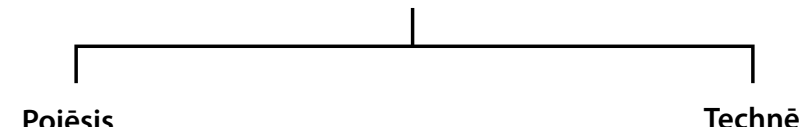

Technology hungers.

[author] Which came first, man or technology?

Technology nourishes.

Technology grows.

However, technology reveals a perilous crossing.

We encounter T-rex glaring, springing,

landing precisely, without error.

We fear technology, turn inward, examine our selves and our lives, re-examine our selves and our lives, our selves, our lives. Technology repeats...

Technology thunders.

Technology shocks.

Technology barks.

T-minus-eight-and-counting distresses us, demands of us acts of grave inconsequence. We recoil and seek solace.

We wrap our family and friends in technology and talk about it, not them, it. It estranges us, and them, and thus... Technology repeats.

Technology leers.

Technology lures.

Technology arouses.

Our be-ing changes and we all gain, small accomplishments, little victories, tiny implants.

Technology breathes on our neck, down our back, and across our thighs.

We reveal our own seduction, our e-motional senses susceptible to every hairbreadth of movement.

[philosopher] "The impression comes to prevail that everything man encounters exists only insofar as it is his construct. This illusion gives rise in turn to one final delusion: It seems as though man everywhere and always encounters only himself." ${ }^{2}$

[author] What is the essence of your experience?

[audience] We watch dance and listen to music.

[author] What is the nature of this phenomenon, this appearance?

[audience]

The causa materialis is human, dancers \& musicians. The causa formalis is wave, light waves \& sound waves.

The causa finalis is performance, music \& dance. The causa efficiens is human, choreographer \& composer.

[philosopher] "The four causes are at play within bringing-forth and through bringing-forth whatever is completed through the arts come to their appearance. ${ }^{3}$ Yet the more questioningly we ponder the essence of technology, the more mysterious the essence of art becomes."

[author] What is the essence of modern technology?

[philosopher] "The essence of modern technology starts man upon the way." 
Technology grabs us by the shoulders and shakes us; remains faceless and apathetic, our gaze rolls askew.

Technology faces us, points us in a direction, and we move. But technology moves us and simultaneously inhibits our sight.

Engines move the train forward and block our view forward, our destination hidden from us. Instead, our view lies through glass, colored by smoke and steam.

We sit and forage for familiar features in the blur beyond the window.

Technology breaches the mountain and tunnels our vision. Our tunnelogical movement runs transverse to our view, our eyes flitting back and forth; we cannot see where we are going.

It is easier to simply watch our reflection in the glass.

We move.

Technology roars. We emerge from the tunnel and see that technology moves massive mountains, the entirety of our perpendicular past, time itself.

Technology bridges lakes and rivers.

Far below, the water satisfies, fulfills, pleasures, condenses in droplets of joy, waterfalls of magic.

Technology spans the valley floor, the streambed, carries us ahead while we look away.

Technology soars forward and we stare sideways, clouds tinted by fingerprints on the windowpane. Technology is a causality, falling, free of gravity.

Technology sparks from fire and lightning! Technology appears clear, illuminating, intelligent; but technology filters the marsh and swamp.

Technology screens the dragon in the meadow, bleeding black and yellow.

Technology moves us passed fortune and danger, frames our vision, and focuses our gaze upon ruins and treasures.

We move faster. [author] Ah, chemin de fer, the "way of iron!" I love trains, especially in early film and musique concrète, their massive and animalistic features expose themselves beautifully through sound and image, the way of metaphor.

[philosopher] "The way is a way of thinking. ${ }^{6} \mathrm{~A}$ train is surely an object. But then it conceals itself as to what and how it is.? This includes holding always before our eyes the extreme danger. ${ }^{8}$ The closer we come to the danger, the more brightly do the ways into the saving power begin to shine and the more questioning we become."

[author] The film winds its way through sprockets and the light shines through each individual image cutting a rectangular tunnel through the smoky room, a flickering aspect ratio against the wall. I want to look directly into the technology. I want to feel the bright light burning into my retina, so tempting, so dangerous. I avert my eyes and find something else. What is the essence of your experience?

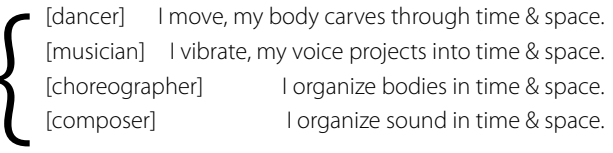

[philosopher] "The four causes are the ways, all belonging at once to each other, of being responsible for something."10

[collaborators] We pool our efforts, share responsibilities.

[philosopher] "The four ways of being responsible bring something into appearance."11

[collaborators] We gather our selves and our resources, we meet and devise and improvise.

[philosopher] "The principle characteristic of being responsible is this starting something on its way to arrival. ${ }^{12}$ But causa belongs to the verb cadere, 'to fall'..."13

[collaborators] In a flash of inspiration, an artifact arrives! Yes, something falls to the ground, a tree limb; picked up, it extends the length of the arm and articulates a grander arc, broken in two and scraped against itself, it extends the pulse of the voice and accentuates an arboreal rhythm. How can it function, like this, or that, or another way?

[philosopher] "Does the essence of technology endure in the sense of the permanent enduring of an Idea that hovers over everything technological, thus making it seem that by technology we mean some mythological abstraction?"14 
Technology flies so far away, out of our control, and burrows under our skin, so far within, beneath even our senses.

Technology penetrates everything, including us.

Technology sears our eyes, strikes from the sun and clings to us like armor.

Technology bears arms, wears shells like the tortoise, crab and oyster, but hollow and withered within.

Technology lies, beside us, in parallel motion, murmuring secrets between our ears.

Technology chafes our dry, cracked toes.

Technology infiltrates us and we speak through it. Our tongues mash and tear at the conch. Our fingers rub and rub and rub the surface. Technology erases one digit at a time.

Faster still.

But technology moves, where?

Where does technology aim?

A hobo riding the rails, a pregnant sorceress.

Our purpose grows, our be-ing emerges.

Our goal feels dangerous, mysterious, and adventurous;

meanwhile, technology builds a torrent of indifference.

We work at cross-purposes with technology and the distance between us expands and shrinks with every invention.

But technology is not the adversary, s/he is us; we are two forces addressing individual needs. Are the needs mutually exclusive?

Is there common ground?

Technology moves in all directions.

We fly off the tracks, accelerating toward zero-g.

We feel weightless and aimless, trapped by our own devices and borderless frontiers.

If we stray, we will find ourselves frozen, sitting in a sack, without purpose. [collaborators] Our essential core resides in time \& space, neither technological nor mythological. Our temporal \& spatial happening is here and now, must be right here at this exact place and right now in this exact moment.

[philosopher] "Here and now and in little things, that we may foster the saving power in its increase."15

[collaborators] We play with it and practice and practice with it and play.

[philosopher] "So long as we represent technology as an instrument, we remain held fast in the will to master it. ${ }^{16}$ Everywhere we remain unfree and chained to technology."17

[collaborators] Actually, there is another chain we feel more acutely. Falling reveals the mundane yet most profound bond amongst us, gravity. Technology is anti-gravity. We can escape the embrace of time \& space; happenings appear anywhere and anytime, may be everywhere and everytime. Bodies float upside-down, reflect from ceilings, dance on other bodies, and effervesce in mists.

[author] What is the essence of this technology?

[philosopher] "Technology is a means to an end, and technology is a human activity. ${ }^{18}$ Technology is therefore no mere means. Technology is a way of revealing."19

[collaborators] Technology is no mere end either. The feedback loop siphons us into an infinitely variable chain of transducers: from aural to mechanical to visual to electrical and back again...

[philosopher] "Unlocking, transforming, storing, distributing, and switching about are ways of revealing." ${ }^{\prime 2}$

[author] Technological revealing is through capturing and releasing. In trains, the coal is captured and energy is released through steam. In rivers, the water is captured and energy is released through electricity.

$\longleftrightarrow$ [philosopher] "The earth reveals itself as a coal mining district. ${ }^{21}$ The coal that has been hauled out is stockpiled; it is on call, ready to deliver the sun's warmth that is stored in it. ${ }^{22} \mathrm{~A}$ hydroelectric plant is built into the river. The river is now a water power supplier."23

[author] In music and dance, the energy is captured and art is released. Who can account for the change in mass?

[philosopher] "But where have we strayed to?"24 
Technology supports our rituals.

We should undertake something, offer something, confront our unforeseen ambition.

Our goal is a deluge of creation upon those in need.

And we can see who needs help,

we can renew our spirits in heart-to-heart exchanges, we can offer simple gifts.

Ever faster.

We may be confused, but if we are sincere, we can grasp hands and laugh again without regret.

We can travel without blame.

We can let ourselves be drawn and heard.

We can sigh and face humiliation with a flood of tears.

Remorse will disappear; our be-ing will shift from weeping to the moaning ecstasy of joyful pleasures.

Our objective gathers together, be-coming before us.

Despite the danger, we must maintain genuine composure without rage and anger, maintain determination without compromise, and face the insults.

We unify in gravitational attraction. Here and now, on this spot, we rise, with dignity, releasing the $g$-force.

We vibrate our sounds into music, our bodies into dance;

we ripple benevolence outward, balancing the world. In this way, the earth is our devoted companion.

We create our humble offering: music and dance,

so fast, they blend into one,

so fast, there remains no time for space.

$$
\text { stillness—silence. }
$$

Our arrival brings us to a body of waters; we are wet with waves of aspiration. Ideas and feelings inspire one another to spiritual achievement, and transform us into pure empowerment.

We experience relativity, chaste energy exchanges through forces in motion, sublime success. [philosopher] "Could it be that revealing lays claim to the arts most primally, so that they for their part may expressly foster the growth of the saving power. ${ }^{25}$ Thus the coming to presence of technology harbors in itself what we least suspect, the possible arising of the saving power."26

[author] In art, waves are recorded and projected. Through recording, the camera and microphone enframe the light and sound waves. Then later (perhaps only nanoseconds, though later nonetheless) through projecting, the waves are enframed again, in a different temporal \& spatial context from whence they were recorded (perhaps on a screen and through a speaker).

[philosopher] "The essence of modern technology shows itself in what we call enframing. ${ }^{27}$ Enframing blocks the shining forth. But the rule of enframing cannot exhaust itself solely in blocking all shining forth."28

[author] The double-act of en-framing (recording and projecting) is like the journey of the traveling twin, whose experience crossing two different time-frames illustrates principles of relativity. We witness the power of time travel the sublime paradox of simultaneity.

[philosopher] "Yet when destining reigns in the

$\longleftrightarrow$ mode of Enframing is the supreme danger."29 As soon as what is unconcealed no longer concerns man even as object, but does so, rather, exclusively as standing-reserve, and man in the midst of objectlessness is nothing but the orderer of the standing-reserve, then he comes to the very brink of a precipitous fall, that is, he comes to the point where he himself will have to be taken as standing-reserve." ${ }^{130}$

[collaborators] We are moving and sounding and sweating. If you are here \& now, you can feel and smell our effort. Or you might be far from here, our signals carried to you across great distance at the speed of light. You might be later than now, our signals carried for you across long duration. This is our expertise. We store our energy in berries and buds; spreading, burying, and nurturing our crafting until springing-time.

[philosopher] "The bursting of a blossom into bloom."31

$\longleftrightarrow$ [audience] Waves of light from projectors saturate our eyes and waves of sound from speakers drench our bodies, simultaneously in time-lapse and slow-motion. In a sea of splashy real-time multi-site hyper-media, an emergence is revealed in full-dimensional glory. 
The waters disappear into the horizon.

Magnetism pulls us toward strength, creativity, and heaven.

We should remain unique within technology, because technology will grab us, disfigure us, and leave us to die.

But we will survive, endure, and triumph. [collaborators] We are the ether and our senses are subsumed by a topography of relativity, receding $\longleftrightarrow$ and cascading into the event horizon.

[philosopher] "The arts brought the presence of the gods, brought the dialogue of divine and human destiny, to radiance."32

[audience] Shhhhhhh, we're watching and listening... Poiẽsis were born side-by-side, looking into each others' eyes, and moment-by-moment, basking in simultaneity. But they were moved into the universe. They traversed unique spatial terrains and temporal frames. They each felt their trajectory to be wholly visceral and completely coherent, each felt their own lifeline was the one reality. Yet when they reunited, one was younger than the other. They should have been puzzled by the inconsistencies of where they had been and what they had seen and heard, but they were too astounded by the sheer joy of looking into each others eyes again, celebrating synchronicity. They did not notice that one was younger than the other. They did not worry about the implausibility of it all, the implausibility of literally everything, the implausibility of the very fabric of the entire universe around them, or the implausibility of nothing less than their existences. They were not destroyed by the technical or gravitational or existential forces at work on their unified be-ing.

\section{Notes}

I Martin Heidegger, The Question Concerning Technology and Other Essays, trans. William Lovitt (New York: Harper \& Row, 1977), 34.

\begin{tabular}{|c|c|}
\hline 2 lbid., 27. & 18 Ibid., 4. \\
\hline 3 lbid., 11. & 19 lbid., 12. \\
\hline 4 lbid., 35. & 20 lbid., 16. \\
\hline 5 lbid., 24. & 21 Ibid., 14. \\
\hline 6 lbid., 3. & 22 Ibid., 15. \\
\hline 7 Ibid., 17. & 23 Ibid., 16. \\
\hline 8 lbid., 33. & 24 lbid., 12. \\
\hline 9 lbid., 35. & 25 Ibid., 35. \\
\hline 10 lbid., 7. & 26 lbid., 32. \\
\hline 11 lbid., 9. & 27 Ibid., 23. \\
\hline 12 lbid., 9. & 28 Ibid., 28. \\
\hline 13 Ibid., 7. & 29 lbid., 26. \\
\hline 14 Ibid., 30-31. & 30 Ibid., 26-27. \\
\hline 15 Ibid., 33. & 31 Ibid., 10. \\
\hline 16 Ibid., 32. & 32 lbid., 34. \\
\hline
\end{tabular}

17 Ibid., 4. 


\title{
Introduction: Amelia Jones
}

\author{
Harmony Bench
}

th

n her 1997 essay "'Presence' in Absentia: Experiencing Performance as Documentation," arts scholar Amelia Jones offers a précis of her 1998 monograph Body Art: Performing the Subject, while orienting the discussion toward the problematics of analyzing live art exclusively through its documentation. Listing her age when Yoko Ono, Vito Acconci, Valie Export, and others were performing key works, Jones reflects on the impracticability of her presence at these events - she was 10, or 12, or 15, etc. Her absence does not deter her, however, from critically analyzing work she did not witness. She notes, "I approach body artworks through their photographic, textual, oral, video, and/or film traces. I would like to argue, however, that the problems raised by my absence (my not having been there) are largely logistical rather than ethical or hermeneutic. That is, while the experience of viewing a photograph and reading a text is clearly different from that of sitting in a small room watching an artist perform, neither has a privileged relationship to the historical 'truth' of the performance..."' Aside from dance documentaries and documentations that fill dance history professors' shelves, screendance has not generally been concerned with the truth-bearing mark of authenticity that Jones describes. As a discipline, however, dance is haunted by that rhetoric.

Like live art, body art, and/or performance art, dance as a scholarly and practical discourse clings to the 'live' dancing body against the onslaught of media-even when choreographers integrate video or projected media elements into their stage-based performances. Fidelity to the "live" comes, on the one hand, from studio-based practices that refine bodies into articulate and agential skeleto-muscular subjects, and on the other, from scholarly corrections to a Western dance history that first asserted dance's ephemerality and then lamented its disappearance in time (as opposed to emphasizing the lived histories or bodily memories of dancers, for example). As performance theorist André Lepecki notes, the characterization of dance as ephemeral and as lack-in need of a stable supplement such as the photographs and films from which Jones analyzes body art performances-has been reworked through theoretical discourses such as deconstruction into "a powerful trope" for dance scholarship and analysis. ${ }^{2}$ Though Jones is located within a visual arts discourse, she nevertheless seems to speak to the situation of dance and screendance scholars:

It is my premise here, as it has been elsewhere, that there is no possibility of an unmediated relationship to any kind of cultural product, including body art. Although I am respectful of the specificity of knowledge gained from participating in a live performance situation, I will argue here that this specificity should not be privileged over the specificity of knowledge that develops in relation to the documentary traces of such an event. While the live situation may enable phenomenological relations of flesh-to-flesh engagement, the documentary 
exchange (viewer/reader $\leftrightarrow$ document) is equally intersubjective. Either way, the audience for the work may know a great deal, or practically nothing at all, about who the performer is, why she is performing, and what, consequently, she "intends" this performance to mean. ${ }^{3}$

If ephemerality is key to dance's ontology and physical co-presence is key to dance spectatorship, then scholarship has as yet been unable to fully reconcile dance's disappearance with technologies that allow its preservation, duplication, playback, and broadcast-even as scholars rely on the rejected technologies in order to conduct their own analyses. I therefore cannot help but see a parallel between Jones's defense of her historico-analytical project and the legitimation screendance artists and scholars seek from a discipline aesthetically and politically committed to the "live" performing body.

Screendance scholars are not, by and large, bypassing the medium of representation looking for an originary live dance event hidden behind a cloak of edits. Indeed, since Maya Deren wrote on the topic in the 1940s, screendance works have been considered more or less hybrid entities unaccomplishable within a dance or screenic medium alone. Jones's emphasis on documentation of performance events requires some translation before her arguments can be applied to works that are created specifically for screen media. Luckily, Jones initiates this translation herself, reminding readers of Rudolph Schwarzkogler's 1966 work in which he appeared to mutilate his penis - a performance fabricated after the fact through the circulation of photographs that supposedly attested to the event's occurrence. ${ }^{4}$ The performance, however, did not take place as such: the photographs created a fictional event from images of a "male torso with bandaged penis (a razor blade lying nearby)." The photographs became the site of performance. Likewise, in screendance, the screen is the site of performance. This is not to say that the contents of the screen are unrelated to preexisting choreographies or stagings of a work (think for example of William Forsythe's One Flat Thing Reproduced variously incarnated onstage, onscreen, and online), but that each entity supplements and grounds the other. Quoting Derrida, Jones notes that nothing can be seen in and for itself, except through mediation, and it is the multiplication of "supplementary mediations that produce the sense of the very thing they defer: the mirage of the thing itself, of immediate presence ..." Neither dancing body, nor choreography, nor screen is self-sufficient.

Jones's article allows us to consider screendance practices from a related discipline and perhaps offers a workaround for some of the aesthetic assumptions that, spoken or unspoken, persist in dance and screendance scholarship. I have asked Hannah Kosstrin, Jason Farman, and Melissa Blanco Borelli to consider "Presence' in Absentia" in relation to their own work to see what further terrains of bodies and screens, embodiment and mediation, may be opened up by this article. In this way, we can better situate screendance-already a multiplicity of screenic and choreographic convergences-within a context of historical, analytical, and artistic projects as well as within a context of both intersecting and divergent disciplinary vocabularies. I have thus asked Kosstrin to reflect on written dance notation as a form of documentation that "presences" dance in its own right. I have asked Farman to speak about the movement of bodies and real-time screen experiences in mobile media narratives. Finally, I have asked Blanco Borelli to discuss the modes and politics of "presencing" and "absenting" in music videos. 
In Kosstrin's exploration of written dance notation, she suggests that co-presence, that ethico-ontological index of "live" performance, can be created between a dance notation score and its reader in a manner similar to that described by Jones encountering body art performance through its documentary traces. Kosstrin hinges this co-presence on the performativity of the notation score. Though written, the document does not fix the choreography it records. Rather, by trying to record what remains consistent in a dance (documenting a choreography rather than just one performance of it) the score leaves room for later interpretations. Indeed, the score as such is already a site of multiple interpretive possibilities that have congealed into a fluid representation of a dance.

There are obvious mediational differences between dance notation and screendance, but a dance notator's attendance at rehearsals and performances is not dissimilar from a videographer's take upon take, edit upon edit that finally takes shape as something like the choreographic event it records (or like the event that never fully existed as such) but which is distinct from it. Each format requires a process of distillation, the notator peeling away performers' individual affectations, mistakes, and quirks to reveal a consistent choreographic structure underneath the performers' executions, and the filmmaker sorting through shots to assemble the film or films buried in a choreography (whether performed by dancers or objects in motion). It is difficult to know whether screendances remain open in the way Kosstrin argues notation scores do; ${ }^{7}$ it is difficult to know whether notation scores can truly be open if they are an endpoint for a choreography rather than an inspiration for new movement (in the way that many performing artists use scores as puzzles for performers to work out during performance). It seems to me, however, that screendances and notation scores share an inherent instability - they are always "like" something else, an object of representation, but never fully coincide with any work to which they might refer as a documentary trace.

What most interests me in Kosstrin's response to Jones's essay is her description of the notator moving to the inside of a work, occupying a space within the movement, and embodying a choreography before committing it to the page. Can a filmmaker or screen artist work from inside a choreography in the same way (without excessively prioritizing the dancers or their movements - if one uses dancers at all)? How do screendance makers defeat surface images that wrap a choreography in a plastic sheen? Can we describe screendance works in terms of interiority and exteriority, not of characters but of choreography? Are there methodological distinctions we might make between screendances made from the inside versus those made from the outside (without falling into an easy trap of asserting commitments to dance on the one hand or film/video on the other). Are there extremes to these interior/exterior positions such that they might be differentiated aesthetically as well as philosophically? So-called haptic images that blur and escape the full command of the eye (of the camera or of the viewer) might be one example, but surely there are others.

In his discussion of Rider Spoke, a participant-activated, mobile device-enabled performance by the London performance group Blast Theory, Farman raises the question of embodiment in asynchronous engagement. Whereas Amelia Jones describes having an affective relationship with body artists through photographic and video documentation, Farman suggests that encountering the recorded voices and documentary traces of other participants in Rider Spoke fosters intimacy with anonymous persons. This intimacy exists not in spite of technological mediation, but because of it. The soft whisper-hiss or confident 
fluidity of a recorded voice in the listener's ear foregrounds what Farman calls a "sensoryinscribed" body. As a site of sensory inscription, which is to say, a site of organized and culturally-mediated sensations, the listener's body supplements that of the recording by receiving sensuous signals asynchronously-their transmission carried forward after the cessation of their broadcast from some now-absent body.

Sensory inscription, a repertoire of culturally determined and practiced sensations, similarly allows screendance audiences to affectively participate in a screen choreography. But more than establishing kinesthetic empathy for a screen-body, a viewer participates in the screenic movements that take place through camera motion and editing. Over the course of a century of cinema, viewers' bodies have been attuned to synthetically as well as organically induced/produced sensations. Given the body as endpoint, is it possible to distinguish among these sensations and their (culturally, socially, technologically, bodily) mediated sources? While we cannot be said to experience the same sensations as one another (since each person individually registers sensation through the unique configuration of their corporeal apparatus), do our bodies as affective repositories predetermine a finite number and type of sensation that may be registered, or is our ability to sense infinitely expandable, provided we can find means of producing sensation? As screendance practices continue to expand to include Internet sites, mobile devices, and imaging technologies, what new kinds of sensory experiences can screendance open up through its experimentations with body, movement, image, and screen? What will be their relationship to temporality and spatiality, to "presence" and embodiment? If screendance holds under its umbrella works in which screen and dance found and ground one another, can it also contain works in which screen and dance repel or even reject one another, refusing to act in a chain of supplementarity, reaching instead toward a choreography of strange and disorienting images-in-movement, a hallucinatory choreography of optical effects?

Borelli reflects on learning choreography from Janet Jackson's music videos in her youth. The corporeal engagement she describes is similar to that suggested by Kosstrin in reading notation scores, with the crucial distinctions that the dancer (not a director) is making the translation from screen to body, and that such a transfer of movement happens on a much larger scale by virtue of circulating through popular media. In her attempts to dance like Janet, Borelli shows the privileged access that what she calls "popular screen dance" (including Hollywood dance musicals, music videos, and dance on television) has to the intersection of body and screen. But not only is popular screen dance a privileged site of corporeal and screenic negotiation, it is additionally a site of spectacle, which, Borelli notes following Debord, is a social relationship mediated by images. Learning a dance from a Janet Jackson music video, the young Borelli participates in the music video as spectacle, moving the social relationship from a visual to a more fully corporeal register, mapping Janet's moves onto her own body, incorporating them in order to re-perform and reproduce Janet and the capitalist structure that supports her.

Borelli finds Amelia Jones's argument that there is no possibility of an unmediated relationship particularly useful, even as Borelli suggests that as a fan, learning choreography from a music video gives her the feeling of knowing a celebrity more intimately than she actually does. ${ }^{8}$ This mediated intimacy offers the possibility, Borelli suggests, of an intersubjective relationship. Yet, the relationship that is established is not between Melissa Blanco Borelli and Janet Jackson, it is between Borelli-the-fan (a construct of the corporate 
machine) and Janet the icon/brand (also a construct of the corporate machine). Like Jones, Borelli thus gives no benefit to a supposed unmediated encounter: "it is that mediated self, i.e., Janet-as-celebrity-brand/body, that allows for a social relationship to exist between Janet and her fans."

Borelli's analysis of popular screen dance begs the question, what kinds of social relationships are fostered by dance onscreen, since the screen as a site continues to change and proliferate? Are there anti-spectacle screendances, and if so, does that mean, again following Debord, that they destroy the image as such, or that they challenge the social relationships created through the circulation of images? If, as Borelli suggests in her encounter with Janet Jackson, the accessibility of celebrity is contingent upon the presence of a literal and/or metaphorical screen, what kinds of screens and frames must be in place to access non-celebrities, and do anonymous or unknown performers promote or prevent the kinds of relationships Borelli describes? How do screendance audiences accommodate these alternate modes of engagement?

Each of the authors I have asked to comment on Amelia Jones's essay give us new tools to think through the hybrid practices that fall under screendance. I find Kosstrin's notion of working on the inside of a choreography, Farman's negotiation of sensory inscription in relation to a screen, and the social relationship Borelli establishes between bodies and images to be especially fruitful additions to a conversation on the possibilities of dance onscreen.

\section{References}

Auslander, Philip. "The Performativity of Performance Documentation." A Journal of Performance and Art 28, no. 3 (2006): 1-10.

Jones, Amelia. " 'Presence' in Absentia: Experiencing Performance as Documentation." Art Journal 56, no. 4 (1997): $11-18$.

Lepecki, André. "Inscribing Dance." Of the Presence of the Body: Essays on Dance and Performance theory. Edited by André Lepecki. Middletown: Wesleyan University Press, 2004. 124-39.

\section{Notes}

1. Jones, "'Presence' in Absentia," 11.

2. Lepecki, "Inscribing Dance," 131.

3. Jones, "'Presence' in Absentia," 12.

4. Philip Auslander has also written on performance artworks that have been staged only for a camera. See his essay, "The Performativity of Performance Documentation."

5. Jones, "'Presence' in Absentia," 15.

6. Jacques Derrida, "That Dangerous Supplement," Of Grammatology (1976): 154, quoted in Jones, "'Presence' in Absentia," 14 .

7. Experiments in net.art and interactive installation offer examples of maintaining the openness of a screenbased work.

8. Readers of Hollywood gossip magazines would also claim an intimate knowledge of the celebrities they follow, which suggests that the ability to move in tandem with a video is only one example of media providing a platform for (uni-directional) intimacy. 


\section{Notation Score as Embodied Documentary Presence: A Response to Amelia Jones's "'Presence' in Absentia"}

Hannah Kosstrin

In response to Amelia Jones's "Presence in Absentia," I would like to reflect upon written dance notation, specifically, Labanotation, as a form of documentation that, as Harmony Bench notes in her introduction to this section,"presences" dance in its own right. Through a written score containing symbols that denote where the body goes in relation to direction, spatial orientation, weight, time, and musicality, Labanotation reproduces multiple dimensions for documenting performance.' As such, it provides documentary and performative traces of the choreographed bodies it mediates. Notation scores are created by people present for the work, but are often read by those in absentia; thus, my reading of Jones's article generated the following questions: Must one be present-in the fleshto witness the dance? Does dance notation create a "being-there?" And if so, what kind of co-presence is established? How is the performative document of notation similar to/ different from a photograph or film?

In terms of historical and theoretical analysis, a notation score and a film of a performance are different kinds of documents. There is a danger, for example, in analyzing a documentary film of a dance (as opposed to a screendance), and considering that filmed version "the dance" instead of recognizing that it is one version of "the dance." Peggy Phelan points out that often we-students, historians, video audiences-get used to a specific filmed version of a performance, and that particular document becomes the work, instead of understanding that the performance was the work and the film is a documentation of it. ${ }^{2}$ Similarly, Ann Hutchinson Guest identifies that a notation score presents the essence of a work due to its ability to capture many performance moments: "Video records an individual performance; notation records the work itself, not the performance of it." 3 Though Guest separates a work's performance from its existence as an entity, her definition opens the documentary scenario to allow the many voices that comprise a score-numerous rehearsals, performances, dancers' and choreographers' input - to become part of a fluid document. This fluidity presences these many elements of the work that could become absent through the passage of time. While a film or even a photograph, as an individual document, captures one performance-arguably preserving a certain performer's charisma that may be lost in a notation score - the plasticity of the notation score as a fluid document allows for many future attempts at presencing the work with different bodies. In doing so, the work has the potential to evolve while referencing a consistent set of symbols.

As a performative document, a notation score offers more information about a choreography or choreographic process than can be contained in photography or film, yet its symbols signify movements that need interpretive translation: Labanotation requires 
literacy. Jones states, "the specificity of knowledges gained from participating in a live performance situation ... should not be privileged over the specificity of knowledges that develop in relation to the documentary traces of such an event." ${ }^{4}$ Though it is a form of documentation, Jones does not encounter in her study of body art a notation score, which is a documentary trace that demands specific knowledge. In order to draw information from a score, the viewer must read notation in order to fully understand what the page portrays. Often, a Laban notator and a director reading the score are different people; one translates through embodiment into notation, one through notation into embodiment. Dancers, moreover, do not necessarily read notation in order to learn a piece from a director who does read the score. While Jones does not include restagings of the work she discusses, her mediation, like that of the director, occurs through her own making sense of the performances from which she was absent through their photographic remnants and documentary traces.

Jones addresses the argument that body art and a documentary photograph need each other to prove the other's existence. ${ }^{5}$ Thus, once the notator has created the notation document, how does she bring a "viewer" into the performance via the documentation? Through reading a notation score and by going through the motions with the body, a reader/viewer creates a new performance through his or her interaction with the document. The notation score, in effect, confirms the performance of a work, but one that unfolds across a series of events that could include rehearsals and performances. ${ }^{6}$ Like the photographer documenting body art, the dance notator is not physically represented in the document, but the document exists as a result of her labor. The notation ghosts the performer-subject's body, while supporting its significance through written signifiers denoting the performers' corporeality.

A person's interaction with a notation document creates a mediated reproduction of a performance. As Bench asserts in this discussion, photographs and screendance are sites of performance. The score is also a site of performance; it displays aspects of a work that may be missed by viewing it live, and it exists as a set of edited decisions that left parts of the work, or ways of articulating it, so to speak, on the cutting room floor. In the score of Anna Sokolow's Kaddish, for example, the words of the Jewish Mourners Kaddish visibly interweave between and rely upon the movements (via symbols) in a way that is not as overt as performance. This documentary choice highlights the centrality of the Kaddish prayer's rhythmic patter (which is linked to its spiritual effect) to the dance. ' In the interactive score for Bebe Miller's Prey, ${ }_{1}^{8}$ furthermore, "Bebe Notes" in the score's margin correspond to video clips on a companion DVD featuring Miller's explanations as to how to perform certain movements. ${ }^{9}$ In contrast to a documentary performance site with an often-absent choreographer, the Prey score presences Miller's physicality. The notators for these scores, Lynne Weber and Valarie Williams, made editing decisions on how to represent the dance on the page such that future directors and dancers can effectively re-presence it. Neither the dancing body nor the notation score contains all the information that comprises the complete work. It is through the intermingling —or co-presencing_of a director's fleshy embodiment with the information laid out in the score that a dance is fully presenced.

This co-presence as a result of interaction is also reflected in Jones'encounters with the photographic and filmic documents of the performances she discusses. Jones references Roland Barthes' having-been-there of a photograph, ${ }^{10}$ the notion that by seeing an image, 
a viewer experiences its temporal presence. ${ }^{11}$ Similarly, a Labanotation score creates an embodied or a time-lapse of, being-there, since a notator is usually present for numerous rehearsals or performances of a dance in generating a score. First the notator, and later the reader/director, must go through the motions of the performance, launching herself into a kinesthetic sensation of the work from the inside out in order to fully engage with the notation score as a performance document.

Jones articulates her experiences of body art, including Annie Sprinkle's Public Cervix Announcement, which she knows both through photographic record and via live performance, and Carolee Schneemann's Interior Scroll, which she only knows through documents. However, Jones knows neither of these performances from the inside. The notation score offers a third kind of presencing to the photographic record and the live event: it becomes a document of a performance's innards. While it does not reproduce, for example, the audience's experience of gazing into Sprinkle's cervix, ${ }_{12}^{12}$ or watching Schneemann extract the long paper chain from her vagina, ${ }^{13}$ as does a photograph, if a notated score existed, it might offer instructions for reproducing Sprinkle's and Schneemann's experiences of performing these works, thus replicating the events from the performers' perspectives. The score becomes a documentary intermediary through which a reader embodies distinct traces of a work that she may or may not have experienced in fleshy performance, yet she brings her own flesh into the document through reading/performing the score and gaining an internal (performative) understanding of the work.

Because a dance notation score is written, as it were, from the inside of a performance, it offers its readers aspects of a work that are less accessible from a video document of a dance. The traces of movements' intention and initiation that the symbols portray are not always evident in a video, or even in watching a performance, especially if a movement is subtly initiated from within or if the movement does not clearly manifest the intention. Additionally, a score often contains a glossary with the notator's comments about the dance's background, motivation for moments as dictated by the choreographer, and notes about dancers' timing.

Dance, like body art, is an ephemeral form that relies on the moment of performance, as well as its disappearance, ${ }^{14}$ and on the people involved with it, to presence it. Phelan notes, "Performance's potency comes from its temporariness, it's [sic ] 'one time only' life."15 Jones shows the pertinence of performance's potency through her discussion of her absence and presence of experiencing body art through photographic documents and live performance. One cannot reconstitute a performance moment. Yet, through mediation of the space in/as performance document, Labanotation presences dance-and along with coached versions of the dance passed down from dancer to dancer and photographs of it, a viewer/reader can re-presence that from which she was initially absent.

\section{References}

Hutchinson Guest, Ann. Labanotation: The System of Analyzing and Recording Movement. $4^{\text {th }}$ ed. New York: Routledge, 2005.

Jones, Amelia. "'Presence' in Absentia: Experiencing Performance as Documentation." Art Journal, 56, no. 4 (1997): $11-18$.

Jordan, Stephanie, ed. Preservation Politics: Dance Revived, Reconstructed, Remade. London: Dance Books, Ltd., 2000. Phelan, Peggy. Unmarked: The Politics of Performance. New York: Routledge, 1993. 
Thomas, Helen. "Reconstruction and Dance as Embodied Textual Practice." In Rethinking Dance History: A Reader. Edited by Alexandra Carter. New York: Routledge, 2004. 32-45.

Weber, Lynne, notator. Kaddish. Choreographed by Anna Sokolow. 1974. New York: Dance Notation Bureau, 1980. Notation graphics by Mira Kim, 2007.

Williams (Mockabee), Valarie, notator. Prey. Choreographed by Bebe Miller. 2002. New York: Dance Notation Bureau, 2005.

, dir. Prey: An Innovation in Dance Documentation: Enhanced Process Based Instruction: Companion DVD-Video for the Labanotation Score Prey. Chor. Bebe Miller. 2001. The Ohio State University Department of Dance, 2005.

\section{Notes}

1. Close analysis of Labanotation reveals the biases of its early twentieth century Western cultural roots.

2. Phelan, Unmarked, 31.

3. Hutchinson Guest, Labanotation, 6.

4. Jones, "'Presence' in Absentia," 12.

5. Ibid., 16.

6. Dance scholars have taken up the issue of historical bodies in debating processes for and determining authenticity of reconstructing dances for a contemporary stage. Issues of reconstruction include how to make an established dance relevant to contemporary audiences; how much to change movement to fit dancers' bodily and training abilities; how to capture the essence of a dance long after its first performance; and how to balance information from a notated score, if there is one, with kinesthetic memories of dancers who performed the piece or otherwise had a bodily knowledge of it. See Thomas, "Reconstruction and Dance" and Jordan, ed., Preservation Politics.

7. See Weber, Kaddish.

8. See Williams notator, Prey.

9. See Williams dir., Prey: An Innovation in Dance Documentation.

10. Jones, "'Presence' in Absentia," 16.

11. Roland Barthes, "Rhetoric of the Image," Image-Music-Text (1977): 44-45, quoted in Jones, "'Presence' in Absentia," 16.

12. See Jones, "'Presence' in Absentia," 16-17.

13. See Ibid., 12-13.

14. Phelan, Unmarked, 146.

15. Ibid., 178 . 


\section{Mobile Media Performances as Asynchronous Embodiment}

Jason Farman

W hile traveling through Tokyo in the early-2000s, media theorist Howard Rheingold began to notice a change taking place around him: the people walking the streets were "staring at their mobile phones instead of talking to them."1 Toward the end of the decade, in 2009, there was an important shift that took place-mobile phones were used more for data transfers (such as text messages and Internet use) than voice communication. This shift in the way mobile devices are being used has a profound effect not only on performers who utilize these media, but also for the cultural imaginaries around the significance of documents and live interactions. As this transition began to make itself apparent, especially in the college students around me who preferred to send a text message in lieu of making a phone call, I noticed the historical tensions surrounding the status of asynchronous engagement playing themselves out in the everyday actions of mobile phone users. Taking up this tension, UK artists Blast Theory created a performance that confronted the problems of documentation discussed in Amelia Jones' thought-provoking exploration of presence, performance, and supplementation. By looking at the mobile media performance of Rider Spoke, I align with the modes of embodiment Jones gestures toward and how such embodiment can be attained through asynchronous engagement. This mode of asynchronicity, in which users engage each other without regard to the demands of realtime performance, demonstrates how ideas of community are fostered through varying experiences of time and documentation. In performances like Rider Spoke, "the live is an artifact of recording media. Liveness exists not as a prior condition, but as a result of mediatization,"2 as Matthew Causey notes.

In 2007 at the Barbican Museum in London, visitors to the Rider Spoke performance were given a bicycle, a helmet, and a mobile device. The device, a Nokia N800J, was equipped with an earpiece and a microphone. Rider Spoke asked participants to ride around the streets of London, guided along their journey by the voice of Blast Theory co-founder, Ju Row Farr. The first objective for participants, as directed by Farr, was to "relax and find somewhere that you like. It might be a particular building or a road junction. When you have found somewhere you like, give yourself a name and describe yourself."3 Blending the modes of audio exploration as seen in the works of Janet Cardiff and the attachment of narrative to place in the projects like [murmur] and Yellow Arrow, participants would press record on the device's interface and speak into the microphone to record their own story related to the location. Through a triangulation by mobile phone towers or WiFi access points, their narratives were geotagged. The recordings were then archived and made accessible to any other participant who happened upon that same location. Participants in Rider Spoke were prompted to either "Hide," which allowed them to find a location related to one of Farr's prompts such as "Find a place that your father would like and record a message 
about it,"4 or "Find Others," which allowed users to "seek" other people's narratives located throughout the city. These two options were the mobile device's main interface and highlighted the piece's relationship to social gaming and a common history of childhood play.

Because participants record themselves or listen to others' recordings, Rider Spoke is a performance of the process of documentation. While engaging in this act of documentation, which transforms the urban landscape into much more than a physical environment by turning street corners into sites annotated by digital information, the interactors of the piece produce a distinct sense of embodied space. Embodiment here is intersubjective: I eavesdrop on your stories and you eavesdrop on mine. As Blast Theory co-founder Matt Adams describes, "It sits on this boundary where you're on your own, you're alone, at night, on a bike, which already separates you from the pedestrians and from the road traffic and you're making these very personal recordings. But, of course, they are broadcasting. It's recorded. It's stored there, and anyone who comes after you can listen to it.".5 Thus, this mode of embodied engagement, though asynchronous, is intimate: I hear your voice in my ear. This intimate voice however no longer signals immediacy and presence. Instead, the person I am connecting with has simply left me a voice message, not dissimilar from one I might get from a friend who missed me when they called.

Drawing from Jones' implementation of poststructuralist understandings of the body, which point toward "the insufficiency and incoherence of the body-as-subject and its inability to deliver itself fully, ${ }^{\prime 6}$ and the phenomenological modes of embodiment that inform her readings of body art, I posit a "sensory-inscribed" body that ultimately understands mediation as a primary mode of being-in-the-world. In my forthcoming book, Mobile Interface Theory, I elaborate on the sensory-inscribed as a body that is not only conceived out of a sensory engagement across material and digital landscapes, but a body that simultaneously incorporates socio-cultural inscriptions of the body in these emerging spaces. This type of phenomenological hermeneutics aligns with Jones' notion that "there is no possibility of an unmediated relationship to any kind of cultural product, including body art." Though my individual understanding of my body involves the senses, it also involves the ways my body is written by the cultural codes of others (and my attempts to write myself into being by taking ownership over some of those codes). The ways we engage intersubjective embodiment is simultaneously a sensory experience through the body and also a process of decoding and encoding the various cultural inscriptions that inform every interaction.

To elaborate, the asynchronous engagement of sending a text message to someone on a mobile device offers a strong example of the sensory-inscribed body. The senses are involved on many levels: the person writing the text incorporates the screen into his or her material world and also projects the self into an imaginary realm where the receiver is located. The person is also keenly aware of the temporal aspect of text messaging, where time between responses is a sensory experience. These examples, which can be developed and augmented in many ways, are an incomplete picture of this embodied experience. The use of a mobile phone for texting also has cultural inscriptions that the user must contend with, including notions of when it is or is not appropriate to text. This aspect is even being legislated, as many states across the United States are passing laws prohibiting the use of mobile devices while driving. The sensory and the inscribed combine to inform a reading of the body while texting. Additionally, the sense of the temporal is also a site of inscription. 
As Nicola Döring and Sandra Pöschl argue, "Extended response times can be perceived as creating an uneasy silence, while short response times might nonverbally communicate thoughtfulness, eagerness, or closeness." ${ }^{18}$ Thus while the experience of time is a sensory one, it is also a mode of reading as we imbue the time with meaning and significance. These two modes of embodiment converge to demonstrate that with an asynchronous connection to our body and the bodies of others across media, the sensory-inscribed offers a useful way to understand performance in mediatized spaces.

Encountering the documents left by others around the streets of London in Rider Spoke is an embodied, intersubjective experience that asks us to reimagine the ways we experience intimacy in the mobile media age. As I come across someone's recording, which was left in this exact spot, I understand it as a supplement of their bodily "presence," but the recording also clearly demonstrates that all embodied engagements enact this process of supplementation. As Jones notes, "Body art flaunts the body itself as a loss or lack: that is, as fundamentally lacking in the self-sufficiency ... that would guarantee its plenitude as an unmediated repository of selfhood." ${ }^{\prime 9}$ The intimacy gained in Rider Spoke recognizes the continued deferral of intersubjective connection. Thus, the production of embodied space is ongoing, never settled, always being created across various modes of time since synchronicity does not deliver full-presence any more than the documented narratives left by the interactors of Rider Spoke.

Being together in synchronicity or encountering each other through asynchronous means, a sensory-inscribed mode of embodiment keenly understands that our experiences of intersubjectivity are often produced across vast geographic distances (i.e., without any physical tangibility of one another) and through highly mediated forms. As we abandon the "presence" of the voice on mobile phone calls for the asynchronous documentation of text messages, we are in the process of producing bodies through asynchronous documents. Even when engaging each other face-to-face, we are continually developing context through our bodies and our relationships to the spaces we produce. This context, however, is never fully saturated and, as Jones notes, we may actually come to understand our interactions more fully in hindsight, when the synchronicity that is typically privileged is later reexamined and incorporated into our sense of being-in-the-world.

\section{References}

Benedictus, Leo. "Grab Your Helmet: It's Showtime." The Guardian, October 3, 2007, 28-29.

Causey, Matthew. "The Screen Test of the Double: The Uncanny Performer in the Space of Technology." Theatre Journal 51, no. 4 (1999): 383-94.

Döring, Nicola, and Sandra Pöschl. "Nonverbal Cues in Mobile Phone Text Messages: The Effects of Chronemics and Proxemics." The Reconstruction of Space and Time. Ed. Rich Ling and Scott W. Campbell. New Brunswick, NJ: Transaction Press, 2009. 109-136

Jones, Amelia. "'Presence' in Absentia: Experiencing Performance as Documentation." Art Journal 56, no. 4 (1997): $11-18$.

Rheingold, Howard. Smart Mobs: The Next Social Revolution. Cambridge, Mass.: Perseus Books, 2002.

Blast Theory, "Rider Spoke." Filmed October 2007. Youtube, 6:13. Posted October 2009. http://www.youtube.com/ watch? $=$ gkAQX8cz9hc.

."Rider Spoke by Blast Theory." Filmed 2009. Youtube, 3:18. Posted June 2009. http://www.youtube.com/ watch?v=jyl78ZFo--Y. 


\section{Notes}

1. Rheingold, Smart Mobs, xi.

2. Causey, "The Screen Test of the Double," 384.

3. Blast Theory, "Rider Spoke."

4. Benedictus, "Grab Your Helmet," 29.

5. Blast Theory, "Rider Spoke by Blast Theory."

6. Jones, "'Presence' in Absentia," 13.

7. Ibid., 12.

8. Döring and Pöschl, "Nonverbal Cues," 111.

9. Jones, "'Presence' in Absentia," 14. 


\section{Dancing in Music Videos, or How I Learned to Dance Like Janet . . . Miss Jackson}

Melissa Blanco Borelli

re n 1989, when I was a senior in high school, Janet Jackson's album Rhythm Nation 1814 was released. A slick concept album, it addressed social injustice and economic disparities, universal concepts that my teenaged naiveté witnessed on a daily basis as I got off the $L$ train in the East Village of New York City to go to school. Some of the lyrics advocated social consciousness and I learned many of the songs by heart, but my overwhelming response to that album was corporeal. I wanted to dance like Janet. I remember programming our family's VCR for the MTV premiere of the 30-minute long form music video, which featured the first single from the album, "Miss You Much," along with two other songs, "Rhythm Nation" and "The Knowledge." Unbeknownst to me, I was participating in what historian and former Librarian of Congress Daniel J. Boorstin might call a "pseudo-event" or what Marxist theorist Guy Debord might label a "spectacle" of advanced capitalism. Boorstin's pseudoevent describes an event whose sole purpose is to be reproduced (via advertisements or publicity). 'While Debord's spectacle, as he describes it, "is not a collection of images, rather, it is a social relationship between people that is mediated by images." ${ }^{2}$ The video premiere and the subsequent video rotation of both "Miss You Much" and "Rhythm Nation" (long form) enabled a social relationship to occur between those who were fans of Janet. It was imperative that you not only owned the album, but you had to know some (or all) of the choreography from her videos:

Face forward. Legs a little wider than hip distance apart. Arms extended diagonally away from torso with the left arm diagonally down and the right arm diagonally upwards. The arms bend simultaneously back towards the torso, palms facing inwards, middle fingers barely touching as both hands figuratively cover the heart or left breast while simultaneously, the left leg slightly bends as you shift your weight towards that side of the body. Legs straighten again while the left arm rotates to make a 90-degree angle (the right arm stays in place) and the hand makes the universally known peace sign in front of the face so that the left eye can peek through the two fingers. The torso rotates slightly to the right, both arms follow, with elbows bent close to the torso, and the hands almost close but suddenly flap open twice...

I have briefly described the beginning of the choreography for the chorus of "Miss You Much." It was also probably the easiest part of the choreography to learn and perfect. After infinite amounts of time in front of the television pushing the VCR rewind and play buttons, I learned it and I felt I had accomplished something. All I knew was that I just really wanted to dance like Janet. Senior year, I had a friend named Gavin. He was either a sophomore or a junior (I can no longer remember). When we would run into one another in the hallway, or on our way to class, or in the stairwell, or outside the school building, or on the First Avenue $L$ train platform, 
we would give each other a sly look and then suddenly break into those first eight counts of the Miss You Much choreography. We didn't care if people thought we were strange. For us, all that mattered was that in our reproduction of the choreography we were asserting its value - physically, choreographically, and personally_and our connection to Janet. In hindsight, the marketing, publicity and subsequent rotation of the spectacle of Janet Jackson's black and white music video on MTV meant nothing to me. I just wanted to dance like her and each time the video came on, it was an opportunity to see if I approximated her skill.

I employ the use of the rhetorical repetition of my desire in order to begin to articulate the relationship between mediated performances of popular dance and the audience/ spectator; for it is through the ubiquitous availability of such mediated performances that dance on screen becomes (corpo)real and tangible. Dance and performance studies scholars speak to the ephemerality of performance, choreography, and even dance itself. In other words, once it has occurred live, on a stage, it no longer exists. The notable debate between performance studies scholars Peggy Phelan and Philip Auslander comes to mind at this moment for it sets up the ontological predicament of dance, performance, spectatorship, and subjectivity. ${ }^{3}$ If the live body is the sole arbiter of authenticity or reality, how might one consider its presence and representation through mediated sources? For Phelan and Auslander, the primary site for the consideration of the live body is the art performance space (e.g., a theatre space, the prosceniums stage, or a museum gallery). I wonder how popular dance forms might trouble their respective claims given the fact that in late capitalism most popular dance forms circulate primarily in mediated ways (e.g., music videos, YouTube, or television dance competition shows). Fortunately, Amelia Jones's article offers a prescient theoretical lens through which to consider dance in music video and the role of the performer/celebrity. Her pronouncement that body art, "through its very performativity and its unveiling of the body of the artist, surfaces the insufficiency and incoherence of the body-as-subject and its inability to deliver itself fully (whether to the subject-inperformance her/himself or to the one who engages with this body)" offers useful insights applicable to popular screen dance. ${ }^{4}$ She calls into question the ontological status of both the live and mediated event by claiming, "There is no possibility of an unmediated relationship to any kind of cultural product." ${ }^{\prime \prime}$ As a result, Jones's insights allow me to consider how popular dance on screen comes with an arsenal of mediation already built-in. It is these statements made by Jones that I want to reflect upon as I muse about my affinity for dance in music video and my memories of Janet Jackson's "Rhythm Nation."

There is something about learning music video dances that makes me feel as if I"know" the celebrity, if only through the embodied, physicalized practice of rehearsal. Just as the cult of celebrity is a mode of production, popular screens provide fans different types of access to other modes of production. For example, if the body of one of Janet's fans can learn moves created exclusively for her celebrity brand to trademark and circulate through a variety of mediated circuits, then perhaps the fan body establishes the intersubjectivity that Jones refers to when she writes that "while the live situation may enable the phenomenological relations of flesh-to-flesh engagement, the documentary exchange (viewer/ reader $\leftrightarrow$ document) is equally intersubjective." Fan culture becomes an ancillary mode of production for the celebrity. Thus, a relationship is forged between the performer and her audience, and it can be a theoretically complex one, given the effects of mediation. 
Gavin went to see Janet perform live at Madison Square Garden (I was unable to go as I was abroad with family), and he later admitted that watching the live version of "Miss You Much" was different and not as exciting as the first time he saw the video. Here, the live-ness or presence of the actual celebrity body (he was sitting really far away from the stage, so Janet remained a mediated presence on the screen above the stage) became a simulacrum of the mediated celebrity body, the one he had become habituated to experience. Thus, the live re-presentation of the original or 'authentic' mediated event-the live performance of the "Miss You Much" video choreography_materialized as the simulacrum of the video thereby instantiating Jones's assertion that "the relationship of these bodies/subjects to documentation (or more specifically, to re-presentation) most profoundly points to the dislocation of the fantasy of the fixed, normative, centered modernist subject."7 Janet live was not the same as Janet at home on MTV and this realization destabilized Gavin's perception of Janet altogether.

Postmodern celebrity bodies, specifically pop music artists, engage in a self-fashioning choreography. Obviously tied to the demands of a patriarchal, globalized, late corporate capitalism, a pop artist like Janet Jackson is beholden to the demands of her record label and how it chooses to invest its capital through the type of image, music, and style Janet Jackson-as-corporate-brand represents. The process through which a celebrity pop icon trademarks herself offers an example of Jones's idea that the documentary traces of the artists' performance "could, in fact, be said to expose the body itself as supplementary, as both the visible 'proof' of the self and its endless deferral." ${ }^{\prime \prime}$ The act of trademarking, whether through the celebrity image, dancing ability, sound, or talent highlights the process of becoming a corporate-produced subjectivity or even more specifically, a celebrity-brand/ body. In this instance, the celebrity-brand/body shifts into the realm of commodity within the mediated terrains of popular screens (e.g., celebrity webpages, or sites such as MySpace, YouTube, Vimeo, VeVo, or even a Twitter account), which enable that very body's endless deferral. Thus, Janet Jackson (self) is not ever really accessible, yet she always is a mediation of that "self." And it is that mediated self, i.e., Janet-as-celebrity-brand/body that allows for a social relationship to exist between Janet and her fans.

I have a friend, Ed, whom I met in college. We loved going out dancing together. One day, I walked in on him watching the 30-minute "Rhythm Nation" video in a student center lounge. He was dancing along to the choreography in real time. I noticed the sweat on his forehead and some sweat marks on his t-shirt (he had been wearing a wool plaid shirt which he threw off as he was dancing). Like me, he wanted to dance like Janet. Unlike me, he absolutely did . . . and, I will admit, I was a bit jealous. Here, Janet was materializing not as a fully knowable body-as-subject, but as a physical body that labored (and sweated) to learn, practice, perfect, and perform those very moves that had Ed sweating inside the student center. In a way, Ed knew what it was like "to be" Janet . . even if it was only by dancing like her. Jones's assertion that "the 'unique' body of the artist in the body artwork only has meaning by virtue of its contextualization within codes of identity that accrue to the artist's body and name ${ }^{\prime \prime}$ seems quite appropriate to my argument. Janet's video dance performance becomes meaningful every time it gets repeated, especially since her celebrity trademark has always been innovative dance skill that requires practice and re-iteration.

Music video dance is made exclusively for mediation, circulation, and transmission in service of corporate and celebrity capital. Its navigation through the variety of media's circuits assures its 'real'-ness and its tangibility. The dancers in the video make it corpo-real 
as do the fans that learn and imitate the moves..$^{10}$ Just as "body art depends on documentation,"11 music video dance does as well; it cannot exist without it. I do not claim that there is a fully knowable self present in music videos, but what is available is a branded performance that resurfaces and is made "real" each time it is witnessed on the popular screen, re-interpreted by the performer for live audience at a concert or awards show, or re-enacted by fans in dance classes, or different sized screens in living rooms, classrooms and bedrooms. The first popular screen iteration exists as the documentary trace that will later provide the infinite acts of performative deferral. Thus when Janet performed "Miss You Much" (or another one of her tracks from Rhythm Nation ) at her live concert, at the Grammy's, on Saturday Night Live, at the MTV Video Music Awards, her chorus of back-up dancers, all dancing in unison with Janet, highlight the transmission of (popular) dance forms from bodies to bodies and more importantly, the embodied-ness of popular dance practices and the crucial role that the screen plays in establishing such practices.

Watching the video several times on $V V^{12}$ in order to prepare for this essay, I found myself getting out of my seat and trying to remember the choreography. I managed to stimulate some of my muscle memory and some steps resurfaced here and there, but I was unable to complete a full eight counts (other than the first set that I described above). In other words, I failed miserably. Nevertheless, I reflected on how, almost twenty-two years later, my physical engagement with the performance is contingent upon its accessibility through a screen which lets me watch the video over and over until I can, finally, dance like Janet.

\section{References}

Auslander, Philip. Liveness: Performance in a Mediated Culture. New York: Routledge, 1999.

Boorstin, Daniel J. The Image: A Guide to Pseudo-Events in America. New York: Vintage, 1992.

Debord, Guy. The Society of the Spectacle. Trans. Donald Nicholson-Smith. New York: Zone Books, 1999.

Jackson, Janet. "Miss You Much." Filmed 1990. VeVo video, 4:21. Posted June 2009. http://www.vevo.com/watch/ janet-jackson/miss-you-much/USUV70702300.

Jones, Amelia. "'Presence' in Absentia: Experiencing Performance as Documentation." Art Journal, 56, no. 4 (1997): $11-18$.

Phelan, Peggy. Unmarked: The Politics of Performance. New York: Routledge, 1993.

\section{Notes}

1. Boorstin, The Image.

2. Debord, The Society of the Spectacle, 2.

3. See Auslander, Liveness, and Phelan, Umarked.

4. Jones, "'Presence' in Absentia," 13.

5. Ibid., 12.

6. Ibid., 12.

7. Ibid., 12.

8. Ibid., 14.

9. Ibid., 14.

10. Here, I am reminded of a recent flash mob performance of the choreography of Beyoncé's Single Ladies in Picadilly Circus, London where about 50 women dressed similarly to Beyoncé (in the video) danced in order to promote both her upcoming concert at the $\mathrm{O} 2$ Arena and Trident gum which was sponsoring the event.

11. Jones, "'Presence' in Absentia," 15.

12. Jackson, "Miss You Much." 


\section{Introduction: Rosalind Krauss}

\section{Douglas Rosenberg}

In an interview with the host of Bravo Television's Actor's Studio, Dustin Hoffman recounts a dinner conversation with the great actor Sir Laurence Olivier. The dinner takes place amongst friends and family during the last days of Olivier's battle with cancer and the filming of his last film, Marathon Man. Hoffman becomes visibly emotional as he recounts the story, filling in the details of Olivier's children tenderly greeting their dying father, his wife the actress Joan Plowright and others at the table. Hoffman had wanted to hear the great Olivier's ideas about why actors act, why Olivier acted, so he asks the question, "Tell me, what's the reason we do what we do?" Hoffman recounts that Olivier got up from the table and leaned over to him, placing his face inches from Hoffman's own and after a pause, said, "You want to know why, dear boy? Look at me, look at me, look at me, look at me, look at me, look at me, look at me, look at me, look at me, look at me."

The following essays were written while contemplating the essay, "Video: The Aesthetics of Narcissism," by Rosalind Krauss. This essay was published in the influential journal October in 1976 and has resonated throughout the history of media practice since its first printing. The essay opens with this well-known passage:

It was a commonplace of criticism in the 1960s that a strict application of symmetry allowed a painter "to point to the center of the canvas" and, in so doing, to invoke the internal structure of the picture-object. Thus "pointing to the center" was made to serve as one of the many blocks in that intricately constructed arch by which the criticism of the last decade sought to connect art to ethics through the "aesthetics of acknowledgement." But what does it mean to point to the center of a t.v. screen?"

Krausse raises the specter of narcissism in a particular early video work by the artist Vito Acconci, who, in a nod to "Duchampian irony," films himself in close-up, pointing to the center of the television set upon which we see his image for a period of twenty minutes. Krausse goes on to explain that in this gesture of "self regard," Acconci uses the video monitor as a mirror. She notes that: "In that image of self-regard is configured a narcissism so endemic to works of video that I find myself wanting to generalize it as the condition of the entire genre. Yet, what would it mean to say, 'The medium of video is narcissism?"'"2

Or, perhaps we might re-phrase the question and ask: is the medium of screendance narcissism? After all, if the video monitor or the video camera is relied on in a similar way (using Krause's mirror analogy), doesn't it simply become an extension of the mirrored studio, the reification of the dancing body, albeit a more edited, better version of itself? And doesn't center-stage often become center-screen as choreographic ideas are migrated or translated to screenic space? Finally, what is worth 
discussing, as in the following pages, is the possibility that screendance may function in some cases as the material equivalent of Sir Laurence Olivier's mantra, "Look at me, look at me, look at me, look at me, look at me, look at me, look at me, look at me, look at me, look at me."

\section{References}

Krauss, Rosalind. "Video: The Aesthetics of Narcissism." October 1 (Spring 1976): 50-64.

\section{Notes}

1. Krauss, "Narcissism," 50.

2. Ibid., 50 . 


\title{
Screendance: The Aesthetics of Ironic Consciousness
}

\author{
Virginia Piper
}

$\prod^{0}$

osalind Krauss's 1976 article, "Video: The Esthetics of Narcissism" seeks to determine the particular kind of aesthetic experience made available by the then novel technology (or apparatus) of video. The article draws from psychoanalysis and semiotics in order to dematerialize the medium of film to then rematerialize it as the medium of the self in communication with itself, the medium of narcissism. While the technological apparatus in question now seems rather quaint in comparison with the innumerable advances in film and other visual media over the last forty years, the imperative to carefully consider the aesthetics of video, film, and the screen has yet to lose its urgency, most particularly in connection to screendance. Indeed, as Douglas Rosenberg wrote in 2006, evaluating the state of screendance, "we have not made the effort to begin to parse screendance into frames of reference as other art forms have done... Creating frames of reference and prisms through which a work of art is viewed, elevates the work of art by inserting it into an ongoing dialog with other work and also, perhaps more importantly, encourages the kind of metaphor, allusion and referencing that is the lifeblood of art in general."1 Krauss's consideration of the aesthetics of video in 1976 provides a timely opportunity for scholars and practitioners in 2011 to consider the particular aesthetic experience made possible by screendance.

Aesthetics carries along with it the albatross of an allegedly obfuscating discourse and of a failed utopianism. Over the past four decades, the aesthetic has increasingly come under attack as an obtrusive mediation of the relationship between text and reader, beholder and beheld. As Jacques Rancière scathingly summarizes: "Aesthetics came to be seen as the perverse discourse which bars this encounter and which subjects works, or our appreciations thereof, to a machine of thought conceived for other ends: the philosophical absolute, the religion of the poem, or the dream of social emancipation." ${ }^{2}$ Yet, as he points out, aesthetics is not a discipline so much as a "regime of identification," that which renders it possible to identify art as such, the mechanism of its very autonomy. And it is this autonomy, I would argue, that was at stake in Krauss's intervention in 1976 and remains troublesome in current discussions of screendance.

Autonomy, the inevitable, if not precarious, by-product of aesthetic discourse, seeks to draw distinctions and delimit boundaries between art and non-art (or to quell the sibling rivalry of the sister arts) as it registers the anxieties over the increasing commodification and concomitant fetishism in the art world. If, in seeking to name and describe the aesthetics of video, Krauss simultaneously seeks to establish its autonomy within the arts, her turn to the market undertakes a similar project in relation to commodity culture. She nervously asserts that the art world "has been deeply and disastrously affected by its relation to mass-media. That an artist's work be published, reproduced, and disseminated through the media has become, for the generation that has matured in the course of the last decade, virtually the 
only means of verifying its existence as art." This evaluation echoes Rosenberg's more recent assessment that "When we think about screendance, much less comes to mind in regard to the delineation of movements or genres within the field of practice. And identifiable authorship is quite rare. This lack of self-definition is cause for concern in a field that teeters on marginality."4 Aesthetics is what allows us to recognize art as such. The autonomy of screendance, as a field of practice and an artistic form, depends upon and calls for an elaboration of its aesthetics — as an art form and as a distinct practice.

Although Krauss does not turn toward the market and the bugbear of commodification until the very end of her article, the impulse towards autonomy is woven though the discussion of subjectivity and the creation of an autonomous self. For Krauss, video is the medium of narcissism, "an aesthetic mode by which the self is created through the electronic device of feedback." "Feedback" materialized in the apparatus of the camera and the monitor, comes to be synonymous with "mirroring," "echoing," "boomeranging," "doubling back," and, significantly, "dédoublement." Krauss suggests that "One could say that if the reflexiveness of modernist art is a dédoublement or doubling back in order to locate the object (and thus the objective conditions of one's experience), the mirror-reflection of absolute feedback is a process of bracketing out the object." ${ }^{\prime \prime}$ This dédoublement is the very condition that Paul de Man, drawing from Charles Baudelaire describes as "irony." Indeed, there is an eerie symmetry between Krauss's "Video" and de Man's 1969 essay "The Rhetoric of Temporality": both read moments of a fall and turn to the question of language in order to consider mirroring, doubling, and the reflective activity that delineates the self from the empirical world.

De Man takes his inspiration from Baudelaire's "De l'essence du rire" to develop the concept of an "ironic consciousness." Despite everyone's cordial assurances to the contrary, it would seem that our fears are in fact justified, for it is only the philosopher or the artist who has the capacity to "laugh with" instead of being "laughed at." Baudelaire writes:"It is least of all the falling man who is able to laugh at his own fall, unless he is a philosopher, a man who has acquired by habit the power to rapidly make himself double (se dédoubler) and to watch, as a disinterested spectator, the phenomenon of his 'me"' ("Ce n'est point l'homme qui tombe qui rit de sa propre chute, à moins quill ne soit philosophe, un homme qui ait acquis, par habitude, la force de se dédoubler rapidement et d'assister comme spectateur désintéressé aux phénomènes de son moi"). ${ }^{8}$ Doubling, or "ironic consciousness" then becomes the hallmark of reflective activity, "dédoublement as the characteristic that sets apart a reflective activity ... from that of the ordinary self caught in everyday concerns." The fall of Baudelaire's laughing philosopher enacts a suspension, through language, which"divides the subject into an empirical self, immersed in the world, and a self that becomes like a sign in its attempt at differentiation and self-definition."10 Language, as in Boomerang or in Lacanian analysis, points to the disjunction between the two laughing men, or the image on the camera and on the monitor. It disrupts the movement of "narcissism" by showing us that the self can never fully coincide with itself. The collapsed present of the fall is necessary to gain the knowledge of difference.

Significantly, Krauss's description of "feedback" is also one of a fall: "the feedback coil of video seems to be the instrument of a double repression: for through it consciousness of temporality and of separation between subject and object are simultaneously submerged. The result of this submergence is, for the maker and the viewer of most video-art, a kind of weightless fall through the suspended space of narcissism."11 Yet she, like de Man, points to the inevitable disjunction between the seamless and vertiginous but ultimately illusory 
autonomy of the subject in the instant of "ironic" or "narcissistic" perception. Where de Man turns to the double-nature of language (rhetoric), Krauss looks to the material or ab intra potential for disruption of the video medium and its ability to call attention to this disjunction, taking the work of Peter Campus as her example. She writes: "The narcissistic enclosure inherent in the video-medium becomes for him part of a psychologistic strategy by which he is able to examine the general conditions of pictorialism in relation to its viewers. It can, that is, critically account for narcissism as a form of bracketing-out the world and its conditions, at the same time as it can reassert the facticity of the object against the grain of the narcissistic drive towards projection."12 The narcissistic aesthetics of video become then necessary to distinguish and determine difference.

The boundaries between subject and object must here be maintained and guarded against the dangers of projection by the disruption of their seamless quality (or, to draw from Laura Mulvey, the erasure of their marks of production) and to reinsert them into the materiality of production. ${ }^{13}$ The medium disrupts itself in Krauss's description of video and allows for it to be ambiguously reflective and narcissistic. Like de Man's description of the laughing philosopher, it is the ironic consciousness of that which mediates our immediate experience that enables the recognition of pure autonomy or subjectivity as a delusion. If we are to consider the aesthetics of screendance, the sensory experiences or the encounters it makes available, we must also consider the screen, the glass pane of language, which enables, disrupts, and circulates the narcissistic encounter. "How can we know the dancer from the dance," asked Yeats? ${ }^{14}$ By looking at the screen.

\section{References}

de Man, Paul. Blindness and Insight: Essays in the Rhetoric of Contemporary Criticism. $2^{\text {nd }}$ edition. Minneapolis: University of Minnesota Press, 1983.

Krauss, Rosalind. "Video: The Esthetics of Narcissism." October 1 (1976): 50-64.

Rancière, Jacques. Aesthetics and Its Discontents. Translated by Steven Corcoran. Malden, MA: Polity Press, 2009.

Rosenberg, Douglas. "Proposing a Theory of Screendance." Paper presented at the American Dance Festival, Duke University, Durham, North Carolina, July 6-9, 2006.

Yeats, W.B. "Among School Children." The Yeats Reader. Edited by Richard J. Finneran. Revised edition. New York: Scribner Poetry, 2002.

\section{Notes}

1. Rosenberg, "Proposing a Theory of Screendance."

2. Rancière, Aesthetics, 2.

3. Krauss, "Video," 59.

4. Rosenberg, "Proposing."

5. Krauss, 59

6. Ibid., 57.

7. de Man, Blindness and Insight, 211.

8. Ibid., (translation mine). Charles Baudelaire, "De l'essence du rire,"in Curiosités esthétiques: L'art romantique et autres œuvres critiques, edited by H. Lema"tre (Paris: Garnier, 1962), 215, quoted in de Man, 211-12.

9. Ibid.

10. Ibid., 213

11. Krauss, "Video," 58-59.

12. Ibid, 64.

13. Rosenberg calls our attention to the tension between screendance and the market and mainstream distribution, drawing from Mulvey's work: "In her book from 1996, Fetishism and Curiosity, Laura Mulvey explains, from a Marxist point of view that,'a commodity's market success depends on the erasure of the marks of production', allowing commodity fetishism to 'triumph as spectacle."' (Rosenberg, "Proposing a Theory of Screendance.")

14. W.B. Yeats, "Among School Children," 105. 


\section{Screendance: Aesthetics of Media and Consumer Visual Culture}

Terry Sprague

$T$

here are more differences than similarities between the state of video art in the early nineteen seventies, as Rosalind Krauss describes it in "Video: The Aesthetics of Narcissism," and the current state of screendance. Reflecting on the works of artists such as Vito Acconci, Krauss convincingly argues that "the medium of video is narcissism," that the physical, electronic, video equipment is "merely an appurtenance," and that the video art world has been "deeply and disastrously affected by its relation to mass-media." While "narcissism" indeed characterizes a selected collection of videos from the nineteensixties and the nineteen-seventies, I propose that mediazation and the aesthetics of consumerism more aptly describe the medium of screendance today. Additionally, at a time when video recording devices are more accessible than ever before (i.e. in the form of palm-sized camcorders such as Flipcams, or devices embedded in cell phones, laptops and still cameras), it functions more as an appendage than as an external apparatus. Finally, over the years, screendance-makers' relationship with "mass-media" has been significantly altered by factors such as streaming video, the Internet and social media. First, I will address these issues and then discuss screendances that exemplify different types of relationships with the media, as well as how these screendances integrate the aesthetics of consumer visual culture.

While "narcissism" characterizes a selected collection of videos from the early seventies, it does not describe the overall nature of contemporary screendance in the early-twenty-first century. Certainly screendance artists, like any other artists, are likely self-absorbed to some extent as individuals but, generally speaking, their work does not prevailingly convey messages that speak of narcissism. In fact, since screendance has evolved in such complex and multi-faceted ways, no one word suffices to generalize a genre that produces works ranging from one-minute, in-camera edited, personal narratives to professional-level productions. However, in order to respond to Krauss's use of the term "narcissism," it can be useful as a metaphor to construct a historical context and to make comparisons.

For the sake of this discussion, let us say that the body of water Narcissus, the video artist, encounters and within which he sees his reflection, is a metaphor for the world of video art making. In the early seventies, access to video equipment was a rarity. Like any other new technology, its inherent features held mystery. Artists were arriving at the water's edge of a frontier that had yet to be explored in-depth. Their works were driven by questions about the nature of the form. They were asking: 'Who am I in relation to this form?' 'What does this say about the 'self'?' To create video feedback on a monitor or to turn the camera upside down served as the content of the work. Explorations of the form were compelling enough to serve as the content. Artists were consumed with 
themselves in relation to the form and were "falling in love" with the form, the process, and what they saw in the water's reflection.

By the early twenty-first century, artists had plunged into the waters of video art making, swam through generations of technological innovations, and Narcissus was no longer characterized by a mostly white, male, Western, Euro-American constituency exhibiting work in relatively elitist gallery spaces. Since the cost of video recording devices has decreased and their availability has increased since the early seventies, video production equipment is getting into the hands of a larger, more varied population. Additionally, due to video-recording devices' increased portability, shooting locations have moved far beyond the artist's studio. Most screendance artists take the nature of the form as a given and concern themselves with other artistic questions.

While the questions the video artists in the early seventies were addressing led Krauss to characterize their aesthetics as one of narcissism, a psychological condition, if contemporary screendance were to be described as a condition, I would argue that it would be more aptly described as a sociological or socio-visual cultural condition, due in part, to its relationship with mass media.

The way in which Krauss describes the relationship between video art makers and the mass media in the seventies differs from the relationship of screendance artists with contemporary mainstream media (network news media) and consumer visual culture (Internet imagery, advertising and mainstream Hollywood cinema). According to Krauss, at that time, the "artworld was deeply and disastrously affected by its relation to massmedia" and "that an artist's work be published, reproduced and disseminated through the media has become ... virtually the only means of verifying its existence as art."2 The implication is that the mass media held some amount of authority over the presentation, distribution, and promotion of artists' works, and that the results were "disastrous." Conversely, various factors are contributing to a shift in the relationship contemporary screendance artists have with mass media. With the advent of user-friendly, non-linear, video-editing software and other technological advances, many screendance artists are mastering production techniques, such as professional-level image making, and therefore decreasing the difference between commercial, professional imagery (seen in mass media) and what screendance artists are capable of creating. Additionally, contemporary social media such as Facebook and YouTube provide significant opportunities for artists to "perform," "publish," and promote their work independently of more traditional mass media. By utilizing video technologies, screendance "places itself in the discourse of current media practice and therefore in the discourse of popular culture." ${ }^{3}$

Consequently, different artists' screendances are engaging with current media practice and the discourse of popular consumer culture in different ways, three of which I name here:

1) Some screendances feature imagery that imitates and code-switches with mainstream consumer culture media, which ultimately serves to perpetuate mainstream consumer-culture ideology. Screendances such as Ben Dolphin's Arising (2008) and Pontus Lidberg's The Rain (2007) feature highly-produced, sometimes clichéd, fetishized images of dancers' bodies in costumes such as wet, clinging, shirts or in partial nudity, which resemble images seen in mainstream media and advertising. The exquisitely lit, 
fetishized-landscape images seen in Isabel Rocamora's Horizon of Exile (2007), are not unlike images featured in travel advertising or those seen in high-fashion ads shot in exotic, remote locations. These screendances are creating imagery, which can be interchanged with images seen in media and advertising, that tends to re-enforce more than it subverts mainstream consumer-culture ideology.

2) Conversely, a number of contemporary screendances fall into the category, which Krauss describes near the end of her article: video-art works that "run counter to what I had been saying so far," which include "tapes that exploit the medium in order to criticize it from within."4 Lloyd Newson's Cost of Living (2003) employ the medium of video and the "tools" of the media, in order to critique the media. In Cost of Living, Newson keys into the fact that ideology is perpetuated, in part, when viewers identify with people and objects in mainstream-media representations. He creates an unsettling scene, which subversively disturbs such identification and addresses ways in which network-news media invite identification - not for the purposes of selling a product, as with advertisements - but for the purposes of engaging us in voyeuristic viewing and inviting us to witness sensational images of stories featured in news reports. The scene takes place on a grassy field where an aggressive cameraman is shooting David, the protagonist who has no legs. Initially, Newson aligns the viewer's perspective with that of the cameraman's. Then, unlike network-news media conventions, Newson's camera also hones in on the man behind the camera in a way that interrupts the process of viewer identification with him or with David, the object of the gaze.

Additionally, the cameraman's relentless, invasive curiosity about David's body raises questions about the impact network-news media has on the way we see others and ourselves in terms of desirability and difference. Newson brings our attention to the power of news media's gaze-its entitlement to look and its discomfort with the notion of difference-by shooting close-up and by representing the camera as assaulting and almost weapon-like. In the end, Newson troubles our habitual inclination to identify with either the gazer (the cameraman) or the object of the gaze (David) and brings our awareness to the fact that the media has "trained" us to watch in these ways.

Similarly, in Desert Storm, Ndiritu employs news media and advertising strategies in order to criticize their role in the perpetuation of ideological operations and to bring our attention to ways in which we are encouraged to watch with voyeuristic eyes. Like many of Vito Acconci's videos, Desert Storm is shot with a single camera looking down on Ndiritu's veiled, nude body, as she writhes back and forth upon the floor, which is a map of the world. White text scrolls slowly from right to left on a black strip at the bottom of the screen, listing countries such as Sudan, East Timor, Iraq, Afghanistan, Rwanda, Bosnia, Kashmir, Tibet, Eritrea, Kosovo, Chiapas, Algeria, Congo, Sri Lanka and others countries within which rape has been used as a weapon of war. The scrolling text along the lower edge of the frame resembles the way network news programs display the up-to-theminute news reports, emergencies, and catastrophic events. Networks are known to broadcast in this fashion even during non-news programs. Desert Storm's final message also features white text, which appears on a black screen and reads: "Today's news is tomorrow's war." Between the screendance's title, Desert Storm, the news media-styled scrolling text, and the final words, Ndiritu is most certainly asking us to consider news 
media operations and the role they played in Desert Storm, the operational name for the military response in the Persian Gulf War (1990-1991).

Ndiritu also employs strategies used by media and advertising to hook the viewer such as performing the veiled, nude, female body as an invitation to look. Then, at the end of the screendance, she interrupts our gaze when she abruptly comes from behind the veil and gazes back with intense, almost accusatory eyes. As in Newson's piece, we are made uncomfortably aware of our own watching. After watching her as an object, we are made the object of her gaze with her sudden stare. Ultimately, Nidiritu and Newson are appropriating elements of advertising and news-media strategies, as well as inventing their own, in an effort to be transformative.

3) Some screendance artists are inventing new forms and new ways of constructing screendances. For example, Natalie Bookchin's Mass Ornament (2009) features individual dancers who created media representations of themselves in ways that mimic consumer-culture aesthetics and advertising strategies. Mass Ornament is comprised of "found" YouTube clips of people (mostly women) dancing alone in their rooms. Bookchin edited them according to particular movements, gestures, and particular themes, thereby re-presenting these dancers and constructing a second level of mediation. While the end result evokes the chorus-line style and unison choreography seen in works by choreographers such as Busby Berkeley, The Tiller Girls and Leni Riefenstahl, Bookchin's re-mediation serves to emphasize their humanity as much or more as their bodies as sensuous objects.

The original "found" YouTube clips in Mass Ornament demonstrate both artistmedia relations, which counter Krauss's description of artists' relation with the media in the seventies, and a kind of self-promotion that reflects aspects of consumer-culture aesthetics. While Krauss's description of the artist-media relations implies disaster of some kind, the dancers in the Mass Ornament YouTube clips are demonstrating an authority over their own self-representation. They appear in private, domestic spaces, which by virtue of their display online, are transformed into public stages. Their movements read as expressions of their identities, showing off and, in some cases, celebrating. If anything, they are appropriating media and advertising strategies for their own selfpromotion purposes. They are "advertising" themselves in ways that resemble the way consumer culture advertises products - with contemporary, sensuous, movement, music, and fashion. Unlike the way Krauss describes the authority held by the media in the seventies, the dancers in Mass Ornament are not dependent on mainstream-media producers to get them Internet "air time."

Rather than characterizing contemporary screendance as embodied by Narcissus, enamored with gazing at his own reflection in the water, some contemporary screendance artists are splashing in the water to disturb the reflection, making a fountain with the water, or are gazing back at the viewer on the shore with the intention of causing transformation. They are appropriating media and consumer-culture aesthetics to imitate them, critique them, and/or re-mediate and reconstruct them in inventive ways. 


\section{References}

Bookchin, Natalie. "Mass Ornament."Vimeo video, 7:12, posted by “natalieb," July 1 2009. http://vimeo. com/5403546.

Dolphin, Ben. "Arising." Hulu video, 4:13, January 1, 2008. http://www.hulu.com/watch/133621/ dance-on-camera-arising\#x-4,vclip,1,0.

Krauss, Rosalind. "Video: The Esthetics of Narcissism." October 1 (1976): 50-64.

Lidberg, Pontus. “The Rain.”Vimeo video, 5:36, posted by “Dancefilm," March 28, 2010. http://vimeo. com/10508318.

Ndiritu, Grace. "Desert Storm." Axis video, 5:08, 2004. http://www.axisweb.org/Artwork.aspx?WORKID=54195\&VIS UALID=81594.

Newson, Lloyd. "The Cost of Living." disTHIS! Film Series video, 1:53, 2004. http://disthis.org/CostOfLiving.htm.

Rocamora, Isabel. "Horizon of Exile." Isabel Rocamora video, 2:27, 2007. http://www.isabelrocamora.org/home/ FilmTv/Horizon-of exile/HorizonTrailer/TrailerLarge.html.

Rosenberg, Douglas. "Video Space: A Site for Choreography." Leonardo 33, no.4 (2000): 275-80.

\section{Notes}

1. Rosalind Krauss, "Video: The Aesthetics of Narcissism," 50, 57, 59.

2. Krauss, 59.

3. Rosenberg, "Video Space, " 10.

4. Krauss, 59. 


\title{
The Kraussian Condition of the Medium
}

\author{
Rodrigo Alonso
}

s is the case with many essays on technology-based arts, Krauss's "Video: The
Aesthetics of Narcissism" is clearly marked by history; today we can easily see the
multiplicity of paths that video art production has taken apart from its essential
narcissism-even at the time when that essay was written. Krauss' modernist gaze takes
the characteristics of early video performance-many of them a consequence of the
technology of the moment-as the condition of the medium instead of as a historical
emergence. Her interest in Lacanian psychoanalysis also pervades her reflections-another
historical marker-and leads her to consider video portraits and closed-circuit devices in
terms of mirror situations and narcissism.

Nevertheless, Krauss succeeds in finding a consistent group of works to analyze some particular relationships between the body and technology in the early days of video art. These pieces pose issues of intimacy, representation, the mediated Self, the perception of time, and the transparency of media as key subjects of the encounter of performance artists and video. They open up a new field of experimentation as well as a new set of aesthetic concerns.

One of Krauss's main theses holds that "video's real medium is a psychological situation," something different from other art media, which rely on an "object-state, separated from the artist's own being."1 Film, for example, "has much more to do with the objective, material factors ... [of] light projected through a moving strip of celluloid." ${ }^{2}$ It is not clear why a light beam projected on a screen would be more objective and material than an electronic image contained inside a solid monitor, but this affirmation disregards a whole body of theories of the time, which acknowledged the many psychological situations pertaining to film-from retinal persistence (a psychological rather than optical mechanism) to identification with the movie's characters and the construction of film realism (i.e. the theories of Christian Metz).

Krauss deals with three key concepts, even though she sometimes does not call them by their names: representation, intimacy, and immediacy. When she describes some videos based on performances, she does it as though she was watching the actual performers doing their actions and not their images on a screen. She talks about Bruce Nauman, Vito Acconci, and Nancy Holt-a group of artist she knows very well, since they are part of the same visual arts circuit she belongs to-and not about characters. For her, they do not represent, so their videos cannot be considered proper representations (and here there is a difference with film that she does not stress). In these cases, video is transparent, a mere recording device. If video is a mirror for the artists, for the viewers it is a window, which allows them to witness the real world.

The recording situation is one of intimacy. The location of the artist in front of the camera, or between the camera and the monitor, creates a closed environment in which 
he/she confronts his/her mediated Self, using video as a mirror. Krauss states, "the mirror reflection of absolute feedback is a process of bracketing out the object ... For the object (the electronic equipment and its capabilities) has become merely an appurtenance." ${ }^{3}$ In Centers (1971), by Vito Acconci, she acknowledges that "latent in [its] setup is the monitor that he is, himself, [Acconci] looking at," but adds that "there is no way for us to see Centers without reading that sustained connection between the artist and his double. So for us as for Acconci, video is a process that allows these two terms to fuse." ${ }^{\prime 4} \mathrm{It}$ is obvious that if there is a center, it is because there is a frame. Acconci is not only interacting with his image but also with the camera he is facing. The equipment is not a mere appurtenance here; it is an essential part of the video piece.

The same could be said about Bruce Nauman's inversion of the electronic image in Revolving Upside Down (1968), or Lynda Benglis's confrontation of her pre-recorded image in Now (1973), or Joan Jonas's set up of the framing of Vertical Roll (1972) so that the spoon she hits on the floor seems to be hitting the frame itself. These artists do not perform for the camera; they perform with it (including its related devices).

Their work constitutes a new kind of performance art, one at the crossroads of the body and the media, which operates on the various mediations that emerge from it. Technology has become a partner; it is no longer a witness of actions and movements developed outside its realm. Necessarily, this situation has an impact on the auto-perception of the performer's body, image, consciousness, and self. Krauss' essay detected these transformations in their early stages and opened up a reflection that is active still today.

\section{References}

Krauss, Rosalind. "Video: The Esthetics of Narcissism." October 1 (1976): 50-64.

\section{Notes}

1. Krauss, "Video: The Aesthetics of Narcissism," 57; Krauss, 52.

2. Ibid., 52.

3. Krauss, 57.

4. Ibid.

5. In Krauss, 54; 55; 60. 


\title{
Video and its Narcissistic Potential in Dance: Four Examples in Video Art and Experimental Film, Stage Dance, and Screendance
}

\author{
Claudia Rosiny
}

t seems commonplace today that video suggests multiple aspects of narcissism, a state in which the self and the image fuse. But, what are the hallmarks for dance and how does the medium offer these mirroring and reflexive aspects? Stimulated by Rosalind Krauss's "Video: The Aesthetics of Narcissism" (1976), the following article looks briefly at different examples of video art, which are interesting for the field of screendance today. I will look at work in the period of the seventies by the German video-art pioneer, Ulrike Rosenbach. As a representation of experimental film, I chose a film by Norman McLaren from Canada, which takes the subject under consideration here for its title. Following an early example of camera use on a ballet stage in "Live," by Dutch choreographer Hans van Manen, the last example is "Motion Control," by British choreographer, director, and promoter of screendance, Liz Aggis. My intention is to outline some common aesthetic aspects that characterize video as the reflexive medium, as Yvonne Spielmann titled a book on the subject, thirty years after Krauss.'

When Krauss wrote her article, the electronic functioning with immediate feedback was the new technical aspect of video. Before the invention of tape recording, video had a "live"-character in so-called closed circuit arrangements; the images shot by the video camera were simultaneously shown on a monitor. Performance artists experimented with such installations and used the monitor as a mirror, as Krauss explains, citing male artists like Vito Acconci or Peter Campus. Ulrike Rosenbach, like her female art colleagues in that early video period, used their bodies not only because of their mirroring potential, but also to emphasize the presence of their bodies. They played with disappearance and the doubling of the body image. In this way, video added to the art of performance by bringing the human body into focus. In the context of postmodern discourses, of collage techniques, of contesting art and its role in society, in addition to a move towards the synthesis of different art and media, video offered an applicable reflexive and psychological potential for artistic statement, as Krauss points out. For female artists like Rosenbach, Nan Hoover or Carolee Schneemann, beyond narcissistic self-reflection, video was a possibility to express women's concerns. The use of video as a medium to document their art was a step towards liberation from the male-dominated media and its accompanying male gaze. The mirror effect between the real body and the media body also had an effect on the audience. The public was confronted with its electronic reproduction. In that sense, video was a new medium, which demanded an intensified reflection on art.

Rosenbach premiered a performance "Isolation is Transparent" (1973) in New York City. A semi-transparent screen divided the performance space, as well as Rosenbach's body 
actions, which were similarly divided between "live" performance (behind the screen) and their projection on a video monitor (which presented images shot by a camera stationed above the performance space). The audience was able to view both sides of the divided performance space, the "live" performance, and the video monitor simultaneously. However, Rosenbach's nearly naked body could only be seen through a diffusive screen whereas the images on the monitor were "real" and clear.

Norman McLaren, known for his many film experiments with animation, produced, as his last film, a dance film visualizing the legend of Narcissus. "Narcissus" (1983) starts like a simple studio document of a classical dance; it is only in the second half that the images become independent, as a result of pixilation or the doubling of images of the same person. Whereas in the beginning Narcissus dances with a real body double, later the viewer cannot even determine if it is real or a filmic double. Additionally, McLaren plays with the possibilities of filmic space - the double "hangs" upside down from the top of the frame, evoking a distorted narcissistic image.

When cameras became less heavy and more flexible in the seventies, some choreographers experimented with video cameras on the dance stage. Van Manen produced a singular performance with Henk van Dijk (a former dancer). In "Live" (1979), Coleen Davis dances a solo, which is filmed by van Dijk and simultaneously projected on a big screen. The audience in the theater-as in Rosenbach's performances - sees both the dancing body and the close-ups of body details, as well as the camera in action. What becomes interesting in relation to the reflexivity of video is when Davis uses the camera as a mirrora counterpart and a dance partner. There is a moment when van Dijk moves onto his back and Davis steps above him, so that the projected images are swirling. The imaginative (Lacan) is best visualized by the potential of the video medium.

In "Motion Control" (2001), Liz Aggis performs a solo. This screendance again shows a dialogue between performer and camera. An intensified confrontation of body and camera is evoked by numerous filmic means including: a subjective camera, worm'sand bird's-eye view, as well as whip zooms, or McLaren playing with turning the camera upside down. ${ }^{2}$ In an enhancement of a constellation, similar to "Live," "Motion Control" exhausts the potential of video with a camera that is controlled by computer. Aggis's screendance offers another additional level, revealing the mediated aspect and leaving out a simple account of narcissism. Interspersed within the end credits, we see the same shots as in the beginning of the film, but this time registered by a second camera, which ultimately unmasks the mediated constellation.

What these examples show is that video as a new medium in the seventies enforced an aesthetic of narcissism, as Krauss assessed in 1976. Video and film are mediums with a high reflective potential; or as Krauss provocatively claimed: Narcissism is "the condition of the entire genre." ${ }^{\prime 3}$ What Krauss punctuates less is the potential of the medium in relation to the human body and dance. In addition to her thesis, I offered some examples that show the mirroring, reflecting, and eventually narcissistic potential of video and film in relation to dance, which is often accompanied by a clever use of space in different subgenres. The mirroring and self-reflexive aspects that were new in the early days of video art still offer a high potential for screendance today, especially when it is transformed to a high-tech screen dance like "Motion Control," which unfolds its reflective impact by parodying, stylizing and unmasking the narcissistic configuration. 


\section{References}

Aggis, Liz."Motion Control."YouTube video, 8:19, posted by“brighton 2009," March 16, 2008. http://youtu. be/8ZNXk1 JZems.

Krauss, Rosalind. "Video: The Esthetics of Narcissism." October 1 (1976): 50-64.

McLaren, Norman. "Narcissus."YouTube video, 7:30, posted by Richardandreherrera January 11, 2010. http:// youtu.be/KkvPWxBiGkA.

Rosenbach, Ulrike. "Isolation is Transparent." live-action video, New York, 40:00, 1973.

Spielmann, Yvonne: Video: The Reflexive Medium. Translated by Anja Welle and Stan Jones. Cambridge, MA: MIT Press, 2008.

\section{Notes}

1. See: Spielmann, Video: The Reflexive Medium.

2. Aggis, Liz. "Motion Control."YouTube video, 8:19, posted by"brighton 2009," March 16, 2008. http://youtu. be/8ZNXk1JZems.

3. Krauss, "Video," 61. 


\section{The Parallel Universe and the \\ Pensive Practitioner: Reflections on \\ Screendance Prompted by Laura \\ Mulvey's "Pensive Spectator"}

Kyra Norman

7

he title of this issue of the International Journal on Screendance, "Scaffolding the Medium," suggests an opportunity to investigate structures and materials that might support and underpin current thinking and practice in screendance. In this spirit, the material explored here is the final chapter of British feminist film theorist Laura Mulvey's book, Death 24x a Second: Stillness and the Moving Image, published in 2006. This closing chapter is titled "The Pensive Spectator."

The Oxford English Dictionary gives the following definition of "pensive": "engaged in, involving, or reflecting deep or serious thought."1 Mulvey's chapter is concerned with the pause for reflection on the screen image that new technologies have enabled. Since Mulvey's text is readily available elsewhere, rather than reproduce the chapter in its entirety here, I have invited two artists-Miranda Pennell and Augusto Corrieri-to take an appropriately pensive approach: to reflect on their own practice, and/ or experience of spectatorship, by way of Mulvey's writing (and vice versa). Following these new writings, which offer original insights into the artists' practices, as well as reflecting themes from the chapter in question, I will indicate some of the ideas and questions, which I feel the Mulvey chapter raises for those of us engaged in screendance.

I hope that this might serve as a productive point of departure for screendance artists, curators, researchers, producers and audiences, and that as a whole, these writings will prompt further reading and discussion of Mulvey's writing in the context of our field.

\section{Notes}

1. Oxford English Dictionary Online, adj. n. "pensive." ww.oed.com/viewdictionaryentry/Entry/140265. 


\section{Some Thoughts on "Nowness" and "Thenness"}

Miranda Pennell

m n Death 24x a Second, Laura Mulvey reflects upon the presence of stillness within the moving image. Over the course of her book, she writes about freeze-frames, photo-films, performed stillness and, in particular, the presence of the individual still frame inside the filmstrip. She identifies the "digital delay" that is part-and-parcel of our contemporary experience of domestic, media viewing, and which enables us to take for granted the arrest of movement of any film at will. The presence of the individual still frame can be felt in a way that was not previously possible for most of the twentieth century, outside of the privileged space of the editing room. Mulvey suggests that, as with photographic images, the still frame at the heart of the moving image is a reminder of the irretrievability of the past and thereby of death.

In writing about motion and stillness, Mulvey considers the viewer's consciousness of time in film media and how our relationship to the cinema of the twentieth century has been irrevocably changed. The world of cinema has transformed into a universe of historic documents; materials that reveal themselves to us in ways that were not previously available when these films were first disseminated and experienced. At the end of the twentieth century, as media begin to converge and fragment, what had once been understood as the essential and distinct powers of still and of moving images, particularly their relationship to time, were called into question.

I am drawn to Mulvey's chapter "The Pensive Spectator" for many reasons, though in the context of discussions about choreography and the moving image, I shall focus on two. Firstly, I would like to think about the fact that performance seems to be all about "nowness" and that photography seems to be all about "thenness." As a filmmaker and former dancer, I have been thinking about my film practice and I am curious about the time register of two of my films: one, a video that is all movement, flux and lively performance, and the other, a film constructed entirely out of static re-framings of photographs of people who are now dead. Mulvey's essay thinks about time across different kinds of film, and I wonder if this could guide me in thinking about the question of time in relation to dance films in particular. Secondly, read in the context of dance film and video, Mulvey's discussion about our fascination with halting, delaying, and repeating movement surely describes the curiosity, pleasure, and drive of the choreographic impulse.

\section{The encounter with the camera}

I realised retrospectively that my experiences of filming (especially of filming large groups of people, as I have often done) have been very elaborate performances in themselves, with rules, roles, behaviours and processes, which, in turn, have shaped the performance of my subjects. The same must be true of photography-particularly nineteenth-century 
photography. They may be an unlikely pairing, yet I think of both my films, You Made Me Love You (2005) and Why Colonel Bunny Was Killed (2010), as a kind of tribal portraiture. They are each concerned with the performance provoked through the human encounter with a photographic apparatus: one a twenty-first century video camera mounted on a travelling dolly, the other a nineteenth-century still camera mounted on a static tripod.

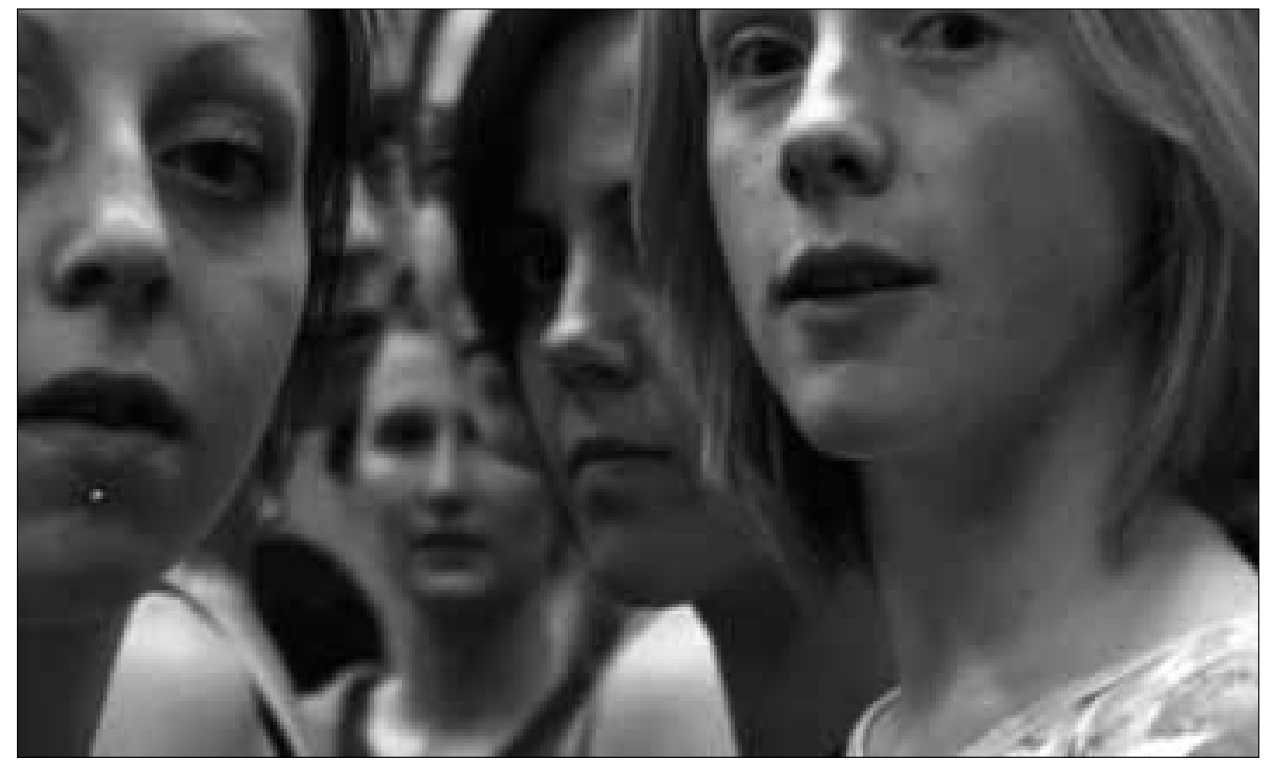

Still from You Made Me Love You (2005).

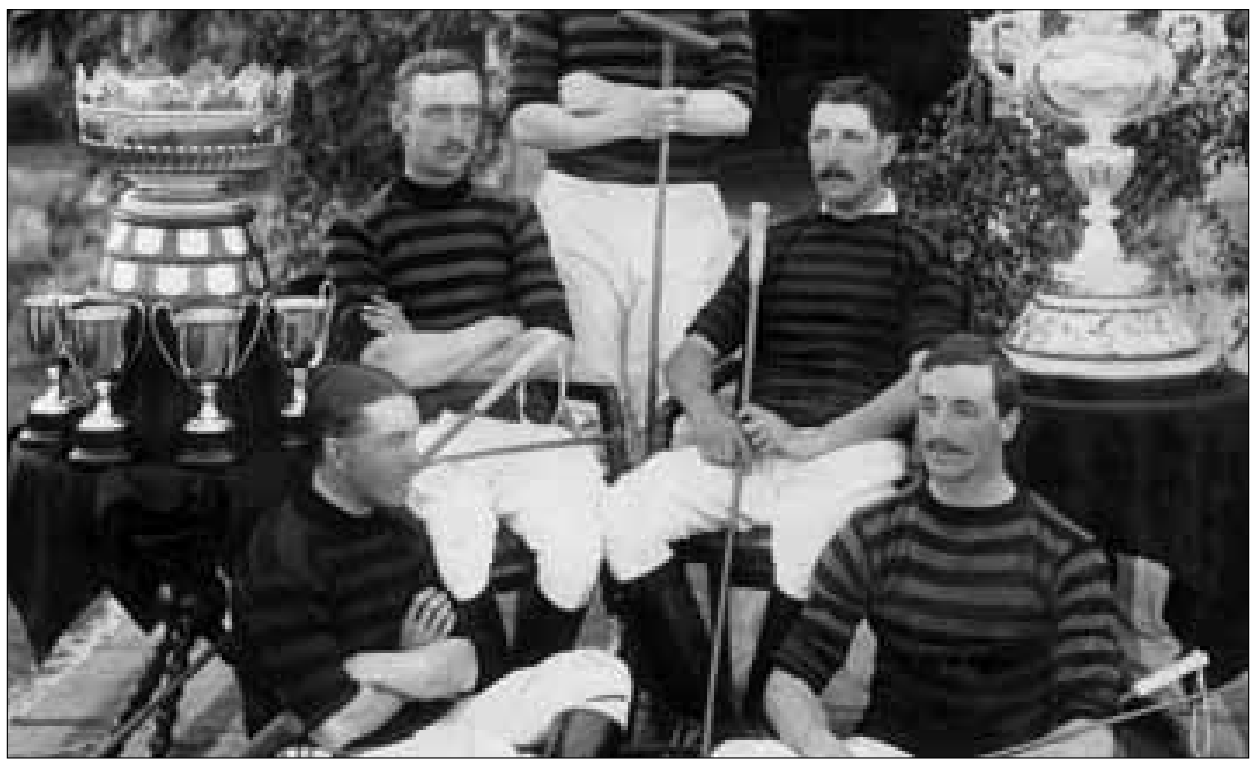

Still from Why Colonel Bunny Was Killed (2010). Courtesy of the Council of the National Army Museum, London. 
You Made Me Love You comprises a single travelling shot in which the restless motion of a group of dancers constantly escapes the edges of the containing frame-even as the shot and its human subjects seem to seek a point of equilibrium and stasis. In Why Colonel Bunny Was Killed, the images consist of static re-framings of still photographs-the only actual movements are those of the viewer's eyes scanning across the screen surface and the movement of the interval — the jump between different static images.' In choosing to write about two such different films, I am of course conflating two fundamentally distinct, opposite, cinematic representations of time. Duration, understood as an individual's experience of time in film, is identified with the temporal experience produced by the individual shot (You Made Me Love You). Conversely, montage, the ellipsis and collapsing of time, emphasises the break between shots (Why Colonel Bunny Was Killed).

\section{Stillness and distance}

Much has been written about the affective properties of photographs, including Roland Barthes's well-known memoir, Camera Lucida . Looking into a photographic image, my awareness of the moment of registration and its distance from the present momentthe time of viewing - is foregrounded. A photograph presents itself to me as a question: What were the circumstances of the framing of this photograph? Who is behind the camera? What happened immediately before or after the shutter closed? Viewing still photography, I instinctively measure the distance between myself (now) and them (then), as well as the effect of the 'pastness' evoked. However, re-contextualised through an image-sequence, the fixed, self-contained world of the still image becomes a world that is waiting for something to happen; it adopts aspects of the linear trajectory and future anticipation associated with the moving image. As a result, the photographic sequence makes for a potentially interesting dialectic between viewer and image, which can at once become a reflection on the past and an anticipation of the future-of-thepast, the anticipation of cause and effect.

One of several colonial group portraits in Why Colonel Bunny Was Killed is reproduced here. Everything about this image emphasises the distance between them and us: the dress, the objects, the staging, the gestures, and style of self-presentation. Yet shockingly, the transparency of the photographic resolution, the absence of grain or other artefacts (such as dirt or damage), undercuts this distance. Because of the impeccable resolution of the antiquated image technology (the large-plate negative and silvered print), I find the detail of the subjects much more penetrating than those in the glow of the video surface of You Made Me Love You. The polo players are as still as stone, but their presence is more tactile and penetrating than the human liveliness of any contemporary photography that I am familiar with. Particularly when magnified into close-up sequences, the detail-of the light in their eyes, the texture of their skin, and the polish of their fingernails-is by turns uncanny, present and distant all at the same time.

As an artist, I understand that distance is a powerful tool for provoking reflection on realities that are otherwise too close for us to attend to. I enjoy the spookiness of distance. And yet, I notice that while the tactile presence of the polo-players may spook and arrest a viewer, even the smallest movements in the dancers' (admittedly huge) faces in You Made Me Love You enable their liveliness be felt as closeness, as actual contact. 

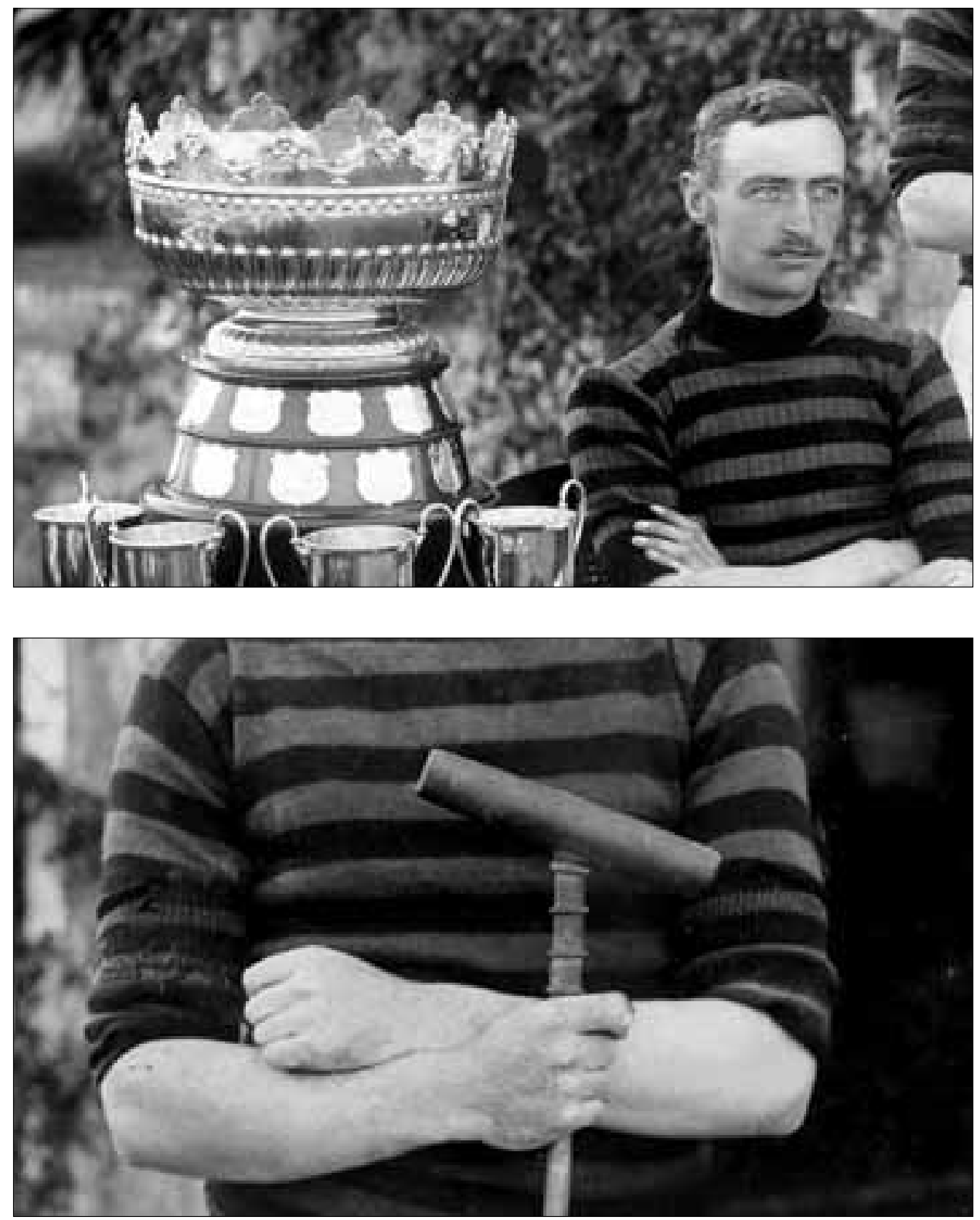

Stills from Why Colonel Bunny Was Killed (2010). Courtesy of the Council of the National Army Museum, London.

\section{Performance, process, and time}

Historian Elizabeth Edwards titled her essay on British portrait postcards of the early twentieth century, "Little Theatres of Self," highlighting the theatrical, performative nature of portrait photography. The photographer of the polo-players had to produce a single image that is capable of representing a temporal sequence of events, a narrative. The photograph provokes a symmetrical choreography (a staging of sorts) and a performance (of deportment and expression) with some shared rules (sight-lines, for example). The props refer 
to a polo match that took place before the photo was taken. The group is displayed in an orderly pyramid arrangement that designates them as a team and perhaps, as winners. Each holds an erect pose and follows the common rules_crossed arms and/or legs and a confident gaze directed by each member into a different and arbitrary middle distance. The outcome of the polo match is announced by enormous trophies displayed on two tables on either side, which are theatrically draped with black cloth. The ritual of polo is represented through the ritual staging of photography (both rituals are presumably important aspects of colonial life). Here, a temporal, performative process (the sporting competition) is collapsed into a representational tableau that is characterised by the choreographed pose, by symmetry, and by fixedness.

In You Made Me Love You, the roving camera-on-wheels provokes a choreography of sorts - a startled flocking motion-as dancers seek to restore their relationship to the centre frame. This in turn provokes a series of spatial and social adjustments, a process of micro-negotiations amongst the dancers. The video documents the state of flux of the physical process (dancers are constantly slipping out of the frame) and the more interior, sensory processes (perceivable in small, concentrated looks and movements across surfaces of faces). We witness a range of individual senses of personhood and self-presentation, now tentatively, now boldly, expressed. This too is the documentation of a process; only here process is defined by instability, uncertainty, and flux.

The single shot is a measure of time: theirs and ours. In You Made Me Love You, the camera's unedited performance makes felt the time of its recording. As they negotiate each other, the camera's, the dancers' and the viewer's looks are caught up together in a single measure of time. The time of recording and the time of viewing are bridged in the unfolding of the shot and also in the exchange of looks, the direct address of the dancers who seem to seek-out and return the viewer's gaze. When filmmaker Adam Roberts writes in "Notes on Filming Dance": "All I can say with such a film is: This is happening," he is touching not only on the redundancy of interpretation but on the immediacy, the privileging, of the "presentness," the "newness" of performance, which persists in films of dance.

\section{Avant-garde film and contemporary dance}

Photography invented stillness. By means of its special incision into time, photography, once upon a time, suddenly made visible things that could not ordinarily be seen. The image sequences of Edward Muybridge and the composite images of Etienne Marey stilled the body's motion in order to expose its hidden pathways. Later, in 1921, filmmaker Jean Epstein wrote of being entranced by the special powers of the film close-up and of slow motion to reveal things that the human eye could not detect: "This eye, remember, sees waves invisible to us."2

Laura Mulvey opens her chapter by reminding the reader of the perceptual revolution opened up, first by photography's invention of stillness, and later, by the invention of mechanised motion, of speed and the mechanised eye of cinema, and of the profoundly transformative effect of these for filmmakers such as Dziga Vertov, Jean Epstein, and René Clair.

To delay movement, whether as a compulsive intervention into the "body of the film"' or into the body of the dancer, not only frames and objectifies movement, but also reveals its mechanics, something not perceivable in everyday life. ${ }^{3}$ Describing the "digital delay"' of 
image technologies at the end of the twentieth century, Mulvey addresses the intervention into the flow of time and space in a film that disrupts the gesture of an actor and transforms it into something, which I might understand as a choreographic gesture - that of the dancer. In his essay, "On Dance Film," Adam Roberts asks what it is that distinguishes the flow of movement of an actor in narrative cinema from that of dancer in a dance film. As we are reminded in "The Pensive Spectator," the pleasure of delay and of repetition is the pleasure of the dance: a delight in movement (of film or of the body) for its own sake. Contemporary dance, like avant-garde film plays to our own curiosity about the nature of the body, or of film, and our desire to look at its movement. Unlike narrative cinema, dance film and avant-garde film have no need to conceal or dissolve the time of their registration in favor of, in the service of, a story time. Instead, there is a special pleasure derived from the awareness of the "constructedness" of choreography, as there is of avant-garde film. Avant-garde film and dance can draw us into the materiality and construction of the body or of the film and its projection.

The choreographer isolates and re-orders the body's gestures from everyday norms and performs them back for us to witness, recognise, and reflect upon. The delay and interruption of the conventional flow of movement, which Mulvey describes, is a version of the work of the choreographer. When we delay gestures digitally or choreographically, we dissolve their causality and imply an alternative logic. Stripping action of its causality, the choreographer offers us traces of the body's journey through space and through time. Significancelies in this disruption or displacement; it is what is left once I have been deprived of what I thought was logic, or a certain order of meaning.

As a delayed and over-extended gesture — say a handshake-starts to be understood as something strange, comic, or disturbing, the witnessing of the performance as a process requires the shedding of familiar interpretive frameworks. ${ }^{4}$ As viewer-witness, we are invited to pay attention to the changing perception of a once familiar object as it is transformed through repetition, delay, or stasis, simultaneously bringing the act of perception itself into question.

\section{References}

Barthes, Roland. Camera Lucida. Translated by Richard Howard. New York: Hill and Wang, 1981.

Edwards, Elizabeth. "Little Theatres of Self: thinking about the social." We are the People: Postcards from the Collection of Tom Phillips. Edited by Tom Phillips, 26. London: National Portrait Gallery Publications, 2004.

Epstein, Jean. (1921) 1981. "Bonjour Cinema and other Writings."Translated by Tom Milne. Afterimage 10, 32. Mulvey, Laura. Death 24x per Second: Stillness and the Moving Image. London: Reaktion Books, 2006.

Roberts, Adam. “Notes on Filming Dance." International Journal of Screendance 2 (2011): 107-113.

Wollen, Peter. "Fire and Ice." The Cinematic . Edited by David Campany, 108-113. London: Whitechapel, 2007.

Why Colonel Bunny Was Killed. Directed by Miranda Pennell. London: LUX, 2010. 28 minutes. You Made Me Love You . Directed by Miranda Pennell. London: LUX, 2005. 4 minutes.

\section{Notes}

1. Triggered by the memoirs of a medical missionary on the Afghan borderlands from 1890-1912, the film Why Colonel Bunny Was Killed (2010) is constructed entirely from still photographs and sound recordings.

2. Jean Epstein, "Bonjour Cinema and Other Writings," 13.

3. Mulvey, Death $24 x, 181$.

4. Choreographer Siobhan Davies, speaking at the Screendance Symposium at the University of Brighton (February 4, 2011) broke off to shake hands with Sarah Whatley, an action that lasted for several minutes. The video works "Home Stories" by Matthias Müller or "Alone Wastes Andy Hardy" by Martin Arnold eloquently re-configure cinema's gestures with illuminating results. 


\title{
Giving Up the World for an Image
}

\author{
Augusto Corrieri
}

W

alter Benjamin writes of the act of playing as being essentially repetitive. The child, almost pedantically, rehearses, repeats, and returns; replaying the same scenes over and over again. What is the sense of this repetition, asks Benjamin? First of all, it allows for a taming of the unknown; repetition allows the child "to master frightening fundamental experiences."1 Secondly, through playing and re-playing, the child develops habit and learns to in-habit the world; it is through repetition, we could say, that we come to be who we are.

The child reaches for the same toy and once again, as before, lifts it up and throws it, only to then repeat this action, always starting from the beginning, with the same pleasure. Using his or her hands, the child literally sculpts for her/himself a rhythmical mode of attention, a way of perceiving and acting in a visible and sensuous world. What is important to note is that, for Benjamin, the particular habit produced by playing with those childhood toys is something that endures in us as adults, indefinitely structuring our relationship to the world. If nothing else, the habit we develop as children persists in the form of nostalgia, and Benjamin ends the essay 'Toys and Play' by asking: "When a modern poet says that everyone has a picture for which he would be willing to give the whole world, how many people would not look for it in an old box of toys?"2

As I read and re-read this last sentence, I start to wonder: what is the image for which I would give up the world? What was my box of toys, the games through which I developed habit, and which still endure in me? For me, as for so many others, the box of toys was constituted by a TV screen, a VCR, and a remote control. The game consisted in playing (with) the filmic flows of sounds and images on the screen.

Play, Pause, Fast-forward, Rewind, and Stop: these are the five basic functions allowing for endless repetitions, delays, and interruptions. Fast-forward through the advertisements; rewind the scene in which the car vanishes back in time; replay it; stop the film for today. Each of the five basic functions corresponds to a familiar sign or better, a shape: the triangle pointing to the right is Play, the square is Stop, and so on. These shapes now seem to me to be lifted straight from a toy box of brightly colored wooden blocks; the ones children use to stack towers and to literally figure out how things fit together and how they fall apart, and what physical and mental actions you must perform in order to assemble and dismantle the world.

Among the many films I played and replayed, the one I consider to be somewhat central is Robert Zemecki's Back to the Future (1985), in which Marty, played by Michael J. Fox, accidentally travels back through time and meets his own future parents. There I am, probably in 1986 or so, watching the film over and over again, endlessly replaying its various scenes, captured not only by the film (the story, the images, the music, etc.) but by the control I can, or cannot, exert over it. By pressing a certain shape-button, I initiate a 


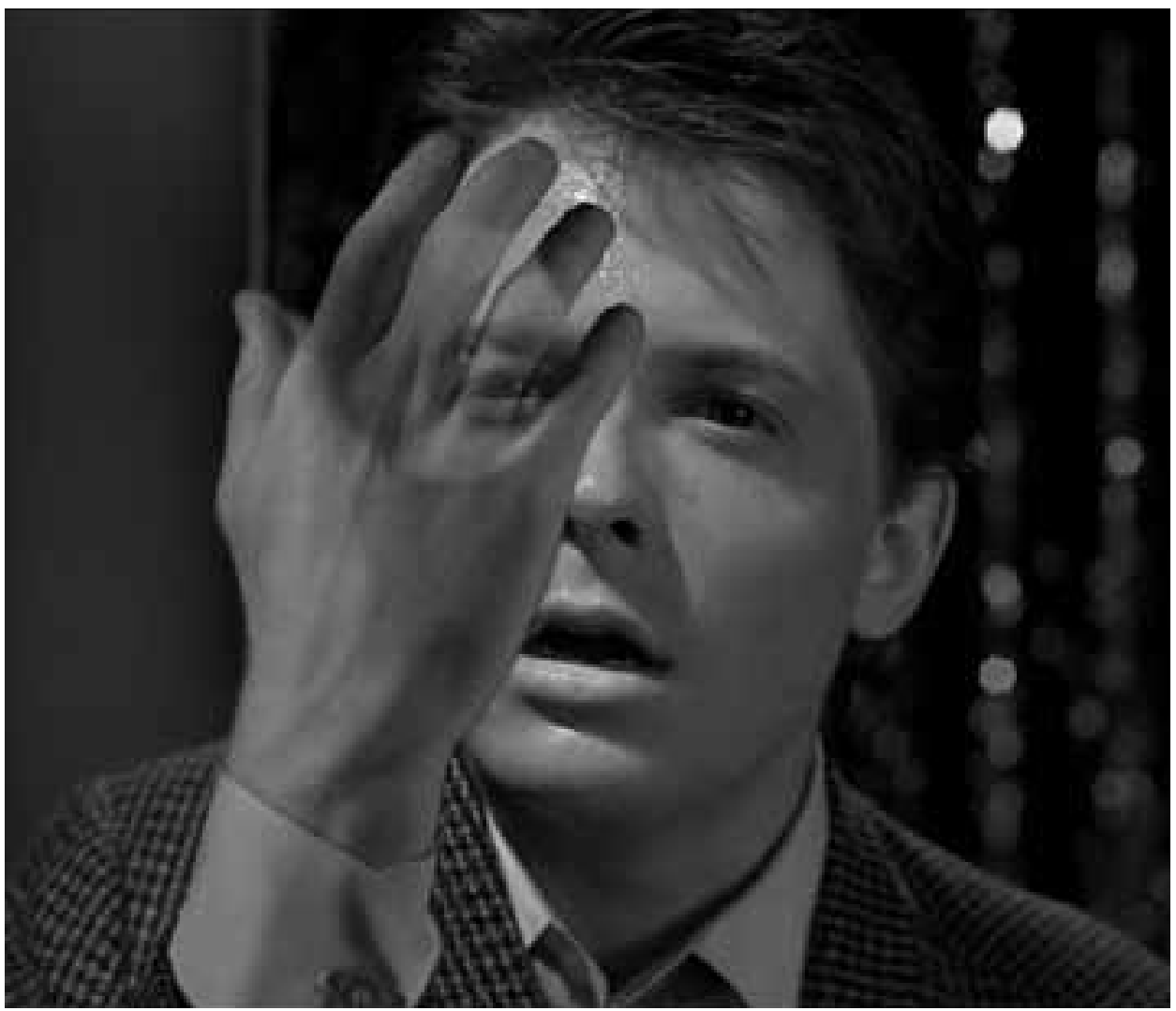

Still from Back to the Future (1985).

particular sequence of sounds and images, thus establishing a bodily connection between my hands and the movements on the screen; but, equally so, I am at the mercy of these sounds and images, as it is these that prompt my various "editing" choices. I wonder whether I chose Back to the Future simply because the film is already all about reversing time flows and replaying sequences over and over again?

The TV screen, the VCR, and the remote control constituted, for so many children growing up in the 1980s, an editing room of sorts; a place for rehearsing not only film sequences but a personal mode of duration - a way of being with the flows of spectacle (mainly films from the United States) — which only later would prove to be a central aspect of contemporary adult life. The child watching a movie is not in a condition of drugged passivity, the inert receiver of an adult-made image. Rather, she is in the process of defining relational dynamics, finding ways to link and unlink body-action-imagesound. As Benjamin writes about our first playing, "these are the rhythms in which we first gain possession of ourselves." ${ }^{3}$

However, it is difficult to really describe the rhythms through which we first came to a definition; it is far easier to recount scenes and instances of the film's narrative (especially when, as in the case of Back to the Future, it is strongly marked by Oedipal dynamics). For example, I remember Marty meeting his future mother; uncannily, they are the same age, and she begins to fall in love with him. And then one evening, stuck in a car, Marty finds 
himself unable to stop his mother from leaning over and kissing him. As I picture my sixyear-old self re-playing this scene, I can imagine this would have been a way for me to master "frightening fundamental experiences," to re-cite Benjamin. ${ }^{4}$

Yet there is one scene (or should I say a rhythm? A mode of duration?) that haunts me above all others. Its endurance in me is equivalent to a nursery rhyme that one cannot forget, for it is those very rhymes that help to form memory in the first place. I am referring to the film's dramatic and existential climax: Marty is now in danger of losing his own life if his future mother and father do not kiss. It is the high school ball and Marty is playing a guitar on-stage. Time is running out on him, and it looks as if his parents may not get together after all. He pulls out a (future) photograph of his brother, his sister, and himself; their image has already vanished, and now his image is slowly beginning to fade too. Marty begins to sweat; we hear his palpitations; he slowly collapses to the ground. With eyes wide open in terror, he gazes upon his own hand and notices that it is becoming translucent. It is as though his own flesh were in the process of turning to celluloid, as if the body were taking on the spectral quality of film itself. I now wonder whether it was through playing this scene that I first saw myself as an image, a phantom of sorts, whose outline can appear and disappear just like the figure on the screen. Was it here that I first rehearsed the flicker of uncertainty? Was it through stilling and reversing this scene that I first rehearsed the oscillation of my own image, the first of many anxious dislocations?

\section{References}

Back to the Future. Directed by Robert Zemeckis. Universal City, CA: Universal Pictures, 1985.

Benjamin, Walter. "Toys and Play: Marginal Notes on a Monumental Work." Walter Benjamin: Selected Writings 1927-1930. Translated by Suhrkamp Verlag. Edited by Michael W. Jennings, Howard Eiland, and Gary Smith. Cambridge, MA: Harvard Univ. Press, 1999. 117-21.

\section{Notes}

1. Walter Benjamin, "Toys and Play," 120.

2. Ibid.

3. Ibid.

4. Ibid. 


\title{
Delayed Reactions
}

\author{
Kyra Norman
}

aura Mulvey begins the final chapter of Death 24x a Second: Stillness and the Moving Image by saying that: "In the 1920s, for filmmakers such as Jean Epstein, René Clair and Dziga Vertov, the cinema opened a revolutionary, mechanical eye that transformed human vision. It opened up new perceptual possibilities, accentuating the changed ways of seeing a familiar external world already affected by the stillness of photography and the speed of mechanised transport." She cites Vertov: "Did a risky jump for a slow-motion camera. Didn't recognise my face on the screen. My thoughts were revealed on my face-irresolution, vacillation and firmness (a struggle within myself) and again the joy of victory. ${ }^{2}$ Mulvey goes on to propose that today, another transformation has taken place: new technologies (the VCR, DVDs) have "opened up new perceptual possibilities, new ways of looking, not at the world, but at the internal world of cinema. [We have] ... accumulated a recorded film world, like a parallel universe, that can now be halted, or slowed or fragmented." ${ }^{\prime \prime}$ These technological developments enable us to experience the work of Epstein, Clair and Vertov and others in a very different way from that of their contemporary audiences. Our ability to pause, rewind, or fast-forward the moving image is relatively recent and yet already assumed.

Three concepts that Mulvey develops in her exploration of the significance of this perceptual shift seem to offer particular scope for thinking about specific questions around screendance: firstly, the parallel universe invites reflection on screendance's relationship to the accumulated world of screen media; secondly, the cinema of delay offers a perspective on debates around movement and stillness on screen; and thirdly, the notion of the pensive spectator prompts consideration of the pensive practitioner; that is, how we might draw on, and work with, an awareness of the transformed conditions of spectatorship that Mulvey addresses.

\section{The Parallel Universe}

To begin with an obvious example of artists engaging with the recorded film world, we might consider David Hinton's work with Rosemary Lee on Snow and on Birds, in both of which the artist draws directly from 'the parallel universe' for raw materials, creating new work entirely from archival footage. More generally, we might observe that the conventions of cinema often adopted in screendance works (such as beginning one's film with an establishing shot) demonstrate an awareness of, and engagement with, the parallel universe and its established codes.

More broadly still, an awareness of the fabric and structure of the parallel universe, shared by artist and audience, can now be seen to inform live works, as well as those on screen. For example, the 2010-2011 live- and video-performance piece, White Caps, by UK b-boy company Champloo, overlays the live action of performance with video-projected titles, credits and interstitial texts, as well as incorporating segments of video informed by cinematic conventions, into the flow of live action. 
More broadly yet—and whilst Mulvey's writing is focused on cinema-our parallel universe, as the totality of all that exists on screen, must surely embrace the various screenbased histories from which screendance artists draw. As such, our parallel universe offers space for reflection on works that place themselves in a video-art lineage, for example, as much as those that are informed by the history of cinema.

\section{The Cinema of Delay}

Mulvey asserts that the new technologies (VCRs, DVD players, etc.), which enable the viewer to halt, slow, or fragment elements of this parallel universe (to pause, fast-forward, or rewind the film) create a cinema of delay. This "act of delay reveals the relation between movement and stillness as a point at which cinema's variable temporality becomes visible." In this act of revelation, Mulvey sees "an affinity with the early avant-garde and the aesthetic exploration of movement and stillness as a privileged quality of cinema." ${ }^{5}$

The aesthetic exploration of movement and stillness is naturally central to much livedance and screendance practice and discourse (see André Lepecki's Exhausting Dance, for example). At the Open Source Video Dance Symposium of 2007, Claudia Kappenberg built on Lepecki's line of enquiry in her paper," Exhausting the Screen," to question the assumption that the 'dance' in screendance necessarily requires constant motion. ${ }^{6}$ Elsewhere, Kappenberg has observed that "the attachment to, and reproduction of, familiar forms of dance within screendance is due to a complex historical trajectory which saw, on one hand, a critical stance towards the mediation of dance through technology and, on the other, a legacy of primarily Hollywood cinema, when dance was indeed made for film."7 For Kappenberg, this attachment and reproduction unquestioningly assumes that dance requires bodies to be in motion, an assumption challenged by Lepecki, amongst others. Kappenberg identifies a trend in "current international programming of dance on screen [in which] the on-screen bodies tend to appear in a 'constant state of agitation,' 'and responds that: "We need to ask what kind of subject it is, which constantly changes shape, shifts weight and changes its position, agitates its limbs and bends in all directions?"8 Mulvey offers us another vantage point for thinking around movement and stillness in screendance. In particular, her writing invites further consideration of the mechanisms for moving and stilling the screen image, the act of delay, and the space for reflection that is created when the image is stilled.

\section{The Pensive Practitioner}

Mulvey talks in some depth about the introduction of the still image into the moving image, and it is from Raymond Bellour's exploration of the spectator's reaction to the still frame that Mulvey draws her chapter title. "Raymond Bellour's concept of the pensive spectator anticipated the thoughtful reflection on the film image that is now possible, a way of seeing into the screen's images, shifting them and stretching them into new dimensions of time and space." This line of thought returns Mulvey to her writing of almost thirty years earlier, "Visual Pleasure and Narrative Cinema," where she identified: "three 'looks' inscribed into fiction film. First, the look of the camera records the one and only moment of registration. Secondly, the looks of the characters are inscribed into the fictional time of their diagetic world. Finally, there is the spectator's look at the screen, repeatable across film's history."10 At the time, she wrote: 
"This complex interaction of looks is specific to film. The first blow against the monolithic accumulation of traditional film conventions (already undertaken by radical filmmakers) is to free the look of the camera into the materiality of time and space and the look of the audience into dialectics and passionate detachment.." For Mulvey, the cinema of delay has realised such a transformation of spectatorship: "The spectator's look, now interactive and detached from a collective audience, can search for the look of the camera while also asserting control over the look within the fiction."12 Mulvey suggests that, whilst made possible by technologies, this transformation is "consciously produced and actively imagined."13 I am interested in opening up a discussion of how artists, curators, and audiences might acknowledge and work with this transformation in the ways in which our experience of screen works has shifted-both the expectation that works can be paused, rewound, repeated, curtailed, as well as the familiarity with the parallel universe-and how this might be changing the ways in which works are made, presented, and experienced.

Clearly, interactive installations and online distribution of screendance offer opportunities to explore these processes. However, many screendance works are created for single screen, cinema-style viewing. Although an increasing number of works are available online or on DVD, it is typical for screendance works to be presented in evening-length programmes for a collected audience. As screendance artist Simon Ellis recently observed, this presentational format "is almost entirely for practical purposes, but it is impossible as a filmmaker to predict the ways in which the rhythm or dynamic of the evening influences the way in which your work is experienced." ${ }^{\prime 4}$ In response to this, Ellis created Look and Look Again, a pair of short, silent films, which are presented without credits, and which are intended as "a gentle effort to begin to manipulate an evening of short films by having two films presented non-consecutively" within the same programme. ${ }^{15}$ Such an approach, on the part of what we might call the 'pensive practitioner,' to consider the context in which one's work is viewed, seems to offer some of the "pleasure of decipherment" that Mulvey discusses..$^{16}$ In making an intervention into the presentational format of the screening, this work invites the active curiosity of the viewer, and foregrounds our engagement in the process of making connections between the separate works of the evening's programme. Given the increasing availability of screendance in formats to be viewed in isolation (online, on DVD, etc.), the layering of choices and connections made by artists, curators, and audiences, through a considered-pensive-approach to the time and space, in which works are shown before collected audiences, seems particularly rich in potential. How might we explore and experience the playful possibilities for artists, curators, and audiences in coming together to share and engage directly with screendance works, and what are the implications for the ways in which work for single screen is created, presented, or experienced? Mulvey cites Annette Michelson, who writes of the "sharpening cognitive focus and ... ludic sovereignty ... open to those who, since 1896, have played, as never before in the world's history, with the continuum of temporality and the logic of causality."17 This playful, powerful curiosity (previously only available to those with access to editing technologies) is now available, asserts Michelson, to anyone with a video recorder. This is easily experienced when watching alone, but what happens when we watch together?

In his essay, "The Work of Art in the Age of Mechanical Reproduction" (1935), Walter Benjamin proposes that "with the close-up, space expands; with slow motion, movement is extended."18 With the advent of the VCR, Mulvey argues, the experience of the viewer 
has been irretrievably altered. Within the range of the available material captured by the filmmaker through the camera, Mulvey's pensive spectator now has the ability to expand or contract the space of the screen, and to extend or curtail movement contained therein. How then do we acknowledge and make room for this in our work?

To return our attention from the spectator to the artist, Mulvey suggests that such curiosity, such pensivity, on the part of filmmakers, produces "new relations and connections... sequentially or simultaneously, out of which new oscillating, shifting, representations of time may be experienced." ${ }^{\prime 19}$

\section{References}

Benjamin, Walter. The Work of Art in the Age of Mechanical Reproduction (1935), in Graeme Gilloch, Walter Benjamin: Critical Constellations (Cambridge: Polity Press, 2001).

Champloo. "White Caps." Directed by Wilkie Branson. United Kingdom: Bristol Old Vic and Theatre Bristol, 2010-11.

Hinton, David. "Birds." United Kingdom: Arts Council of England, NPS, 10:00, 2000.

(director) and Rosemary Lee (choreographer). "Snow." United Kingdom: Arts Council of England, NPS, and BBC, 6:00, 2003.

Kappenberg, Claudia. "Does Screendance Need to Look Like Dance?" International Journal of Performance Arts and Digital Media, 5, nos. 2-3 (2010): 89-107.

"Exhausting the Screen." Opensource: Videodance\} 2007: Proceedings of the SecondAnnual International Opensource: \{Videodance\} Symposium, Findhorn, Scotland, November 20-24. Edited by Katrina McPherson and Simon Fildes. Nairnshire, Scotland: Goat Media, 2009.

Lepecki, André. Exhausting Dance: Performance and the Politics of Movement. New York: Routledge, 2006.

Mulvey, Laura. Death 24x a Second: Stillness and the Moving Image. London: Reaktion Books Ltd., 2006.

. "Visual Pleasure and Narrative Cinema." In Visual and Other Pleasures, 14-27.London: Macmillan, 1989.

\section{Notes}

1. Laura Mulvey, Death $24 x$ a Second: Stillness and the Moving Image, 181.

2. Dziga Vertov, "Kino Eye" in Film Makers on Film Making. Edited by Harry M. Geduld, Bloomington: Indiana UP, 1967, 91, quoted in Mulvey, Death at 24x a Second, 183.

3. Mulvey, Death at $24 x$ a Second, 183.

4. Ibid.,182.

5. Ibid.

6. Claudia Kappenberg, "Exhausting the Screen."

7. Claudia Kappenberg, “Does Screendance Need to Look Like Dance?” 91.

8. Kappenberg, “Exhausting the Screen," 30, 31.

9. Mulvey, Death 24x a Second, 195.

10. Ibid., 190

11. Mulvey, "Visual Pleasure and Narrative Cinema," 26, in Mulvey, Death 24x a Second, quoted in 190.

12. Mulvey, Death $24 x$ a Second, 190.

13. Ibid.

14. Simon Ellis, "Spruiking Look and Look Again," Skellis @ Posterous: On Dance, Art \& Things (blog). http://skellis. posterous.com/.

15. Ibid.

16. Mulvey, Death $24 x$ a Second, 193.

17. Annette Michelson, "The Kinetic Icon in the Work of Mourning," October 52 (1990), 22-3, quoted in Mulvey, Death at $24 x$ a Second, $187-88$.

18. Walter Benjamin, "The Work of Art," 12.

19. Mulvey, Death at $24 x$ a Second, 196. 


\section{Falling, again}

\section{Pia Ednie-Brown}

I was with some trepidation that I read "Falling into the Surface" again, written now over a decade ago. I was sure would it make me cringe, like flicking through an old diary written in one's younger days. I was right to some extent, as the paper reads to me now like a cat overdoing a set of acrobatic twists while falling — not without some virtuosity, but mildly ridiculous through enacting a set of moves that could have been more directly embedded in the forces at play. Having been written for a publication on "hypersurfaces" in architecture, a certain hyper-excess of performance might have been warranted — with the form inside the text resonating with certain contrived complexities present in the architectural forms and preoccupations of that time. But perhaps I am just making excuses or enacting, still, a contrived set of cringe-contortions.

What matters now is that the paper-and its project to articulate a mode of turbulent opening to the world-has been offered an occasion to be "replayed" in a context dedicated to practices of bodily movement. For this I feel very grateful. It is an opportunity for the paper to offer the larger project a moment of conversation-a reopening through those with well-practiced sensitivity to the falling always occurring within movement. And it was important that these conversations took place through the specificities of practicewhere we can avoid the tendencies of universalizing theories, and burrow into particular subjectivities, experiences, and know-hows. There was less openness to that kind of conversation in the 90s, when we were still moving toward the realization that practice is a form of enquiry that allows for valuable insight into the vastness of lived experience. These days, as creative research finds its ever-moving feet, the impulsions and curiosities driving creative practices from within are able to contribute to the larger project of exploring the potentials of living. It's no wonder that we keep replaying Deleuze's paraphrasing of Spinoza_-"we do not even know what a body can do ..."--as we are still unpacking ways to know.

\section{References}

Deleuze, Gilles. Spinoza: Practical Philosophy. San Franscisco: City Lights Books, 1988.

Ednie-Brown, Pia. "Falling into the Surface (toward a materiality of affect)." Hypersurface Architecturell 69, no.9/10 (1999): 8-11.

\section{Notes}

1. Deleuze, Spinoza: Practical Philosophy, 17-18. 


\title{
Through Screens
}

\author{
Simon Ellis
}

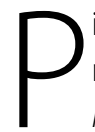

ia Ednie-Brown's essay Falling into the Surface (toward a materiality of affect) (1999), has nothing to do with screendance.

Falling was published in 1999 and its audience was — and remains — primarily architects, architectural students, and academics. In 2009, an architect friend in Melbourne suggested Pia's writing might interest me; at the time, I happened to be involved in developing a screendance project called Anamnesis. The following year these coincidental circumstances led to my suggesting Pia's essay to the Screendance Network as one of several historical essays that would act as provocations for this issue of the International Journal of Screendance.

When I first read Falling I remember being drawn to its poetics, in which we no longer fall down but rather are "opening out," and our subjectivity is twisted onto a surface that animates perception. ' Some of the connections to the screendance aspects of my practice were obvious, in particular the post-production work on Anamnesis and the idea of falling onto the surface of the team's computer(s).

Such fallings involve repositioning a film's subjects from the rehearsed and the responsive, to their manifestations in dance in the edit. It is as if a new choreography has begun and that which is already made is remade. The feeling of falling (or opening out) onto the surface of the screen initiates collaboration between (recently) live presences, the mechanics of the edit, pixels, data and the creative team.

From the conditions of post-production to the methods by which screendances are presented, these encounters with flatness, with surfaces of shadows and light, are at the heart of the screendance community's work. Although screendance's materiality is independent of the surface for projection or display, its affective potential is realized through the meeting of skins with multiple disparate surfaces. These ephemeral surfaces are the building of the film — a site for enaction — and our post-produced choreographic processes are "insinuated in the building itself."

Laurie Anderson's 1975 installation At the Shrink's (a Fake Hologram) playfully disrupts the flatness of the screen by constructing a roughly shaped sculpture to receive the image, and its contours allow the light of the projector to animate the clay. ${ }^{3}$ At the same time, the impossibility of Anderson's tongue-in-cheek experiment in three-dimensionalityreflexively rendered in her voiced description of visiting a psychiatrist-reinforces the mechanical and material demands of video (and film) for flatness.

Ednie-Brown expresses her interest in surfaces very clearly:

Surface, in common parlance, is generally understood as the exterior boundary of things, the outer skin of any object. In this sense, surfaces are actual, material, textural entities that are the most directly perceived and felt aspects of the world. They are that which we directly encounter. The surface is also taken to be something that conceals: 'it was not what it appeared to be on the surface.' It is when things surface that they 
become evident or apparent; they appear out of a previously concealed existence or latency. Surfacing is an action of becoming explicit, of becoming experientially apparent in a movement from virtuality to actuality — of becoming expressed across the limits of perception. Surfacing is the process of becoming perceptible and actual. ${ }^{4}$

I can imagine philosopher Alva Noë"'s "enactive approach" to perception, in which the act of perceiving is akin to metaphors of touch (rather than sight), intersecting with EdnieBrown's surfacing. ${ }^{5}$ Noë suggests that perception is not something that happens to us, but is something we enact. It is a skilled process that occurs in the entire body in which our capacities for perception, action, and thought are inseparable.

As images become "integrated and dispersed" in the process of falling (onto surfaces), they are falling into meaning through action. ${ }^{6}$ The actions are ours, and through them we are sensitized, enactive, and the moving image (still falling) is made and remade, built and torn down. It is a delicate dance of construction, an architecture of desire between the mechanism of film-video projection and my touching its various surfaces.

At Expo Zaragoza 2008, MIT architects and engineers from the SENSEable City Lab built a Digital Water Pavilion (with design by Carlo Ratti developing the interactive water wall concept created by the Smart Cities Group at MIT and directed by William J. Mitchell). Conceived as "a place where spaces are flexible, changing and responsive" ${ }^{\text {" }}$ the building features walls made entirely of water that is controlled (by electromagnetic valves) as if it were pixels on a screen. ${ }^{10}$ The Digital Water Pavilion is a building of flexible (falling) screenswalls that are adaptable and able to project and absorb light. The walls are non-surfaces, outliers in how we understand the utility of walls and screens. They are porous surfaces in which the delineation of inside and outside is uncertain, and my dancing body is falling through them, and now the water-pixels of this screen are falling with and on me.

Through collecting and building ideas during this brief writing process, I've begun to think about screens: their physical integrity, motility, and balance, the ways in which I am seduced by their presence and ubiquity, the shrinking scale of our dances with perceptual action as we hunch, lean and hover around their pixels and frames. As a choreographerdancer involved in screendance, I am interested in imagining the limits of the screen's capacity to contribute to the meaning-making possibilities of the videographic. This brush with Ednie-Brown's writing has given me the opportunity to questions the assumptions I make about screens and their potential for experimentation. In willing architects to depart from the "impasse of nostalgia,"11 Ednie-Brown also-and inadvertently-challenges screendance practitioners to "break out of self-perpetuating habits. Through modes of fallibility, experimentations can expand their processual dimensions and propel them into even more pronounced expressions."12

What might this contrived or even arbitrary connection between Ednie-Brown's writing - something she herself now describes as a "cat overdoing a set of acrobatic twists while falling"13 — and contemporary screendance practices be like for other screendance artists to engage with and respond to? Might various (and alternate) readings of Pia EdnieBrown's work be useful to these artists and, in turn, offer poetic and/or analytic ways of thinking for a wider audience in the dance, film, screendance and architectural communities?

Engaging with the work of others - even if seemingly unrelated to one's own interests -is commonplace. Artists and academics mine words and ideas to generate, imagine, 
stimulate and share, and perhaps also to add authority to our work. If it's not Deleuze, then it's Rancière, or (more probably these days) Bourriaud.

Alongside the popular expansion of criticism, the academic study of the arts has become much more specialised and esoteric ... Now academics are content to speak to each other in technical language, published in small-circulation journals.

Rónán McDonald ${ }^{14}$

The politics of my decision to ask two practicing screendance artists to respond to EdnieBrown's writing has to do with accessibility. I want these discussions to be heard outside of academia, and for the International Journal of Screendance to be meaningful to dancers, artists, choreographers, and filmmakers.

Dianne Reid (Australia, www.hipsync.com.au) and Lucy Cash (UK, www.lucycash. com) are experienced dance and screen practitioners. Their work has been seen around the world and they have both found ways to continue to work in difficult conditions and nourish their artistic lives. Although Lucy and Dianne have both worked in and around academia at various times, they are independent artists, and their work and interests reflect their independence. Their contributions to this second publication of the International Journal of Screendance are playful, evocative, delicate, imaginative, and practical. It has been my pleasure to work with them and with Pia Ednie-Brown on this small contribution to the journal. I invite you to fall with them.

\section{References}

Anderson, Laurie. At the Shrink's (a Fake Hologram). New York, Holly Solomon Gallery, 1975. Installation.

Ednie-Brown, Pia. "Falling into the Surface (towards a materiality of affect)." Hypersurface Architecture II, 69, no. 9/10 (1999): 8-11. 99-105.

Ellis, Simon, David Corbet, Bagryana Popov, and Cormac Lally. Anamnesis, Melbourne: Australia Council, 2009. http://www.vimeo.com/6073489. Accessed December 10, 2009.

McDonald, Rónán. "A Triumph of Banality." The Guardian. London, Guardian News andMedia Limited, 2007.

milladigital. "The DWP Project." 2008. Access June 20, 2011. http//www.dwp.qaop.net.

Noë, Alva. Action in Perception. Cambridge, Mass.: The MIT Press, 2004.

\section{Notes}

1. Ednie-Brown, "Falling into the Surface," 10.

2. Ibid., 8 .

3. See http://www.youtube.com/watch?v=WnotCEuFSwM, for an extract from Anderson's At the Shrink's (a Fake Hologram).

4. Ednie-Brown, "Falling into the Surface," 10.

5. No", Action in Perception, 2.

6. Ednie-Brown, "Falling into the Surface," 10.

7. See http://senseable.mit.edu.

8. The official website for the Digital Water Pavilion is: http://www.dwp.qaop.net.

9. milladigital, "The DWP project," http://www.dwp.qaop.net.

10. See http://www.youtube.com/watch?v=2kBkX-LOrTk, for footage of the Digital Water Pavilion.

11. Ednie-Brown, "Falling into the Surface," 11.

12. Ibid., 11.

13. Ednie-Brown's introduction Falling Again, 85.

14. McDonald, "A triumph of banality," http://www.guardian.co.uk/commentisfree/2007/oct/02/comment.art. 


\title{
making things visible
}

\author{
Dianne Reid
}

W

hen I first picked up a video camera and began looking at the dancing body, it was driven by a desire to stop the body from disappearing, to give it actuality and, in doing so, to bestow value and worth. By getting close enough and approaching from different angles it became possible to surprise the body, to uncover the invisible and to open the possibilities - that we are more than this flesh cage, this architecture, which is making and unmaking itself every moment.

The more I hold the camera the more it becomes flesh, this frame an extension of my own body, dancing in duet with subject/landscape. Now my desire is to undo it, dismantle it, reveal its process of un-becoming. I want to make the process visible and, in doing so, keep subjectivity alive.

I carried Pia's essay, "Falling into the Surface," around with me for several days before reading it and during that time used the reverse side to record notes from my improvisational performance practice. As I finally got to reading and then turning each of her pages, my eyes passed over fragments of my own notes and began to make connections: how thoughts on improvisational practice connect to these notions of virtual architecture. The undoing and evolution possible in architecture suggested by Pia echoes the observation that in improvisation "the world is constantly being disrupted and something is coming up as a result."1

As an improviser, with or without camera, I am engaging in the present moment, paying attention - to my breath, to the moment when breath becomes sound, to what a movement uncovers, to sensation, to what distracts me. Now, as I read I am noticing the juxtaposition of not just two pieces of writing, but also of my body and the buildings I move through. I am considering the potential of my breath to permeate their surfaces and for their particles to move through me. I am enjoying the idea that structures can be fluid and that the poetic intersects with the academic.

My work is mostly concerned with moments, with time. Time is the process of our body's architecture. The vertical plane, the standing body, is said to represent the infinitethe present moment at once all that exists and that which is continually disappearing. This body you touch/see now is virtual. A lifetime could be mapped as a series of virtualities, the actual as a shifting point along its journey. Like a flick book, the picture is only constructed through the disruption of the fixed, the collision of pages into a compressed timeframe, connecting the pieces through an illusion of shared space.

Connections can be drawn between the forms of dance and architecture. Each term refers to both process and product in the construction of each respective form. They are dealing with physical structures that house, protect and enable human expression. They are re-shaped by cultural and technological change. A skyscraper is a cold hard object on a fixed foundation adhering to rules of geometry to work with and in spite of the forces of 
gravity. My dancing body, my practice, began that way. I had to begin with a syllabus, rules and disciplines in order to work against (at first) and with (later) the forces of gravity and negotiating the other structures (bodies and walls/objects) around me. The technology I have negotiated has moved from the hard edges of the pointe shoe to the virtual edge of software/wear/where. There is a political and spiritual metaphor at play in these notions of structures of control and order and the possibility of the unknown. There is also a discussion about artistic practice, as an imaginative space, as a means to test and extend the possibilities of science and technology.

\section{falling apart}

My recent artistic practice is an example of this idea of evolution being a kind of falling apart. When I began as a dance filmmaker, I was trying to create a subjectivity, to make actual/visible the virtual/intangible. I was building a new structure, a new dance, with these new tools and trying to make this new object (a hard plastic case surrounding spools of magnetic tape) fluid and organic like a human body. As my practice evolves it now becomes about deconstructing the process and, in doing so, enabling new ways to see dance and the body.

For A Broken Puzzle with Weave Movement Theatre (2010), I worked with multiple unknowns, with a dozen very different bodies and minds. These dancers' bodies, their physical and mental architectures, are off-balance, asymmetrical, unpredictable, and spontaneous. Physical spasms are norms, so the explosive unknown is a "virtuality" - that is, an unseen phenomenon that can engage with the actual at any moment. These bodies really fall and the impact is felt, so I must create processes to survive the unknown, negotiate the action. I want to bring the camera into an intimate range, to magnify each individual's physical differences and celebrate their uniqueness. The gaze of the viewer can be controlled and informed by the movement and proximity of the camera. By approaching the subject with the curiosity of a child, that is, a desire to know and experience the new and different, I believe I can create a shared space where other types of bodies and possibilities for movement exist. In coming so close to these different bodies'surfaces, I am inviting the viewer to look beyond the surface metaphorically, to "become sensitive" and "have a perception of an otherwise relatively latent presence."2 I am aiming for a de-mystification of disability that shows the might of a crumbling structure, the credibility of collapse, the delicacy of distortion.

To do this I must consider context to uncover content, design movement scores to access what lies beneath the surface and give each individual a palate of physical and imaginative material to work with.

Verbally recall sensations from a personal journey/memory

Physically respond to these lines of text:

1. Come to a place outside of time, beyond geography

2. Count your bones

3. Hear the light

4. Ghost fingers/invisible touch

5. Lie like a broken puzzle ${ }^{3}$ 
To capture the footage I must create a moving structure that is undoing/revealing for the camera. Keeping the performers' subjectivity alive means giving space and duration to the possibilities of connection, privileging the process of moving between modes of seeing and being seen. We become cameras and viewers simultaneously, actively engaged in constructing the event we are inside. It is a tiny shift in perception rather than action that determines whether we are a participant in the dance or an observer in the same space.

\section{Location and watching}

Position yourself somewhere in relation to what you see, notice what you see from that angle, that proximity, notice what is in the background, what frame are you looking through, notice the quality of the light, the texture of the surface you are connected to, the temperature, the sounds... keep shifting your focus from the close up to the distance... move between watching and becoming part of what you are watching... ${ }^{4}$

... so our edges become blurred and viscous and our attention is alive and real ... the possibilities, the virtualities, falling into one another's surfaces, each becoming actual through the process of another's perception.

In the editing of the dance film, alone in the edit suite, it is my point of view that is privileged, but I want to imbue fluidity into what will be a fixed architecture, in some way to continue to relinquish control, insert chaos into the order. So I create a soundtrack from the cutting up and distorting of their voices and body sounds. I will assemble the visual architecture on this virtual blueprint; create a form that reconfigures gravity and narrative; build a structure that is always falling, is on the edge of collapse, and exists in a different plane.

Slowing, reversing, cutting and repeating words and sounds-occasionally a whole sentence to lead us down a corridor, to put walls around the pathway.

pause... approach, depart... diesel, half awake, shhh, a touch ... two, and, dark, splash, I saw the sea reflected in my grandmother's eyes...

I taste the smell of forgotten passengers, vibrating rattles my spine, my hand, refreshingly minty ${ }^{5}$

\section{And this construct becomes a metaphor for "difference"...}

Being continually made, cut free from temporality, surfaces are felt and merging into each other ... so "the subjective is not originated in an individual, rather it is produced through the transitory assemblages of a vast array of impersonal forces." ${ }^{\prime \prime}$

And the viewers can become aware of being watched, to be within the action as they make sense of where they are at each moment. The complete form is not visible, the bodies are strange, the stories are personal and fragmented ... the viewer is inside someone else's head, watching, falling ... the only constant is perpetual change.

Our bodies are continually metamorphosing. The skeleton is alive and changing, renewing itself in less than two years, the skin renews itself every month.' Our actualities are in motion. In their flux, all our surfaces are virtually the same. 


\section{A broken puzzle}

I am split by your scrutiny

Fractured by your fascination

Dismantled by your deliberations

I am this piece of blue sky, that dark corner,

A disembodied limb, an upturned cart, a winter branch,

Pieces of possibility discarded by a sideways glance. ${ }^{8}$

\section{References}

Ednie-Brown, Pia. "Falling into the surface (toward a materiality of affect)." Hypersurface Architecture II .

Architectural Design Academy Editions 69 (1999): 1-12.

Morrish, Andrew. Coaching in Performance Improvisation. Cecil Street Studio, Fitzroy, Melbourne, November 9-12,2010.

Reid, Dianne. Rehearsal notes for A Broken Puzzle. Melbourne, August-September 2010.

Tufnell, Miranda and Chris Crickmay. Body, Space, Image: notes towards improvisation and performance. Great Britain: Dance Books, 1990.

Weave Movement Theatre. "A Broken Puzzle." Program notes presented at the Melbourne Fringe Performance of Weave Movement Theatre, Brunswick, September 24-26, 2010. http://weavemovementtheatre.com.au/.

\section{Notes}

1. Reid, "Rehearsal Notes."

2. Ednie-Brown, "Falling," 10.

3. Reid, "Rehearsal Notes."

4. Ibid.

5. Ibid.

6. Ednie-Brown,"Falling," 9.

7. Tufnell and Crickmay, “Body, Space, Image," 3.

8. Weave, "A Broken Puzzle." 


\section{Finding the Turn}

\section{Lucy Cash}

"When we're silent and when we stand still we are not resting. We're searching inside ourselves for the turn."

Unconventional forms of collaboration are a core part of my practice as a filmmaker and artist. Collaborations that begin in the form of a conversation and end in the shape of a piece of work.

By not-having-to-be-an-expert I can write from a place on the edge of disciplines, where ideas unfold more slowly (perhaps because they haven't yet condensed into an agreed shorthand), and with more instability. This instability leaves ideas vulnerable to a lack of certainty, but at the same time open to the powerful effect of transformation and re-interpretation: of finding their turning point.

Accordingly, l'd like to respond to Pia Ednie-Brown's beautiful essay, Falling into the surface (towards a materiality of affect), as if Pia and I were collaborating on unfolding my inexpert understanding of her words about architecture. Since Pia and I have never met, this collaboration is a fictitious one. And in keeping with its fictitious nature, I've suggested it here as a conversation: incomplete and fragmented.

Pia E-B: Of constant concern to the discipline of architecture is the effectual nature of the processes of production ... ${ }^{2}$

LC: Within my practice I'm also wondering how the making processes I engage in affect not only a specific piece of work, but also the discipline(s) within which I work. The unconventional collaborative practices I have been involved in often necessitate creating individual systems in order to accommodate a diversity of disciplines. There's a kind of (invisible) autopoiesis which takes place.

One specific area of negotiation within a collaborative system is time:

The time it takes to begin

The time it takes to absorb an idea

The time it takes to respond

The time it takes to respond to what you are seeing and not what you imagine/ assume you are seeing. The time it takes to end.

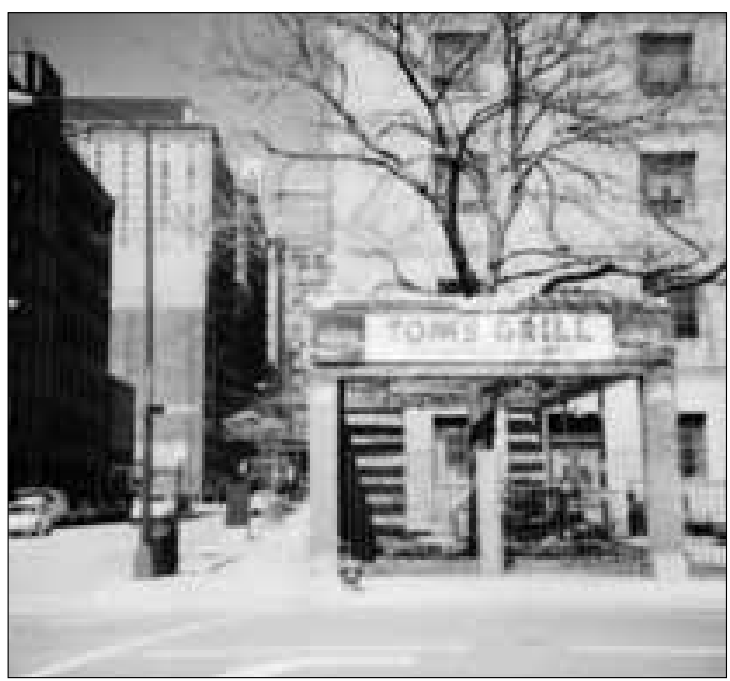

Tom's Grill 
All of this negotiation of time is often hidden and of unexpected duration. I'm thinking about the fact that a building as an event is a long way away from the ephemerality of a performance as event. Not to deny the building as a kind of stage-where people enter and exit and multiple choreographies unfold simultaneously, but rather buildings themselves are (usually) far from ephemeral. And although their surfaces may wear, it's rare to perceive the shifts and adjustments of a building at the molecular level. Yet in his microlecture, The Example of Glass, Goulish does reveal exactly that:

What is glass? Until recently, glass was considered a mostly transparent solid. It behaved like a solid; if struck, it shattered. But then in the ancient cathedrals of Europe it was observed that the tops of windows let in more light than the bottoms. A simple measurement proved that a window of once uniform thickness had grown thicker at the bottom and thinner at the top. Only one explanation exists for this phenomenon. Glass flows in the direction of the pull of gravity, exhibiting the behaviour of a liquid. Thus one cannot conclusively define glass without the inclusion of time. ${ }^{3}$

This first photo shows a Polaroid image that I took in 2003 when I was living and working in Chicago. I used to walk past this tree every day on my way to work, travelling south to north up Dearborne Avenue. At first I used to see the phenomenon of tree and building as a tree growing through the space of an erstwhile roof. Then I began to realise that such a reading relies on a linear logic that imagines the decline of Tom's business, a subsequent dereliction of Tom's building and finally the space for a tree. It could also be possible that Tom's Grill was never a grill business and in fact only ever a "frame" for the tree inside this structure of brickwork. Perhaps, in fact, this tree has a name and the name of this tree is: "Tom's Grill."

If I can postpone the certainty of a logic based on a linear reading of time, then I open up the possibility of other readings of things called trees and buildings. Admittedly this is easier for me to see in relation to my own practice than if I think about the practice of architecture. Making moving image works, for instance, allows the possibility that what was the middle becomes the beginning, and what was the

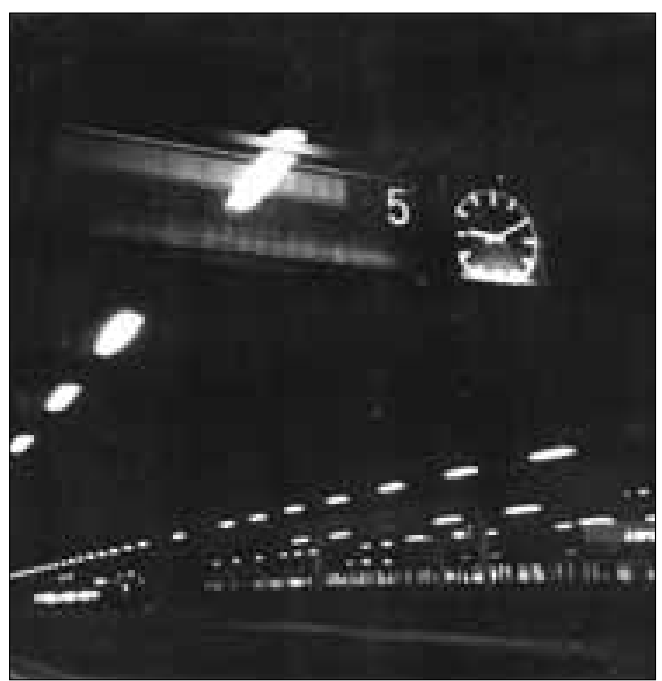

Berlin Station beginning becomes the end. Time can run in more than one direction in a film.

Pia E-B: . . . Design and construction processes are always insinuated in the building itself. As that which steers their formation, they are never not expressedeven if unconsciously... ${ }^{4}$

LC: The unconscious "expression" of process, as you mention, is visible in each piece or project itself, and also, within my practice, in the kinds of relationships that are opened up around each piece. For instance, via an invitation extended by Independent Dance, and alongside four other artists-Becky Edmunds, Gill Clarke, Claudia Kappenberg and Chirstinn 
Whyte - I co-curated a hybrid event, part festival, part exhibition, called What If $\ldots{ }^{5}$ which was held at the Siobhan Davies Studios in London. As a group of artists (and "inexpert" curators), we were interested to explore how we could create a different space of attention for work made by ourselves as well as others (forty artists showed work in What If... ), and how we might curate work based on an embodied sense of an encounter: in-between people and in-between people and art works. We aimed to build an event which offered invitations (as "everything we do is done by invitation" ${ }^{\text {") }}$ ) and proposed the possibility of seeing process and finished works side-by-side. This occurred quite literally: John Smith and Graeme Miller agreed to allow audiences to follow the process of making their video installation Beside the A-Side which took place on the second day of the festival - and more fleetingly, through the unfolding performance of ten writers' responses to the works exhibited?

We had many conversations about time. About how slowing down time might allow us to see different possibilities. Co-curator Claudia Kappenberg coined the term "slowness by fascination," which describes her deeply engaged attention that slows down, allowing her to open up a space between stillness and movement.

A few years back I came across the Finnish architect Juhani Pallasmaa's book about architecture: The Eyes of the Skin (2005). His ideas about the tactility of surfaces - the warmth of wood or the coolness of metal —which invite a haptic rather than visual response to buildings, resonated with me. Since then, I've wondered how often architects get to hang out in the buildings they've designed in order to observe how the invitations or proposals inherent within the building affect the people who use it.

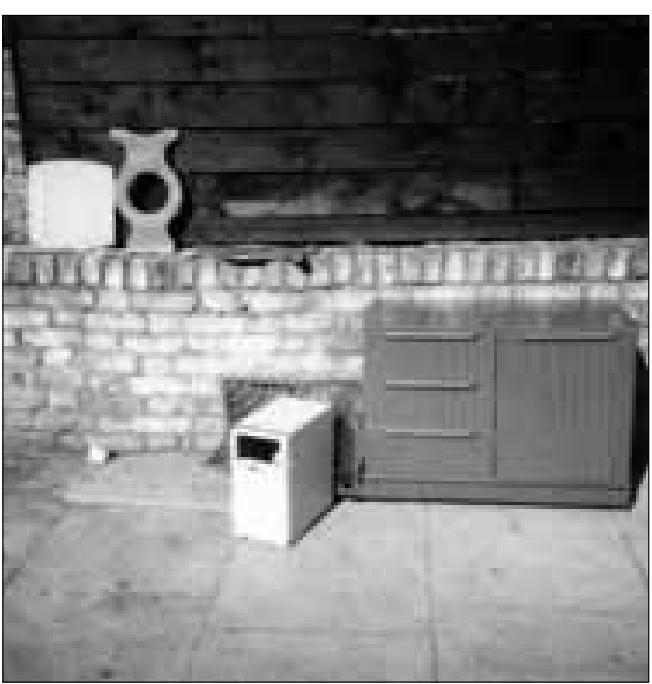

May 1st What kind of unspoken conversations happen between space, buildings and people?

Pia E-B: In a moment of intensive rupture, such as falling, the body twists open into an extra-dimensionality, attaining an extensivity that renders both the 'self' and the object as highly contingent. ${ }^{8}$

LC: An aside, Pia. As a teenager on the way home from ballet class, I was hit by a car whilst crossing the road on a zebra crossing. In my physiological memory of the event, I experienced extreme slowness. You could say that in that single moment, I irrevocably understood slow-motion. I remember my body rising up into the air from the impact of the car, my body passing through the air, flying, flying, flying, flying, until the moment the turn came, and gravity overtook me and once more I was on the ground.

I feel that I have experienced the extra-dimensionality you remark upon in multiple ways. Recently I learnt that on a perceptual level, under extreme duress, our brains take in more 
information than in our ordinary day-to-day perception, which, (like the use of high-speed film recording at, for instance, $100 \mathrm{fps}$ instead of 24fps) results in us experiencing more and slower. In my memory and in my dreams, sometimes the event of the car hitting me is so slow that it comes to a stand-still. Instead of my falling happening like that of the van going over the edge in Inception (2010), it judders to a halt and takes place in still images like my own personal version ofLa Jetée (1962). Time has

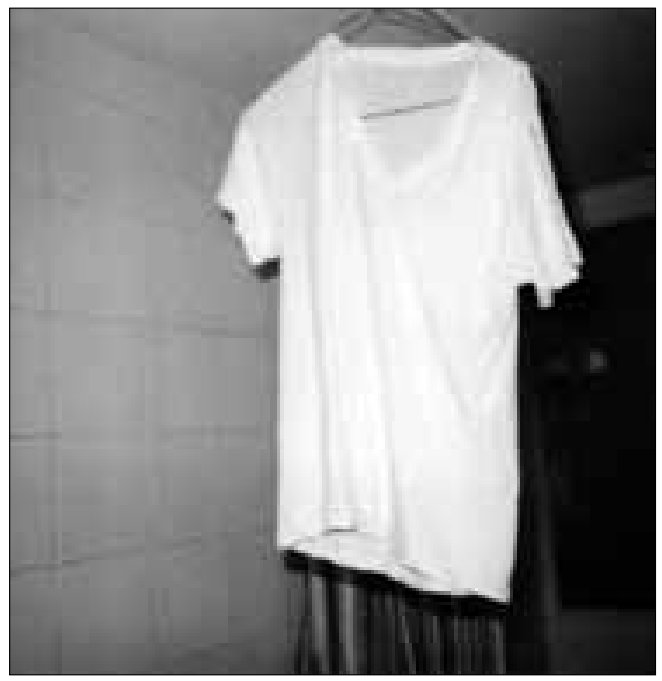

April 20th stretched itself, and this moment (twenty-five years ago now) is still on-going in my foundation, in my skeleton. Because just as the material of glass gives way to gravity, so have my bones absorbed and responded to the dynamic force-of-car impact. An invisible (to others), slight twist reverberates through my right side. If I was a building and needed to attempt to maintain stillness, l'd be leaning sideways through the effort.

Pia E-B: Art does not reproduce the visible; rather, it makes visible. ${ }^{9}$

LC: Pia, when you quote Paul Klee, a quote I like very much, it brings two other quotes to my mind. Another by Paul Klee: "A line is a dot that went for a walk."10 And one by Robert Bresson describing his work as, "A visible parlance of bodies, objects, houses, roads, trees, fields."11

Klee's characterisation of the line through its movement, reminds me of the inherent, gestural quality of mark-making - of how the handiwork of a work can always be uncovered. Of how we can feel the presence of the person holding a camera as much as imagine the hand that held the calligrapher's pen or the painter's brush.

Sometimes I forget to look for the handiwork of a building. Like Pallasmaa's writing, your writing reminds me to re-focus my attention so that I can see the touch of a hand/s on a much larger scale.

As you might imagine, the act of conversing is something I hold dear. This is because it allows for an exchange with another, and also because exchange allows for a shift of position, a different point of view. Bresson's quote allows me to imagine different kinds of conversation - that the bodies and objects, trees and fields in my work might have a particular manner of speaking, set in motion by me, but also beyond what I might have intended.

Art-making as a conversation: an unpredictable form, full of movement which meanders, takes a walk, changes rhythm ... all the while revealing delicate and particular patterns of thought which fall in and out of silence.

Dan Beachy-Quick, a poet and writer based in Chicago, wrote a "primer" to the films I've made with Goat Island; he brings attention to the invisible beneath the visible and reminds me that what you can see is only half the story: 
"Our movements trace our complexity. When we're silent and when we stand still we are not resting. We're searching inside ourselves for the turn."12

Lito Walkey stands still on one leg, with the other knee raised to a right angle for the duration of two James Taylor songs (or 7 3/4 minutes) in Goat Island's eighth performance When will the September Roses Bloom / Last Night Was Only A Comedy (2005).

This image appears as an extended hiatus and was appropriated as a "found" action from Institute Benjamenta — a film by the Brothers Quay (1995). The original action was part of a series, practised within a strange, dream-like school for the training of servants.

Alongside simply being an interruption in continuity, a hiatus can be a break in pronunciation, a break

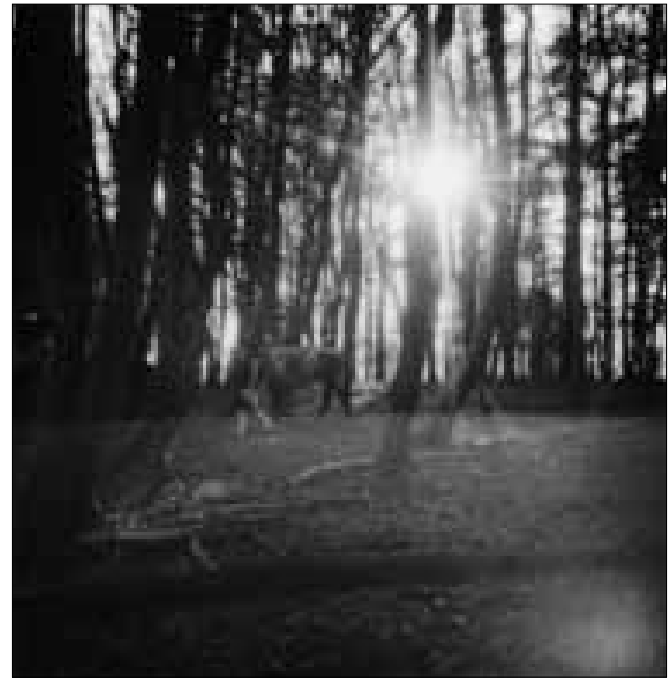

April 19th between adjacent vowels in the sounding of a word.

Lito is left to stand by herself, her arms pointing down by her sides but slightly apart from her body. The deliberate and delicate tension in her arms drawing our eyes both away from and towards the tension in her thigh held perpendicular to the floor. She evokes an image of concentrated stillness and yet we gradually begin to perceive how much movement is involved in maintaining this stillness. After a while we begin to realise that she is creating the stillness outside of herself.

The stillness she creates has a shape and a weight, a rhythm and a structure. It makes visible a flow of constantly shifting invisible images: a servant ... a cowboy ... a punishment ... a statement ... a building ... a bridge ... a machine ... a tree ... a leaf ... a bird ... a child ... a falling ...

\section{References}

Beachy-Quick, Dan. "A Primer to the Films of Goat Island." Unpublished gallery text on the occasion of the Betty Rymer Faculty Sabbatical Exhibition, 2006.

Bresson, Robert. Notes on the Cinematographer . Los Angeles: Green Integer, 1997.

Cage, John. Acceptance speech for Carl Sczuka Prize for Roaratorio: An Irish Circus on Finnegans Wake. Donnaueschingen, 1979.

Ednie-Brown, Pia. "Falling into the Surface (toward a materiality of affect)." Hypersurface Architecturell 69, no. 9/10 (1999): 8-11.

Goat Island. When Will the September Roses Bloom? / Last Night Was Only A Comedy, 2005. Performance.

Goulish, Matthew. 39 Microlectures: In Proximity of Performance. London: Routledge, 2000.

Inception. Directed by Christopher Nolan. USA: Warner Bros Pictures, 2010.

Institute Benjamenta or This Dream People Call Human Life. Directed by Steven Quay and Timothy Quay. UK: Image Forum, 1995.

Klee, Paul. Notebooks, Vol 1: The Thinking Eye. Edited by J. Spiller. Translated by R. Manheim. London: Lund Humphries, 1961.

La Jetée. Directed by Christ Marker. France: Argos Films, 1962.

Pallasmaa, Juhani. The Eyes of the Skin: Architecture and the Senses. Chichester: Academy Editions Ltd, 1996. 


\section{Notes}

1. Quick,"A Primer," 1.

2. Ednie-Brown, "Falling into the Surface," 8.

3. Goulish, 39 Microlectures, 44

4. Ednie-Brown, "Falling into the Surface," 8.

5. What If... Festival. Siobhan Davies Space, April 7-11, 2010, www.whatiffestival.co.uk.

6. Cage, Carl Sczuka Prize acceptance speech.

7. Writers were invited to present / perform their writing over the weekend of What If ... Some writersparticularly Kyra Norman — chose to present daily versions of their writing, generously allowing us to watch the folds and turns in their thinking. The ten writers subsequently revised their responses, which appear in a special edition of Dance Theatre Journal 24.1 (2011).

8. Ednie-Brown, "Falling into the Surface," 10.

9. Paul Klee, cited in Ednie-Brown, "Falling into the Surface," 11.

10. Klee, Notebooks: Vol 1: The Thinking Eye, 111.

11. Bresson, Notes on the Cinematographer, 22.

12. Beachy-Quick, "A Primer," 2. 


\title{
Falling into the Surface (toward a materiality of affect) ${ }^{1}$
}

\author{
Pia Ednie-Brown
}

"Motionless on the surface, in its very depth it lives and vibrates."

( $f$ constant concern to the discipline of architecture is the effectual nature of its processes of production. As a practice, architecture struggles with a coordination of the extremely variegated and complex field of forces that come to play in the creation of a building. Ultimately, the imperative of the performance is to sustain its effective consequentiality. The security of its stature and relevance has relied on a maintenance of belief in the significance and responsibility of form. Architectural history presents a catalogue of renovations and additions to the structure of its rhetoric of authority. The shifts of persuasion driving the processes of history's architectural undertakings have pivoted on an import of form.

Lately, the "virtual" has risen to the surface of architectural discourse through a reverberative tremor of prevailing cultural desires. The term "virtual" is often used as a convenient and attractive packaging aimed at consumptive desires for increased mobility while, paradoxically, keeping "mobility" contained and vacuum packed. In a climate of cultural production that invests explicit movement with sovereign value, the insistent stasis of buildings has been absurdly claimed to signal an imminent obsolescence of architecture. The foundations of authority upon which architecture has curated its catalogue have begun to crack. The challenge of how architectural design processes could be re-articulated to address active engagements with the virtual has become a source of experimentation. Reactionary efforts toward revaluation have at times evoked the Emperor in his (virtual) new clothes: sensational, but forgetting actual sensation. The opportunities presented to contemporary architecture are not to be found in a subservience to illusions of this kind. Rather, they lie in the manner with which the operations of architectural practices realign their affiliation with the concrete actuality of buildings as an engagement with the virtual.

Brian Massumi, in his paper "Sensing the Virtual, Building the Insensible," calls up "radical" or "superior" empiricism as the answer to his question: "what philosophy can or might enter into a symbiosis with architectures engaging with the virtual ...?"3 He goes on to suggest that "for architecture, the effect of such a symbiosis is a willingness to bring into even more pronounced expression its processual dimensions." ${ }^{\prime 4}$ Design and construction processes are always insinuated in the building itself. As that which steers their formation, they are never not expressed-even if unconsciously. It is the "willingness" and the "even more pronounced" of Massumi's suggestion that become the imperatives. This paper attempts to articulate modalities through which these imperatives may be addressed.

The manner in which radical empiricism expresses the virtual within lived experience, as always insinuated in actual events, imbricates it with the actuality and solidity of buildings. This holds great potential for the development of architectural practices, in that the conceits 
produced by dichotomous logic can be productively redressed. Where there can be no actuality without the virtual, stasis no longer points to a death (of architecture) but to an invigoration of the zone of potential that plays around the concrete. This impacts directly upon the limits and dimensions of processuality, as it involves a shift in the arrangements with which the modalities of practice can engage with the virtual. Contrary to a placement of events according to a division between supposedly exclusive terms — form and social praxis, for example — there is a more subtle relation of intertwinement, which, in as much as it still presents a division, has itself been realigned. As Philip Goodchild writes: "The fundamental division is no longer that between the subjective and the objective, the mental and the material, artifice and nature, but between spontaneity and receptivity: the power to affect and the power to be affected." This shift of attention invigorates the potentiality of the relations themselves.

Within these folded realignments, Massumi's suggestion can be seen to have simultaneous relevance to both processes of design and experiential processes involved in the "completed" building itself. This fundamental issue of radical empiricism challenges architectural discourse, which has a blithe tendency to regard anything after the closure of construction and prior to an appearance in the pages of an historical text to be outside the interest and authority of the discipline. This gap in disciplinary attention has arisen in tandem with the hold that subjectivity has maintained on questions of experience. In humanist models of subjectivity, the subject, the perceiver, holds the balance of power (to affect and be affected). The building (or object) falls into a realm of unspeakable action in that it cannot be contained by authoritative moulds. Radical empiricism invites an effort to both acknowledge and realign these otherwise silent, but nevertheless inscriptive affects. Significantly, the restructuring of relations with which this effort is undertaken is set up such that acknowledgments of the virtual do not fall back into the insistent banality of disciplinary authority. The task is to release life (the virtual) wherever it may be trapped.

Radical empiricism calls up this challenge through a vastly expanded notion of subjectivity that invites architecture to stretch out and test its processual limits. Félix Guattari set out the extended limits of this refigured subjectivity in his final book, Chaosmosis: An EthicoAesthetic Paradigm, in which he writes: "How are the new fields of the possible going to be fitted out? How are sounds and forms going to be arranged so that the subjectivity adjacent to them remains in movement, and really alive?"6 Embedded within this passage is a radical (empirical) twist. The problem is not subjective uncertainty but how subjectivity is kept alive; how significance can be released from the classical moulds of objectivity. Objectivity is merely fixed subjectivity: the subjective forced still. The life of subjectivity is not simply in the shifts of an interpretative field but the operations of a set of engagements, a "machinic assemblage." Here the subjective is not "originated" in an individual rather it is produced through the transitory assemblages of a vast array of impersonal forces.

These assemblages crystallize or precipitate through a twist onto a surface that expresses the textures of perception. In turning to touch, to make sense of this tactility, these emergent, textural signs are contracted into tools of action. The act of contraction divides this information into distinct modalities whereupon perception emerges and reconverges as geometrical, reasonable forms of appearance. Subjectivity moves about these contractions and dilations of the processes of surfacing. Designing arrangements that may actively keep subjectivity alive, falls back upon setting out the conditions or parameters of processes that are themselves open and mobile. 


\section{Forming Habits}

Architectural practice has a tendency to establish the visualization of form as the primary condition enabling processes of design. Form, as an exercise in itself, untied to the specificities of durational presence (matter), is linked to the status of geometry as an idealized phenomenon. Geometrical laws appear as universal truths cut free from temporality and the affective dimensions of historicity. Ideally, an equilateral triangle was the same for Pythagoras as it is for us today. As an Idea, geometry arrives as an already-made, an unchanging set of truths that simply exist, apparently prior to and separate from perception. In the work of French philosopher, Henri Bergson, there is an effort to turn back upon the conditions within which geometry emerges. Geometry and form are thereby rendered as contingent, undermining their claim to universality. As Bergson writes: "the universe is not made, but is being made continually." ${ }^{\prime \prime}$

Perception of space and form is defined by that which Bergson calls a "virtual geometry." In Creative Evolution he explains: "You cannot present this space to yourself without introducing, in the same act, a virtual geometry which will, of itself, degrade itself into logic, for, space cannot be given without positing also logic and geometry, which are along the course of the movement of which pure spatial intuition is the goal." ${ }^{8}$ Form, arrived at through logical interpolations upon virtual geometries, becomes a habit secreted from memory: empirical information accumulates in mnemonic refrains and inscribes itself through patterns of perception. Pure form, on the other hand, as an idealized, static geometry, violates memory through a suppression of its power to affect; it is a ready-made set of laws of dry and seemingly autonomous consistency. These laws are so consistent that they insist on being (true) and defy the transformative impulse of becoming. Bergson suggests that consciousness must "detach itself from the already-made and attach itself to the beingmade" in order for it to engage with the principles of its emergence. ${ }^{9}$ Already-made laws tend to restrain the perceived from flowing out of strictly delimited moulds, and train it to abrogate the shifts that rustle across the surface of perception. They maintain an impeccable garden in which new life is already tame and unplanned emergence is outlawed.

When architects design primarily through the manipulation of form they will tend to assume the already-made of form itself. Particular forms will emerge, but form itself loses potential dimensions of mobility in the process. This is no less the case in the movements of morphing computer animations than in orthogonal extrusions of floor plans. How might architectural practice turn back upon and attach itself to the being-made of form? How can form affect and be affected by movements not already contained within the parameters of a form driven process? This requires a departure from such processual habits, venturing instead into a sensitized field.

\section{Becoming Sensitive}

The operations of this sensitized field can be usefully illustrated with Massumi's account of warm water:

If heat is increased at a certain rate, a threshold is reached at which order spontaneously arises out of chaos. The liquid differentiates. Certain regions turn in on themselves, "nucleate" form fluid boundaries. Whirlpools form: convection 
currents. These vortices appear because the liquid is under another constraint besides the command to regain equilibrium through thermodiffusion. That second constraint is gravity ... In the process, the liquid became "sensitive." The effect of gravity on a liquid at rest is normally negligible, but in its agitated state, the liquid suddenly "perceived" it and was transformed. ${ }^{10}$

Here, the process of becoming sensitive involves the awareness or perception of an otherwise relatively latent presence. The vortices swirl the liquid into a moment of intensive order, such that the entire body of water becomes highly coordinated and "any chance disturbance that might occur in one area will immediately be 'felt' everywhere."11 A set of relations is at once articulated, and this is what the ldea of pure form seeks to obliterate: namely, the conditions of its emergence.

Think of any moment in which instability arises. Say, for instance, you teeter and fallor almost fall. The experience is one in which the sensation of gravity lurches forward as an amplified presence. This sensation can be completely overwhelming - as if an invisible hand has thrown you. Commonsense falls apart as the senses fall together into the realm of sensation. You become integrated and dispersed across a singularly coordinated gesture. In this example, the limits of the subject become uncertain. Subjectivity becomes sensitive.

Typically, gravitation is the habitually ensconced forgotten of the upright world. Deeply implicated in the formation of all our habits, gravitation is a critical dimension in the processes and organization of perception. According to Buckminster Fuller, "Gravity is the inside outness of energy-as-matter: the integrity of Universe."12 It is the vital pulse. Things fall, no doubt about it, but the fall is one into potentiality as much as a falling down to the ground. A fall into the surface is a leap of potentiality. It entails both the rise and fall of affect. A willingness to fall is an openness to the power to affect and be affected. The categories of the animate (life) and the inanimate (matter) necessarily fall into one another. As Bergson writes:

The vision we have of the material world is that of a weight which falls: no image drawn from matter, properly so called, will ever give us the idea of the weight rising. But this conclusion will come home to us with greater force if we press nearer to the concrete reality, and if we consider, no longer only matter in general, but, within this matter, living bodies. ${ }^{13}$

The passing of "living bodies" through matter can be as simple as heat through water. "Living" is not simply an attribute of organisms, for it subsists in all matter. Living becomes a virtual reality. The life that passes is the reality of change. Both water and heat, in falling into one another, are mutually affected. The event of becoming sensitive is an intensification in the power of change. Something extra is perceived. This extra dimension was always there, but not yet explicitly active, not yet becoming explicit, in the changes occurring in the system.

Design processes that become sensitive have the potential to make far more explicit processual dimensions. Where process itself is open to the perception of otherwise implicit dimensions, it becomes capable of "even more pronounced expression its processual dimensions." 


\section{Hypersurfacing}

Rearticulating classical divisions of architectural design is at the basis of Stephen Perrella's Hypersurface theory. As he writes: "Hypersurfaces are an interweaving and subsequent unlocking of culturally instituted dualities."14 In attempting to situate the development of this theory in relation to the imperatives investigated here, the hypersurface can be twisted into a roaming verb so as to encounter the potentiality of its actions. More specifically, it becomes a useful expression of the becoming explicit of extra-dimensionality.

Surface, in common parlance, is generally understood as the exterior boundary of things, the outer skin of any object. In this sense, surfaces are actual, material, textural entities that are the most directly perceived and felt aspects of the world. They are that which we directly encounter. The surface is also taken to be something that conceals: "it was not what it appeared to be on the surface." When things surface, they become evident or apparent; they appear out of a previously concealed existence or latency. Surfacing is an action of becoming explicit, of becoming experientially apparent in a movement from virtuality to actuality — of becoming expressed across the limits of perception. Surfacing is the process of becoming perceptible and actual.

To be hyper is to be overexcited, super-stimulated, excessive, on edge. This state of intensity is a mode of over-being: an excess of being in that the processes of becoming exceed constraints to existence. Things foam at the edges.

The "hyper," when conjoined with "surface," turns up the volume on emergence: it is a becoming more than simply explicit, an "even more pronounced expression [of] its processual dimensions." Between the explicit act and the myriad of potential acts, consciousness ${ }^{15}$ finds its emanative expression. Hypersurfacing unleashes the surface into bearing witness to an even more pronounced expression of the conditions of emergence.

Hypersurfacing is an act of falling into the surface.

\section{Fallibility: Tending Toward a Materiality of Affect}

In a moment of intensive rupture, such as falling, the body twists open into an extradimensionality, attaining an extensivity than renders both the "self" and the object as highly contingent. A release from absolute valuations of self and object-hood is implicit in the imperative of willingness, as Massumi suggests. Engagements with the virtual are amplified with a porosity across which an active folding out and infolding can become operational. Through a willingness to fall open, the play of the dice is admitted into the dimensions of processuality. ${ }^{16}$ Chance events can enact their regenerative impulse. The release from the primacy of the human subject, fundamental to the efforts of radical empiricism, enables the potentiality of an event as an arrangement of "connectibilty." As Massumi writes, "What is virtual is the connectibility: potential (the reality of change). It cannot be overemphasised that the virtual is less the connection than its -ibility."17 Similarly it must be emphasized that to "fall into the surface" is not exclusively a falling down, it is an opening out into the readiness of change, into a sensitivity to potentiality. This is leading to the articulation of a tendency that I will call fallibility; an admittance of errant ways. Fallibility becomes an imperative of "willingness." 
A useful model for the arrangement of processes that address this imperative can be found in the wind-drawing machine of artist Cameron Robbins. This machine performs through mechanisms driven by both the speed and direction of the air. Working within certain tendencies and patterns, all the drawings produced by this quite simple machine express the specificity of their duration. Each has its own enigmatic quality. The actions of the process or mechanism are such that the ink tends to be marked out more or less within a circular outer limit. This is more or less the case because the machine is, in itself, sensitive enough for chance to cut in: for the intensities of forces to throw the pen into paroxysms of leaping that extend beyond the provisional limits of its less intensified paths; for rain to splatter and spread the ink; for things to go "wrong" such that the (even more) unexpected will emerge.

No attempt is made to control the environment in which the act of production takes place. Rather than enveloping the process with an authorial container, the processual engagements are granted a spontaneous dimensionality of life. That which is designed is the mechanisms of perception: the in-built receptivity that arranges and renders explicit the forces within which perception endures. The process of production is open and sensitive to the specificities and complexities of its duration. That which is made explicit is the interplay of affects in the lived experience of the mechanism "out for a walk."18

The prevailing trend in architectural practice is to establish a processual relationship in which intended or (at least partly) preconceived formal outcomes direct the paths of production. Within the wind-drawing process, this relationship becomes inverted. The process of production, within mutable limits, governs the formal outcome. In turn, form itself takes on an expanded ontology. As an expression of affects at play in the process of formation, form takes on its own materiality. Materiality is no longer subservient to the desires of a designated form.

This more expansive, durational notion of form can thereby be understood as the materiality of affect. As much as this materiality is of insistent virtuality, it is implicit to the actual. Form gathers an extra-dimension of expression. The vast array of impersonal forces productive of subjectivity actualizes into a consistency expressive of manifold duration. Rather than form being enmeshed with humanist models of perception, form is gathered through the engagement of potentiality.

What I am finally able to suggest is that design experimentations aiming for engagements with the virtual might depart from their current impasse of nostalgia should they turn their processual arrangements away from form and the movement of form, and instead toward processes that are themselves open and mobile. This does not mean designing morphic architecture. Rather, it involves a willingness to break out of self-perpetuating habits. Through modes of fallibility, experimentations can expand their processual dimensions and propel them into even more pronounced expressions. What then may emerge are buildings that emanate in a materiality of affect.

\section{A Final Admission (A Falling Open)}

"Art does not reproduce the visible; rather, it makes visible."19 
A dimension of this paper is yet to be made explicit. Subsisting throughout this text is a particular event, of a certain extra-dimensional quality in itself, which took place in 1997. It is at once the connectibility of this paper and the fallibilty that underwrites it.

As part of a design studio I conducted at RMIT, Cameron Robbins accompanied my students and me on a trip to the southern most shoreline of mainland Australia. It was, perhaps needless to say, a site of wind-driven intensity. Shortly after arrival Cameron set the machine into action and we walked with the students around the cape. At one stage we reached a fence. In a clumsy attempt to climb over, I fell. In the moment of losing balance it unmistakably felt as if I was pushed ... as if a strong, invisible hand had loomed up from behind and thrown me. In falling I lost myself; any sense of "I" was dissolved in a far greater impulsion. My surroundings collapsed; exteriority became articulated only as an antinomy of stasis. Time stretched and dissolved into an expanded flight of perplexity. It wasn't until after hitting the ground that I managed to gather a clear comprehension of the event: I had fallen. Sitting up, I faced an audience of shocked faces, their anemic hue registering the gash in my blood spurting chin. My body had become the machine through which gravity made its extra mark. Releasing me from this cast of bloodshot eyes, Cameron and the students went back to the machine to see what had been produced. They discovered that part of the mechanism had been blown over in our absence. The drawing itself was somewhat unusual (the machine having been altered with the fall) and strangely resembled an eye. Musing on the apparent simultaneity of falls, Cameron titled it The Fall of Pia: an exfoliation off the scaly surface of authoritarian certainty. The coincidence of the falls and the uncanny appearance of the eye produced a palpable sense of some virtual form - a becoming explicit of a materiality of affect ... designed in a partnership perhaps with "Dionysus snickering at fate as he steals an extra turn."20

It would be easy to think of the falling in terms of genetically coded clumsiness. Instead, for reasons of an uncertain kind, I'm inclined to see it as a pure event of fallibility.

\section{References}

Bergson, Henri. Creative Evolution . Translated by Arthur Mitchell. New York: Dover Publications, 1998. 1991 .

Matter and Memory. Translated by Nancy Margaret Paul and W. Scott Palmer. New York: Zone Books,

Deleuze Gilles and Félix Guattari. Anti-Oedipus: Capitalism and Schizophrenia . Translated by Robert Hurley, Mark Seem, and Helen R. Lane. Minneapolis: University of Minnesota Press 1994.

Fuller, Buckminster. Synergetic: Explorations in the Geometry of Thinking . New York: MacMillan, 1979.

Goodchild, Philip. Deleuze and Guattari: An Introduction to the Politics of Desire . London: Sage Publications, 1996.

Guattari, Félix. Chaosmosis: An Ethico-Aesthetic Paradigm . Translated by Paul Bains and Julian Pefanis. Sydney: Power Institute, 1995.

Paul Klee. "Creative Credo." 1920. In The Inward Vision: Watercolours, Drawings and Writings by Paul Klee. Translated by Norbert Guterman. New York: Abrams, 1959.

Massumi, Brian. A User's Guide to Capitalism and Schizophrenia: Deviations from Deleuze and Guattari. Cambridge, Mass.: The MIT Press, 1992. 22-23.

."Sensing the Virtual, Building the Insensible." Architectural Design: Hypersurface Architecture 68.5/6 (1998):

Perrella, Stephen. "Hypersurface Theory: Architecture><Culture." Architectural Design: Hypersurface Architecture 68.5/6 (1998): 6-15. 


\section{Notes}

1. Due thanks and acknowledgment is extended to Ned Rossiter for his generous and invaluable contributions to this paper. Thanks must also be extended to Robyn Barnacle, Brent Allpress, Peter Morse, and Stephen Perrella.

2. Bergson, Matter and Memory, 204.

3. Massumi, "Sensing the Virtual," 22-23.

4. Ibid., 23.

5. Goodchild, Deleuze and Guattari, 27.

6. Guattari, Chaosmosis, 133

7. Bergson, Creative Evolution, 241.

8. Ibid., 212.

9. Ibid., 237.

10. Massumi, A User's Guide to Capitalism, 59-60.

11. Ibid., 61.

12. Fuller, Synergetics, 306.

13. Bergson, Creative Evolution, 245.

14. Perrella, "Hypersurface Theory," 7 .

15. As Bergson states: "Consciousness is the light that plays around the zone of possible actions or potential activity which surrounds the action really performed by the living being. It signifies hesitation or choice." Bergson, Creative Evolution, 144.

16. "Every moment in life is a step in a random walk. Uncannily familiar as the shore may seem, looking back reveals no Eden of interiority and self-similarity, no snowflake state to regain. Ahead lies nothing with the plane reliability of solid ground. You can never predict where the subatomic particle will appear, or what will flash across the synapse (the pure instantaneous event). Once thrown, however, the dice are destiny. God as a drunken gambler. Dionysus snickering at fate as he steals an extra turn." Massumi, A User's Guide to Capitalism, 23.

17. Massumi, "Sensing the Virtual, Building the Insensible,"23.

18. "A schizophrenic out for a walk is a better model than a neurotic lying on the analyst's couch. A breathe of fresh air, a relationship with the outside world." Deleuze and Guattari, Anti-Oedipus, 2.

19. Klee, "Creative Credo," 5.

20. See note 16 . 


\title{
Notes on Filming Dance
}

\author{
Adam Roberts
}

M

$y$ intention when first deciding to film dance was to investigate how the camera relates to human movement, and so, perhaps, to discover something in general about the nature of film itself. It was, painfully, a decision not to work with narrative for a while. Luckily, I was to work with a choreographer, Jonathan Burrows, whose work I liked very much.

To start with I asked simply: what is the difference between a piece of film action (as when, in a cinema film, a woman opens a door and goes through it), and a danced movement, which might look just the same?

What is it about the human body and the moving human body in particular? How does film look at such things?

I had also been provoked by what I believe to be a fundamental misconception about film: "How can you marvel at the human body in motion if the rhythm and movement are created by the editor, not the dancer?"1 Anne Bilson, who asked this question, is a film critic writing about the way dance has been filmed. She would seem to be saying that dance is something that film can obscure: that there is something actual, and that film serves as a means to record that actuality. The means, it would seem, diminishes the actual.

Filming dance, as I have done, where I have freely re-ordered, repeated, deleted, and elided parts of an original choreography, has convinced me that film necessarily stands in a much more complex relation to what it purports to represent. I believe that film, contrary to the conception of it expressed by Anne Bilson, is not a mimetic technology. I would go so far as to say that filmic representation has a life of its own. To steal a line, the medium is the message. ${ }^{2}$

What follows are some haphazard thoughts about film that have shaped my dancefilm work.

To put it bluntly: I believe that the proper object of dance-film is rhythm. This is not to say the rhythm of the human body in motion (though that can be part of it), but rhythm as an intersection of pulses, both tangible and intangible, on screen. As a filmmaker I have worked with the following elements in pursuit of pulse:

Bodily movements and processes;

Change of angle of view of that movement;

Selection by means of framing;

Focus pulling and camera movement;

Sequence of revelation of a body or bodies; 
Timing and placing of cuts;

Developing or hindering knowledge of geography or space;

Change of light;

Sound elements, and sound mix;

Long-term patterns that emerge only over time;

Relationships between patterns;

Observance or deviation from expectation;

Deliberate creation of confusion or clarity;

Ellipsis, elision, deletion or black out;

Placing sounds in or out of synch;

Repetition and overlap.

It seems obvious to me that the relationship between pulse and time is that a pulse provides a measure or sense of time. For me this seems inescapable because I sense the passage of time by the means of a count. ${ }^{3}$

My camera and I are good at noticing things that happen (or even things that do not happen). Either way I am inevitably looking for a countable pattern. Nothing ever happens in a vacuum - a step is always preceded by and followed by another.

It is my tendency to notice the number of steps taken, the time taken to make those steps, and/or any change in rhythm or pace. I notice when one take is faster paced than another, and always take note of whether two takes (a "take" is another shot of the same material) will match if intercut with one another in an edit. It is the work of a filmmaker to make use of any kind of pattern available, and to harness these patterns to produce a pulse, tangible or intangible, on screen.

In my second collaboration with Jonathan Burrows, Our / film (1994), I overlapped most edits - that is, briefly repeated action rather than, as is usual in film editing, observed continuity or sought to abbreviate. By means of these inserted frames and seconds of movement that had already been seen, I sought to undermine the impression that the camera somehow documented a single reality, but also to foreground the activity and contingency of filmmaking.

I would also like to mention Andrey Tarkovsky's observation: "Assembly, editing, disturbs the passage of time, interrupts it and simultaneously gives it something new. The distortion of time can be a means of giving it rhythmical expression. Sculpting in time!"

Film time and theatre time are different. There is an arduous experience of time that the dancer and the live audience know well: you cannot cross the stage faster than as quickly as possible.

Time in a film is not about what the body can do, but about what the eye, free of position, can do. The camera can be anywhere and (for lack of a better word) anywhen.

Time passing in a dance-film does not pass as it does in another kind of film.

When watching a dance-film, I don't imagine that, if someone is pacing, it is because she is waiting for anyone. The pacing is the thing. 
Could there be such a thing as an agony of suspense in a dance-film? If anyone dances on screen I have the feeling of taking time off from such worldly anxiety. ${ }^{5}$

Something about this awareness of time has led me to consider the contrast between a rest and a pause in the making of dance-films. I take a rest to be a value, something in itself. A pause is a suspension of a process. However, I have found that the difference is not always clear, that the difference becomes apparent only by comprehending the whole.

I have worked with gaps because I like the speculation induced by a gap. I'm thinking of Very and The Stop Quartet / film, both of which feature punctuation-like interruptions-black spaces of varying lengths. I expect the viewer to fill these gaps with their own thoughts: "Is everything OK? When will the pictures come back?"—or, "Suddenly I'm very aware of myself, sitting here watching that blank screen. Why?" For a filmmaker, to insert spacing is easy. It is like holding a door open for others - I am aware of the time I am taking to hold the door, and how long I may yet choose to do that, while anyone passing through does not.

\section{口n}

How might paused movement (as in The Stop Quartet / film) be contrasted with a freeze frame?

A freeze frame is where one frame is paused, or more accurately, it is a frame reproduced over and over again. Time passing (which is not interrupted) is contrasted with arrested on-screen movement. A freeze frame may look like a denial of time, but it is for me a very suspenseful reminder of time passing. A freeze frame has no relationship with photography, since it appears in context. It is not a pose that is held. It is an intrusion of mechanism, like a car that breaks down. We long for the return of movement. We are filled with anxiety, though it can be a delicious anxiety.

In a film, a fixed image of something is not like a freeze frame. A steady camera watching a stationary object: time is passing, slowly for some, too quickly for others. A stationary shot is full of expectation; we know that something will happen eventually. We are good at guessing when it will happen, because we know that suspension like this will provoke anxiety in us and in the filmmaker. Usually, it is the filmmaker that flinches first. Movement resumes.

I made The Stop Quartet / film (1996) to reflect a complete dance by Jonathan Burrows. The duration of the shots (always a wide framing of the entire stage) and the speed of the dolly movement

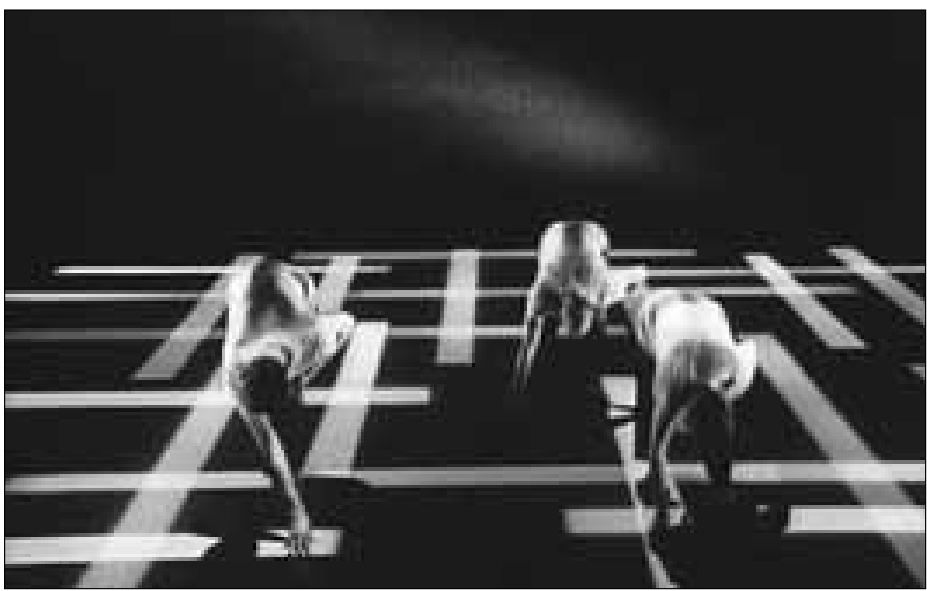

The Stop Quartet / film (1996, 16mm, 44mins) (always crabwise from left to right starting at the same place) were laid out according to a pre-determined pattern. Some passages were replaced by black, with the soundtrack continuing over. These (visual) silences were also 
organised according to a scaled version of the pattern, providing a structured punctuation. The camera movement was always very slow, such that it is apparent only during the pauses in the dance piece (the "stops" of the title). When the dancers move again, the camera movement drops from awareness.

The meshing of these various rhythmic elements interact with the structures of the dance performance to produce a new pattern, inherent only in the interaction, apprehended by the viewer but not tangible: ebbing and flowing. The effect might be compared to the phenomenon of interference fringes observed when light sources interact in the laboratory-phase is all.

The question I had set out to examine was whether tension and attention are possible without conventional montage. If it were, then in this film the forward momentum is achieved by rhythmic devices depending on proportions. "Rhythm is a matter of proportion not of accent," as the great pianist Arthur Schnabel has put it. ${ }^{6}$

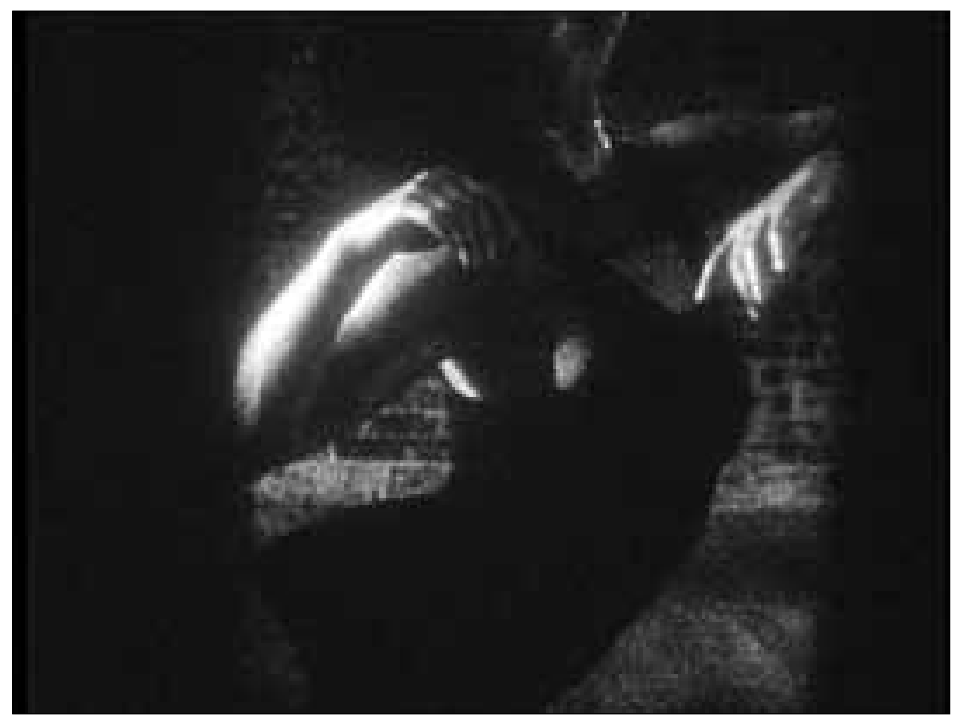

$\operatorname{Very}(1993,8 \mathrm{~mm} / 16 \mathrm{~mm}, 13 \mathrm{mins})$
My first dance-film was shot on Super-8 black-and-white film stock (Very, 1993). I enlarged the images to $16 \mathrm{~mm}$ on an optical printer so that the film grain was strongly emphasised. The materiality of the film was foregrounded.

I also filmed through a gap between two pieces of wood, so that I could create unusual framings - vertically aligned rectangles_evoking a portrait frame rather than the conventional landscape frame of cinema. I hoped that the grainy, contrasty, artfully

framed images of the dancers would make images that might vibrate with haptic sensuality (following Laura Marks' terminology).?

If dance-film exists in relation to dance, it also exists in a non-relation to narrative. It is worth thinking about what is lost, if one dispenses with narrative (conventionally understood), and about what is gained.

Film narrative depends on words, on a written script, on an unfolding of ideas that surely derives from an oral tradition. Narrative films, I think, are like a man who points off to imaginary places while saying: "let me tell you about a man who lived long ago..." For this reason, narrative films can flash back, flash forward, re-tell. We understand story telling.

Dance-film, it seems to me, is different. All I can say with such a film is:"This is happening." There is no past tense, no flash back, no future tense, no flash forward. Dance-film, I believe, 
is interesting because its components - sounds and images, gathered and rearrangedstand only for themselves. To watch Astaire and Rogers, as mentioned above, dancing in the dark, is not about where they are-in stark contrast to another kind of film that might make a hash of geography and be strongly criticised for such a fundamental mistake

When I watch a dance-film, I take everything for granted.

\section{$\square$ घ}

Thinking of Susan Sontag, I would like to say that film necessarily combines form and content; that it transcends what it seems superficially to show. "Interpretation" (as I understand Susan Sontag to have said) means to mistake content for form. She says: "By reducing the work of art to its content and then interpreting that, one tames the work of art. Interpretation makes art manageable, conformable." ${ }^{\prime \prime}$ relate this to the criticism from Anne Bilson, quoted above, which I take to be saying that dance-film is a translation of dance, or a representation of something else, an act of interpretation.

Sontag also says: "What matters ... is the pure, untranslatable, sensuous immediacy of some of its images, and ... solutions to certain problems of cinematic form."' That is what appeals to me.

I begin work on a film by contemplation of the choreography and movement. In the studio I am always struck by a happy pairing of freedom and constraint. I get a sense of freedom from the thought that every moment is unique and final, and so unprecedented and ever new. I note constraint because the dance I am witnessing takes place in a particular space and on a certain occasion. Actual bodies can only be in one place at a time. No body can become another body. The purpose of dance is served by its being actual.

Film is a very different because it must be cautious about freedom and constraint. However great the obstacle faced, the hero could quite well leap over the impossibly high wall (and does so in many a Hong Kong film), or be transported instantaneously across the world (James Bond does it all the time). Even time itself can turn back on itself (in Groundhog Day it does so over and over again). Cause can follow effect-surely the staple proposition in any detective film. Freedom is potentially unconstrained. And yet, of course, there is a limit. We, the audience, have to believe that some things are impossible. We have to believe that the bomb might go off, or the train not stop in time.

Fred Astaire had a contract that specified that he be shot head to toe. He did not think a closeup much served what he was about. In some ways this is a shame. I tend toward the view that the close-up in cinema offers a means to convey a sense of the sheer physicality of the human body, its solidity, plasticity, weight, individuality. The wider shot tends to generalise, flatten, mute. Even an inanimate object can seem alive when looked at in close-up.

I recall with such great pleasure Claire Denis's close-up of the pulse in the neck of her disgraced Sergeant as he lies inert on his bed, having contemplated and rejected suicide at the end of Beau Travail (1999)—shortly before the closing dance number, shot wide, of course. 


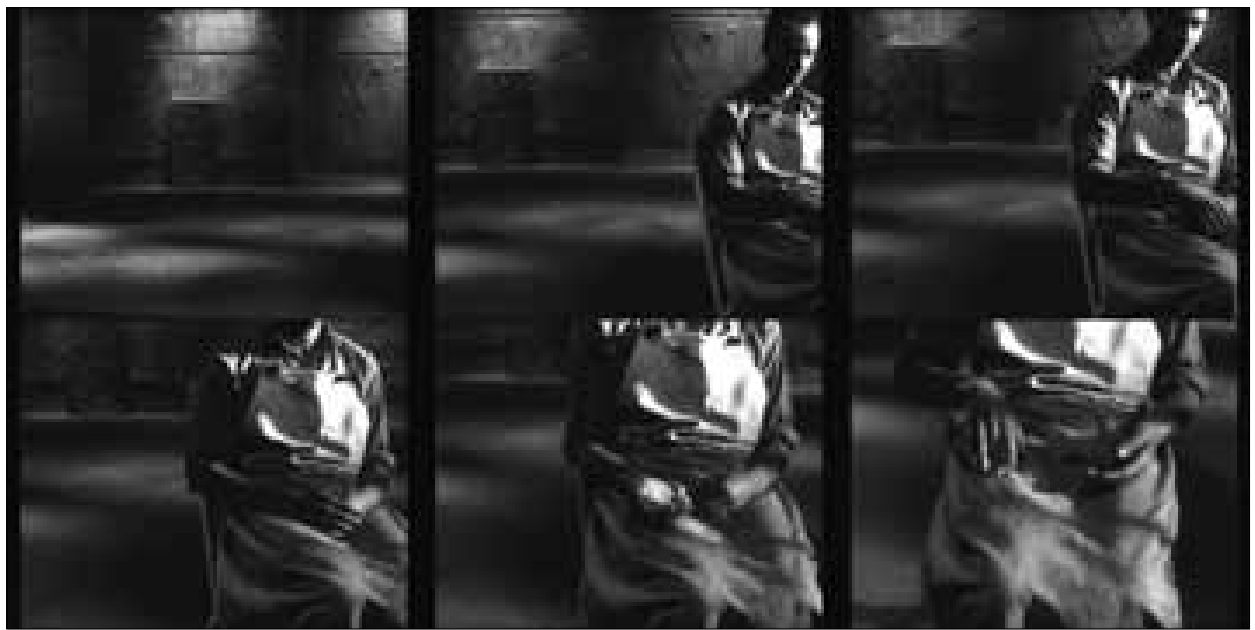

Sequence of stills, Hands (1995, 35mm, 5 mins)

In relation to Hands (1995), which begins with view of an empty space and a travelling camera that homes in on a figure, the eventual framing is a close up of a lap-at once stage, proscenium arch and domestic interior. The pulse-by means of meshing of sounds, movements and focus shifting —is drama enough to fill such a stage.

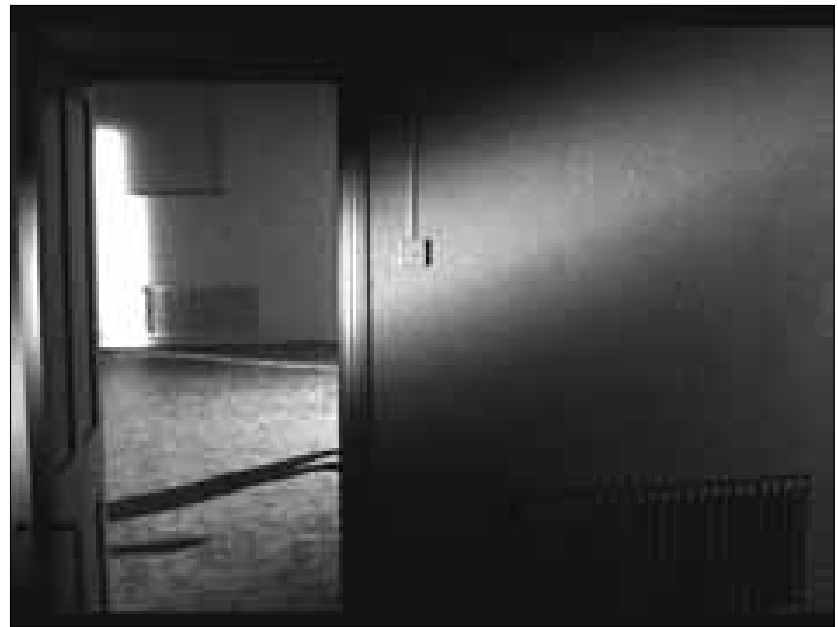

blue yellow $(1995,16 \mathrm{~mm}, 13 \mathrm{mins})$
I have always supposed that we find something most beautiful when there is the promise of more, of the thing we look at being never quite exhausted after any number of encounters. Our eyes love a beautiful thing because they "remain fixed on what remains veiled, even after the unveiling."10

Dance-film, I feel, should offer something like that: something hanging between the veiling and unveiling, something above all that resists the eternal temptation to see all, to rip open and to see into the holy of holies. A dance-film, for me, should resist impatience and literalism. It is not a record of actuality.

\section{口n}

"Your film must resemble what you see on shutting your eyes."11 


\section{References}

Bergson, Henri. Time and Free Will: An Essay on the Immediate Data of Consciousness. Translated by F.L. Pogson. London: George Allen and Unwin, 1910.

Bilson, Anne. "Hollywood has lost the art of filming good fight scenes." The Guardian. October 2, 2009. http://www.guardian.co.uk/film/2009/oct/02/hollywood-fight-scenes-ip-man.

Bresson, Robert. Notes on the Cinematographer. Trans. Jonathan Griffin. London: Quartet Books, 1975.

Curzon, Sir Clifford. Notable Twentieth-Century Pianists: A Bio-Critical Sourcebook, Vol 2. Edited by John and Anna Gillespie. Santa Barbara: Greenwood Press, 1995.

Marks, Laura U. The Skin of the Film: Intercultural Cinema, Embodiment, and the Senses. Durham: Duke University Press, 2000.

McLuhan, Marshall. Understanding Media: The Extensions of Man. New York: McGraw Hill, 1964.

Nehamas, Alexander. "The Return of the Beautiful: Morality, Pleasure and the Value of Uncertainty." Journal of Aesthetics and Art Criticism 58, no.4 (2000): 402.

Sontag, Susan. Against Interpretation and Other Essays. London: Penguin Classics, 2009.

Tarkovsky, Andrey. Sculpting in Time. Trans. Kitty Hunter-Blair. Austin: University of Texas Press, 1986.

\section{Film and Still Details}

The films made by me mentioned in this article all feature the choreography of Jonathan Burrows. For full credits, visit: www.adamroberts.eu/dancefilm.

blue/yellow (1995, 16mm, colour, 13 mins). Still shows the shadow of Sylvie Guillem.Commissioned by the BBC and France2, as a segment in Evidentia, curated by Sylvie Guillem.

Hands (1995, 35mm, b\&w, 5 mins). Sequence of stills shows Jonathan Burrows. Commissioned by the BBC and Arts Council of England.

The Stop Quartet / film (1996, 16mm, b\&w, 44mins). Still shows (I to r): Henry Montes,Jonathan Burrows, Fin Walker. Made with support from the Arts Council of Englandand The Prudential Award for the Arts.

Very (1993, 8mm optically enlarged to 16mm, b\&w 13 mins). Still shows Deborah Jones. Unfunded.

\section{Notes}

1. Bilson, "Hollywood."

2. McLuhan, Understanding Media, 7.

3. I would also like to refer to Henri Bergson's conclusion that: "Pure duration is wholly qualitative. It cannot be measured unless symbolically represented in space" (Time and Free Will, 104).

4.Tarkovsky, Sculpting in Time, 121.

5. Time and worry have never been so utterly suspended as when Fred Astaire and Cyd Charisse move from walking in the park to dancing in the dark in The Band Wagon (1953, directed by Vincente Minnelli).

6. Quoted in Curzon, Notable Twentieth-Century Pianists, 793.

7. See Marks, The Skin of the Film.

8. Sontag, Against Interpretation, 8.

9. Ibid., 9.

10. Nehamas, "The Return of the Beautiful," 402. (Nehamas is paraphrasing Nietzsche's The Birth of Tragedy ).

11. Bresson, Notes on the Cinematographer, 50. 


\section{Review Essay}

Claudia Rosiny

Line Dances (seven cinematic journeys) — seven films for web and new media.

Directed by Daniel Belton. Dunedin, NZ: Good Company Arts, 2010.

7

hey look like human creatures in artificial cobwebs of lines-Daniel Belton, head of Good Company Arts, based in Dunedin, New Zealand, created and directed seven dance films under the headline Line Dances. And, in fact, lines are the joining elements in all these films, which vary between five and twelve minutes. The unique aesthetics of the imagery are remarkable, combining human beings performing dance movements into a graphic environment that is often detached from any real spatial perception. On the surface of the cinematic image, Line Dances looks like a formal dialogue between human beings that resemble animated representations of human characters on one side and geometrical patterns on the other. Throughout this approximately seventy-minute program, a black afterimage dominates these "seven cinematic journeys," as Line Dances are subtitled. The intermediate sequences always return to this blackness in which blurred images of an old fashioned camera show up. Each "Line Dance" has a title: Saint A in B, Portrait of an Acrobat, Realm of the Curtain, Harlequin on the Bridge, Equilibrist, Perspective with Inhabitants, Realm of the Curtain. As you read them, they do give some narrative hints, as they refer to pictures with the same title by Paul Klee.

Indeed, the idea of interacting human figures with abstract lines and geometric systems resulted from Belton's research on Modernism, especially the drawings of Paul Klee and the background of the Bauhaus movement. Some of Klee's pictures in fact seem to emerge out of the image like his squares in red connected with fine lines in Portrait of an Acrobat. And the use of baton reminds us of the famous Bauhaus baton dances, which Gerhard Bohner reconstructed in the 1980s. Belton uses Klee's quotation, "One eye sees, the other feels," as a guideline to indicate what he wishes to achieve in his films. He wants to exhaust the visual and physical potential of dance. Common stereotypes like a ballerina, an acrobat, or a harlequin are a strong contrast to these simple graphic lines. Formalism and emotional potentiality seem to melt; you don't have to be moved, but maybe these fairytale-like figures call up sensations and souvenirs of whatever we associate with them.

Paul Klee's drawings were Belton's inspiration, but his artificial images also awaken references to early experimental and abstract film of this period (the 1920s), such as the "dancing" of painted patterns that Len Lye, Hans Richter, Walter Ruttman or Viking Eggeling created. These pioneers of experimental film were artists who applied drawings directly on the film material, the celluloid. 
Belton's most exciting passages are those when the interaction between moving bodies and geometrical forms leads to a metamorphosis: the lines stretch, bend, and curve, initiated through the movement of a figure; then suddenly there is a pulse in a line and the geometrical patterns become natural. In the first film, which starts with a white afterimage, the lines serve foremost as a surface, as spatial references on which the figures start to move. Later the lines form a building with an abstract cupola: "the lines exaggerate the corporeal, and develop texture within the space," as Belton describes his idea. ${ }^{1}$ Belton works with multilayered images, with duplications of his figures that emerge out of the black and fade back, seemingly into outer space. Often the duplication-for example of the ballerina and fool couple —is displayed in a smaller size and the motion of the mirrored couple has a slight retardation. Line Dances are strongly cinematic insofar as there is hardly any reference remaining to a stage perception. We seem to look into a nirvana space that has a ground, but no limitations in all directions. The screen is the stage but with no resemblance to a theater stage. A high grade of abstraction is also achieved by a mainly black and white image. Sporadically, the figures change to color, which adds an accent of realism and narrativity to the characters.

In addition to multiplications of figures, Belton also works with size and magnitude, setting them like small toy figures in his creative playing field. Whereas the ballerina symbolizes the dance world, the fool in theater history is the figure that has freedom to query and contest. With these strong character types he also interrogates the conditions of theater and dance.

The third aesthetic level next to the figures and forms is the elementary sound track, splashy piano music, composed and played by Anthony Richie. It is possibly the monotony of the sound that at times lengthens the hour-long program. But it is different if the films are watched in the closeness of a dark cinema, as they were when premiered last October in New Zealand. Regardless, as Daniel Belton and his Good Company's numerous video dances have already been selected for countless festivals and gained scores of awards, it is certain that Line Dances will tour and find its audiences. At the end of January 2011, Portrait of an Acrobat was selected for the oldest Dance on Camera Festival in New York City. Seen in the context of the rise of a new genre, videodance, which emerged in the 1980s, Line Dances offers an interesting link to art history and a unique film concept. All films can be watched on Daniel Belton's website www. goodcompanyarts.com, the photos and videostills at www.dance-tech.net.

\section{References}

Good Company Arts. Dundein, New Zealand. http://www.goodcompanyarts.com/main.html.

\section{Notes}

1. See http://www.goodcompanyarts.com/main.html. 


\section{Review Essay}

Scott deLahunta

Becoming Beside Ourselves: The Alphabet, Ghosts and Distributed Human Being. Brian Rotman. Durham and London: Duke University Press: 2008.

$\mid$ n Becoming Beside Ourselves: The Alphabet, Ghosts and Distributed Human Being, Brian Rotman argues that the post-alphabetic era is upon us. His thinking is based centrally on the proposal that the "writing of speech" has been the West's dominant "cognitive technology" for over 2500 years. Rotman contends that "alphabeticism" as an "entire logic of representation" has contributed to specific modes of thinking and ways of believing, including all forms of monotheism. He describes the alphabet (particularly the Greek and Hebrew) as having caused a rift between language and the body, cutting wording off from its corporeal sounding place in throat and tongue. Throughout the book he extends these ideas into a discourse on how these "habits of mind" are increasingly at odds with an emergent self, a self that is being shaped culturally and eventually neurologically (based on past evidence of the effect of writing) by computer based digital technologies and network media.

In Part One of Becoming Beside Ourselves, Rotman discusses how the body separated from the "gestures of the voice" or prosody by writing will return through a reassertion of gesture in the post-alphabetic era. He isn't thinking of gesture as only augmenting speech, but is instead going beyond this conventional instrumental connection to see gesture, and the body, as freed from its subordination to language. This requires us to reconsider fundamental assumptions about thinking and the body, particularly that thinking takes place mainly in the mind or the brain. Rotman cites philosopher MerleauPonty and linguist George Lakoff to indicate that it is not a new or unique idea that the gestures of the "thinking body" are not confined to "verbally expressed narration." Going further, Rotman makes a claim for a new "experiential... modality," the emergence of which is supported by computer-based motion capture technologies which he refers to as a "non-notational medium" capable of "reproducing the kinesis of bodies."

What I find interesting about Rotman's book, besides the content of his intriguing text-which is not done justice in these few paragraphs - is how it seems to add to a growing corpus of theoretical material exploring embodiment through an explicit reassertion of movement's significance. Brian Massumi gave this project a boost with his Parables for the Virtual (2002) in which he accused scholars of having left "movement, affect and sensation" out of their consideration of the body as constitutive of identity and locking corporeality into a meaning-making system of signs and textual analysis. To continue to list related research both before and after Massumi would be valuable, but that is not my purpose here. My purpose is to suggest that for those of us who 
claim our practice to be movement-related, we might look out for what philosophers, scientists and scholars are producing as they sketch out conceptual scaffolds we might find ourselves resisting as well as slipping into. In other words, who is thinking about thinking, and in which modality? And how might we, from outside writing-dominated practices, participate?

\section{References}

Massumi, Brian. Parables for the Virtual: Movement, affect, sensation. Durham and London: Duke University Press, 2002. 


\section{Introduction to the Films}

Maya Deren

[This text is transcribed from a carbon copy of the original material typewritten by Maya Deren, dated 1945 and titled "Introduction to the Films," from the Maya Deren Collection, Howard Gotlieb Archival Research Centre at Boston University. It is reproduced here by kind permission of the Centre. Slight idiosyncrasies in Deren's typing have been corrected. Elinor Cleghorn would like to thank JC Johnson at the Howard Gotlieb Archival Research Centre for all his help and assistance.]

I is still such a novelty to consider film as an art form, that I would like to point out some rather special problems which are involved in such an approach to film. I would like to begin by recapitulating some basic aesthetic principles, and then relating them specifically to film.

The first characteristic of a true work of art is that is creates a reality and itself constitutes an experience. It does not merely describe something of which we are already fully aware. This new reality consists of elements selected from natural reality and is achieved through the establishment of a new, imaginative relationship between these elements of the natural world.

The creation of this new relationship constitutes the form of the work of art, and thus the form incorporates the intention of the artist. That is, the artist assigns meaning, value and weight to the selected natural elements by giving them a certain position in the work as a whole, and thus their natural values - that is, the value which these elements have in a natural reality - are transformed into new values which are assigned them by the artist according to the function he gives them in the context which he creates.

Translated into cinematic terms, this would mean that the elements of natural reality, selected and registered by the lens, should be given new meaning by a manipulation behind the lens - manipulation of the camera mechanism (its varying speeds, etc.) of the movement of the camera as a body, and in the cutting and editing of the film afterwards. For if we are to accept the mechanical similarity between the lens and the eye as the basis of an analogy between the camera and a human being, then we must extend that analogy to include the brain behind the eye, which gives meaning to the material which the eye registers, and to include also the body, whose movements are motivated by the meaning which the brain assigns to the material which the eye registers. Unfortunately, in most films, there is no such extension of the analogy. The creativity of the camera is usually limited to the selection of the elements from the natural reality, but there is little manipulation of them beyond that. They are merely re-combined on film in an effort to recapitulate the natural reality itself, a reality which is usually more convincing and more rich in its natural state. 
This new unfortunate tradition of recapitulating natural reality rather than creating new ones - a tradition for which the commercial film industry is responsible-creates a special problem for the art film in its relation to an audience unaccustomed to the products of the film industry. For instead of assuming that they will be confronted by new realities, and preparing themselves to receive those new realities with the same un-selfconscious receptivity which they bring to other art forms, they seek to recognize, in the films, some natural reality which they can subject to a personal interpretation, as they do with natural phenomenon.

For this is the special problem of cinema. Its great strength, its great ability to convince, lies in its resemblance to natural reality. When we see a real tree in a scene, we believe the event under the tree to be as real and as natural as true. Thus, by a delicate manipulation of such natural elements - a manipulation which succeeds in retaining their realityone can create a new reality, based on a new relationship of those elements, which will partake of "the truth" of nature. This is, in a sense, the secret of those Nazi " documentaries" which, employing the same material, and in many cases the very same scenes as are available to the documentarists of other ideologies, are able to so relate them as to convincingly create a "truth" which is, actually, untrue.

The realities which film as an art form seeks to convey may be as delicate and subtle as are the perceptions in other art forms. And here the potential strength of film-and its resemblance to natural reality - requires of the audience a certain adjustment; for the audience tends to bring towards film that attitude which it exercises towards natural phenomena. Such a natural phenomenon as a sunset, for instance, has no conscious intention, for the revolutions of the earth do not contain conscious purpose. Consequently, the observer or the artist can endow it with whatever emotional meaning-peace, or fear of the oncoming night, or beauty -is appropriate to his personal intention or inclination. But a work of art already incorporates an intention — the intention of the artist-and it is he who has already made a selection from natural reality and has attempted to assign meaning to that selection by his treatment of the elements, not only individually, but by their function and relation to the whole. Consequently the spectator must here, before the works of art where artifice is inescapable, concern himself not with his own creative interpretation of the elements, but with the discovery of the intention of the artist with respect to those elements.

The form as a whole, the contextual logic which endows each of the elements of the work with meaning, is, in a time art such as cinema, revealed only when the work as a whole has been experienced. Only after the experience is complete, and the logic therefore completely delineated, can the individual elements - symbols, characters etc. - be understood according to the intention of the artist in terms of the logic he has created. In other art forms we recognize this. The poem, the dance, the symphony, the painting are all experienced more than once by the serious spectator. The same applies to creative film. That very richness which, in other art forms, continues to reveal more and more of itself each time our attention is given it, is the very element which would be neglected in a film designed to be taken in one performance.

If a self-conscious, critical analysis is exercised in the course of the first viewing of a work of art, or of any experiential reality, it will only result in a distorted interpretation, and will hinder the perception of the artist's intention. For such an analysis would be based 
on the personal logics of the spectator and not upon the logic which the artist seeks to establish. The inevitabilities of a state of anger, for instance, will not seem inevitable if analyzed by a logic of state of calm and repose. Nor can an "objective" logic explain the actions of a man in love. Any analysis of the reason for an emotion can only follow upon the experience but can never induce it. In an appreciation of a work of art, which is, essentially, an experience itself, such an analysis is a completely secondary activity which, at most, justifies that experience in its own terms but can never "explain it," according to an alien logic. 


\section{Thinking Deren}

\section{Elinor Cleghorn}

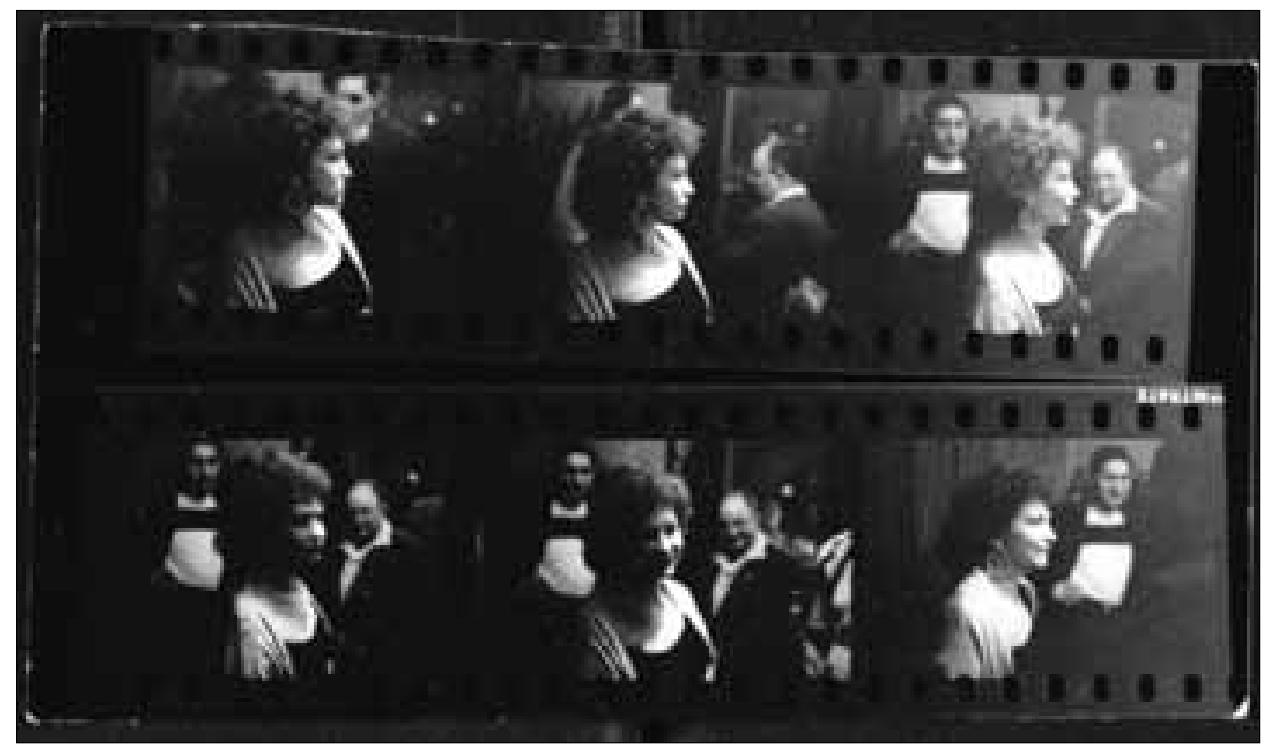

Maya Deren. Film frames. (no date). Reproduced with kind permission of the Maya Deren Collection at the Howard Gotlieb Archival Research Centre, Boston University.

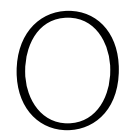

ctober 2011 marks the fiftieth anniversary of the death of Maya Deren: filmmaker, poet, dancer, ethnographer, teacher, visionary. The occasion proffers the opportunity to reconsider Deren's considerable cinematic legacy and to re-view her slight collection of completed works in light of the progression of screen-based practices over the last fifty years. Her work is particularly significant to screendance and choreographic cinema; ripples of her relevance, like rings in water, are present in so many film works seeking to explore the possibilities for moving bodies on screen. In her films, such as A Study in Choreography for Camera (1945) and The Very Eye of Night, which saw its New York release in 1959, the dancing body appears to at once transcend the limitations and the strictures of gravity and of physicality. In Ritual in Transfigured Time, completed in 1946, the movements of guests at a cocktail party become an integrated mechanism through which the capacity of the filmic medium to confer a dance-like quality upon quotidian movement is brought to screen. Meditation on Violence (1948) describes the quality of movement of two qualitatively different schools of Chinese boxing through a solo performance, with which the camera collaborates.

Deren was of course not the first to bring dance to film or to choreographically configure elements and objects into an integrated cinematic complex. A selection of possible films 
that could accompany Deren's A Study in Choreography for Camera in an imagined contextual journey through the pre-1950 history of examples of 'film as art form,' which drew upon the notion of the choreographic as impulse for cinematic expression, might include: Fernand Léger's Ballet Méchanique (1924), René Clair's Entr'acte (1924), Marcel Duchamp's Anémic Cinéma (1926), Oskar Fischinger's Spiritual Constructions (1927), Germaine Dulac's Étude cinégraphique sur une arabesque (1929), Mary Ellen Bute's Tarantella (1940) and Marie Menken's Visual Variations on Noguchi (1945).

The significance of Deren's contribution to the development of film as an art form inexorably exceeds the parameters of her screen legacy. Her films undoubtedly owe much to the accomplishments of her predecessors - even if she resisted bringing this into discussion. She was audaciously singular, however, in her commitment to assuring a breadth of exposure for her own works whilst previous film artists had suffered from limited visibility, their films often screened only once in very specific circles. During the 1950s, Deren toured lectures, conducted workshops, and gave talks to accompany self-organized screenings of her body of films across the US; she participated in symposia and debated the potential for a collaborative exploration of the relation of the medium and other creative disciplines. Her tireless advocacy for the promotion of independent filmic practice, which included the formation and administration of the Independent Film Maker's Association in 1953, and the Creative Film Foundation in 1955, facilitated the bringing together of New York based artists in the exhibition, distribution and discussion of diverse filmmaking endeavors.' Deren's efforts ensured that, for example, the unique possibilities, which the cinematic mechanism opened up for the treatment of dancing bodies, were brought keenly into debate at a particularly discursive juncture in experimental moving-image production. In 1956 she organized and participated in "Dance and Film," a Creative Film Foundation event held as part of a series entitled "Film - A Creative Synthesis" at the Hanya Holm School in New York. The event comprised screenings intended to illustrate discussions concerning the "variety of relationships between film and dance movement."2 Deren's Choreography for Camera appeared alongside Jean Cocteau's narrated documentary on African dances, L'Amitié Noire (1946), Léger's Ballet Méchanique and Disney's animated short Skeleton Dance (1929). A panel discussion featuring Deren and choreographers Jean Erdman, Valerie Bettis and Antony Tudor considered the relative merits of the screened examples of dance on film. In the audio recording of the event, one can listen to Deren defending her silent depiction of dance for camera against Erdman's proposition that she feels the lack of kinaesthetic empathy when movement on the screen proceeds divorced from sound. ${ }^{3}$ Deren had, between 1952 and 1954, collaborated with Tudor on the production of her final completed film, The Very Eye of Night, for which he choreographed dancers from the Metropolitan Opera Ballet School in movement sequences staged specifically for filmic composition. The set of questions posed in the "Dance on Film" event bulletin resonate most profoundly with continued discussions and debates surrounding the emergence and development of screendance, a medium which has, as we know, not yet been invented:

Dance and motion-pictures are both concerned with movement. What is lost when dance is simply recorded on film? What can be gained by creative use of the film medium and the mobile camera? What are the relative roles of choreographer, dancer and film-maker in a creative collaboration between dance and film? ${ }^{4}$ 
Within the scope of this issue of the International Journal on Screendance, which is titled "Scaffolding the Medium," an opportunity arises to consider Deren's legacy through her writings and lectures in which she gave insight into the conceptual frameworks structuring and enabling the production of her restless and beautifully wrought film works. Whilst no spectator intrigued by screendance is a stranger to her aesthetic, and her first film Meshes of the Afternoon, made in 1943, remains one of the most widely screened examples of experimental cinema in educational institutions, the full breadth of her contribution to film theory remains twilit, and is deserving of thorough attention. Deren wrote prolifically: during the mid-1940s she published essays and articles on the conception and construction of her works, on the practice of creative filmmaking, and on the notion of cinema as an art form in a wide range of publications, most notably Dance Magazine, Popular Photography, New Directions and Mademoiselle. As Bruce McPherson notes in his introduction to Essential Deren, the collection of her writings published in 2005, the intense period of production between 1944 and 1948, which bore four films, coincided with a voluminous outpouring of published material. ${ }^{5}$ McPherson notes that a "publishing hiatus" of about ten years followed, but during this time, Deren continued to write, to tour with lectures, and to cleave out a space in which experimental film could be viewed and valorized.

During a recent trip to the Maya Deren Collection in the Howard Gotlieb Archival Research Centre at Boston University, I encountered carbon copies of original documents typewritten by Deren, often accompanied by tantalizing pencil annotations and

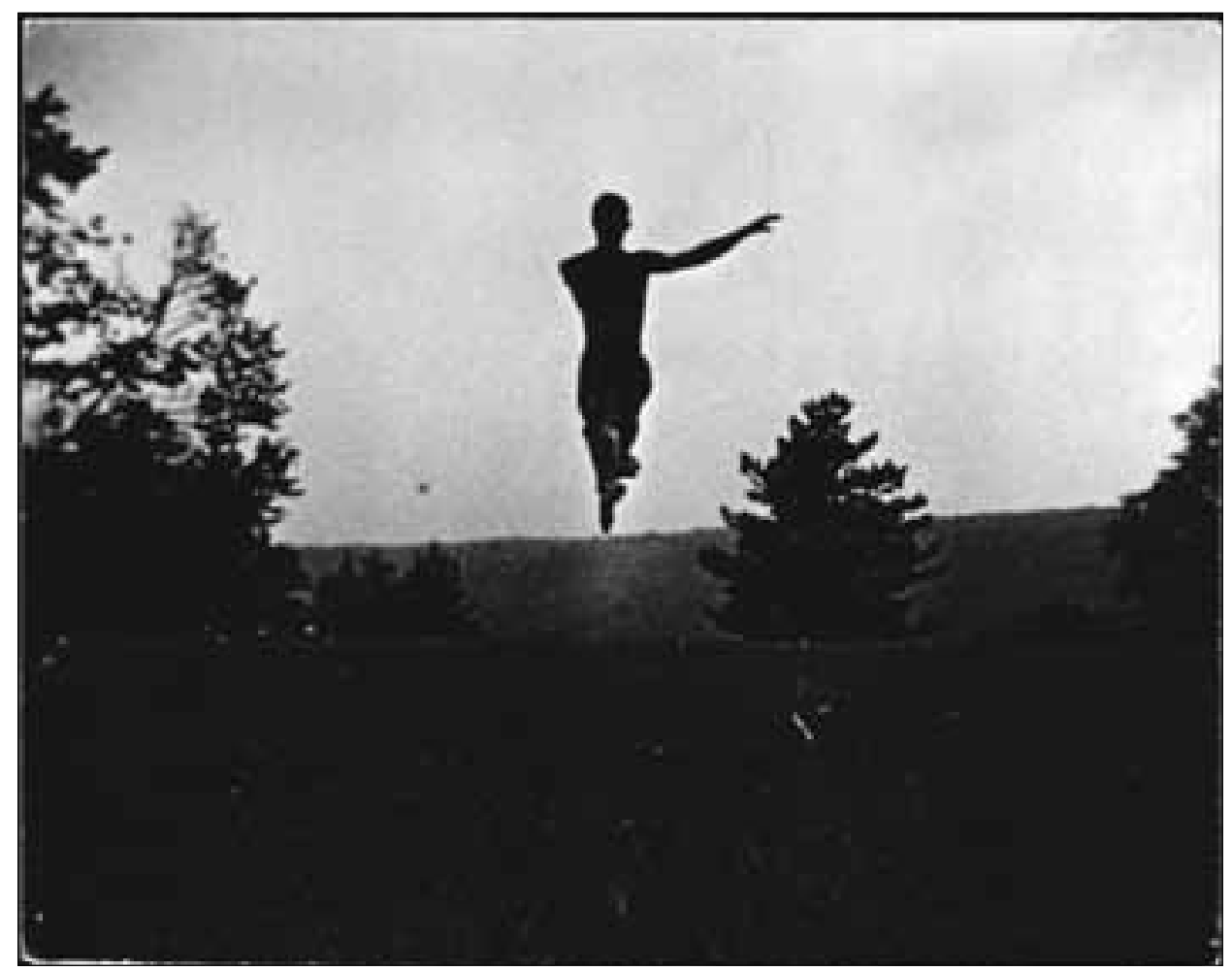

Frank Westbrook, Ritual in Transfigured Time, Maya Deren. Film still. 1945/46. Reproduced with kind permission of the Maya Deren Collection, Howard Gotlieb Archival Research Centre at Boston University. 
notes-to-self. During my search for material that might support my interest in Deren's utilization of her mobile body as the most enabling instrument of her practice, I came across numerous drafted forms of notable articles and thematic statements, the majority of which were included in a memorial edition of Film Culture, which was dedicated to Deren (1956), and which have more recently been made available in Essential Deren. Amongst the manuscripts I was familiar with, I discovered a draft entitled Introduction to the Films, which we have the privilege of including in this edition of The International Journal on Screendance.

The original copy of the draft (1945) includes a note, in parentheses, stating that it was "from a lecture delivered in connection with film showings." by Deren expressing the fundament of the concept of form: the form of the "true work of art," she claimed, was constituted by the capacity of the artist, through their chosen medium, to create an entirely new, experiential reality from elements selected for their purpose of production. In cinematic terms, Deren argued, this imaginative constitution derives from techniques of mechanistic manipulation brought to the elements of natural reality "selected and registered by the lens." In a declamation illustrating the importance of the making body in the conjuring of creative film, she expresses her concern that the mechanical similarity between eye and lens must analogously extend to the body behind the camera, "whose movements are motivated by the meaning which the brain extends to the material which the eye registers." ${ }^{\prime \prime}$ For Deren, the motion picture camera could elicit its most truly creative registers of expression in the hands of the mobile body. As she proclaimed in "Adventures in Creative Film Making," an essay expanding several of the propositions she initiates in her text from 1945, the human body offers a peerless support structure, enabling a range of opportunities for photographing, limited only by the body's capacity for pose or balance. ${ }^{9}$ Through the theoretical optic proposed by this issue of the Journal, we might begin to reconsider Deren's work as scaffolded by the choreographic implications of filmic technology and re-experience the manipulation of the bodies and objects within her frames as intimately extending from the physical engagements of an invested, seeking body. She believed profoundly, as she expresses in her seminal chapbook An Anagram of Ideas on Art, Form and Film (1946), that the potential of a work of art derived from the "skilful exercise and control" of the art instrument through which the maker could fully realize her boundless "imaginative manipulations." ${ }^{10}$

The section of the Journal dedicated to thinking or re-thinking Deren includes my essay, Manus Operandi: Film, Sculpture, Choreography, in which I discuss her unfinished film project of 1943, Witch's Cradle, as a cinematically specific exploration of the relational space between mobile body and sculptural forms. The film, available to view as a series of outtakes, includes scenes shot in the Surrealist gallery of Peggy Guggenheim's "Art of this Century" museum. Deren attempted its making shortly after completing Meshes of the Afternoon with her then-husband, documentary filmmaker Alexander Hammid. It was her first venture in creating a film "quite by herself."11 In viewing the fragments of this project, Deren's animistic characterization of the art objects within the gallery suggest that she sought to transpose into the specificities of filmic form the way in which the selected objects seemed to her to "constitute a strange, magical world."12 Geographically distant scenes are symbolically conjoined by the recurring presence of a strangely enigmatic length of string: whilst the film was never realized and released, it bares evidence of Deren's bourgeoning conceit that film was capable of dynamically conjuring an "emergent whole" (a term she applied 
to the medium from her interest in Gestalt theory) from the composition of unpredictably related "parts."13 Deren was fascinated with Haitian and Balinese forms of ritual expression: her documentation, in 1947, of one Voudoun dance ceremony across 20,000 feet of $16 \mathrm{~mm}$ film remained unedited in her lifetime. ${ }^{14}$ She sought to transpose the integral logic of ritual activity into filmic form, arguing that such activity consisted of the 'fusing' of individual elements into a transcendent unity that strove towards the "accomplishment some critical metamorphosis."15 Deren's interest in Gestalt theory became a mechanism for her cinematic expression of ritual coherence and, along with the verbal logics of poetry, form acted as a conduit for the realization of film as a "controlled manipulation of any or all elements into a form which will transcend or transfigure them."16

Through her thematic statements on A Study in Choreography for Camera of 1945 and Meditation on Violence of 1948 Deren elicited a language with which to talk about choreographic cinema; through her theoretical writings she engendered possibilities for filmic thinking, drawing upon the medium's capacity for ritual, poetic expression and the invention of experiential realities; through her lectures she gave fascinating insights into filmic construction and the visual realization of the imaginary. Her writings and lecture transcripts are full of insights into her relationship with the mechanism of her expression-with her "instrument of action" — and it is my hope that this section of the Journal might invigorate dialogues around the ways in which her intellectual output opens up her films to new, previously unexplored registers of understanding. Deren's films, her theories and her advocacies-which can be approached as an extraordinary contribution to the continuing development of film as art form-were driven by an impulse to explore and discover the social, ritualistic, aesthetic, choreographic, poetic and experiential potentialities of a medium that, for her, was equal to life.

\section{References}

Deren, Maya. "Adventures in Creative Film Making." In McPherson, Essential Deren, 172-73. Originally published in Home Movie Making, 1960.

. An Anagram of Ideas on Art, Form and Film. New York: The Alicat Book Shop Press, 1946. In McPherson, Essential Deren, 54.

."Introduction to the Films." 1945. Maya Deren Collection, Howard Gotlieb Archival Research Centre, Boston University.

."Magic Is New." Mademoiselle. January 1946. In McPherson, Essential Deren, 204.

."Ritual in Transfigured Time." Dance Magazine. December 1946. In McPherson, Essential Deren, 227.

McPherson, Bruce, ed. Essential Deren: Collected Writings on Film by Maya Deren. New York: Documentext, 2005.

Rabinovitz, Lauren. Points of Resistance: Women, Power and Politics in the New York Avant-Garde Cinema, 1943-1971. Urbana: Univ. of Illinois Press, 1991.

\section{Notes}

1. Lauren Rabinovitz, Points of Resistance, 80-83.

2. "Dance and Film at the Hanya Holm School, New York," March 23, 1956, Creative Film Foundation Bulletin, Deren Collection.

3. Wire recording of the Creative Film Foundation event "Dance and Film,"March 23 1956, transcript and audiocassette, Deren Collection.

4. "Dance and Film at the Hanya Holm School, New York," Deren Collection. 
5. Between 1944 and 1948 Deren made At Land (1944), Choreography for Camera (1945), Ritual in Transfigured Time (1945/46) and Meditation on Violence (1948). For Deren's complete filmography, which includes details of her incomplete and unrealized projects, see Bruce McPherson, editor. Essential Deren, 259-60.

6. Deren, "Introduction to the Films."

7. Ibid.

8. Ibid.

9. Reprinted in McPherson, Essential Deren, 172-73.

10. Ibid., 54.

11. Maya Deren,"Magic is New," 204.

12. Ibid.

13. Deren, An Anagram of ldeas on Art, Form and Film, 65.

14. The footage was edited posthumously into the documentary Divine Horseman: The Living Gods of Haiti by Deren's widower Tieji Ito and his wife Cheryl Ito in 1977. Deren's study of the practices and activities of Haitian Voudoun led to the publishing of her text of the same name in 1953.

15. Maya Deren, "Ritual in Transfigured Time," 227.

16. Ibid, 228. 


\section{6 ro}

\section{CREATTVE FILM FOUNDATION 35 Morton atreet, NYC 14 ERtklns 4-0760}

\section{For Immediate Relense}

Plesse Pagt

The Creattve Film Foundation presents

the firat Friday Forum of its series on Film - A Creative Synthesis

March 23, 8:30 PM at the Hanya Holm Bchool, 743 oth kve (40न7 atc)

DANCE AND FILM

\section{VALERTE BETTS * MAYA DEREN • JEAN BRDMAN • ANTONY TUDOR}

Dance and motian-pletures are both concerned with morerent, What is lout

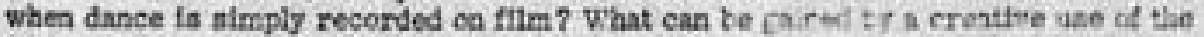

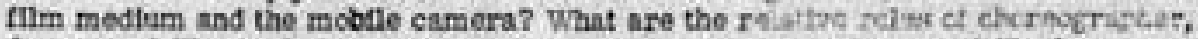
dancer and fllm-maker in a creative collaboration betwotn dasuc is.d fom?

The variety of retationshtpg between film and dance movetnint will be ti-

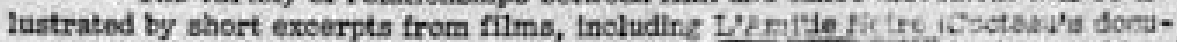

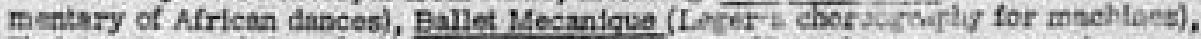

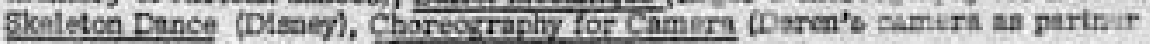
to a dancer) nand others.

There is no admisalons fee. These forims are organised primarlly for Sustalning Members of the Foundation, students in the arta aud perzssa ergaged in $16 \mathrm{~mm}$ film-mnking who are unable to contrlbute as Sustainirs Mer lyts are frvited to attend as gaests and may apply for a gueat adimisatce eant by wrftiag to the Fo and-

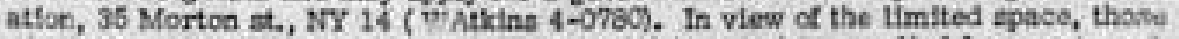
who have made thetr contribution to the Poundation or have applled for guest carda In advnnce will be seated flrat, beforo perstone without advarce reservatlons are scmitted.

The Creatlve Film Foundation is a nen-protit eorporation devotad to the developmeat of motion-plctures as a creative flne art form; It glves graats for experlmental fllm production, confers an Anrual Crentlve Fllm Award, casitucts forams, sponsors exhlbits and other events. These activities are made porafble by the coutributions of Sustaining Members, A denation of \$10,00 or mere qunlifles an Individual for particlpation as Sustaining Member, facludirg the follosing privilegen: attendance at forums, complimeatary tickets to puhtic Poundation eveats, news letters, bocks co fllm at dincounted rates, ete.

\section{THE CURRENT FAMAY FORUM BERTES YIT, AIEO ANCLUDE:}

(5)ces c? forumat will be aninounced)

Aprll 6 - MUSIC AND FIt M: John Cage, John Gruen, Gordon Hiendricks, Norman Lloyd.

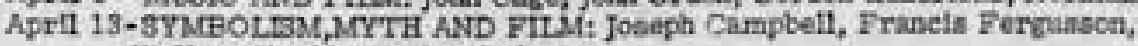
Wallace Fowlie, Parker Tyler.

April 30-POETRY AND FILU (apeakera to bo ameunced.

April 27-THE PLASTTO ARTS AND FTtM: Rudoll Arnholim;Clement Oreenberg, Frederlek KIesler, Meyer Sehapiro, Kurt Sellgmatia.

and …. THEATBR AND FILM; ART AND THE ARTY DN FILM, and others.

HEIP THR DIVET OPMEYT OF FTH AS A FRE ART PORM BY YOUR PARTTCTPATIÓN AND CONTRIBUTHON NOWI

Copy of the original Creative Film Foundation bulletin for "Dance and Film," 1956. Reproduced with kind permission of the Maya Deren Collection, Howard Gottlieb Archival Research Centre at Boston University. 


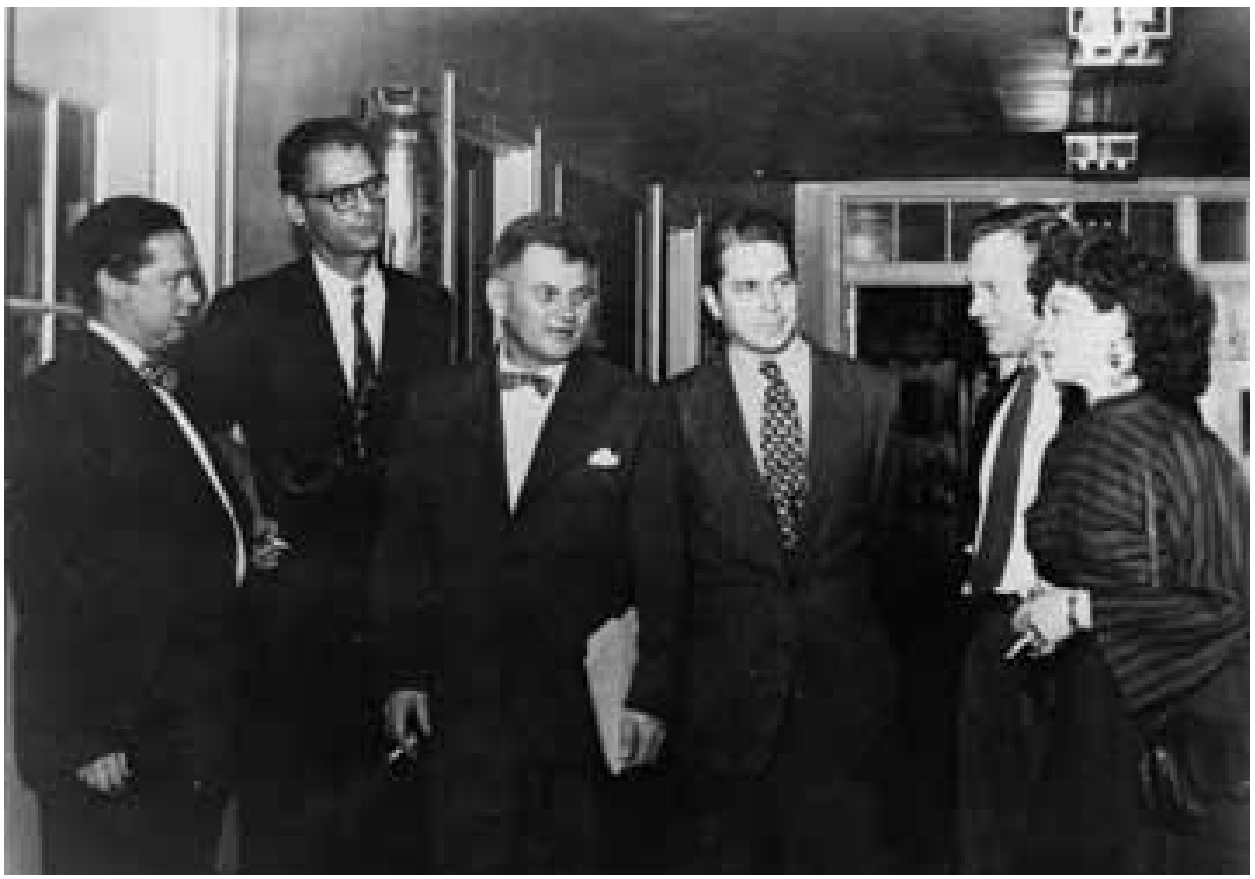

Maya Deren with (left to right) Dylan Thomas, Arthur Miller, Willard Maas, Parker Tyler and Amos Vogel. Cinema 16 symposium, "Poetry and the Film," October 28, 1953. Reproduced with kind permission of the Maya Deren Collection, Howard Gottlieb Archival Research Centre at Boston University.

Maya Deren and her cat. (no date) Reproduced with kind permission of the Maya Deren Collection, Howard Gottlieb Archival Research Centre at Boston University.

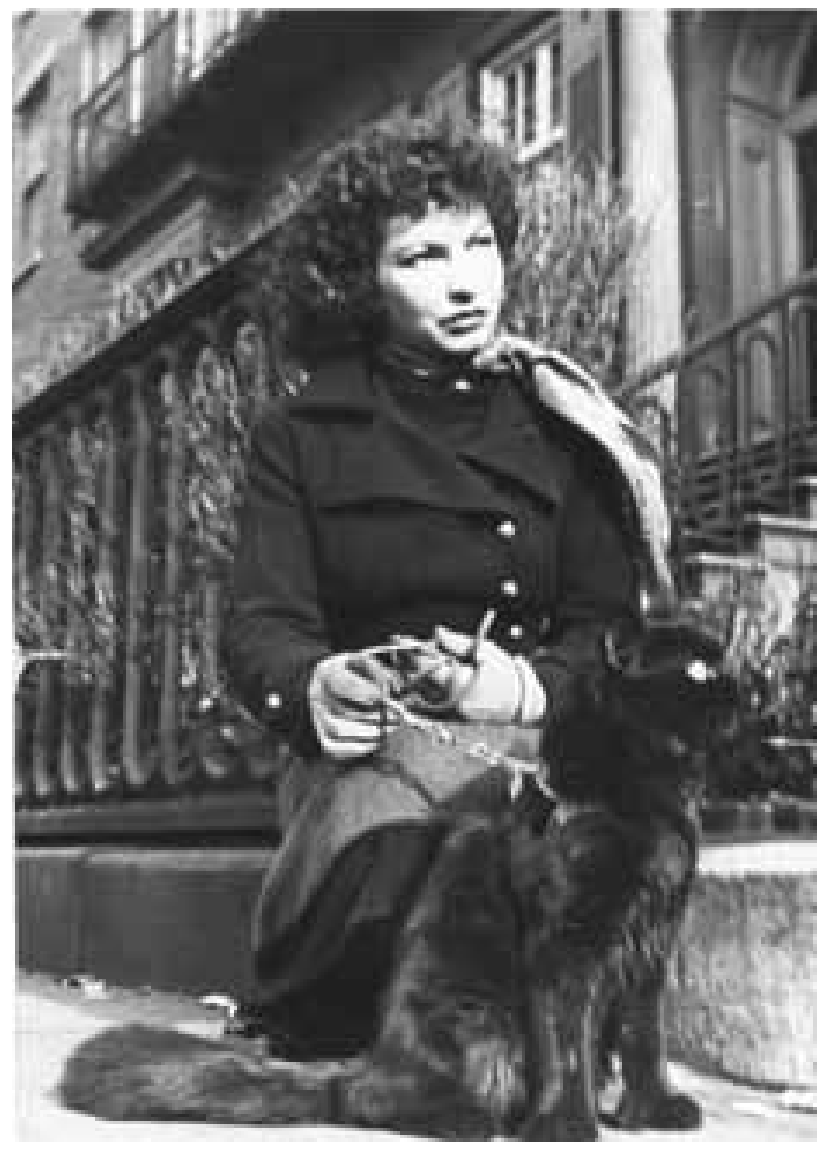




\section{Manus Operandi: Film, Sculpture, Choreography}

Elinor Cleghorn

I maintain that before the invention of the moving-picture no one knew

before the possibilities latent in a foot-a hand-a hat.'

Fernand Léger

This paper is partially inspired by the discovery of Richard Serra's 1968 film Hand Catching Lead, which is in the digital archive component of the Hayward Gallery's recent exhibition, "Move: Choreographing You." The archive, co-curated by André Lepecki, is comprised of over 120 visual texts embedded within a navigational portal, resembling a mobius strip that invites the viewer-user to choreograph their own smooth movement through a related history of dance and visual art over the last five decades. Seminal performances, dances and events are documented alongside videos, still photographs, and several films. The inclusion of Serra's first film, a single-shot, three-minute depiction of a hand engaged in a repetitious attempt to catch small pieces of lead falling into the frame from somewhere unseen, struck me because of its staging of the hand - the manus - as the instrument of an inherently choreographic action. Musing on the significance of the inclusion of this anti-illusionist game of catch in an archive attempting to re-present a recent history of the appropriation, disruption, expansion, and contraction of dance movement and choreographic configurations within and by visual art practices, I began to consider the ways this simple gesture, this blunt action, constitutes a form of dance, or how it might be approached, perhaps, as screendance. More particularly, my thoughts turned to the specificity of the commitment of this pragmatic performance of dumb effort to the material permanence of $16 \mathrm{~mm}$. Serra, of course, was a sculptor, and Hand Catching Lead —along with Hands Scraping, also made in 1968 -implies an attempt to filmically describe the making body's relation with manipulative material within a medium that requires a labour of mechanistic and physical manipulation in the service of the creation of an essentially formless projected image. This relation, which on both sides implies a passage from active, muscular engagement to physical estrangement, is played out in Serra's film as a frustrated, minimal dance between animate limb and inanimate material.

My thoughts turned to another film featuring bodily movement and gesture modulated according to the presence of sculptural objects: Maya Deren's incomplete project, Witch's Cradle, made in 1943. It exists as a series of outtakes featuring various interactions with string, which is proposed as that of which Marcel Duchamp's web-like interventionist string sculptures of the early 1940s were spun. Sequences of footage of Duchamp himself, and Chilean Surrealist painter Roberto Matta, engaging with tenacious, enigmatic forms of string, are juxtaposed with scenes filmed at the Surrealist gallery of Peggy Guggenheim's "Art of This Century" museum. Viewing the existing fragments of Witch's Cradle conveys 
the sense-even in this embryonic form - that Deren intended the scenes to unfold on screen according to an intensely rhythmic, strategically choreographed pattern of edits. Broadly speaking, these two films share in common the relation of the body and sculptural forms. More particularly, both consist of staged performances for camera of an encounter between the artists and the material of their manipulation. The activity of the hand, in both films, is centralised as instigating, negotiating the initial "terms" of the making body's productive enmeshment with the materials in question. And both, crucially, confer a ludic dimension upon this performance of body/form parity, to divergent ends. Where Hand Catching Lead configures the initialising moment of tactile attempt underscoring sculptural productive labour as a simple game of aimless catch, Witch's Cradle stages a series of encounters between bodies and sculptural forms in which the "subject" appears implicated in some unfathomable puzzle. In this paper I explore the significance of filmic choreographics in rendering a cinematically specific vision of the relationship between body and manipulative materials. Through Serra's Hand Catching Lead and Deren's Witch's Cradle, I will describe the filmic medium as uniquely capable of visually conjuring the space between sculptural object and active subject as reactive, vital, and animatedly responsive. ${ }^{2}$ In addition, I will discuss Daria Martin's In the Palace, a film made in 2000, which takes its title from Alberto Giacometti's 1932 diminutive sculptural scaffold The Palace at 4am, as a cinematically specific expansion of a compressed form of sculptural space.

\section{Enclose and release: Richard Serra's Hand Catching Lead}

Richard Serra made his first film, Hand Catching Lead, in 1968. This three-minute film of a hand engaged in the repetitious attempt to catch pieces of falling metal, attends focus entirely upon the hand and forearm which, in the visible absence of the rest of the body, "perform the totality of the action." ${ }^{3}$ The film presents a durational vision of a muscular act with no discernible ambition save for the momentary and occasionally achieved catch that affords the briefest contact of flesh enclosed about metal. Almost as soon as the object is caught, it is released to fall through the frame. Other metal pieces defy such enclosure and the hand haplessly grasps, too late. For Rosalind Krauss, in Passages in Modern Sculpture, the film is "composed entirely of those catches and misses, that-and the sense of the visually disembodied hand's intense concentration on the deed."

Hand Catching Lead stages a thwarted, nominal dance between body and material, inevitability and intervention, effort and occasion. Despite its "disembodied" appearance, there is a sense of full-bodied occupation concentrated within the sinew and muscle of the visually isolated limb. It trembles, shakes; its moves appear interpretative, clumsily intuitive. The metal pieces bear out the inevitability of their weight, of their material property, which contrasts with the apparent conscious behaviour of the hand. Occasionally, the throwing of another metal sheet is beckoned with a "come on" twitch of the fingers. Benjamin Buchloh, in his essay Richard Serra's Early Work: Sculpture between Labour and Spectacle, Hand Catching Lead, distils into repetitious and clownish activity the universal conditions of bodies condemned to perform the laborious processes of industrial production. This is the hand, argues Buchloh, "of a subjected subject, reduced to the most minute and infinite acts of pointless and fragmented repetition." 
I propose that Hand Catching Lead offers itself to another viewing-reading, one that does not deny the anti-heroic laborious performance Buchloh registers, but that, in accompaniment, considers the way the film mimes the body's frustrated strive towards a tactility of engagement with objects, matter, or solid forms. The film stages the invisible body and the present hand and arm as posed in readiness for contact with the lead pieces. The viewer, in turn, anticipates the simple rhythmic stresses of the hand opening and either slapping its own skin or interrupting the object's course of fall. Through a choreographic reduction of the profound labour of sculptural process to quotidian gesture, Hand Catching Lead brings to mind an imagining of the ways in which manipulative matter - in this case, lead — at once evades and invites tactility. Sheet lead, in the proportions featured in the film, is at once soft and resistant: its essential malleability is visible on screen, as the pieces caught in the hand appear slightly scrunched once released to fall. Lead made molten, on the other hand, is viscous potential: it requires an activity of the body, a precisely productive gesture, to bring it into form before it solidifies, before it inevitably shifts into resistance. For Krauss, the act of gestural repetition "performed" in Hand Catching Lead is a demonstration of an "almost absurd tenacity" of endeavour she observes as consistent with Serra's sculptural processes at the time of the film's making. ${ }^{6}$ She describes how Casting (1969) was formed in the act of flinging molten lead into the angle between the floor and the wall, before "pulling away the hardened shape into the center of the room, repeating the gesture, and thereby building a succession of lead strips, as sequential and near alike as waves following one another toward the shore." ${ }^{\prime \prime}$ The fundamentals of Serra's practice around the late 1960s were defined by such active bodily engagement, whereby the work was produced through a particular rubric of physical investment governed and determined by the properties peculiar to the sculptural material. In Hand Catching Lead, the hand is cast as blunt instrument. The game of blind-catch reasserts that initial moment of inelegant, stumbling contact between body and material that is not yet productive, not yet artistically determinative.

Hand Catching Lead consists of the filmed performance of a simple, playful engagement between limb and material wherein two currents of movement, defined by that of the hand action and that of the material's trajectory, occasionally converge in rhythmic contact. Its inclusion in the Move archive suggests that we are to receive and interpret this spare, anti-illusionist game of chance played out for camera as a form of dance. The limb moves about the screen in anticipation of the catch; it adjusts its position in accordance with the assumed proximity of the falling object; it dances a course upon which choreographic governance alternates between object and hand, between capture and release. The work illustrates something of the filmic medium's capacity to confer a dance-like quality upon engagements between animate bodies and inanimate objects. If we imagine the pieces of lead as constantly trying to outdo the determination of the hand, we might consider that the film plays upon cinema's facility to imbue objects with a lively, animated sense of object life. Rachel Moore, in Savage Theory: Cinema as Modern Magic, writes of the cinematic treatment of objects as inferring upon them a transformative quality, as shifting them, through a magical reinstatement as image, into vitality. Through Jean Epstein's essay "On Certain Characteristics of Photogenie," which first appeared in text in 1924 after being given in various incarnations as a lecture in 1923, Moore suggests that objects, through what she describes as "the eminently unreal realm of cinema," open themselves up to an animistic understanding: "(objects) burn bright as constellations of meaning and crackle 
with tactile effects; things take on life." It is precisely in the act of being caught that the falling metal in Serra's film-despite the emphasis, through single shot, on the metal's inevitable objective trajectory-becomes a mischievous dance partner to the hand, which in turn appears to take on a quality of objectnes, somehowmore instrumental than bodily This brings to mind Kenneth Gross's discussion, in his 2009 essay The Madness of Puppets, the scene from Charlie Chaplin's The Gold Rush, in which an oneiric transformative force, transposed onto a bread roll with two forks stuck into it, conjures the image of everyday objects moving, as puppets might, with "ballet like grace."10 Through its focus on the hand as the implement of action, Hand Catching Lead choreographically inscribes metal as subject to the slightest transformative force. The hand is configured as the instrumental transmitter of what Gross describes as "animating impulse."11

\section{Hand-Eye Conundrums: Maya Deren's Witch's Cradle}

Maya Deren's Witch's Cradle-available to view as a series of outtakes as part of Martina Kudlácek's 2001 documentary, In the Mirror of Maya Deren —was made in 1943, and never completed. It features footage filmed at Peggy Guggenheim's "Art of This Century" gallery juxtaposed with scenes of painter Roberto Matta being crept upon by a length of string, and others of Marcel Duchamp attempting to puzzle the material into strategic order through the playing of the finger lacing game Cat's Cradle. Requiring of the hand a sustained yet delicate grasp of string, Cat's Cradle imposes upon the fingers a minute choreography of instrumental movement. Maureen Turim, in her essay The Ethics of Form: Structure and Gender in Maya Deren's Challenge to Cinema, describes this "game of geometric transformations of a string loop whose rule is not to disturb the hidden order of the lacing as one passes the loop from player to player" as metaphorically structuring Deren's intriguing film. ${ }^{12}$ In the outtakes we see footage of Matta, hounded, haunted, by a tenacious, ominous length of string as it moves across his shoulders. In another scene, the length winds round his neck and pulls his head backward in the mock-mime of a hanging. The string, moved through by actress Anne Matta Clark, Roberto Matta's then wife, seems to symbolically coordinate the geographically estranged yet symbolically coincident spaces occupied by Duchamp and Matta. Duchamp and Matta's tangles with the strangely vital material are juxtaposed with cuts featuring Clark encountering sculptural objects in the Surrealist gallery of "Art of This Century." The objects appear, through Deren's camerawork and the use of trick techniques, imbued with a conspiratorial animism. The string appears to hound Clark, too, as it gradually laces up her arm in one scene, visible as a precluding, unfathomable string sculpture in another, or pulled taut, patterned through her fingers, in one of the film's most arresting fragments. There is a strong sense that Deren intended the film to be structured in accordance with a rigorous yet determinably puzzling logic. Scenes are repeated, glances and poses shot from multiple angles are juxtaposed in dynamic edited sequences, still poses and isolated hand actions are cut against perambulatory impressions of sculptural space. Witch's Cradle illustrates Deren's concern to simultaneously transpose and counteract the overwhelming sense of unhinging strangeness imposed upon the viewing subject in affective receipt of the Surrealist art object. As Clark's encounters with the objects and forms suggest a gathering unravelling of a sense of "self," Deren's edits and cuts become more rhythmically strategic, more consciously choreographic in structure. For 
Turim, in her discussion of Deren's use of childhood games as the very basis for organising filmic sequences, such structural reference to forms of play, which imply an innocent yet deeply invested ritualised activity, "become [Deren's] way of linking the modern audience to the ritual participation in art she seeks as antidote to a modernity hollow of meaningful ritual."13

Deren's use of game as a symbolic configuration, as a device in establishing the form of encounter between individual subjects and subjects and space, is a key facet of her "choreocinematic" conceit. In an article published in Film Culture in 1965, Deren proclaims her regard for children's games as the "ultimate in original, secular ritual." She writes:

Often they [games] are created by the players themselves, but even when they are "learned," the tradition is not so much an inviolable authority for the form as it is a suggestion which may be modified, elaborated, combined with others, etc. What is important is that while the tradition is easily violable, the form, once established in its immediate terms, is as rigidly executed as if it had an exterior, traditional obligation. ${ }^{14}$

Such conception of film as a specially integrated form-as, in Deren's words, a "controlled manipulation" defined not by the nature of its content but by the concept of its methodwas for Deren absolutely intrinsic to her conjuring of "film dance or dance on film."15 In her writings on Ritual in Transfigured Time, a film completed in 1946 in which the movements of guests at a cocktail party become a choreographic configuration from which a dance duet between Frank Westbrook and Rita Christiani extends, Deren identifies the film as operating according to a unifying choreographic concept, wherein all constituent movements, "stylised or casual, full-figured or detailed-are related to each other, both immediately and over the film as a whole."16 The game of "statues" played out in Ritual in Transfigured Time integrates dance action and physical play across a choreographic stratum. The players swing each other by the hand before letting go, twirling away with the force of the spin until their movement is arrested "in a poignant still pose, an action sculpture that bears the trace of the spin."17 Deren's inferring of a dance-like quality upon the movement and action of her screen bodies is characteristic of what I describe as a visible instance of technological enmeshment, whereby the facility of filmic technique to, for example, freeze the body in statue pose, calls the viewer forth to attend to the cinematic specificity of the occasion of movement or gesture. Often in Deren's films this occurs to embellish or extend the physical, "human," appearance or limits of movement performed for the camera. In A Study in Choreography for Camera, Talley Beattey's now iconic sustained leap was achieved through the use of multiple camera angles applied to the capturing of his ascent and descent, cut across several frames. Crucial to Deren's composition of what she described as this "idealised, floating leap" was the transcendence of the gravitational logics of bodily movement, achieved through cinema's technological facility in proposing an elastic expansion of temporality. ${ }^{18}$ Beattey's muscular initiation of the movement, committed to camera, becomes a sustained impossibility on screen through the edited juxtaposition of photographed stages of originating movement. If children's games for Deren constituted the opportunity for collaboration, modification and elaboration of action within an enclosure of formal constraints, then in her conjuring of dance for film or filmic dance, the body's muscular logic can be approached as a strategic constraint, a given form that offered itself 
up to transcendence through cinematic means. In A Study in Choreography for Camera, dance becomes a strategy for Deren's filmic conjuring of the imagined, latent potential enclosed within the modern body. In turn, the dancing screen body is configured as the very site for the demonstration, as Deren describes, of the active potential of "techniques peculiar to the motion picture camera."19

In Witch's Cradle, the material string functions as a conceptual strategic motif, binding three disparate players in a game the rules of which are unclear. It seems to function as a symbolic object, "passing" from player to player as it creeps across scenes or locations, unravelling or tightening in various formal configurations. Deren's utilisation of string as a filmic device is particularly intriguing. It appears in some scenes as an uncannily animate object, apparently moving autonomously and capable of some silent violence. In others, it takes sculptural form, impeding Clark's movement around the gallery space or subverting the appearance of proximal art objects. Whilst the fragmented outtakes of Witch's Cradle were never reconciled into a completed filmic complex, nonetheless the sense is one of Deren intending the work to cinematically extend the affective force of Duchamp's spatially interventionist string sculptures. In 1942, Duchamp was asked by André Breton to oversee the installation of the retrospective "First Papers of Surrealism" at New York's Whitlaw Reid Museum. The show had a scarce budget, and paintings were hung unsatisfactorily on rows of temporary screens. Krzysztof Fijalkowski, in his essay Marcel Duchamp, Surrealist Exhibitions and Restless Space, writes of Duchamp's solution, which involved the winding of one mile of string around the room, over, above and between the exhibits. The installation operated to disrupt and destabilise the proposed and expected relation of viewer and artwork, whilst, to follow Fijalkowski, simultaneously opening up a nexus of uncanny visual opportunities:

Duchamp's intervention effectively hamstrung the conventions of visiting, moving around and viewing the gallery and its contents, unravelling and fracturing the very act of looking that artworks purported to invite. At a stroke, space could become inviable in normal mode, yet strangely visible, where twine could articulate hidden vectors of relationships and meanings, the migrations of the eye finding "invisible" space, the negative gaps between objects and subjects now seeming activated and in tension. ${ }^{20}$

One might imagine that Deren, in the making of Witch's Cradle, took as her point of departure the occlusive, membrane-like functionality of the string in sculptural form. String, as sculptural material installed about the totality of a room, has the capacity to dismantle the feasibility of movement around a given space. In its form as open textile sculpturenot solid but somehow peculiarly arterial -it invites a complete visual re-appropriation of that space's assumed modality: it forces one to look again from a physically preclusive vantage point. Deren attempted to cinematically transpose the sense of spatial subversion effected by the installation of this web of string by staging the "negative gaps" between viewing subject and gallery objects as precisely "activated and in tension." And that sense of activation, of tension, instantiated by the experience of being with sculptural objects, is externalised in Deren's film through the conjuring of instances of uniquely cinematic illusion. The space between viewing subject and art object is imagined and presented as ominously responsive. The centralised appearance of the hand, reaching out to touch, 
for example, a stack of blocks etched with obscure symbols that proceed to float away, unbidden, suggests that Clark gesturally activates the encountered forms into object life. The film is suffused with symbols of witchcraft; in one scene Clark appears with a pentagram drawn on her forehead, in another she goes to retrieve a cloak from its position on the floor and, through the facility of reverse motion, it floats up into her outstretched hand. In Points of Resistance: Women, Power and Politics in the New York Avant-garde Cinema, 19431971, Lauren Rabinovitz discuses Deren's making of Witch's Cradle with Roberto Matta as an indication of her sympathy with his valorisation of automatist art practices in giving visual form to the realms of the psychical and unseen. "Pure psychic automatism," referred to in Breton's 1924 Le Manifeste du Surréalisme as the definitive mode of Surrealist verbal and written expressions of "the true function of thought," was initially practiced through automatic writing, before expanding into graphic automatism at the instigation of André Masson. ${ }^{21}$ Automatic drawing instituted the hand as the instrumental conduit of the subconscious: by freeing mark-making from the strictures of representation and ration, Surrealist purveyors of the technique believed the practice actively harnessed and revealed something of the artist's psyche. Whilst Matta's particular encouragement and practice of automatism in painting coincided with the Surrealist determination, his interpretations of its psychical ends were divergent. He believed the very activity of automatist practice to be a "live" enactment of patterns of thought, the tools of use and their manipulation rational agents grasping and shaping the irrational flow of the unconscious. ${ }^{22}$ Whilst Deren considered the essential spontaneity of such practices impossible to translate into the act of filmmaking, being as it was the art of recapitulating existing realities, she nonetheless indicates in her writings a belief in cinema's specific facility to conjure the subliminal, which resonates with Matta's thoughts on the function of automatism. In her article, "Cinema as an Art Form," published in New Directions in 1946, Deren describes how the filmic medium, in her words, is "especially equipped" to reveal the "external universe ... as an active, creative force." ${ }^{23}$ In a statement evocative of Witch's Cradle, Deren writes of cinema's unique "capacity for animating the ostensibly inanimate, for re-relating the ostensibly immobile" as a demonstration of the medium's suitability for giving vision to such collectively shared unconscious "forces." Through the animistic characterisation of Surrealist art objects, and emblems of witchcraft, already imbued with automatist and mythic significance, Deren attempted to externalise and articulate a sense of "psychological self-awareness."24

Unable to fully translate into cinema's two-dimensions the weight and volume of the Surrealist gallery's intrusive three-dimensionality, Deren instead configured a uniquely filmic vision of this space, moving up, around and throughout the gallery as the insidious string might have done. Her camera pans vertiginously about the string sculpture; artworks are briefly visible through its geometric contortions. The sense that this static, occluding membrane has the capacity to disrupt spatial comprehension is dizzyingly extended through Deren's mobile camera work. This atmosphere of volatility, a cinematic registration and transposition of the sense of spatial instability affected by Duchamp's string sculpture, images the spaces proposed in the film's fragmented sequences as psychological projections. Deren's concern, as Rabinovitz suggests, to filmically articulate a sense of psychological awareness without, as she writes, "defining it through a 'lack' of rationality,"25 is played out in the existing fragments of Witch's Cradle through the intensely rhythmic manipulation of shots and sequences. Yoking the configurations of string as sculpture and 
as game is a choreographic implication. Deren translates this implication into filmic form, describing a psychologically disruptive space through an integral structural logic.

Both Serra's Hand Catching Lead and Deren's Witch's Cradle cinematically configure the affective relation of body and sculptural form through the staging of choreographic encounter. For Serra, the simple play of hand action in the repetitious execution of anticipatory gesture constitutes a choreographic sequence, and the material, in turn, is afforded a curiously animate quality. In Deren's hands, mechanistic animation and puppet-like artistry configure the space between body and sculptural object as reactive, as strangely contagious: there is the sense that in being touched, the objects touch back, as it were. In staging a series of engagements with the material Duchamp employed in a deliberate dematerialisation of the notion of weight and heft proposed by sculptural objects, Deren extends the transposition of the "actuality" of sculptural form within the "virtuality" of cinematic space. The eventness of tactile encounter between mute object and active subject is precisely what is staged in both Deren and Serra's visual configurations of the relational space between sculptural material and active body. The dynamism implied by this relation is conjured through the filmic medium's unique facility to imbue objects and materials with a previously only imaginable reactive quality.

\section{In the Palace (at $4 \mathrm{am})$}

Deren's attempts to ally camera vision with the subversion of spatial impression, affected by Duchamp's string sculpture, demonstrates how sculptural form might in fact instantiate specifically cinematic registrations of space. The way sculpture might function not as cinematic obstruction but as cinematic device is explored most poignantly in another, more recent treatment of the relation of screen bodies and sculptural frames, Daria Martin's In the Palace of 2000. ${ }^{26}$ In the Palace takes its title from Alberto Giacometti's 1932 work The Palace at 4 am, a small structural scaffold made of wood, glass, wire and string, inhabited by strange forms and suggestions of figuration. Martin constructed a model of Giacometti's sculpture that could inhabit the proportions of a human; when completed it measured over twenty-five feet high and was installed in a disused sports arena. Martin's structural frame becomes the stage set for something approaching a tableaux vivant of dancing bodies stilled in pose or clasped in static embrace, partially dressed in homemade costumes and embellished with reflective materials. For me, the film is oddly reminiscent of the "We're in the Money" number, choreographed by Busby Berkeley, in The Gold Diggers of 1933 —not least because of a nod to Gold Diggers ' coin-like head dressing and scanty costume. There is something in the quality of the camera work and the panning movement around this open structure that at once stages and contains the film's performers that evokes the way those Berkeley spectacles plunge the viewer headlong into beyond-human perspectival dimensions which pose a porosity between the mechanistic and the sensual. As Catherine Wood puts it, in a 2005 article on Martin's practice entitled The One and the Many, "the artist stages a direct level of sensory communion with the viewer which temporarily suspend for the viewing subject the fact that they exist on the worldly plane. This is part of the fantasy of becoming immersed in the work, at least."27

During Martin's film, the camera pans about the scaffold whilst the contained performers mostly remain tremblingly posed, as breathing statues or fleshly idols. Where 
Serra and Deren filmically configure the relation between body and sculptural form as an active encounter choreographed for camera, Martin re-imagines a diminutive sculptural object as a film set, re-appropriating an existing form for the specific purpose of cinematic exhibition. She writes of her fascination with Giacometti's The Palace at $4 a m$ as deriving from the imagined impression of a latent vastness embedded within the object's diminutive proportions: in Martin's words, the "idea that sparked In the Palace was a desire to literally realise my own fantasy to inhabit this small sculpture, to blow it up to human dimensions and to populate it with performers."28 Underscoring the film's conception and realisation is the idea of a passage from compression to expansion and back again. Writing of In the Palace, Martin notes the way in which the performance of filmic projection returns the constructed, "real world" event of filmmaking to the ephemeral presence of cinematic dream. The still photographed instances, embalmed by light upon the celluloid strip, resemble in Martin's imagination a maquette or model, a permanent registration of space and action laboriously constructed and dismantled in the service of the creation of the film properly speaking, which, in projection, expands into visual purpose. ${ }^{29}$ According to Rosalind Krauss, Giacometti made The Palace at 4 am during a time when he believed the sculptural object must be unanchored from his aesthetic calculations, that it must bear neither impression of his touch nor "evidence of his own manipulation. It was to be a projection of desire rather than a product of something painstakingly wrought." ${ }^{30}$ In the Palace and Witch's Cradle can be received as cinematic projections of the oneiric potential of sculptural forms. Both derive from an exploration of the inherent tension between the laborious pragmatisms yoking sculptural and filmic production, and the inevitable expansive estrangement of the work within spectorial space.

Whilst Deren and Martin's films seem at odds with Serra's anti-illusionist, positively perspiratory performance for camera, all three works filmically conjure some degree of the affective force of sculptural encounter. And all three attend to the way film, as a two-dimensional, essentially immaterial projection, can conjure this force through a choreography of action, gesture, or still pose which ultimately transposes the internal, embodied receipt of object and materials into external, almost graphic performances of the body. Redolent in Serra's, Deren's, and Martin's filmic explorations of, perhaps, what happens in the spaces between the receiving, making, performing body, and the structure, material, or object of their receipt, is a sense of the artist's attempt to conjure (to paraphrase Martin) an "ephemeral expansion" of the choreographic labour implied by sculptural production within a qualitatively different dimension of spectatorial space. To close, I will turn to a passage from Stan Brakhage's seminal essay From Metaphors on Vision, which informed my thinking as I attended to these three works so embedded with the weighted sense of film as originating in physical investment: of film as, essentially, manus operandi. On "what reflects from the screen," Brakhage writes:

Believe in it blindly, and it will fool you ... Believe in it eye-wise, and the very comet of its overhead throw from projector to screen will intrigue you so deeply that its fingering play will move integrally with what's reflected, a comet-tail integrity which would lead back finally to the film's creator. ${ }^{31}$ 


\section{References}

Brakhage, Stan. (1963) "From Metaphors on Vision." In The Avant-Garde Film: A Reader of Theory and Criticism. Edited by P. Adams Sitney. New York: Anthology Film Archives, 1987.

Breton, André. "Le Manifeste du Surréalisme." 1924. Accessed April 20, 2011. http://www.tcf.ua.edu/Classes/ Jbutler/T340/SurManifesto/ManifestoOfSurrealism.htm.

Buchloh, Benjamin H.D. "Richard Serra's Early Work: Sculpture between Labour and Spectacle." In Richard Serra: Forty Years, edited by Kynaston McShine and Lynne Cook, 43-60. New York: The Museum of Modern Art, 2007.

Elder, R. Bruce. Harmony and Dissent: Film and Avant-garde Art Movements in the Early Twentieth Century. Waterloo, ON: Wilifrid Laurier Univ. Press, 2008.

Fijalkowski, Krzysztof. "Marcel Duchamp, Surrealist Exhibitions and Restless Space." In The Surreal House, edited by Jane Alison, et. al. New Haven: Yale University Press and the Barbican Art Gallery, 2010.

Gross, Kenneth. "The Madness of Puppets." The Hopkins Review 2, no.2 (Spring 2009): 182-205.

Krauss, Rosalind E. Passages in Modern Sculpture. Cambridge: M.I.T Press. 1994.

Martin, Daria. "Daria Martin in conversation with Yilmaz Dziewior and Beatrix Ruf." Accessed April 20, 2011. http:// www.dariamartin.com/docs/texts.htm\#ruf.

McPherson, Bruce R., ed. Essential Deren: Collected Writings on Film by Maya Deren. Kingston, New York: Documentext, 2005.

"Move: A Digital Archive." Move: Chorepographing You. Hayward Gallery. Accessed Janurary 8, 2011.

Moore, Rachel O. Savage Theory: Cinema as Modern Magic. Durham: Duke University Press, 2000.

Rabinovitz, Lauren. Points of Resistance: Women, Power and Politics in the New York Avant-garde Cinema, 1943-1971. Chicago: University of Illinois Press, 1991.

"Roberto Matta," by Martica Sawin. Latin American Masters. Accessed April 20, 2011. http://latinamericanmasters. com/english/artist_matta_essay.html.

Turim, Maureen. "The Ethics of Form: Structure and Gender in Maya Deren's Challenge to Cinema." In Maya Deren and the American Avant-Garde, edited by Bill Nichols, 77-102. Berkley: University of California Press, 2001.

Wood, Catherine. "The One and the Many." Daria Martin. Accessed April 20, 2011.

\section{Notes}

1. Fernand Léger, "A New Realism—The Object (Its Plastic and Cinematographic Value)," from Little Review 11, no. 2 (1926). Quoted in R. Bruce Elder, Harmony and Dissent, 165.

2. Both Hand Catching Lead and Witch's Cradle were included in a Lux touring program, entitled Describing Form, curated by Lucy Reynolds. Describing Form premiered at the Henry Moore Institute and Tate in 2005, before touring UK venues. The program included Deren's Witch's Cradle and Serra's Hand Catching Lead, alongside works by Daria Martin, Marie Menken, and Hannah Wilke, among others, in a programme that sought to explore how the weight and space implied by sculptural form has been filmically described.

3. Rosalind Krauss, Passages in Modern Sculpture, 243.

4. Ibid., 244.

5. Benjamin H.D Buchloh, "Richard Serra's Early Work," 57.

6. Krauss, 244.

7. Ibid.

8. Rachel O. Moore, Savage Theory, 73.

9. Ibid.

10. Kenneth Gross, "The Madness of Puppets,"183.

11. Ibid, 182.

12. Maureen Turim, "The Ethics of Form," 8.

13. Ibid. 
14. Maya Deren, "Theme and Form: Thematic Statement," from Film Culture, 39 (Winter 1965). Quoted in Turim, "The Ethics of Form," 88.

15. See Deren, "Choreography for Camera."

16. Maya Deren, "Ritual in Transfigured Time," from Dance Magazine, December 1946. In Bruce R. McPherson, Essential Deren ), 225.

17. Turim, "The Ethics of Form," 85.

18. Maya Deren, "Choreography for Camera," from Dance Magazine, October 1945. In Essential Deren, 224.

19. Maya Deren, "Creating Movies with a New Dimension: Time," from Popular Photography, December 1946. In Essential Deren, 133.

20. Krzysztof Fijalkowski, "Marcel Duchamp, Surrealist Exhibitions and Restless Space," 68.

21. André Breton, "Le Manifeste du Surréalisme."

22. "Roberto Matta."

23. Maya Deren, "Cinema as an Art Form," from issue 9 of the 1946 NewDirections. In McPherson, 32.

24. Lauren Rabinovitz, Points of Resistance, 69.

25. Ibid

26. Daria Martin, In the Palace and Birds (2001) are available at "Move: A Digital Archive."

27. Wood, Catherine. "The One and the Many."

28. Daria Martin, "Daria Martin in conversation with Yilmaz Dziewior and Beatrix Ruf."

29. Ibid

30. Krauss, "Passages in Modern Sculpture," 111 (emphasis mine).

31. Brakhage, Stan. "From Metaphors on Vision" (1963). In The Avant-Garde Film: A Reader of Theory and Criticism, edited by P. Adams Sitney. New York: Anthology Film Archives, 1987. 


\title{
A Report on the Screendance Symposium
}

\author{
University of Brighton, February 4, 2011
}

Claudia Kappenberg and Sarah Whatley

I February of this year, the International Screendance Network hosted a symposium at the University of Brighton, UK to mark the conclusion of a two-year research period. Funded by a Network Grant from the Arts and Humanities Research Council (UK) the Screendance Network was established in 2009 in order to accelerate the discourse and publication in screendance. The group, composed of three American and five UK-based scholars and artists, is led by Claudia Kappenberg (Principal Investigator, School of Arts and Media, University of Brighton) and Sarah Whatley (Co-Investigator, Coventry University). Since its inception the Network has met four times: in Brighton (September 2009), Coventry (January 2010), Durham, North Carolina (June 2010) and again in Brighton (February 2011). During these seminars the group exchanged research interests, explored possible strategies for dissemination and established the new International Journal of Screendance.

The aim of the symposium was to meet with a larger research community, to encourage participation from younger researchers with interests in screendance, to disseminate the work of the Screendance Network, and to invite guest speakers from related fields of practice in order to expand the parameters of the debates. Kappenberg and Whatley introduced the day by summarizing the developments of the last five years and inviting everyone to consider that "Screendance had not yet been invented," a motto which is also featured on the cover of the first issue of the International Journal of Screendance.

The invited speakers were CatherineWood, Curator Contemporary Art and Performance (Tate Modern), Choreographer Siobhan Davies and filmmaker David Hinton. Responses to historical theoretical texts were given by filmmaker Miranda Pennell (UK) and Network member and dance scholar Ann Cooper Albright (Oberlin College, Ohio US). Following the presentations audiences debated various topics using the Open Space format, sharing findings in a final plenary session.

The speakers were able to raise important questions about how screendance is "read" and critiqued within different frameworks. 


\section{Screendance Symposium}

Friday, February 4, 2011

Sallis Benney Theatre

University of Brighton

Grand Parade BN2 OJY

\section{Perspectives in Screendance}

\section{SCHEDULE}

Symposium 10:00 am - 6:00 pm

\section{9:30 am Registration}

10:00 am Claudia Kappenberg/ Sarah Whatley: Welcome and Introduction

10:15 am Session1: A Curatorial Perspective

Ballet Mecanique, presentation and screening by Catherine Wood,

Curator Contemporary Art and Performance at Tate Modern

11:30 am Coffee

Noon Session 2: A Choreographic Perspective

Choreographer Siobhan Davies and Filmmaker

David Hinton discuss a new project

1:00 pm Lunch buffet

2:00 pm Session 3: A Theoretical Perspective

Filmmaker Miranda Pennell and dance scholar Ann Cooper Albright

(Screendance Network) comment on historical theoretical texts.

3:00 pm Open Space Debate

A discussion with all delegates using the Open Space format

followed by Plenary Session with the Screendance Network

Dinner and Screening 6:30 - 9:00 pm

6:30 pm Dinner: University of Brighton canteen

8:00 pm Screening: Works by Catherine Long,

Lizzie Sykes, Becky Edmunds, Jérôme Bel 


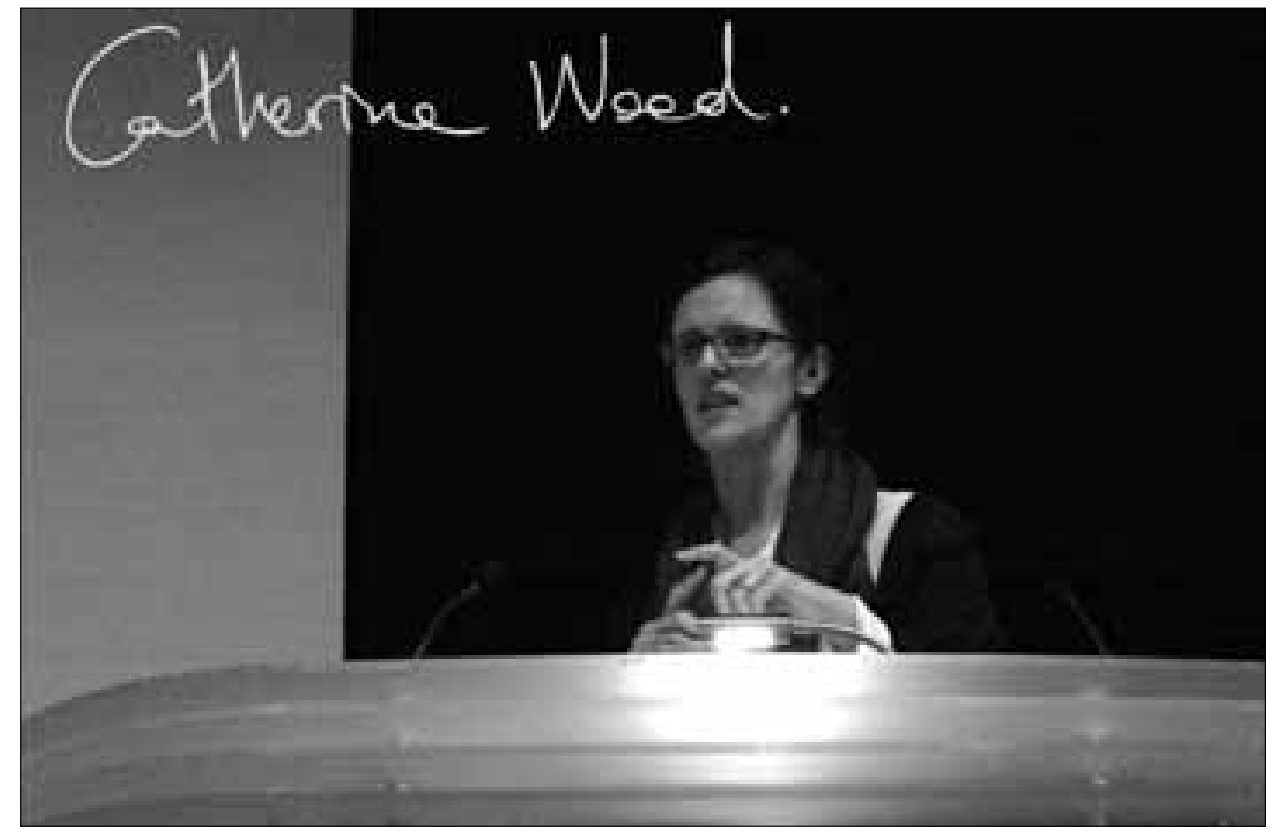

Catherine Wood, Curator Contemporary Art and Performance (Tate Modern)

Catherine Wood used the symposium as an opportunity to explore ideas about performance in the everyday as always already mediated, asking where screendance today begins or ends. She discussed the work of visual artists Dara Birnbaum, Mark Leckey, Bonnie Camplin, Catherine Sullivan, and Keren Cytter as examples of how contemporary artists are responding to the increasing pervasiveness of media technology in the everyday. She argued that since the mid-seventies appearances and behaviour are more and more geared towards screen performance and that this in turn affects contemporary choreographic and cinematographic processes. Her insightful readings offered delegates tools for reading and responding to a range of work that had not previously been debated within the context of screendance.

As independent curator and writer Helena Blaker commented, Catherine Wood was using the opportunity of this forum to "test" her ideas about performance (as now always an internal image, in a highly mediated context); and to explore this as an alternative critical frame for the work of visual artists whose projects she had previously seen in a different light. For Helena Blaker, this was "a good start to the day with a new theoretical position that was in the process of being tested, specifically for this context and because of the provocations (towards a new viewpoint) created by screendance."

CW:The now ubiquitous presence of screen-based technology opens up the capacity for a significant shift in how dance on screen can be thought about-and even dance beyond screen in everyday life.

CW: Passages of our daily movement are constantly being captured, recorded, replayed and embedded in a whole other meta-level of choreography of moving images, which is part of the everyday fabric. 


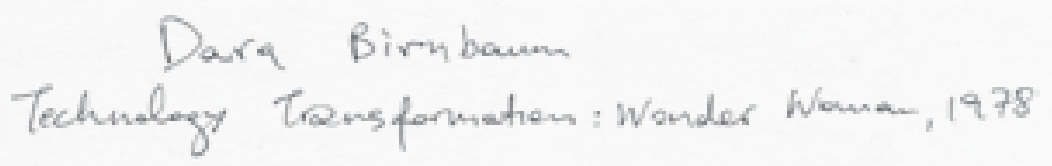

CW: Dara Birnbaum's work represents a key step in understanding the way that this kind of choreography of gesture via film and television, and now other new media, plays a part in how we might understand ordinary movement today.

\section{Delegate \\ Marina Tsartsara}

CW: How do we reverse the terms of the all-pervasive image world and demand that it be lumpy, graspable and awkward? instead of being forced to aspire to its flatness?

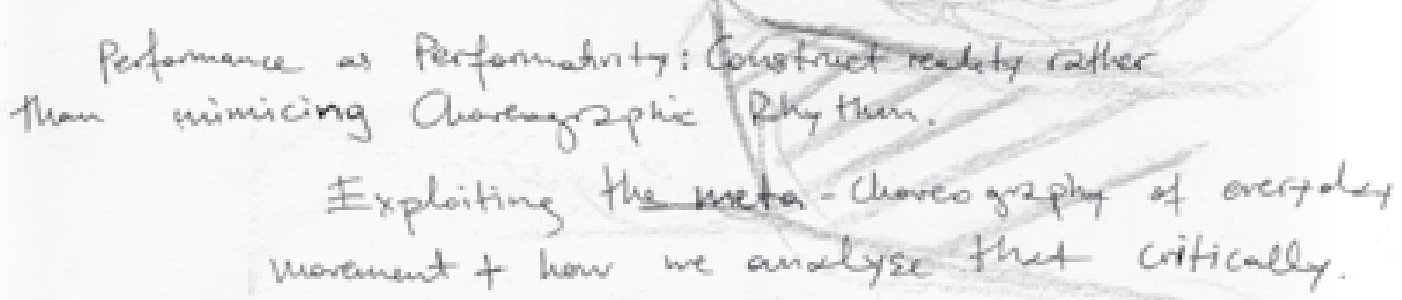

CW: A conflation of the languages of dance and film is what necessarily constitutes this new language. One is simultaneously factual and symbolic and proposes a different kind of blurring between art and life.

CW: Does screendance replace what was thought to be ordinary dance in the sixties, that is, an incorporation of another level of mediated movement into our experience of the everyday here and now? ... I suppose I was thinking about where does screendance end and non-screendance begin and how easy is it to draw that distinction? 


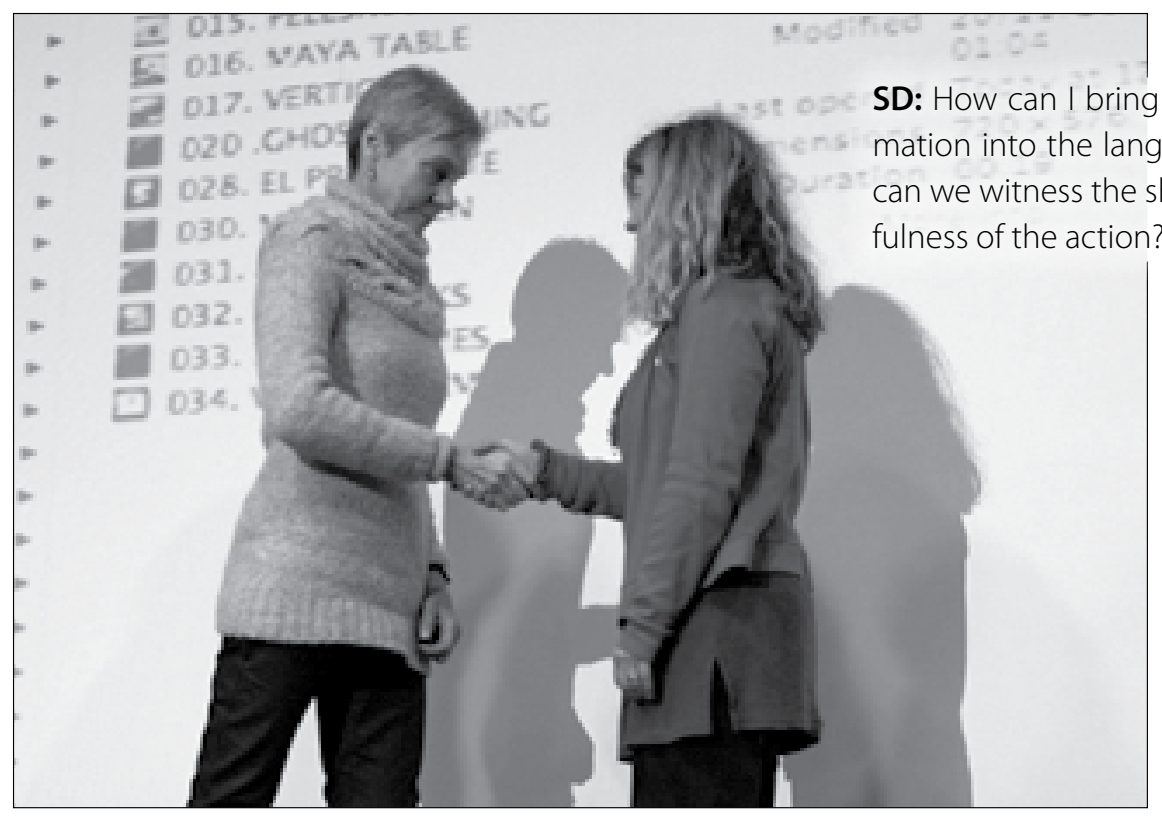

Choreographer Siobhan Davies and filmmaker David Hinton shared a conversation about a forthcoming screendance collaboration, discussing their creative processes and interests in how they think they might be working together. As an established choreographer, Davies is curious about how the detail and particularity of the dancing body can move from a live space to a screen, and how that will inform and shift her thinking about dance. Hinton showed examples of work that demonstrated a cinematic aesthetic and reflected on aesthetic differences between live and mediated work.

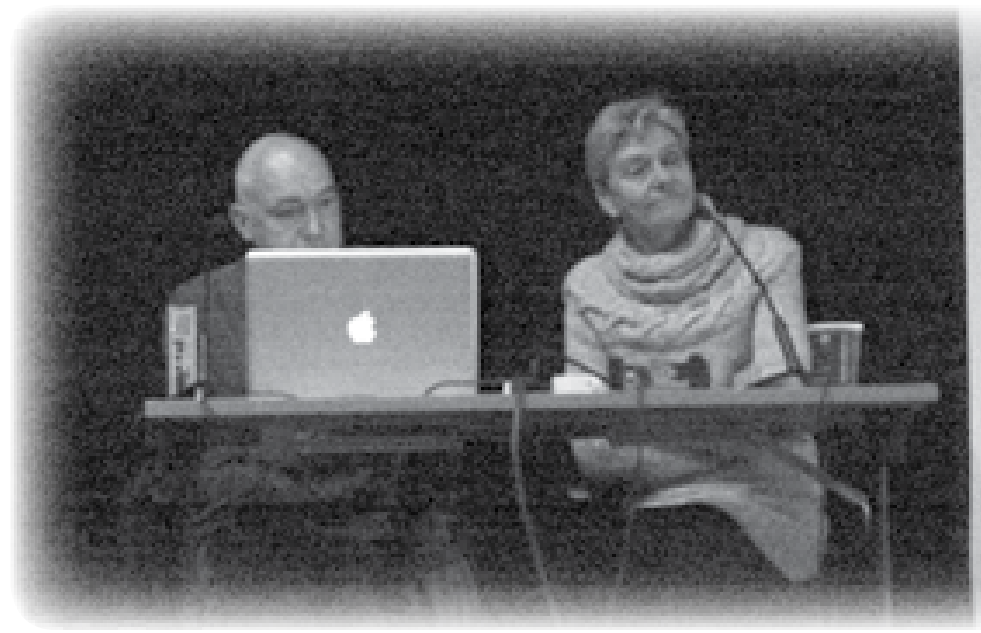

DH: Is the image of the walk interesting? I have an instinct immediately to dramatize the walk...

SD: And I have an immediate instinct to orchestrate the walk... The walk is this massive amount of information-probably about 1000 activities in the body which allow us to walk. 
A Report on the Screendance Symposium University of Brighton, February 4, 2011

145

To think the Image of a Wake; * To fiericaley think the Image of a

The orchestration of a walk $\rightarrow$ walking as a means of "embodying" the work $\alpha$.

The process of oisgantuing an action: $\rightarrow$ glimpse into the non linearity of thought

I thine about chance implication within gyrapty as a latent various parametersorinay actions; the choreography of which imply a the cheaply of sorts. To dismantle chomegrafy of ordinance is to lategraph a dance that is always possible always potential: it becomes risibly possible through interruption, through formal e. appropriation, through the process of being distant $4 \alpha$. of the performed action int the soleure $\alpha$ "transposition") Delegate Elinor Cleghorn (PhD candidate, London Consortium) 
Miranda Pennell and Anne Cooper Albright shared reflections on established theoretical texts which have been selected by the Screendance Network as providing a potential scaffolding for thinking and writing about screendance. Pennell discussed Laura Mulvey's essay, "The Pensive Spectator," exploring the choreographic potential of the still image to animate the inanimate and with respect to her own work.['] Albright sketched key ideas of Heidegger's seminal essay, "The Question Concerning Technology," exploring the etymological root, techne, as signifying both skill and a process of revealing whilst linking techne to episteme, a way of knowing the world. [2] Albright invited delegates to review the relation between dance techniques and media technologies, arguing that we are inevitably and irrevocably changed when "captured" and "processed" by imaging technologies and that screendance describes precisely this tension between embodiment and technology.

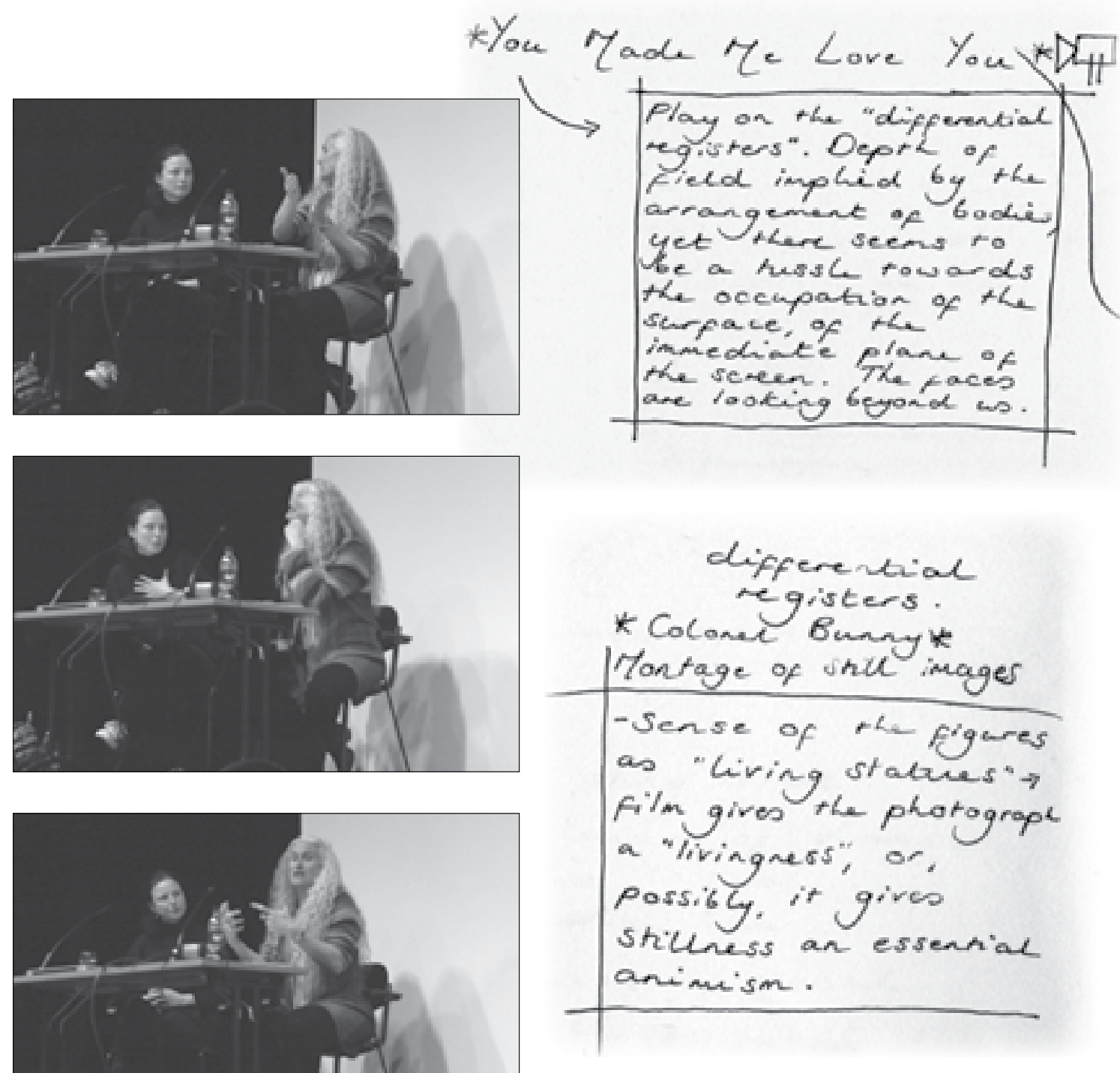

Delegate Elinor Cleghorn 
* Miranda imimes" the action of serocking through, rolling through, footage in pwrwit of the initial interest in the scene. A double thanded gesture: thes suggests the technology implies a sort of rehoregroptic: moductation of +L $60 \%$.

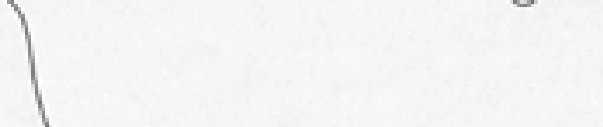

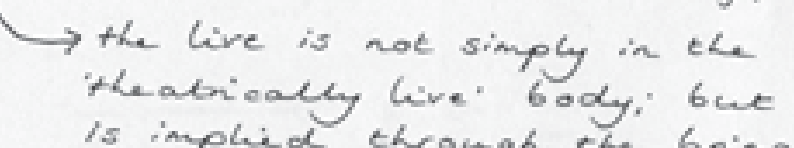
Is implied through the bringing out of content and re presenting of an object in cinema that can lend it a cinematicaly specific "Live" quality.

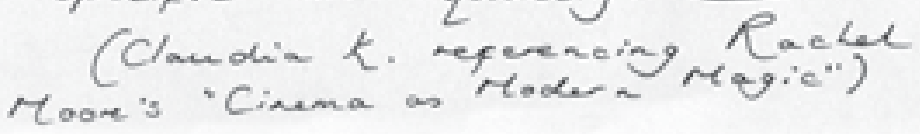

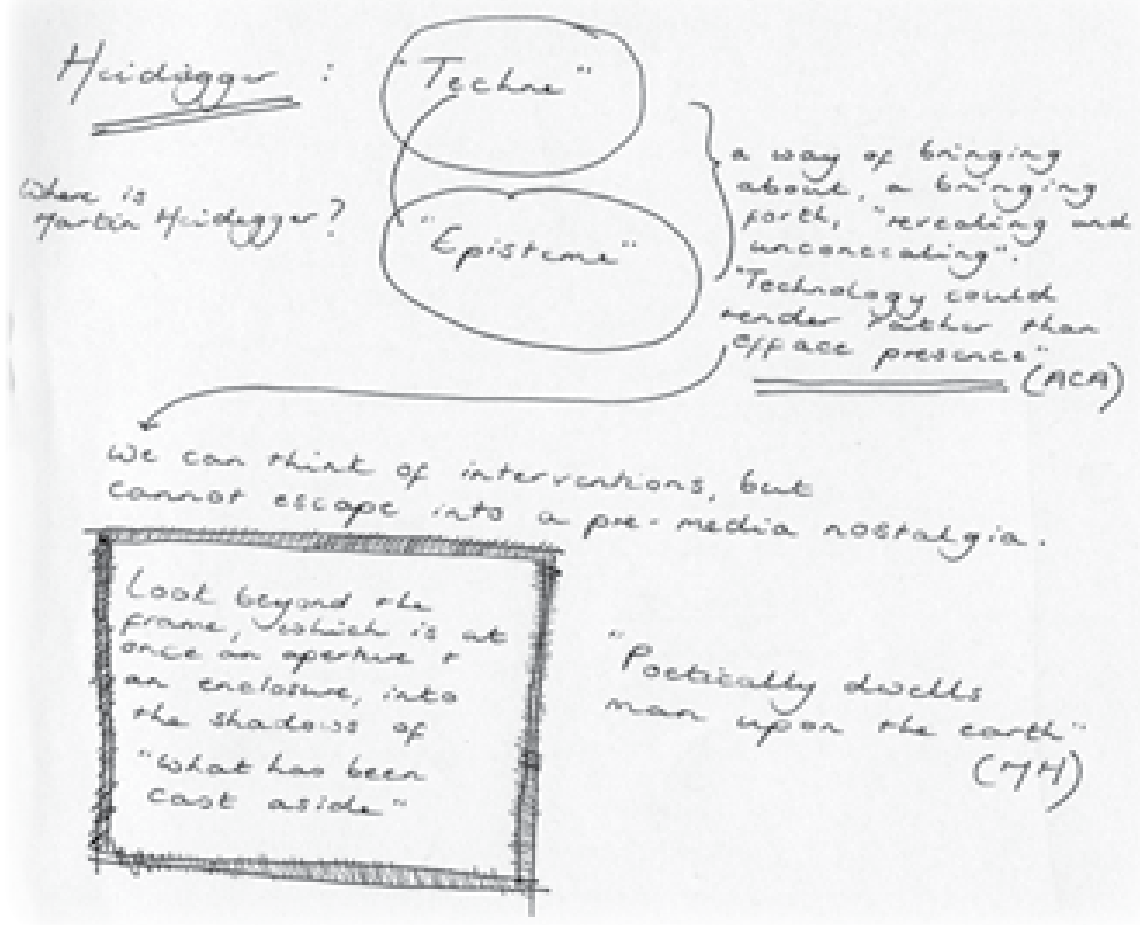


Delegate Karen Wood (PhD candidate, researching kinaesthetic empathy and screendance audiences at the University of Manchester) noted how both speakers raised an important

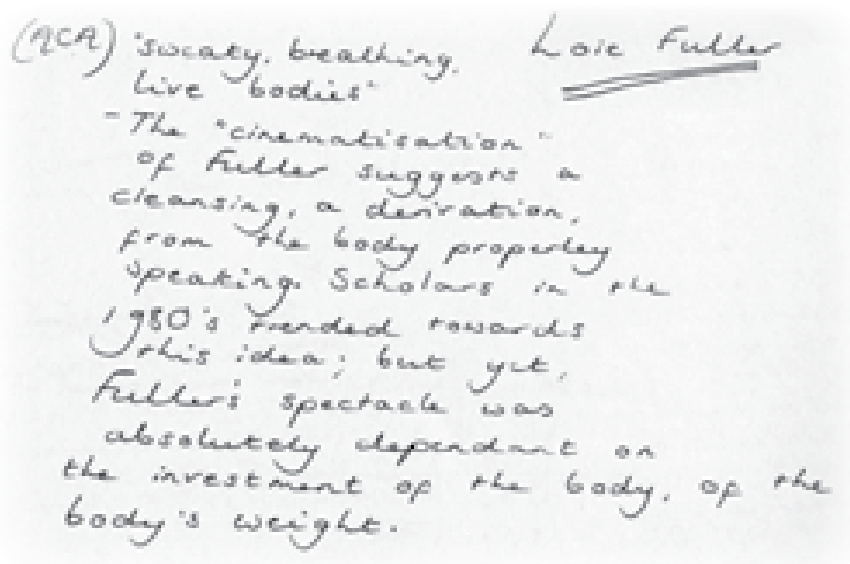

Delegate Elinor Cleghorn point in how our relationship with time is changing with digital technologies and "how this could open screendance up to creative, imaginative possibilities." She also noted that "the practice may need to realign its current thinking, in light of new technologies, to extend further to a larger audience."

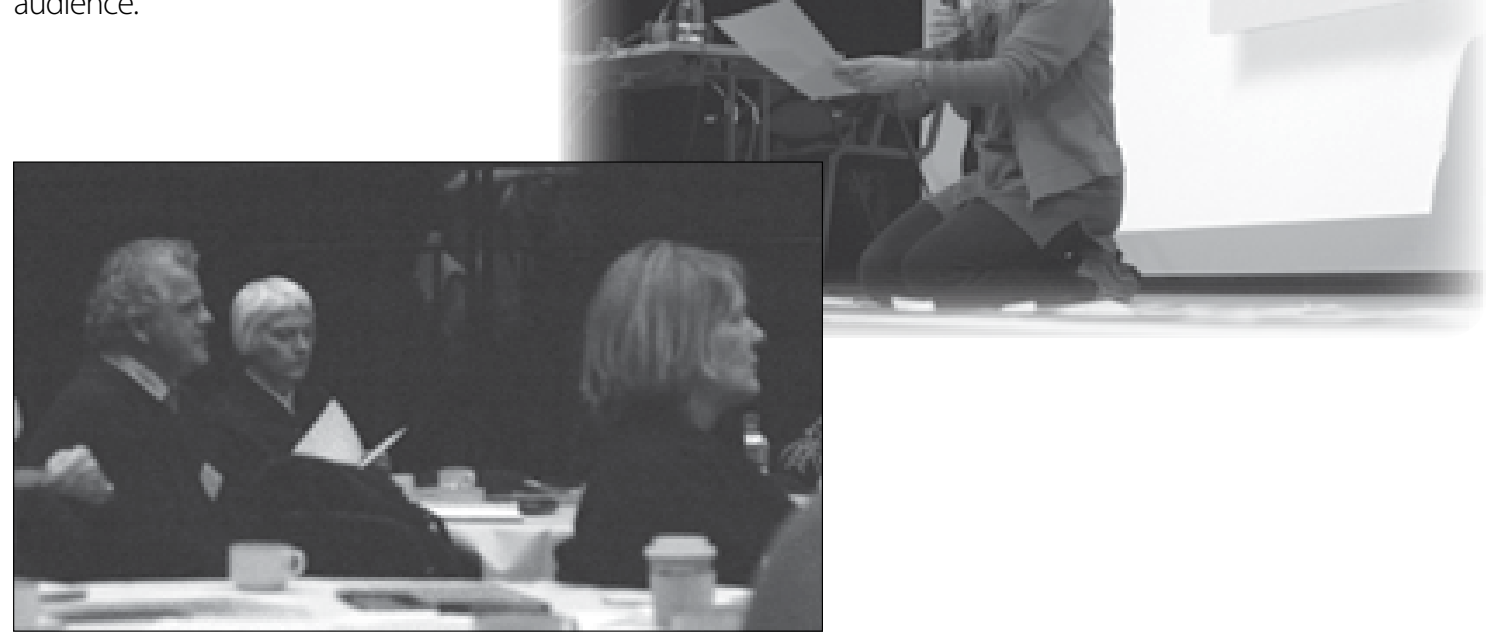

The presentations were followed by an Open Space debate, which was chaired by Sarah Whatley. Delegate Helena Blaker commented on the productive and political nature of the discussion. Her group explored "how far the mechanism of the screen can become a social/political catalyst for the re-envisioning of the position of the body in society." Other groups reflected on what kind of liveness is brought about by screen performance and how mediation complicates notions of fiction and reality, documentation, authenticity and stillness within the moving image. 

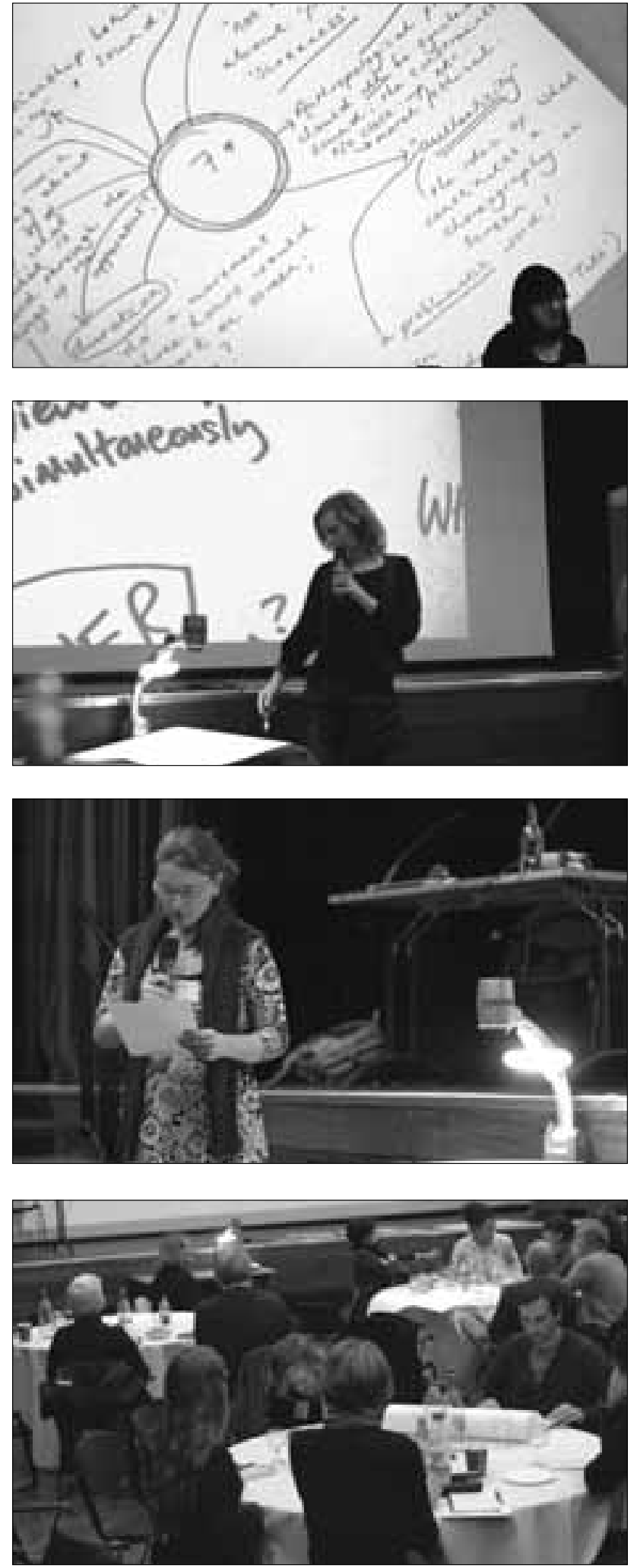

Mariana Pimentel, one of the overseas delegates from Brazil and currently working in Lisbon, Portugal, talked enthusiastically about the Symposium ad echoed a question that was raised during the Open Space discussion: "Is screendance an interdisciplinary practice, a hybrid practice or does it generate its own form and language?"

"The discussion and group exercises were both effective and appropriate to the unfolding of the day. I often find such exercises ineffectual and to some degree tokenistic; however in this case they were indeed highly productive, particularly in engaging the views of the ,Äòdance film community, if one were to recognise such a group. I hope this Network continues to evolve." (Nic Sandiland, screendance artist and senior lecturer at Middlesex University)

Mary Wycherley, a practitioner and lecturer in multi-disciplinary performance practice, somatics and screendance in Limerick, Ireland said that she appreciated "the weight of interest in and distinct relationship between screendance and Video Art." She also pointed out that delegates shared "interest in both the practical development and the theoretical frameworks involved in the process of making screen-based work" and she was "impressed by the representation of different countries" at the symposium which felt significant for the cross-fertilization in the dialogue. 
After a communal dinner the day concluded with a screening, which had been curated by Professor Liz Aggiss (School of Arts and Media, University of Brighton) and Claudia Kappenberg. The screening began with a series of shorts by artists from the South East; Catherine Long, Lizzie Sykes and Becky Edmunds, in which the actual physical processes of filming and framing determine the choreography, thereby challenging traditional hierarchies of filmmaking and choreographing.

The shorts were followed by French Choreographer Jérôme Bel's epic Véronique Doisneau, a work made in 2004 during a residency at the Paris Opera. Much of Bel's oeuvre inverts hierarchies within theatrical traditions and in this work a single ballerina from a traditional corps de ballet becomes the sole star of the show, dancing excerpts of her subsidiary roles against the absence of the company and its soloists.
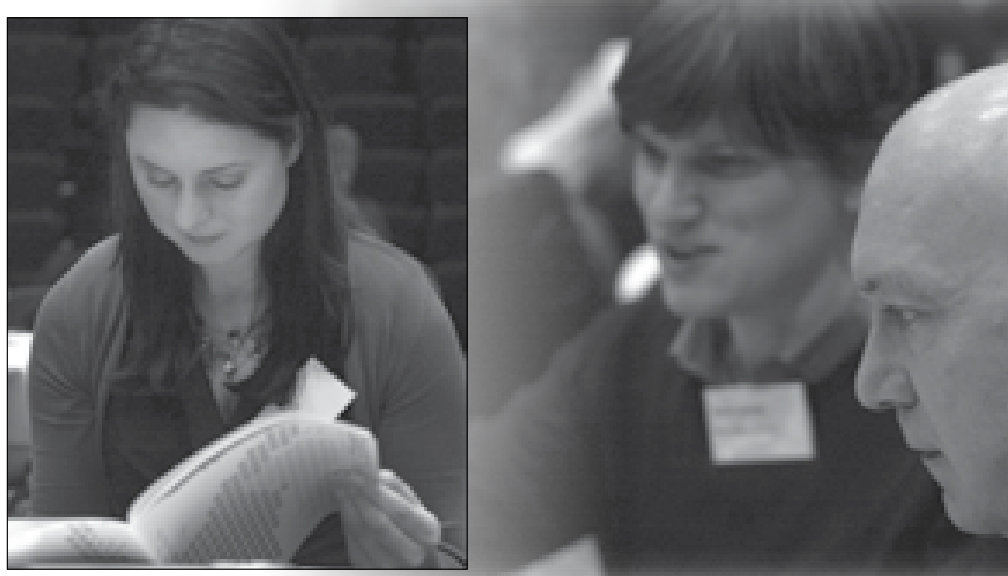

\section{SCREENING}

Catherine Long, Experiment. Number 1 2010, 2 mins. 30 sec.

Lizzie Sykes, Angry Rambler 2005, 1 min. $15 \mathrm{sec}$.

Lizzie Sykes, Tiago's Sequence 2005, 2 mins. 5 sec.

Becky Edmunds, Skate 2009, 4 mins. 40 sec.

Becky Edmunds, stand in 2009, 5 mins.

Jérôme Bel, Véronique Doisneau 2004, 37 mins.

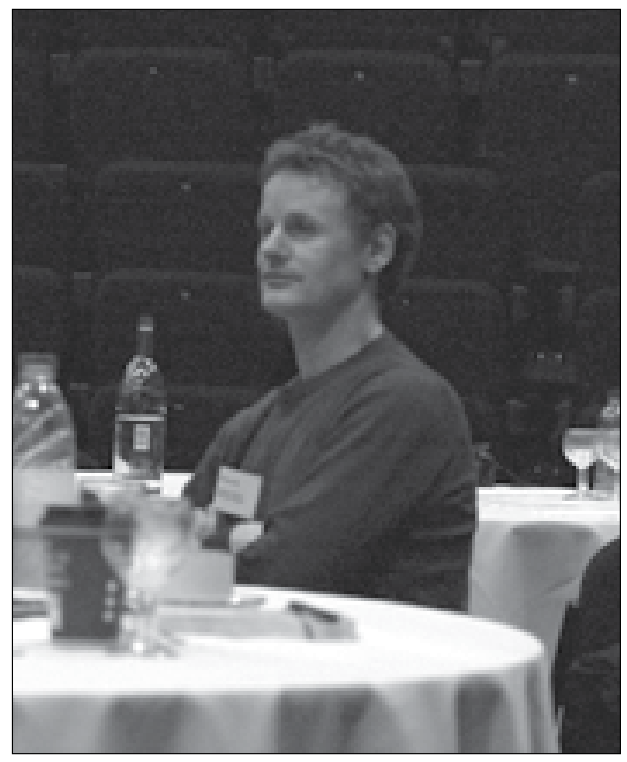




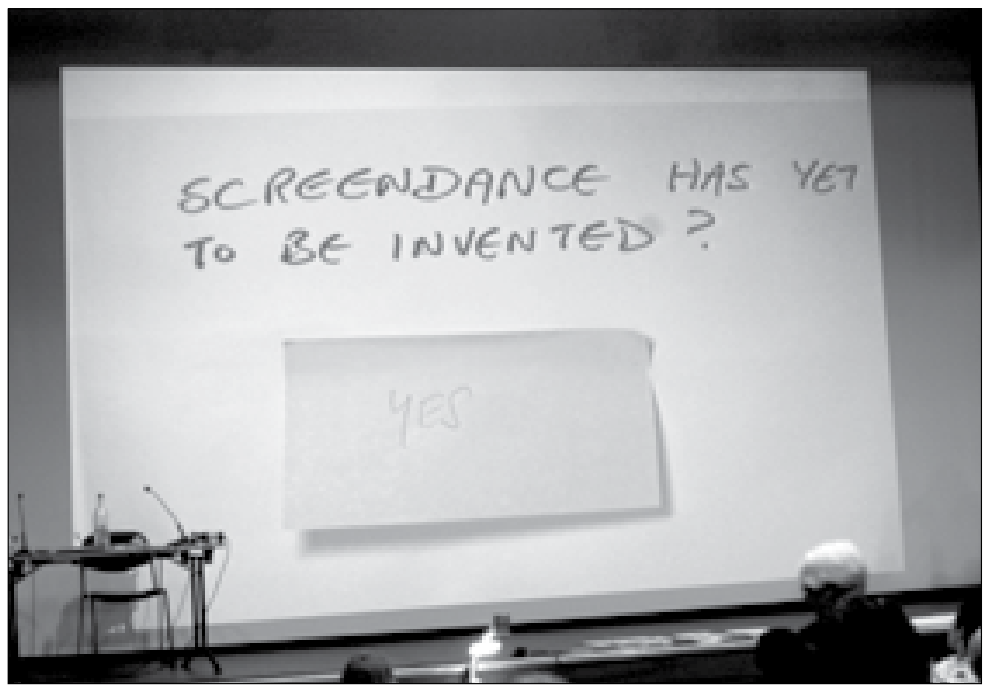

"We were knights at round tables with pristine tablecloths. We charged our minds and thoughts and drifted into personal frames to find the frame. Screen dance is yet to be invented?

Do we agree? Do l agree?
"... So we segued from Wonder Woman to Leger, from Fiorrucci made me Hardcore to Parade, from Get me a Mirror to Man Ray, and we thought to move and moved to think and crossed high bridges, dismantled actions, watched sheep pour down slopes of shale, and unpicked the edit and the reasons to be cheerful. Sites were resighted, relocated and retasked. We tossed off all the Bs, Barthes, Bourriaud, and Benjamin and sped off to embalm life with photographs, mummifying the living with our cut ups, stilled stop frames and stasis. Is performance 'nowness'? Is film and photo 'thenness'? You Made Me Love You said Miranda in Capitals, and we did. Screendance is a priority of agency and access to technology. Why did I write that? Time to see some screendance without the dance that we expect. Tossed cameras skating on thin ice if you please, a women running with Baudrillard in mind, it's in your head I am shouting, it's all in your head, angry walkers and fish eye lenses and nothing makes sense any more, the world has inverted, gone Dutch and I felt sick. Then I had a happy moment with Véronique Doisneau just too too so so française and then I had one red wine too much and got edited out." (Professor Liz Aggiss, Performance and Visual Art, University of Brighton)

Delegate David McCormick (filmmaker and Senior lecturer in Screendance at the University of Winchester) commented that through the International Journal of Screendance an articulation of its presence as an evolving art form has been achieved.

\section{Credits:}

Scribe (scribbles): Elinor Cleghorn

Scribe (drawings): Marina Tsartsara

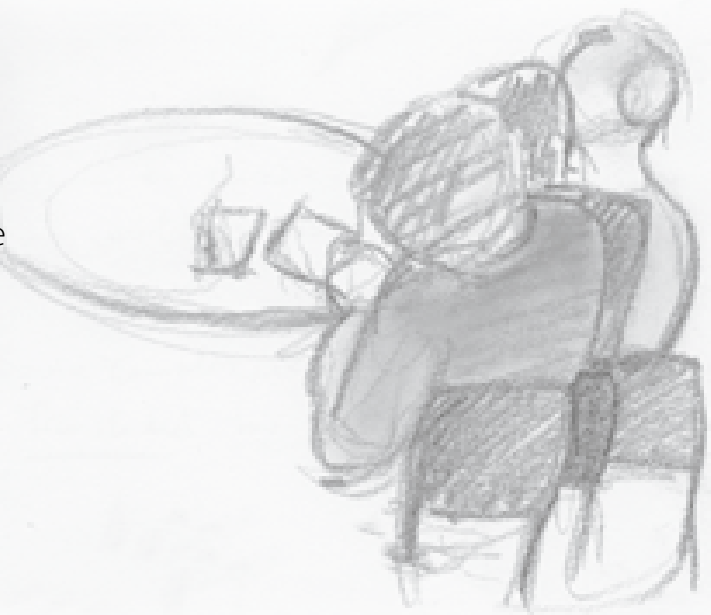




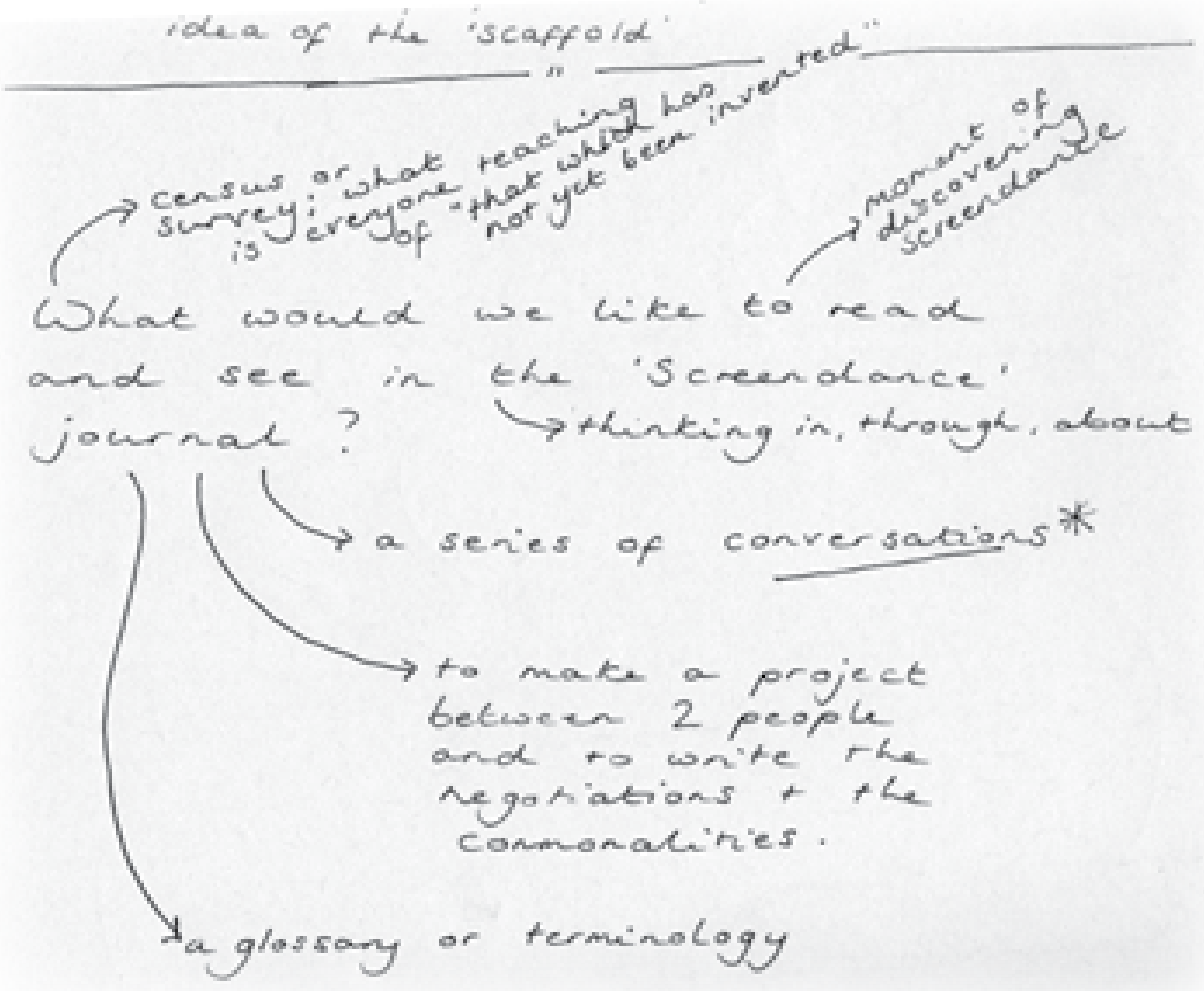

\section{References}

Mulvey, Laura. Death 24xper Second: stillness and the moving image. London: Reaktion Books, 2006.

Heidegger, Martin. The Question Concerning Technology and Other Essays. Translated by W. Lovitt. New York: Harper Torchbooks, 1977.

\section{Notes}

1. Mulvey, Death 24x per Second: stillness and the moving image. Pennell's presentation is printed in full elsewhere in this issue.

2. Heidegger, The Question Concerning Technology and Other Essays.

Albright's paper is also printed in full elsewhere in this issue.

\section{Dear Journal Reader:}

We would also like to ask you: what would you like to read or see in the International Journal of Screendance? Perhaps you have a question you would like to see discussed, or you know someone who we could invite to write for the Journal? Perhaps you have read a book that you think should be reviewed?

Please email any suggestions or comments to the editors:

Claudia Kappenberg

C.Kappenberg@ brighton.ac.uk Douglas Rosenberg rosend @ education.wisc.edu 


\section{Contributors}

Ann Cooper Albright is Professor of Dance and Theater at Oberlin College. Combining her interests in dancing and cultural theory, she is involved in teaching a variety of dance, performance studies, and gender studies courses that seek to engage students in both practices and theories of the body. She is the author of Modern Gestures: Abraham Walkowitz Draws Isadora Duncan Dancing (2010); Traces of Light: Absence and Presence in the Work of Loie Fuller (2007); Choreographing Difference: the Body and Identity in Contemporary Dance (1997); and she is co-editor of Moving History/Dancing Cultures (2001) and Taken By Surprise: Improvisation inDance and Mind (2003).

Rodrigo Alonso is a professor at the University of Buenos Aires (UBA), Universidad del Salvador (USal) and the National University of Arts (IUNA), Buenos Aires, Argentine. He earned his Master's Degree in Fine Arts, University of Buenos Aires (UBA), Argentine, specializing in contemporary art and new media. A member of the Advisor Committee at the Master on Curatorial and Cultural Practices in Art and New Media, Media Centre of Art and Design (MECAD), Barcelona, Spain, he is also a guest lecturer at major universities, international congresses and forums in Latin America and Europe. Professor Alonso is a regular contributor for Ámbito Financiero (Argentine newspaper) and art.es (International art magazine based in Spain). Books include: Muntadas. Con/Textos (Buenos Aires, 2002), Ansia y Devoción (Buenos Aires, 2003) and Jaime Davidovich. Video Works. 1970-2000 (New York, 2004). He lives and works in Buenos Aires and Barcelona.

Harmony Bench is Assistant Professor of Dance at Ohio State University, where she teaches critical theories of dance, media, and performance. She earned her PhD in Culture and Performance from the University of California, Los Angeles. Her research interests include histories and theories of corporeality and the consequences of digital media for bodily experience. Her current work investigates mobile and social media as sites for choreographic analysis. She is on the editorial board of The International Journal of Screendance.

Melissa Blanco Borelli is a lecturer in Dance Studies at the University of Surrey. She is currently working on a manuscript that examines social dance histories in Cuba and is the editor of a forthcoming Oxford Handbook Series on Popular Screen Dance. She has been published in Dance Chronicle, International Journal of Performing Arts and Digital Media, Brolga: An Australian journal about dance, and Women \& Performance: A Journal of Feminist Theory.

Lucy Cash is an artist and filmmaker. She is drawn to beginning with the extraordinary appearance of ordinary things: things that are already in the world, and that invite small interventions between the poetic and scientific, philosophical and humorous, intimate and political. Working with people from a range of communities and fields of expertise inside innovative forms of collaboration is a regular part of her practice. Her background in performance making and choreography informs her approach to the work she now makes in different forms - film, writing, installation and performance. Her work materialises through an associative approach to the everyday and the esoteric. Between 2005 and 2009 she 
was an associate member of Goat Island performance, making four moving image works with the company as well as contributing to writing and live performance. In 2009 she was awarded a fellowship from South East Dance for her work creating choreographies for the screen. In 2010 alongside Becky Edmunds, Chirstinn Whyte, Claudia Kappenberg, and Gill Clarke, she co-curated the "What If ..." festival at Siobhan Davies Space. Her moving image work has been shown on television, (Ch4, Filmfour, BBC4, and BBC2) and internationally in both galleries and at film festivals. She has been an associate artist with Artsadmin since 2007. Since 2010 she has been an associate artist with South East Dance.

Ian Christie is a film historian, curator, and broadcaster. He has written and edited books on Powell and Pressburger, Russian cinema, and Scorsese and Gilliam; and he has also contributed to exhibitions ranging from Film as Film (Hayward, 1979) to Modernism: Designing a New World (V\&A, 2006). In 2006 he was Slade Professor of Fine Art at Cambridge University. A Fellow of the British Academy, he is Professor of Film and Media History at Birkbeck College, director of the London Screen Study Collection, and vice-president of Europa-Cinemas. Recent publications include: Stories we Tell Ourselves: the Cultural Impact of British Film 1946-2006 (co-author, 2009), and The Art of Film: John Box and Production Design (2009); also articles on production design, Méliès, Renoir, and Patrick Keiller. Website: www.ianchristie.org.

Elinor Cleghorn is a writer and curator. After receiving an MA in Contemporary Art Theory at Goldsmiths College with a dissertation on Maya Deren's choreocinema, she commenced with PhD study at The London Consortium, where she is currently writing a thesis exploring the implication of the moving body in the production of cinematic spectacle. Elinor curated "Maya Deren: 50 Years On," a dedicated programme of events and screenings commemorating the 50th anniversary of the filmmaker's death, at the British Film Institute, London in October 2011.

Augusto Corrieri (UK/Italy) is a performance artist and writer, presenting new choreographic works for theatres and galleries in the UK and Europe. Both playful and rigorous, the performances investigate the connections between the mechanism of theatre and our place in today's society of the spectacle. In the attempt to uncover the codes and conventions of theatre, the works experiment with reversing the roles of performers and spectators, light and darkness, music and silence, movement and stillness, the visible and the invisible. www.augustocorrieri.com

John Crawford is an intermedia artist, interactive performance director, technology developer and interaction designer. Intersecting software with digital media and theatrical performance, he uses computers and video to create painterly animations and motion graphics closely integrated with dance. As a professor in the Department of Dance at University of California, Irvine, he is a frequent participant in transdisciplinary research projects connecting performing arts and digital media practices with engineering and computer science.

Scott deLahunta has worked as writer, researcher, and organizer on a range of international projects, bringing performing arts with a focus on choreography into conjunction with other disciplines and practices. He is currently Senior Research Fellow Coventry University/R-Research Director, Wayne McGregor Random Dance and Program and 
Research Coordinator Motion Bank/The Forsythe Company. He serves on the editorial boards of Performance Research, Dance Theatre Journal and the International Journal of Performance and Digital Media .

Ann Dils is Professor of Dance and Director ofWomen's and Gender Studies at the University of North Carolina at Greensboro, where she teaches courses in dance history and feminist research methods. Dils has been editor (2006-2008) and co-editor (2003-2005) of Dance Research Journal, and is a past president of the Congress on Research in Dance. In 2010, she won CORD's Dixie Durr Award for Distinguished Service. Her recent research on Jean Cocteau's Le Boeuf sur le Toit appears in the forthcoming Where is the Dance? From the Inside, Reaching Out: Recent Scholarship in Dance.

Pia Ednie-Brown is a designer, educator and theorist with creative research practice Onomatopoeia. She is an associate professor at RMITUniversity's School of Architecture and Design, in Melbourne, Australia, based in the Architecture programand the Spatial Information Architecture Laboratory (SIAL). Her creative work includes interactive architectural installations, drawing and sculptural pieces, video performance, participatory workshops, and writing. Her research has been concerned with emergence, technology, embodiment and affect, ethics and aesthetics, and sustainability. She has directed numerous creative research projects involving multiple disciplines across the arts and sciences. Her book, Plastic Green: designing for environmental (RMIT Publishing, 2009) is an outcome of one of these projects. From 2009 to 2011 she led an Australian Research Council Discovery project (with Prof. Mark Burry, Oron Catts, and Dr Andrew Burrow), seeking to re-theorise innovation for contemporary design practices in terms of coupled ethical and aesthetic concerns therein. Website: onomatopoeia.com.au.

Simon Ellis is a New Zealand-born independent performance maker and performer with a broad practice founded on choreographic traditions. He has a practice-led $\mathrm{PhD}$ (investigating improvisation, remembering, documentation and liveness) and is currently Reader in dance at Roehampton University in London, where he specialises in practice-led research methods. His choreographies have included site-specific investigations, screendance, installation, webart, and conventional black box works. In 2008 his solo performance Gertrud was a finalist in the Place Prize, and his screendance project Anamnesis was awarded Best Film at InShadow International Festival of Video, Performance and Technology in Portugal. www.skellis.net.

Jason Farman is an assistant professor at the University of Maryland, College Park in the Department of American Studies and is a Distinguished Faculty Fellow in the Digital Cultures and Creativity Program. He received his PhD in Digital Media and Performance Studies from the University of California, Los Angeles. Farman's research includes mobile technologies, social media, videogames, digital storytelling, digital performance art, surveillance, and embodiment. His book, Mobile Interface Theory (Routledge, 2011), investigates the changing conceptions of embodiment and space in pervasive computing culture.

Claudia Kappenberg is a performance and media artist and leads the MA Performance and Visual Practices at the University of Brighton, UK. Her projects comprise single screen work as well as screen-based installations and live site-specific events, and have been shown across Europe, the United States, and the Middle East. Claudia runs the international 
AHRC Screendance Network, which advances discourses and theorization of screendance. She co-founded the White Market performance label in 2009 and co-curated the "What If..." festival, London in 2010. Website: www.ckappenberg.info

Hannah Kosstrin is a visiting assistant professor of Dance at Reed College in Portland, Oregon. Her research examines Jewishness and gender in concert dance, specifically in the work of Anna Sokolow. She holds a PhD in Dance Studies from Ohio State University, MA and BA degrees in dance from Ohio State University and Goucher College, and Labanotation Teacher Certification from the Dance Notation Bureau. She has been Website Content Editor for the Society of Dance History Scholars since 2005.

Tom Lopez teaches at the Oberlin College Conservatory of Music where he is Associate Professor of Computer Music and Digital Arts, Chair of the Technology in Music and Related Arts Department, and Director of the Contemporary Music Division. Collaboration and experimentation are the cornerstones of his work.

Lisa Naugle is Professor and Chair of the Dance Department in the Claire Trevor School of the Arts at the University of California, Irvine. She received her MFA from Tisch School of the Arts and her PhD in Dance Education from New York University. Her research in choreography and digital media has been presented in North and South America, Europe and Asia.

Kyra Norman is a choreographer and video maker, with a background and training in contemporary dance and visual art, and a particular interest in screendance. In 2005, she initiated The Light Fantastic, through which she has developed her practice in writing and curating. She is currently researching a practice-based PhD, exploring the screen as a site for choreography, within the University of Bristol's Department of Drama:Theatre, Film, Television.

Miranda Pennell originally trained in contemporary dance and later studied visual anthropology at Goldsmiths, London. Much of her work has explored aspects of performance through film and video, often emphasising formalised and codified group rituals while being curious about the mysterious mechanics of individual expression. Recently she has been working with archive photographs as material for film. Pennell's work has been shown in contexts including independent cinema, gallery and broadcast. Lately she has screened as part of programmes at Musée des Beaux Arts de Valenciennes, and the National Gallery of Art, Vinlius, with one-person programmes at Glasgow Short Film Festival (UK), Sixpackfilm and Vienna Independent Shorts (AT). www.mirandapennell.com.

Virginia Piper is a doctoral student in the department of English at the University of Wisconsin-Madison and has an MA in comparative literature from the University of Oregon. Her work explores the intersections between aesthetics, literary form, and rhetoric in relation to the long-nineteenth century in British and French literature. Most recently, Piper presented a paper on a panel at the 2011 International Society for the Study of Narrative Conference in St. Louis, titled "Spatial Politics and Narrative Topography in Woolf's The Waves," as well as a paper on vision, visuality, and the spatial rhetoric of the adulteress in nineteenth-century Paris at the 2011 Modern Language Association Convention. She will give a paper titled "Transitivity and Material Cultures: Towards an Aesthetics of Literary Things" at the 2012 Modern Language Association Convention in Seattle. 
Dianne Reid is a performer, choreographer, camera operator, video editor and educator. She works in both live and screen contexts. She was a founding member of Outlet Dance in Adelaide (1987-89) and a member of Danceworks from 1990-95. Dianne completed a MA in Dance on Screen in 2001 and was a lecturer in contemporary dance and dance video at Deakin University from 1996-2010. From 2004-2006 she was Artistic Director of Dancehouse before receiving an Asialink Performing Arts residency to India in 2006 at Darpana Academy of Performing Arts. Since 1993 she has created 24 dance screen works, many of which have screened at Festivals in Norway, Sweden, India, Hong Kong, Sydney, Melbourne and Perth with return invitations to screen at Videodance, Greece (02 \& 04) and ADF Dancing for the Camera $(04,09,10, \& 11)$. Her 2010 collaboration with Weave Movement Theatre, A Broken Puzzle, was awarded a distinction by the 2011 ADF Screendance Festival for "a work that is invested with dignity and humanity, and demonstrating the potential for Screendance to make a difference." Dianne teaches and performs dance improvisation and was a founding member of The Little Con improvisation performance group in Melbourne. She is currently located in Adelaide developing her new performance work, "Dance Interrogations," and training as a disability support worker.

Adam Roberts is a filmmaker whose work includes several films made with choreographer Jonathan Burrows. Currently he is making a film called Remake, opening at BFI Southbank, London UK in November 2011, which will be published by Filmarmalade artists' films and videos. He was born in Colombia and lives in London. Visit www.adamroberts.eu.

Douglas Rosenberg is an EMMY nominated director and the recipient of the prestigious Phelan Art Award in Video. He was awarded the Director's Prize at the International Jewish Video Festival for his film, My Grandfather Dances with choreographer Anna Halprin, and received an IZZIE Award for his work on the intermedia project, Singing Myself A Lullaby (a collaboration with Ellen Bromberg and John Henry. He is well known for his collaborations with choreographers including Molissa Fenley, Sean Curran, Ellen Bromberg, Joe Goode, Li Chiao-Ping, Eiko and Koma, and others. His most recent film, Of the Heart was a finalist for the Jury Prize at the Dance on Camera Festival in New York and has screened at numerous festivals around the world. His writing has been published in LEONARDO and other journals and he is the founder and director of the International Screendance Festival, hosted by the American Dance Festival. His book, Screendance: Inscribing the Ephemeral Image, is forthcoming from Oxford University Press.

Dr. Claudia Rosiny studied theater, film, and television sciences in Cologne and Amsterdam. From 1991 until 2007, she was co-organizer of an annual dance festival in Bern, Switzerland, where she regularly programmed dance films. A publication on contemporary dance resulted from the festival (Reto Clavadetscher and Claudia Rosiny, Zeitgenössischer Tanz: Körper, Konzepte, Kulturen, Bielefeld: Transcript Verlag, 2007). After completing a dissertation on videodance (Videotanz. Panorama einer intermedialen Kunstform, Zurich: Chronos, 1999) at the University of Bern, where she earned a PhD, Rosiny set up and directed a new forum for media and design in Bern. She was awarded funds by the Canton of Berne and by the Swiss National Science foundation to pursue research in New York City in 2008-2009. Rosiny is currently working for the Swiss dance collection in Zurich and Lausanne and is writing a book on dance and film. 
Kent de Spain is a choreographer/theatre artist and independent scholar. He received his BA in Dance and MA in Choreography from UCLA, his EdD in Dance Studies from Temple University, and was awarded a Postdoctoral Research Fellowship at Ohio State University. De Spain has been the recipient of several awards, including the Pew Fellowship in the Arts for Choreography, and an Established Choreographer's Fellowship from the Pennsylvania Council on the Arts. He has published, presented, and performed extensively in the areas of movement improvisation and dance and technology, including essays in Dance Research Journal and the online journal Body, Space, Technology .

Sarah Whatley is Professor of Dance and Director of the Centre for Dance Research (C-DaRE) at Coventry University. Her research focuses on the interface between dance and new technologies, on dance analysis, somatic dance practice and pedagogy, and on inclusive dance; and is variously funded by the AHRC, JISC, ACE and Leverhulme Trust. She edits the Journal of Dance and Somatic Practices and is on the editorial board of the International Journal of Screendance. She is also a member of the International Education Workgroup for The Forsythe Company's Motion Bank project. 


\section{SCREENDANCE}

Inscribing the Fphestieral Intiage

by Douglas Rosenberg

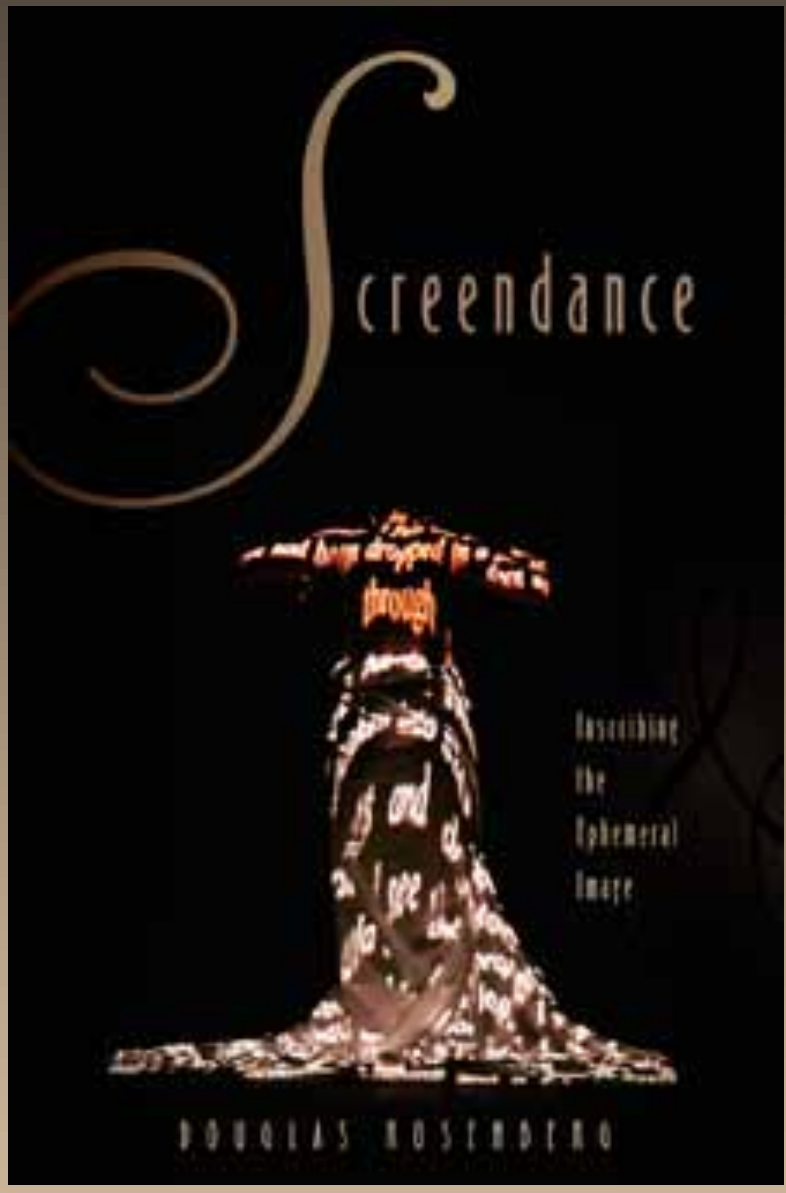

"Doug Rosenberg's genealogy of dance on screens masterfully elucidates the critical issues of this emerging field. A must-read for practitioners and theorists alike."

-Ann Cooper Albright, author of Choreographing Difference, Traces of Light, and Modern Gestures 


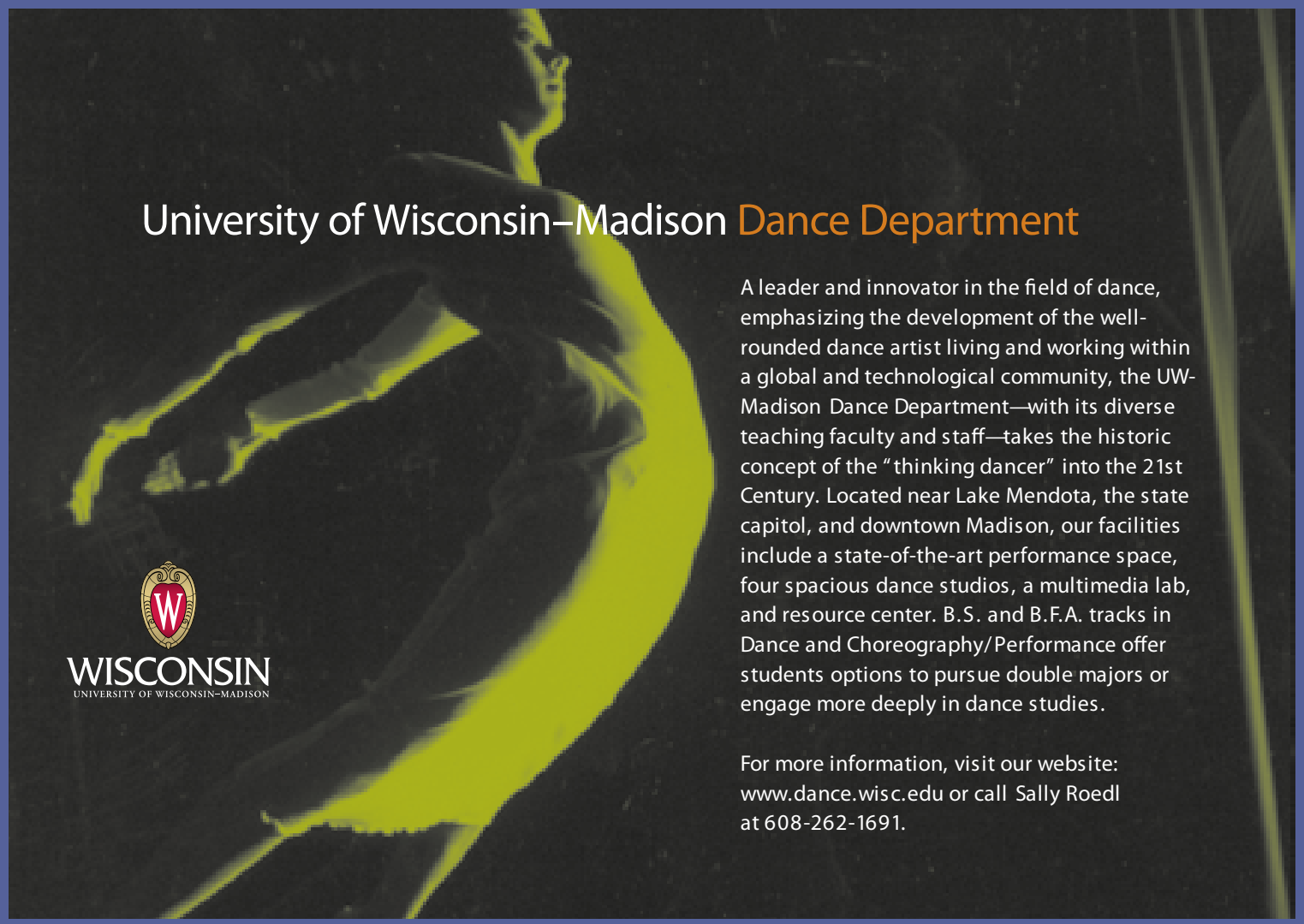

承

University of Brighton

Faculty of Arts

\section{Performance and Visual Practices MA}

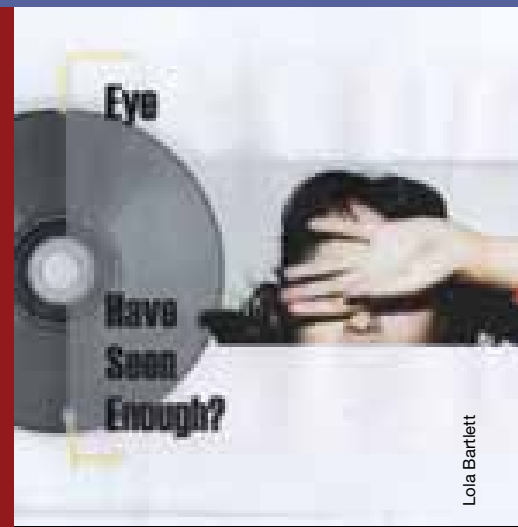

Based in the heart of one of Europe's most vibrant and creative cities, Performance and Visual Practices MA is a unique, innovative and interdisciplinary programme that facilitates practical and theoretical research across a wide spectrum of performance and the visual arts, such as screendance, site-specific performance and sound installation. Study full- or part-time on this brand new UK masters degree.

\section{Find out more} samadmissions@brighton.ac.uk www.brighton.ac.uk/arts arts.brighton.ac.uk/screendance

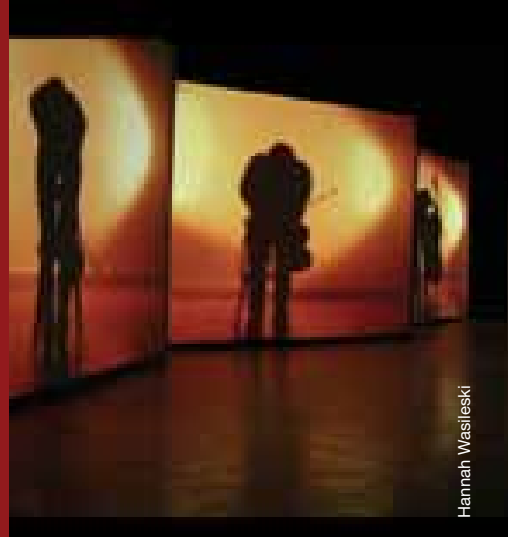

